UNIVERSIDADE DE SÃO PAULO

FACULDADE DE FILOSOFIA, CIÊNCIAS E LETRAS DE RIBEIRÃO PRETO DEPARTAMENTO DE PSICOLOGIA PROGRAMA DE PÓS-GRADUAÇÃO EM PSICOLOGIA

Fatores de risco psicossocial, estresse e saúde em agentes de limpeza terceirizados

Marina Bernardo Mandarini

RIBEIRÃO PRETO 


\title{
Fatores de risco psicossocial, estresse e saúde em agentes de limpeza terceirizados
}

\author{
Marina Bernardo Mandarini \\ Versão corrigida \\ (Versão original encontra-se na unidade que aloja o Programa de Pós-Graduação)
}

Dissertação apresentada à Faculdade de Filosofia, Ciências e Letras de Ribeirão Preto da Universidade de São Paulo como parte das exigências para a obtenção do título de Mestre em Psicologia.

Área de Concentração: Psicologia em Saúde e Desenvolvimento

Orientadora: Prof ${ }^{a}$. Dr ${ }^{\mathrm{a}}$. Marina Greghi Sticca

RIBEIRÃO PRETO 


\title{
Fatores de risco psicossocial, estresse e saúde em agentes de limpeza terceirizados
}

\author{
Marina Bernardo Mandarini \\ Versão corrigida \\ (Versão original encontra-se na unidade que aloja o Programa de Pós-Graduação)
}

Dissertação apresentada como parte das exigências para a obtenção do título de Mestre em Psicologia financiada pela CAPES/CNPq 
Autorizo a reprodução e divulgação total ou parcial deste trabalho, por qualquer meio convencional ou eletrônico, para fins de estudo e pesquisa, desde que citada a fonte.

Catalogação na publicação

Serviço de Biblioteca e Documentação

Faculdade de Filosofia, Ciências e Letras de Ribeirão Preto - USP

Mandarini, Marina Bernardo.

Fatores de risco psicossocial, estresse e saúde em agentes de limpeza terceirizados / Marina Bernardo Mandarini; orientadora: Marina Greghi Sticca - Ribeirão Preto, 2018.

167 p.: il.; $30 \mathrm{~cm}$

Dissertação de Mestrado, apresentada à Faculdade de Filosofia, Ciências e Letras de Ribeirão Preto, Universidade de São Paulo - USP. Área de concentração: Psicologia em Saúde e Desenvolvimento.

1. Estresse ocupacional. 2. Fatores de risco. 3. Serviços terceirizados.

4. Saúde do trabalhador. 
Nome: Mandarini, Marina Bernardo

Título: Fatores de risco psicossocial, estresse e saúde em agentes de limpeza terceirizados

Dissertação apresentada à Faculdade de Filosofia, Ciências e Letras de Ribeirão Preto da Universidade de São Paulo para obtenção do título de Mestre em Psicologia

Aprovada em:

Banca Examinadora

Prof. Dr.

Instituição: Assinatura:

Prof. Dr.

Instituição: Assinatura:

Prof. Dr.

Instituição: Assinatura: 


\section{Agradecimentos}

Agradeço primeiramente aos meus pais, José Alberto e Maristela, que sempre me incentivaram, me ensinaram o real valor da dedicação, me auxiliaram com os recursos financeiros necessários e estiveram ao meu lado ao longo desta trajetória acadêmica. Agradeço também ao meu irmão, Matheus, pela disponibilidade em me ouvir e pelo companheirismo constante.

Agradeço imensamente à minha orientadora Marina Greghi Sticca, pela paciência e dedicação ao direcionar meus caminhos e acolher minhas dúvidas e angústias, pela generosidade em compartilhar seus conhecimentos, por ser sempre atenciosa e por priorizar meu desenvolvimento e autonomia enquanto pesquisadora.

À banca examinadora, pela acessibilidade e por todas as orientações, apontamentos e sugestões realizados.

À empresa participante, pela abertura e colaboração, e a todos os participantes do estudo, que foram receptivos e se colocaram à disposição para colaborar. Sem eles, esta pesquisa não teria sido realizada.

À agência financiadora, CAPES, agradeço por todo o subsídio prestado ao desenvolvimento deste estudo.

Aos colegas do LabPOT, agradeço pela convivência, pela troca de conhecimento, pelas experiências e pelas parcerias nos trabalhos realizados.

Aos meus amigos mais próximos, agradeço pela compreensão, pelo apoio e por me lembrarem constantemente que outras coisas são tão importantes quanto o trabalho. Agradeço especialmente à Marcela, pelo suporte em períodos difíceis, pela disponibilidade e companheirismo, e por sempre reforçar meus pontos positivos nos momentos de dúvida. 


\section{Resumo}

Mandarini, M. B. (2018). Fatores de risco psicossocial, estresse e saúde em agentes de limpeza terceirizados. (Dissertação de Mestrado). Faculdade de Filosofia, Ciências e Letras de Ribeirão Preto, Universidade de São Paulo, Ribeirão Preto.

A terceirização é uma forma flexível de emprego que tem sido largamente utilizada no contexto internacional e nacional, sendo que no Brasil essa prática passou a ser comum a partir de 1990. Segundo dados da literatura, a terceirização é responsável por gerar impactos negativos para os trabalhadores, principalmente em relação à sua saúde, e o estresse tem sido citado como o impacto mais recorrente. O estresse contribui para a manifestação de problemas físicos e psicológicos, para o empobrecimento da saúde e para o aumento do absenteísmo e diminuição da produtividade nas organizações, e pode ser causado por fatores do contexto de trabalho, chamados fatores de risco psicossocial. Mediante revisão de literatura, nota-se a escassez de pesquisas brasileiras que visam identificar os fatores de risco psicossocial no contexto da terceirização. Sendo assim, o objetivo do presente estudo foi identificar os fatores de risco psicossocial que podem interferir no estresse e na saúde de agentes de limpeza terceirizados e as estratégias que podem ser adotadas para a melhoria do trabalho terceirizado. Esta pesquisa consistiu em um estudo de caso de caráter exploratório, com utilização do método misto. Os dados foram coletados individualmente e os aspectos éticos envolvidos foram respeitados. Com os agentes de limpeza, foi realizada uma entrevista e aplicado o COPSOQ II e um questionário de dados sociodemográficos. Com os gestores da empresa terceirizada, foi realizada uma entrevista. Foram realizadas análises estatísticas descritivas e de correlação, os dados qualitativos foram analisados por meio da análise temática e os resultados de ambas as análises foram integrados e sintetizados. Os fatores de risco psicossocial identificados foram agrupados nos seguintes temas: Organização do trabalho e conteúdo das tarefas, Relações sociais e liderança, Exigências no trabalho e Interface família-indivíduo. As sugestões de estratégias para melhoria do trabalho, fornecida pelos participantes, consistiram em estratégias primárias de nível organizacional e grupal. Foi possível estabelecer relações entre as características da terceirização, as características do serviço de limpeza, questões de gênero e os fatores de risco psicossocial. Entre as características da terceirização que podem levar à exposição a fatores de risco psicossocial, destacou-se a existência de dupla hierarquia e as singularidades do contrato de trabalho. Tais resultados indicam a relevância das particularidades do trabalho terceirizado para a exposição dos trabalhadores aos fatores de risco psicossocial. Mais estudos são necessários a fim de verificar e sistematizar a existência de relações entre as variáveis estudadas, e estruturar e testar programas de intervenção para a redução do estresse no ambiente de trabalho.

Palavras-chave: Estresse ocupacional. Fatores de risco. Serviços terceirizados. Saúde do trabalhador. 


\begin{abstract}
Mandarini, M. B. (2018). Psychosocial risk factors, stress and health in outsourced cleaning agents. (Dissertação de Mestrado). Faculdade de Filosofia, Ciências e Letras de Ribeirão Preto, Universidade de São Paulo, Ribeirão Preto.
\end{abstract}

Outsourcing is a flexible form of employment that has been widely used in the international and national context, and this practice has become common since 1990 in Brazil. According to the literature data, outsourcing is responsible for gerenating negative impacts on workers, especially in relation to their health, and stress has been cited as the most recurrent impact. Stress contributes to physical and psychological problems manifestation, to health impoverishment and to absenteeism increase and productivity decrease in organizations, and can be caused by work context factors, called psychosocial risk factors. A literature review shows few Brazilian research aimed to identify the psychosocial risk factos in the outsourcing context. Thus, the objective of the present study was to identify the psychosocial risk factors that may interfere in stress and health of outsourced cleaning agents and the strategies that can be adopted to improve outsourced work. This research consisted on a exploratory case study using the mixed method. Data were collected individually and the ethical aspects involved were respected. An interview was conducted and COPSOQ II and a sociodemographic data questionnaire were applied with the cleaning agents. An interview was conducted with the outsourced company managers. Statistical descriptive and correlation analysis were performed, the qualitative data were analyzed through the thematic analysis and the results of both analysis were integrated and synthesized. The psychosocial risk factors identified were grouped into the following themes: Work organization and task content, Social relations and leadership, Work requirements and Family-work interface. Work improvement suggested strategies, provided by the participants, consisted of primary strategies at organizational and group level. It was possible to establish relationships between outsourcing characteristics, cleaning service characteristics, gender related factors and psychosocial risk factors. Among the characteristics of outsourcing that can lead to exposure to psychosocial risk factors, it was highlighted the existence of a double hierarchy and the singularities of the work contract. These results indicate the relevance of outsourced work particulatiries for workers' exposure to psychosocial risk factors. More studies are needed to verify and systematize the existence of relationships between the studied variables and to structure and test intervention programs for stress reduction in the work environment.

Palavras-chave: Occupational stress. Risk factors. Outsourced services. Occupational Health. 


\section{Sumário}

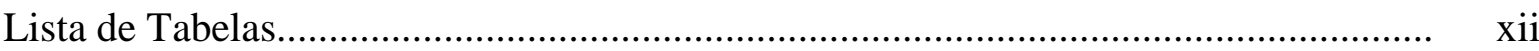

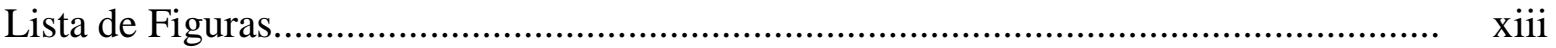

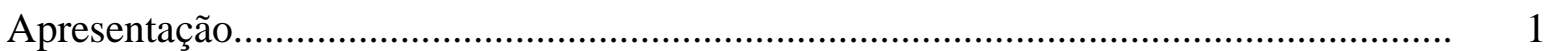

Capítulo 1. Terceirização e seus impactos para os trabalhadores.......................................... 6

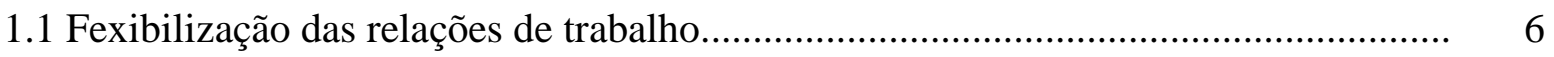

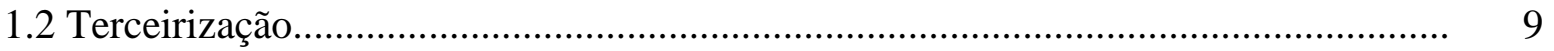

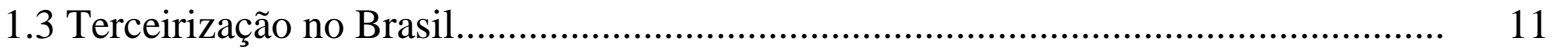

1.4 Impactos da terceirização para os trabalhadores....................................................... 15

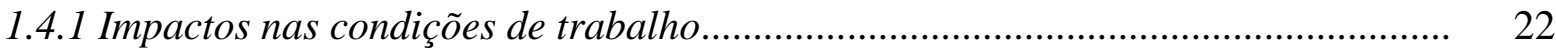

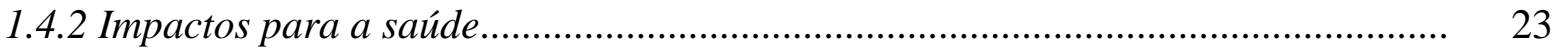

1.5 Serviço de limpeza terceirizado..................................................................... 25

Capítulo 2. Estresse, saúde e fatores de risco psicossocial.......................................... 29

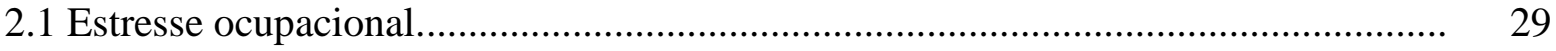

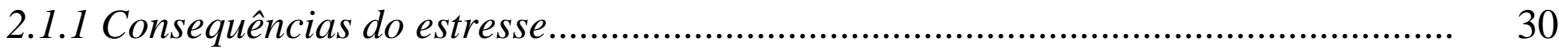

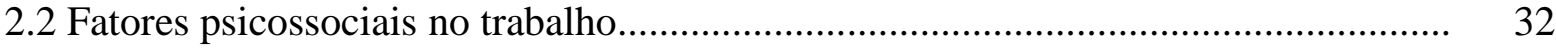

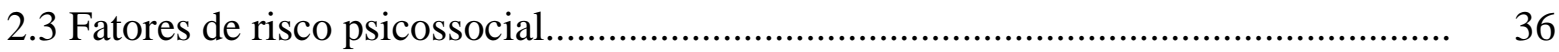

Capítulo 3. Revisão de literatura: fatores de risco psicossocial e estresse em trabalhadores

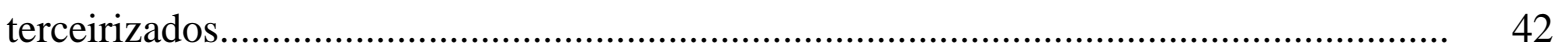

3.1 Revisão sistemática da litertura: descrição do percurso.......................................... 42

3.2 Componentes do modelo de investigação: achados de pesquisa............................... 54

3.2.1 Organização do trabalho e conteúdo das tarefas.................................................. 55

3.2.2 Exigências no trabalho..................................................................................... 58

3.2.3 Relações sociais e liderança............................................................................ 59

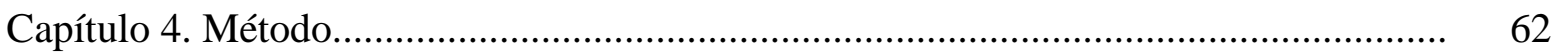

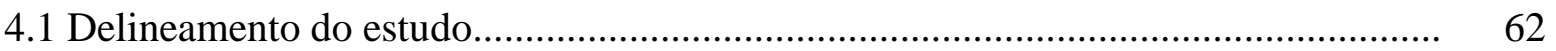

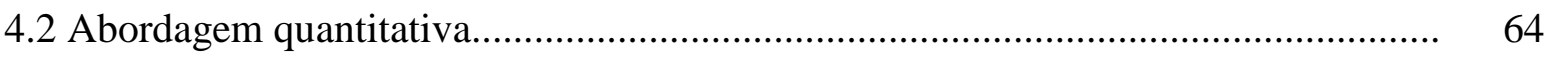

4.2.1 Questionário de dados sociodemográficos........................................................... 64

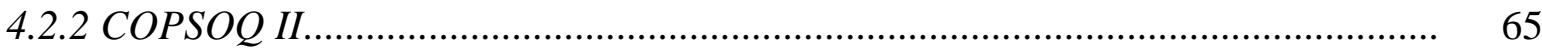

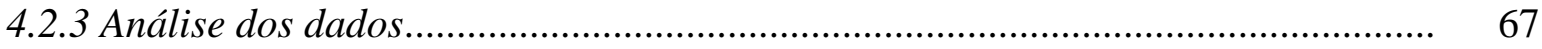


4.3 Abordagem qualitativa.

4.3.1 Roteiro de entrevista semiestruturada utilizado com os gestores.......................... 68

4.3.2 Roteiro de entrevista semiestruturada utilizado com os trabalhadores................. 69

4.3.3 Análise dos dados..................................................................................... 70

4.4 Adaptação dos instrumentos de medida................................................................... 71

4.4.1 Validação semântica......................................................................................... 71

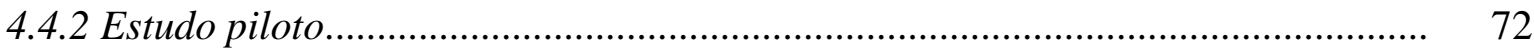

4.5 Características da organização participante.......................................................... $\quad 72$

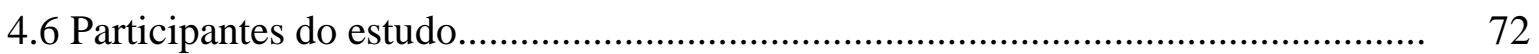

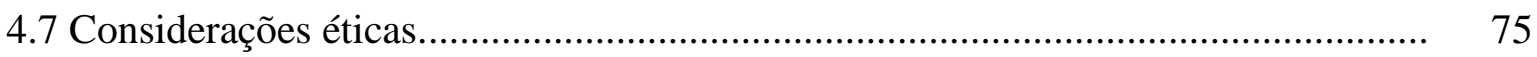

4.8 Procedimento de coleta dos dados..................................................................... 76

4.9 Procedimento de análise de dados......................................................................... 77

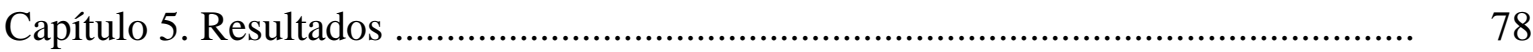

5.1 Adaptação dos instrumentos de medida................................................................ 78

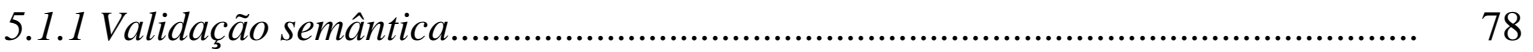

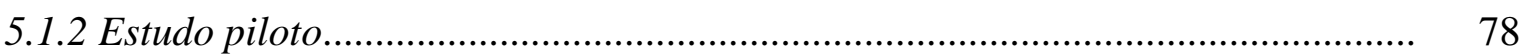

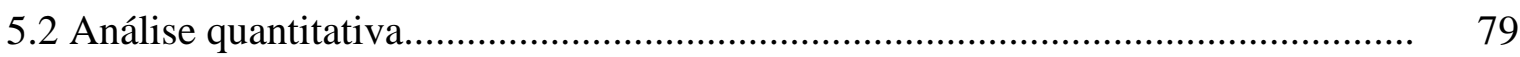

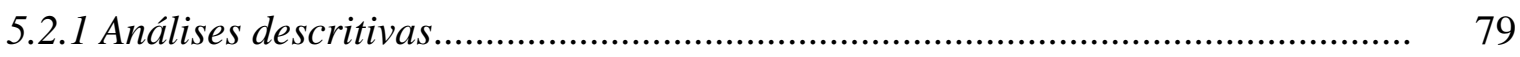

5.2.2 Distribuição normal dos dados.......................................................................... 83

5.2.3 Análises de correlações bivariadas................................................................... 86

5.3 Análise qualitativa......................................................................................... 91

5.3.1 Organização do trabalho e conteúdo das tarefas................................................ 91

5.3.2 Relações sociais e liderança ............................................................................ 103

5.3.3 Exigências no trabalho................................................................................... 110

5.3.4 Interface família-indivíduo.................................................................... 114

5.3.5 Saúde e estresse ........................................................................................ 116

5.3.6 Sugestões de melhoria ................................................................................ 120

5.4 Triangulação e síntese dos dados.......................................................................... 123

Capítulo 6. Discussão............................................................................................ 124

6.1 Fatores de risco psicossocial e suas relações com o estresse e a saúde.................. 124

6.2 Estratégias organizacionais........................................................................ 131

Capítulo 7. Considerações finais.......................................................................... 134 


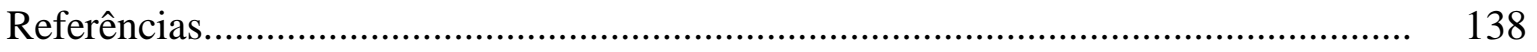

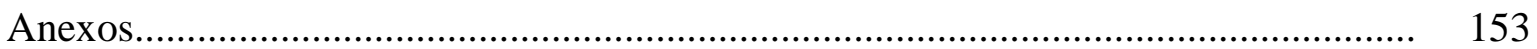

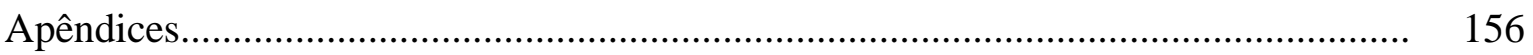




\section{Lista de Tabelas}

Tabela 1 - Objetivo de pesquisa, participantes e subcategorias referentes aos artigos selecionados $(N=20)$

Tabela 2 - Objetivo, metodologia, tipo de pesquisa, participantes e instrumentos referentes aos artigos selecionados $(N=25)$

Tabela 3 - Fatores de risco psicossocial, número de artigos e relação com o

estresse.

Tabela 4 - Número de questões referente a cada tema abordado

Tabela 5 - Escalas, dimensões, número de itens, consistência interna e nível da dimensão utilizados da versão média portuguesa do COPSOQ II

Tabela 6 - Número de questões referente a cada tema abordado no roteiro de entrevista utilizado com os gestores

Tabela 7 - Número de questões referente a cada tema abordado no roteiro de entrevista utilizado com os trabalhadores

Tabela 8 - Perfil das agentes de limpeza participantes

Tabela 9 - Resultados descritivos das dimensões referentes ao COPSOQ II.

Tabela 10 - Valores de consistência interna das escalas e das dimensões Estresse e Saúde referentes ao COPSOQ II.

Tabela 11 - Valores de assimetria e curtose das dimensões referentes ao

COPSOQ II.

Tabela 12 - Valores do teste de Levene das dimensões referentes ao COPSOQ II

Tabela 13 - Valores do coeficiente de correlação de Pearson $(r)$ das escalas referentes ao COPSOQ II.

Tabela 14 - Valores do coeficiente de correlação de Pearson $(r)$ das dimensões referentes ao COPSOQ II 


\section{Lista de Figuras}

Figura 1 - Modelo de investigação proposto................................................................. 3

Figura 2 - Estrutura geral de desenvolvimento do texto............................................... 5

Figura 3 - Classificação das teorias de estresse no trabalho......................................... 30

Figura 4 - Diagrama dos fatores psicossociais relacionados ao trabalho....................... 33

Figura 5 - Resultados da exposição aos riscos psicossociais....................................... 35

Figura 6 - Fatores de risco psicossocial relacionados ao conteúdo do trabalho............. 40

Figura 7 - Fatores de risco psicossocial relacionados ao contex to do trabalho.............. 41

Figura 8 - Fases componentes da seleção dos artigos da revisão sistemática................ 45

Figura 9 - Delineamento de pesquisa a partir do arranjo convergente.......................... 63

Figura 10 - Origem e objetivo dos instrumentos utilizados na abordagem

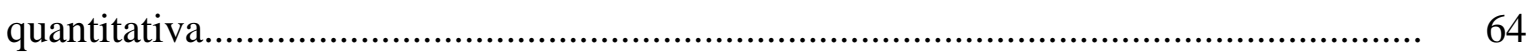

Figura 11 - Resumo das informações sobre os instrumentos a serem utilizados na abordagem

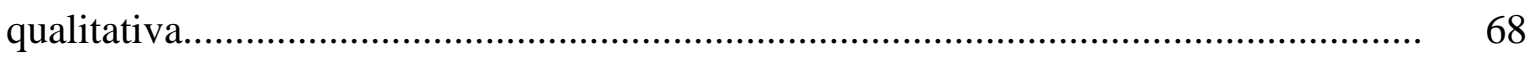

Figura 12 - Fases da análise temática................................................................... 71

Figura 13 - Características individuais das participantes.......................................... 75

Figura 14 - Dimensões do COPSOQ II organizadas de acordo com os tercis............... 82

Figura 15 - Valores extremos correspondentes às dimensões do COPSOQ II............... 84

Figura 16 - Diagrama de dispersão da escala Exigências no Trabalho e da dimensão

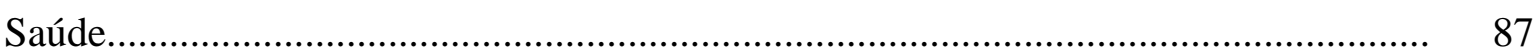

Figura 17 - Diagrama de dispersão das dimensões Conflito de Papeis e Estresse......... $\quad 89$

Figura 18 - Diagrama de dispersão das dimensões Exigências Emocionais e

Estresse

Figura 19 - Diagrama de dispersão das dimensões Exigências Quantitativas e

Saúde.

Figura 20 - Características das unidades participantes............................................ 94

Figura 21 - Organograma funcional da empresa................................................. 96

Figura 22 - Fatores de risco psicossocial identificados pelas participantes e associados ao estresse, frequência e exemplos de relatos. 
Figura 23 - Fatores de risco psicossocial identificados pelas participantes e associados à saúde, frequência e exemplos de relatos.

Figura 24 - Sugestões de melhoria fornecidas pelas participantes, frequências, nível a que se referem e exemplos de relatos.

Figura 25 - Relações entre as características da terceirização e os fatores de risco

psicossocial

Figura 26 - Relações entre as características do serviço de limpeza e os fatores de risco psicossocial.

Figura 27 - Relações entre o gênero e os fatores de risco psicossocial 


\section{Apresentação}

A terceirização constitui uma forma flexível de emprego que surgiu como meio de suprir as demandas do mercado sem alterar o número enxuto de trabalhadores permanentes (Martins, 2015), e pode ser definida como o processo de contratação de trabalhadores de uma empresa externa, cujo objetivo principal é a redução dos custos com mão-de-obra (Marcelino \& Cavalcante, 2012). Segundo Lima (2010), as empresas optam por utilizar a terceirização como forma de obter vantagem competitiva frente ao mercado, por meio da centralização dos esforços em suas atividades-fim, delegando a terceiros todas as atividades que não se relacionam com o objetivo principal da empresa.

No Brasil, a terceirização passou a ser largamente utilizada no final da década de 1980 e início da década de 1990, a partir da abertura econômica do país ao mercado externo (Rego, 2000) e do início da privatização de empresas e redução de gastos sociais com saúde e educação (Jorge, 2011). Desde então, o número de empresas e trabalhadores terceirizados têm aumentado significativamente (Pochmann, 2011), sendo que o número aproximado de trabalhadores terceirizados no ano de 2013 era de 12,7 milhões (DIEESE-CUT, 2014).

Segundo a revisão sistemática de literatura realizada por Mandarini, Alves e Sticca (2016), a prática da terceirização pode gerar impactos nas condições de trabalho e na saúde dos trabalhadores terceirizados, sendo o estresse o principal impacto na saúde. O estresse no trabalho, de acordo com as teorias contemporâneas, é um estado emocional desencadeado pela avaliação do trabalhador sobre seu contexto de trabalho e pode desencadear significativas mudanças fisiológicas, no modo de pensar e de se comportar, além de elevar o risco de doenças (Leka \& Houdmont, 2010). Também gera consequências para as organizações, tais quais aumento do absenteísmo, diminuição da produtividade e rotatividade dos trabalhadores (Krumm, 2013).

Os aspectos do contexto de trabalho que podem desencadear o estresse são constituídos pelo conteúdo das tarefas, pelo ambiente de trabalho e pelas condições da organização (ILO, 1984). A interação entre tais fatores organizacionais e as características individuais pode causar efeitos adversos físicos ou psicológicos na saúde dos trabalhadores por meio da experiência de estresse, sendo que na literatura os fatores relacionados ao contexto de trabalho que podem levar ao estresse são chamados de fatores de risco psicossocial (Cox, Griffiths \& Rial-González, 2000; Leka, Griffiths \& Cox, 2003; Schabracq, Winnubst \& Cooper, 2003). Tais fatores e o estresse ocupacional são reconhecidos como os 
principais problemas de saúde e segurança no trabalho, gerando altos gastos para a saúde pública (Leka \& Cox, 2008).

Embora haja um interesse crescente de pesquisadores em contribuir com a identificação dos fatores de risco psicossocial, são poucos os estudos que se propõem a identificar tais fatores relacionados ao contexto de trabalho terceirizado. Segundo DavisBlake e Broschak (2009), a terceirização modifica a natureza das tarefas, a distribuição das atividades, a organização dos relacionamentos entre as empresas e a interação entre os indivíduos, e tais alterações podem contribuir para a emergência de novos fatores de risco psicossocial no trabalho (Leka \& Houdmont, 2010).

A análise sistemática da literatura aponta para um número reduzido de pesquisas que buscam identificar os fatores de risco psicossocial relacionados ao contexto da terceirização, sendo que a maioria é de origem estrangeira e aborda tal temática de forma indireta ou superficial. Apesar das contribuições dos estudos, em sua maioria, estudos de caso de abordagem qualitativa, para a produção de conhecimentos na área são necessárias mais investigações nacionais que não apenas identifiquem os fatores de risco psicossocial, como também sejam capazes de verificar possíveis relações existentes entre tais fatores, o estresse e a saúde dos profissionais, e que possam propor estratégias organizacionais a fim de minimizar a influência dos fatores de risco psicossocial. Tendo como base a revisão da literatura apresentada, nota-se que a identificação de fatores de risco psicossocial relacionados ao contexto de trabalho terceirizado tem sido pouco estudada no Brasil, sendo que a maioria dos estudos brasileiros apresentam apenas os efeitos de tais fatores, como as consequências do estresse no trabalho e seus danos à saúde.

A partir da apreciação das questões empíricas que permeiam o campo literário nacional e estrangeiro acerca da saúde do trabalhador, com foco nos fatores de risco psicossocial que podem contribuir para o estresse ocupacional e prejuízos à saúde dos trabalhadores terceirizados, além de agendas de pesquisas anteriores que se voltaram a essa temática, o problema de pesquisa desse estudo foi delimitado.

Além disso, deve-se ressaltar que atualmente a terceirização consiste em um tema de grande relevância nacional, devido principalmente à recente aprovação do Projeto de Lei 4.330/2004, que permite a ampliação da terceirização para todas as atividades, incluindo as atividades-fim das empresas, o que pode contribuir para o aumento significativo do número de trabalhadores terceirizados.

Nesse sentido, o presente estudo pretende fornecer elementos que auxiliem na compreensão dos fatores de risco psicossocial que vêm sendo relacionados ao estresse 
ocupacional e a prejuízos à saúde dos trabalhadores terceirizados. Para tanto, propõe-se a identificação das possíveis relações existentes entre tais fatores, o estresse e a saúde dos profissionais, como mostra a Figura 1.

Figura 1 - Modelo de investigação proposto

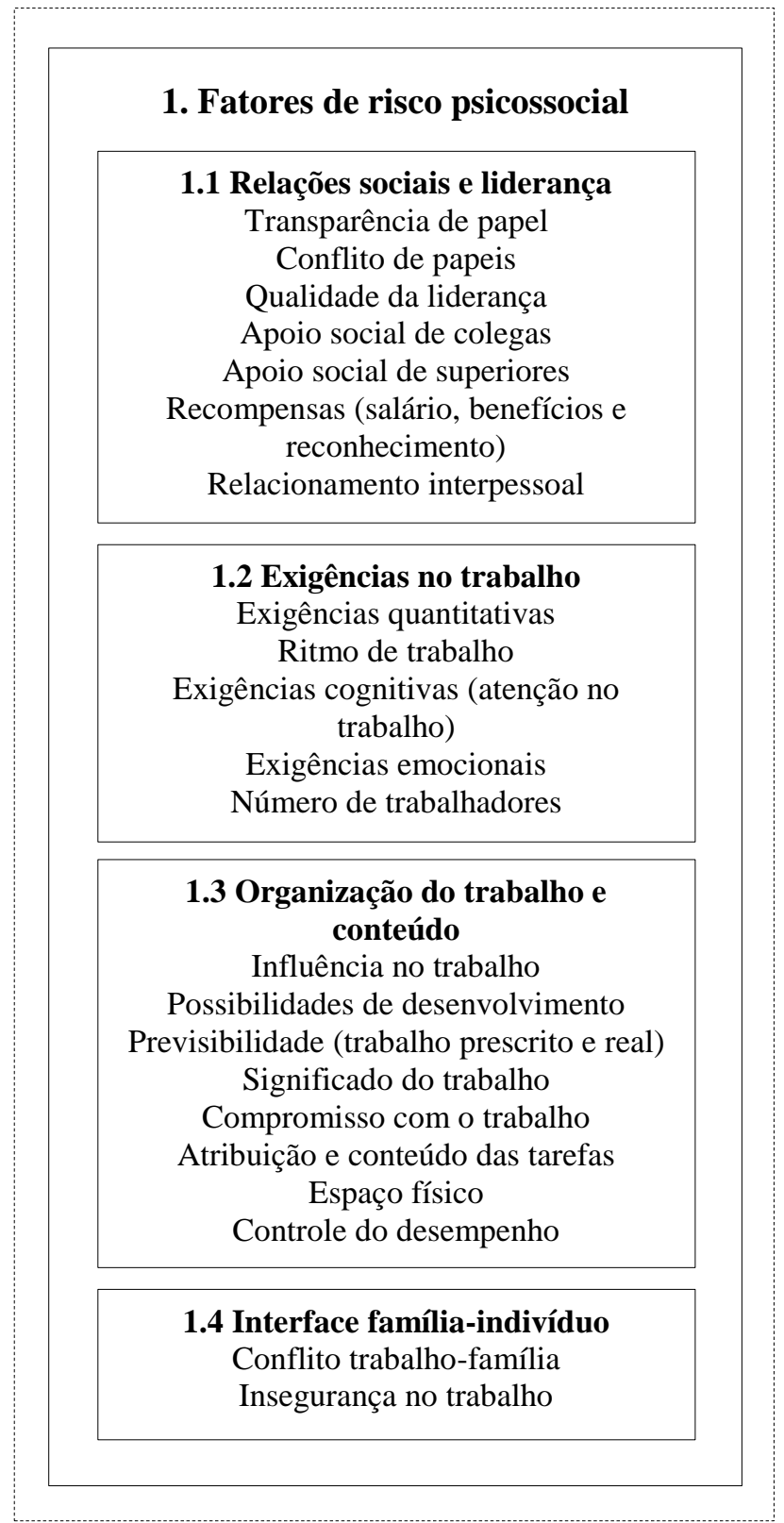

\section{Impactos para os profissionais}

2.1 Estresse

2.2 Saúde

Fonte: elaboração da autora.

Em decorrência do modelo apresentado, são propostas as seguintes questões de pesquisa:

1. Quais são os fatores de risco psicossocial que podem ter relação com o estresse e a saúde de trabalhadores terceirizados? 
2. De que forma os fatores de risco psicossocial podem interferir no estresse e na saúde dos trabalhadores terceirizados?

3. Que ações e estratégias organizacionais podem ser adotadas para minimizar os impactos negativos decorrentes de tais fatores?

A fim de responder às questões empíricas acima descritas, foram traçados os objetivos da pesquisa, apresentados a seguir:

\section{Objetivo geral}

Identificar os fatores de risco psicossocial que podem interferir no estresse e na saúde de agentes de limpeza terceirizados que prestam serviços para uma universidade pública brasileira, assim como propor ações e estratégias organizacionais para minimizar a influência de tais fatores, a fim de alcançar melhorias na qualidade de vida destes profisisonais.

\section{Objetivos específicos}

- Realizar correlações entre os fatores de risco psicossocial, o estresse e a saúde dos profissionais terceirizados.

- Identificar características específicas da terceirização que podem interferir no estresse e na saúde destes profissionais.

Para facilitar o acompanhamento do texto, a Figura 2 mostra o modo como os capítulos e seções estão estruturados. 
Figura 2 - Estrutura geral de desenvolvimento do texto

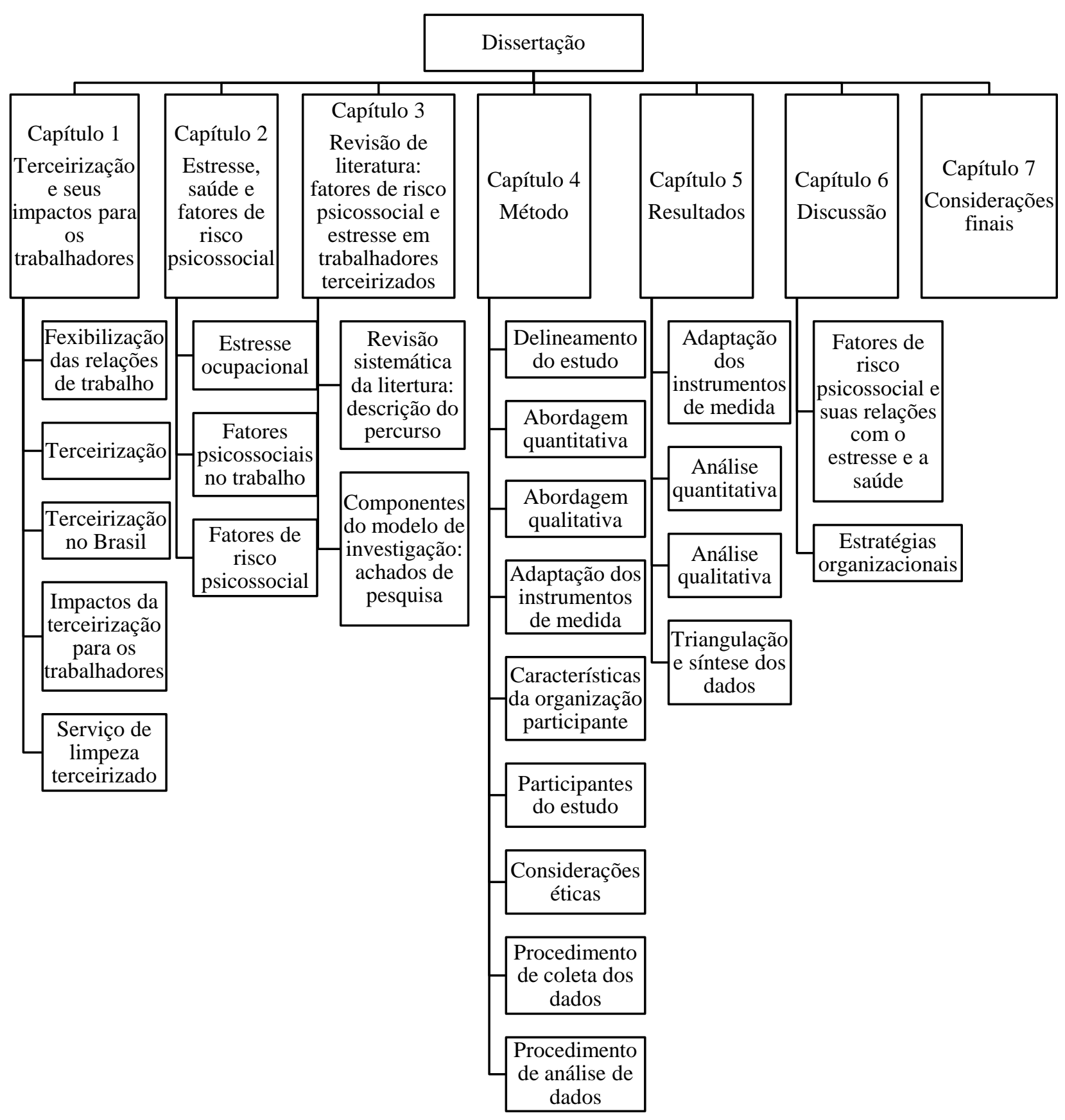

Fonte: elaboração da autora. 


\section{Capítulo 1. Terceirização e seus impactos para os trabalhadores}

\section{Objetivo do capítulo 1}

O presente capítulo apresenta o contexto de trabalho terceirizado. Inicialmente, traça o histórico da terceirização no mundo e no Brasil, assim como suas características, vantagens e desvantagens, e impactos para os trabalhadores. Em seguida, discorre sobre o serviço de limpeza terceirizado, contexto em que estão inseridos os participantes deste estudo.

\subsection{Flexibilização das relações de trabalho}

No sistema capitalista, as transformações nas formas de organização da produção são fenômenos constantes que acontecem de acordo com as necessidades do processo de acumulação do capital, visando assegurar sua expansão e acumulação (Previtali, 2009). Nesse contexto, a atual reestruturação produtiva constitui uma intensa transformação do processo produtivo, resultado de uma crise estrutural do capitalismo iniciada em 1970. O sistema de produção fordista, vigente até então, já não era considerado suficiente para suprir as necessidades de reprodução do capital em escala global, e aos poucos passou a ser substituído pelo sistema de produção chamado toyotismo (Vasapollo, 2005).

Caracterizado como um sistema produtivo pautado na eliminação de desperdícios, este passou a ser utilizado mundialmente a partir da década de 1970, constituindo uma nova forma de flexibilização da acumulação de capital. A incorporação do toyotismo visa à redução dos desperdícios e à adequação da produção à dinâmica do mercado, e para isso busca a redução de todos os custos e do tempo referentes à produção, a adequação dos horários de trabalho de acordo com o mercado e a utilização de formas flexíveis de trabalho como forma de adequar o número de trabalhadores às necessidades do mercado (Garza, Valencia \& Fernández, 2012).

Uma das principais características do modelo de produção toyotista é a horizontalidade da estrutura organizacional, sendo que aproximadamente apenas $25 \%$ da produção total é realizada no interior da fábrica toyotista. A responsabilidade pela maior parte da produção é transferida para outras fábricas, garantido a horizontalidade do processo produtivo e a possibilidade de aumentar a produção sem aumentar o contingente de trabalhadores, constituindo, assim, a flexibilização da produção (Antunes, 2002). Em relação aos funcionários fixos, é esperado que estes trabalhem em equipes e que sejam capazes de efetuar múltiplas tarefas, de acordo com a necessidade da produção (Jorge, 2011). 
Para Antunes (2002), o modelo de acumulação flexível proposto pelo toyotismo

(...) trata-se de um processo de organização do trabalho cuja finalidade essencial, real, é a da intensificação das condições de exploração da força de trabalho, reduzindo ou eliminando em muito tanto o trabalho improdutivo, que não cria valor, ou suas formas assemelhadas. . . . Reengenharia, lean production, team work, eliminação de postos de trabalho, aumento da produtividade, qualidade total, fazem parte do ideário (e da prática) cotidiana da "fábrica moderna". Se, no apogeu do taylorismo/fordismo, a pujança de uma empresa mensurava-se pelo número de operários que nela exerciam sua atividade laborativa, pode-se dizer que, na era da acumulação flexível e da "empresa enxuta", merecem destaque, e são citadas como exemplos a serem seguidos, aquelas empresas que dispõem de menor contingente de força de trabalho e que, apesar disso, têm maiores índices de produtividade. (Antunes, 2002, p. 29$30)$.

Segundo Previtali (2009), a expansão desses novos paradigmas introduzidos pelo toyotismo foi intensificada a partir da internacionalização dos mercados, da entrada de multinacionais em países considerados de terceiro mundo, da difusão de novas técnicas de controle do trabalho e da intensificação da inovação tecnológica. Além disso, a emergência de um novo tipo de consumidor, que deixa de ser dominado pelo consumo de massa e passa a consumir produtos diferenciados e específicos, contribuiu de forma significativa para a adoção da flexibilização da produção como alternativa a essas mudanças.

Tal forma flexível de trabalho:

(...) se apoia na flexibilidade dos processos de trabalho, dos mercados de trabalho, dos produtos e padrões de consumo. Caracteriza-se pelo surgimento dos setores de produção inteiramente novos, novas maneiras de fornecimento de serviços financeiros, novos mercados e, sobretudo, taxas altamente intensificadas de inovação comercial, tecnológica e organizacional. (Harvey, 2008, p. 140)

De acordo com Costa e Sartori (2005), a flexibilidade é um conceito heterogêneo que combina duas séries de variáveis: quantitativa e qualitativa, e externa e interna, o que resulta em diversas possibilidades de combinações para o trabalho, como flexibilidade numérica (contratos permanentes, temporais, trabalho sob demanda), flexibilidade geográfica (subcontratação/terceirização), flexibilidade funcional (trabalho em equipe, grupos de projeto) e flexibilidade temporal (trabalho noturno, trabalho em turnos, trabalho em tempo parcial, horas extra). 
Para Martins (2015), apesar da flexibilização das condições de trabalho gerar alterações em algumas regras, a proteção dos trabalhadores pelo Estado e o cumprimento das leis trabalhistas ainda são garantidas, mesmo que em menor grau. Tais alterações podem estar relacionadas ao número de trabalhadores contratados, à quantidade de horas trabalhadas, às funções atribuídas aos funcionários, às formas de contratação e à remuneração. A quantidade de trabalhadores contratados pode variar de acordo com as necessidades da empresa, o que também engloba as funções a serem atribuídas, as formas de pagamento e as formas de contratação a serem empregadas.

Neste contexto flexível, a polivalência e a participação em diversas etapas da produção são exigências atribuídas aos profissionais permanentes, sendo que a empresa controla as atividades dos funcionários e organiza seu trabalho em metas e projetos a serem cumpridos, garantindo a multiplicidade funcional dos mesmos. Além disso, a remuneração dos trabalhadores pode ser vinculada ao desempenho, cumprimento das metas e resultados atingidos individualmente ou pelas equipes de trabalho, o que concede aos funcionários certa responsabilidade por seu salário e, em casos de remuneração vinculada ao desempenho coletivo, garante maior comprometimento dos trabalhadores (Baltar \& Krein, 2013).

Em relação às novas formas de contratação, destaca-se o aumento na utilização de diferentes formas de trabalho temporário como meio de suprir as demandas do mercado sem alterar o número enxuto de trabalhadores permanentes. Entre as novas formas de trabalho, pode-se citar o contrato por tempo determinado, o trabalho temporário, o trabalho em domicílio, o trabalho em tempo parcial, o trabalho intermitente, a subcontratação e a terceirização (Batista, 2006; Martins, 2015).

A flexibilidade da jornada de trabalho é outro componente importante da flexibilização das condições de trabalho. Com o objetivo de adaptar a organização da produção às exigências do mercado, a jornada de trabalho pode adquirir diversas formas, como a adoção do banco de horas, que consiste no registro do número de horas trabalhadas e na compensação das horas trabalhadas a mais por horas de tempo livre, a utilização de escalas de trabalho e trabalho em turnos, e a liberação do trabalho aos domingos, entre outras (Krein, 2007). Apesar das diferentes formas de organização da jornada de trabalho, no atual contexto flexível o tempo destinado ao trabalho e o tempo destinado ao descanso não possuem mais uma distinção nítida entre si, sendo que os trabalhadores tendem a permanecer conectados ao trabalho mesmo após o término da jornada, o que é intensificado pelo uso de aparelhos eletrônicos no contexto de trabalho, como celulares e computadores (Baltar \& Krein, 2013). 


\subsection{Terceirização}

A terceirização, também conhecida como outsourcing, é uma das principais práticas de gestão flexível utilizadas atualmente (Davis-Blake \& Broschak, 2009). Segundo tais autores, ela é definida como o ato de obter produtos ou serviços de indivíduos ou organizações que estão fora dos limites de uma empresa, sendo que esses produtos ou serviços poderiam ser produzidos por funcionários e gestores da própria organização. Para Marcelino e Cavalcante (2012), a terceirização é o processo de contratação de trabalhadores de uma empresa externa, com o objetivo principal de se reduzir os custos com mão-de-obra, deixando de estabelecer uma relação de contrato trabalhista e passando a compor uma relação comercial entre empresas. Fontanella, Tavares e Leiria (1995) definem a terceirização como uma técnica administrativa, que consiste na compra contínua de serviços específicos relacionados às atividades periféricas e secundárias da empresa, cujo objetivo final é possibiliar que a organização se ocupe apenas com suas atividades centrais, permitindo ganhos em competitividade.

No contexto da terceirização, alguns termos específicos são utilizados. É denominada empresa-mãe ou empresa contratante aquela organização que contrata produtos ou serviços de outra empresa, que é chamada de empresa terceira ou contratada. A empresa contratante terceiriza a atividade, que pode ser atividade-fim ou atividade-meio. A atividade-fim é aquela que faz parte do processo específico da produção, que é a razão de ser da empresa, enquanto a atividade-meio faz parte do processo de apoio à produção da atividade-fim, abrangendo as atividades periféricas e de apoio (DIEESE, 2007).

Segundo Clott (2004), trabalhos divulgados por teóricos e especialistas em gestão administrativa foram essenciais para a distinção das atividades componentes de uma organização entre atividades-fim e atividades-meio. Tais trabalhos recomendavam que, para se alcançar maior qualidade, agilidade, melhorias contínuas no serviço e redução dos custos para os clientes, as empresas deveriam manter o foco apenas em suas atividades-fim, repassando as atividades-meio a empresas especializadas no setor.

O processo de terceirização pode adquirir diferentes formas, como operações pontuais, contratos de longo prazo e alianças estratégias envolvendo contratos que garantem exclusividade entre as partes e, além disso, pode ocorrer entre organizações geograficamente próximas ou envolver diferentes países, o que é conhecido como offshoring (Davis-Blake \& Broschak, 2009). Além disso, a empresa contratante pode optar por comprar parte da produção de uma empresa contratada ou por contratar essa empresa para realizar tarefas 
dentro da empresa-mãe, o que geralmente acontece com as atividades de limpeza, vigilância e alimentação (DIEESE, 2007).

Segundo o trabalho publicado por R. Silva (2015), a prática de terceirizar atividades surge como uma alternativa propícia à redução de custos nas organizações, principalmente dos custos relacionados à força de trabalho. Para Lima (2010), as empresas optam por utilizar a terceirização como forma de obter vantagem competitiva frente ao mercado, por meio da centralização dos esforços em suas atividades-fim, delegando a terceiros todas as atividades que não se relacionam com o objetivo principal da empresa e, consequentemente, reduzindo custos fixos de produção.

Apesar de não haver consenso em relação ao período em que a terceirização começou a ser utilizada pelas empresas, sabe-se que ela não constitui um fenômeno recente (Clott, 2004). Existem indícios de que tal prática já era utilizada no final do século XVIII, principalmente no setor têxtil, sob a forma de trabalho domiciliar (Batista, 2006; Davis-Blake \& Broschak, 2009), mas foi a partir da década de 1980 que a mesma passou a ganhar popularidade devido à transferência de serviços rotineiros a terceiros, tais como limpeza, alimentação, administração de benefícios e folha de pagamento (Davis-Blake \& Broschak, 2009). Nos Estados Unidos, a transferência de parte da produção para países considerados menos desenvolvidos, com o objetivo de reduzir os custos com a mão-de-obra, tem acontecido desde 1950, pricipalmente nos setores automobilísticos e têxtil, e na produção de brinquedos e eletrônicos (Clott, 2004).

Atualmente, os serviços mais terceirizados internacionalmente pertencem aos setores de indústrias têxtil, calçados, máquinas industriais, equipamentos elétricos, equipamentos de transporte e produtos químicos (Grossman \& Helpman, 2005). Além desses, os serviços terceirizados de tecnologia da informação (TI) e de atividades relacionadas às áreas de finanças, contabilidade, departamento pessoal, call center, vendas e suporte ao cliente (chamadas de Business Process Outsourcing - BPO) também são amplamente utilizados (Clott, 2004). Segundo Bardhan e Kroll (2003), no ano de 2003, o setor de serviços de TI na Índia empregou mais de 200 mil trabalhadores terceirizados e, na época, correspondia a um mercado que movimentou aproximadamente 2,3 bilhões de dólares, com média de crescimento de 60\% ao ano. Em 2010, a terceirização de serviços de BPO gerou 775 milhões de euros na Espanha, e o número de empresas que prestavam serviços terceirizados no desenvolvimento de aplicativos passou de 2.700 em 2009 para 13.700 em 2010 (Solera, 2011). Dados publicados pelo grupo Statistic Brain Research Institute (2017) indicam que, no ano de 2016, os Estados Unidos contrataram cerca de 1.457.000 trabalhos terceirizados 
provenientes de outros países, sendo que os países que oferecem maior força de trabalho terceirizado a outros países são a Índia, que possui aproximadamente 1.430 .000 .000 postos de trabalho terceirizado, a Indonésia, com 1.033.000.000 postos e a China, cujo número aproximado de trabalhos terceirizados é de 780.000.000.

Entre as vantagens apontadas pela literatura associadas à utilização da terceirização nas organizações, pode-se destacar: a focalização nas atividades-fim da empresa (Clott, 2004; R. Silva, 2015), a possibilidade de manter uma estrutura mais exuta, o que garante maior agilidade ao realizar mudanças exigidas pelo mercado (Batista, 2006), a redução dos procedimentos burocráticos, resultado da diminuição do tamanho das empresas e da simplificação dos processos (R. Silva, 2015), a possibilidade de melhoria na qualidade dos produtos e serviços terceirizados, por meio da contratação de empresas terceirizadas especializadas em tais atividades (R. Silva, 2015), e a redução de custos, resultado de todos os aspectos anteriores (Batista, 2006; Lima, 2010; Statistic Brain Research Institute, 2017).

\subsection{Terceirização no Brasil}

No Brasil, a terceirização já era utilizada durante o século XIX nas indústrias têxtil e de calçados, mas foi a partir da década de 1950 que ela passou a ser empregada como um método de gestão organizacional, principalmente devido à chegada de indústrias automobilísticas, que introduziram a externalização de parte da produção como estratégia competitiva (Batista, 2006). Apesar de já ser utilizada nesse período, ela se intensificou e ganhou maior popularidade no contexto público e privado no final da década de 1980 e início da década de 1990, a partir de mudanças institucionais e estruturais na economia brasileira. Nesse período, houve um movimento a favor da abertura econômica do país ao exterior, impulsionado pelo esgotamento do modelo de substituição de importações, que dificultava a entrada de produtos importados no país, e pela crescente desregulamentação dos mercados internacionais (Rego, 2000).

Tal processo de abertura econômica acentuou a necessidade de adaptação da produção brasileira aos parâmetros de competição advindos do mercado internacional. Como a indústria nacional estava até então protegida pelo Estado, o que era considerado fonte de prejuízo econômico ao país, certas medidas foram adotadas com o objetivo de estimular a competitividade dos produtos brasileiros (R. Silva, 2015), sendo que tais medidas foram baseadas nas políticas neoliberais vigentes nos países europeus e nos Estados Unidos, tais 
quais a privatização de empresas e reduções nos gastos sociais com saúde e educação (Jorge, 2011).

No contexto privado, a abertura da economia brasileira ao mercado externo induziu as empresas nacionais a buscarem a garantia de seu lugar no mercado nacional e internacional, sendo que essas passaram a utilizar estratégias que permitiam ganhos de produtividade e diferenciais de competitividade, baseadas na redução de custos e do número de funcionários, além da terceirização das atividades-meio. Sendo assim, a terceirização passou a estar presente nas empresas brasileiras principalmente como estratégia competitiva e meio de redução de custos com a produção (Jorge, 2011; R. Silva, 2015), já que o vínculo de trabalho terceirizado pode ser rompido rapidamente pelo empregador sem que haja a necessidade de quitar as despesas legais envolvidas no processo de demissão (Krein, 2013).

No âmbito público, foi realizada uma reforma do Estado composta pela limitação de sua interferência na economia, que ocorreu essencialmente pela transferência de algumas atividades, não consideradas atividades-fim do Estado, do setor público para o setor privado, o que ficou conhecido como Terceiro Setor (DIEESE, 2007; R. Silva, 2015). Essa reorganização do setor público foi pautada pela divisão das seguintes áreas da função do Estado: atividades exclusivas do Estado, serviços sociais e científicos do Estado, e produção de bens e serviços (Santos, Ribeiro, Ribeiro, Santos \& Costa, 2004). A partir deste modelo, as atividades exclusivas do Estado deveriam permanecer como responsabilidade pública, enquanto os serviços sociais e científicos, como escolas, universidades, hospitais e museus, entre outros, deveriam ser subsidiados pelo Estado e contar com doações voluntárias da sociedade, deixando de ser responsabilidade total do Estado. Por fim, a produção de bens e serviços deixou de ser considerada como responsabilidade pública através de programas de privatização. Ademais, as áreas que passaram a compor a responsabilidade do Estado foram diferenciadas entre atividades principais e atividades auxiliares, como limpeza, vigilância e transporte, sendo estas submetidas ao processo de terceirização (DIEESE, 2007; R. Silva, 2015).

Em relação à prevalência do serviço terceirizado no país, Chahad (2002) realizou uma pesquisa com 2002 empresas distribuídas em todo o território brasileiro, abordando as práticas flexíveis de trabalho utilizadas por elas. Os resultados apontaram que $68 \%$ das empresas participantes utilizavam algum tipo de trabalho flexível, sendo a região Sudeste (55\%) a que mais possuá empregados sob formas flexíveis de contrato de trabalho, seguida pelas regiões Sul, Centro-Oeste, Nordeste e Norte. A terceirização foi a modalidade mais utilizada, sendo que 56\% das empresas declararam utilizar essa forma de contratação, e, além 
disso, entre as razões pelas quais as organizações optaram por utilizar modalidades de contrato de trabalho flexível, a redução do custo da mão-de-obra foi o objetivo mais frequente $(33 \%)$.

Apesar da dificuldade em quantificar com precisão o número de trabalhadores terceirizados, principalmente devido à insuficiência de dados disponíveis e aos diferentes arranjos que a terceirização pode apresentar (Batista, 2006), de acordo com Pochmann (2011) o aumento do número de empresas terceirizadas tem sido constante desde 1985 e passou por uma ampliação significativa a partir de 1995. Segundo os dados publicados por Druck e Borges (2002), em 2000, aproximadamente 93\% das indústrias petroquímicas contratavam serviços terceirizados de vigilância e segurança, $87 \%$ contratavam serviços terceirizados de limpeza, e $67 \%$ de manutenção predial. No ano de 2009, foi registrado um número aproximado de 31 mil empresas de serviços terceirizados no Brasil, sendo que 15,3 mil estavam localizadas nos estados de São Paulo, Rio de Janeiro e Paraná (Jorge, 2011). Em 2010, o número de terceirizados era estimado em 10,5 milhões, o que correspondia a 23,9\% dos trabalhadores com carteira assinada, e o número de empresas terceirizadas era de 32.580 (SINDEPRESTEM, 2012). Segundo o relatório publicado pelo DIEESE e CUT (2014), o número de trabalhadores terceirizados no ano de 2013 correspondeu a aproximadamente $27 \%$ do mercado formal de trabalho, totalizando mais de 12,7 milhões de trabalhadores, além dos terceiros que trabalhavam informalmente.

As principais atividades terceirizadas atualmente, de acordo com Pinto (2017), são: montagem e manutenção de equipamentos, segurança e vigilância, tecnologia da informação, limpeza e conservação, pesquisa e desenvolvimento, e telemarketing. Segundo a autora, 1,34 milhões de trabalhadores terceirizados se enquadram nessas áreas de atuação.

As principais formas de terceirização utilizadas atualmente no Brasil, de acordo com Marcelino e Cavalcante (2012), são: cooperativas de trabalhadores, cujo status jurídico é de uma empresa, sendo que estas prestam serviços a empresas contratantes e recebem por produção; empresas externas que são contratadas para tarefas específicas e podem desempenhar o trabalho dentro ou fora da empresa contratante, tais como limpeza e centrais de teleatendimento; empresas externas que pertencem a uma rede de fornecedores, constituindo uma fração da cadeia de trabalho que resulta no produto final da empresa contratante (como fornecedores de autopeças para as montadoras); Personalidades Jurídicas, que consistem em empresas individuais que prestam serviços à empresa contratante; quarteirização, que consiste na contratação de empresas para gerir os contratos terceirizados de uma empresa contratante. 
No âmbito jurídico, a Súmula 331 do Tribunal Superior do Trabalho legaliza a prática da terceirização para as atividades-meio, consideradas como complementares ou de apoio às atividades-fim das organizações:

III - Não forma vínculo de emprego com o tomador a contratação de serviços de vigilância (Lei no 7.102 de 20.06.1983) e de conservação e limpeza, bem como a de serviços especializados ligados à atividade-meio do tomador, desde que inexistente a pessoalidade e a subordinação direta. (Brasil, Tribunal Superior do Trabalho. Súmula no 331 ).

Ainda que redigida de forma clara, a legalização da terceirização exclusivamente para as atividades-meio torna-se adversa em situações em que a delimitação entre atividades-fim e atividades-meio é difusa ou pouco evidente. Esse tipo de situação dificulta a regulamentação desta prática e possibilita que empresas utilizem a terceirização de atividades-fim enquanto forma de redução de custos. No que diz respeito à legalização da terceirização no setor público, o Decreto $\mathrm{n}^{\circ} 2.271$ de 7 de julho de 1997 também possibilita a prática de terceirização apenas para atividades consideradas complementares:

Art. $1^{\circ}$ No âmbito da Administração Pública Federal direta, autárquica e fundacional poderão ser objeto de execução indireta as atividades materiais acessórias, instrumentais ou complementares aos assuntos que constituem área de competência legal do órgão ou entidade.

$\S 1^{\circ}$ As atividades de conservação, limpeza, segurança, vigilância, transportes, informática, copeiragem, recepção, reprografia, telecomunicações e manutenção de prédios, equipamentos e instalações serão, de preferência, objeto de execução indireta.

$\S 2^{\circ}$ Não poderão ser objeto de execução indireta as atividades inerentes às categorias funcionais abrangidas pelo plano de cargos do órgão ou entidade, salvo expressa disposição legal em contrário ou quando se tratar de cargo extinto, total ou parcialmente, no âmbito do quadro geral de pessoal. (Brasil, Presidência da República. Decreto 2.271/1997).

Apesar da terceirização para as atividades-meio ser legalizada tanto no âmbito privado quando no público, deve-se citar a existência do Projeto de Lei 4.330/2004 do Deputado Federal Sandro Mabel, aprovada pela Câmara dos Deputados, que pretende ampliar a terceirização para todas as atividades, incluindo as atividades-fim. O projeto traz contribuições positivas, como a formalização de profissionais terceirizados que trabalham na ilegalidade (Matsuki, 2015) e a definição de responsabilidades da empresa contratante e da empresa terceirizada (Santiago, 2013). Entretanto, ao legalizar a terceirização de atividades- 
fim, possibilita que todos os trabalhadores contratados sejam substituídos por trabalhadores terceirizados, como meio de reduzir os custos da organização, além de possibilitar que os contratos de prestação de serviços sejam repassados de forma ilimitada (Sindicato dos Trabalhadores em Pesquisa, Ciência e Tecnologia - SP - SINTPq, 2015). Por fim, a aprovação deste projeto pode acarretar um aumento significativo no número de funcionários terceirizados no país, tanto nas empresas privadas quanto nos órgãos públicos, havendo também a possibilidade de extinção dos concursos públicos (Granjeiro, 2013).

Atualmente, o PL 4.330/2004 aguarda apreciação pelo Senado Federal. Segundo Assunção-Matos e Bicalho (2016), se este projeto for aprovado e entrar em vigor, a responsabilidade dos empregadores ficará diluída e as categorias profissionais serão extintas, já que os trabalhadores serão reconhecidos como "terceirizados" e não como profissionais de áreas específicas, podendo gerar uma intensificação na precarização do trabalho.

\subsection{Impactos da terceirização para os trabalhadores}

A revisão sistemática de literatura realizada por Mandarini et al. (2016) elencou os principais impactos do trabalho terceirizado para os trabalhadores. Tal revisão teve como objetivo identificar os impactos da terceirização para a saúde, família e trabalho dos profissionais terceirizados. As autoras empreenderam buscas em bases de dados eletrônicas considerando artigos publicados no período de 2000 a 2015, sendo que foram analisados estudos nacionais e estrangeiros dispostos nas bases de dados eletrônicas SciELO, PsycINFO, Scopus e ProQuest.

As palavras-chave utilizadas foram "terceirização (outsourcing)", "saúde (health)", "trabalho (work)" e/ou "família (family)". Foram adotados como critérios de inclusão: (a) trabalhos publicados na língua inglesa e portuguesa, (b) artigos científicos e (c) estudos com a temática da terceirização e impactos para os trabalhadores terceirizados. Os critérios de exclusão foram: (a) livros, capítulos de livros, dissertações e teses; e (b) trabalhos que, apesar de apresentarem a terceirização e seus efeitos, não abordavam impactos para os trabalhadores terceirizados.

Foram encontrados 1754 artigos científicos, dos quais 20 satisfizeram os critérios de inclusão e, portanto, foram selecionados. As pesquisadoras organizaram os dados referentes aos artigos selecionados em categorias de estudo a fim de responder ao objetivo da revisão, sendo elas: Impactos para a saúde do trabalhador $(n=9 ; 45 \%)$ e Impactos nas condições de trabalho $(n=16 ; 80 \%)$. 
A categoria "Impactos para a saúde do trabalhador" foi organizada nas seguintes subcategorias: estresse $(n=6 ; 30 \%)$; sofrimento psíquico $(n=4 ; 20 \%)$; doenças relacionadas ao trabalho e risco ocupacional $(n=3 ; 15 \%)$; falta de suporte à saúde e à segurança $(n=1$; $5 \%$ ). A categoria "Impactos nas condições de trabalho", por sua vez, foi organizada nas subcategorias: diferenças de benefícios e tratamento $(n=8 ; 40 \%)$; diminuição dos direitos trabalhistas e salário $(n=6 ; 30 \%)$; precarização das condições de trabalho $(n=5 ; 25 \%)$; vínculo, identidade profissional e identificação com a empresa $(n=4 ; 20 \%)$.

Tais categorias, assim como os objetivos de pesquisa e os participantes estão sistematizados na Tabela 1. 
Tabela 1 - Objetivo de pesquisa, participantes e subcategorias referentes aos artigos selecionados $(N=20)($ Continua)

Autores (ano)

Objetivo

Participantes

Subcategorias

Estresse

Traçar o perfil e identificar perspectivas em relação ao processo saúde-doença e ao futuro de trabalhadores

50 trabalhadores de limpeza terceirizados

Explorar os efeitos do baixo salário, carga excessiva de trabalho e precariedade no trabalho e vida familiar em trabalhadores

Avaliar os efeitos fisiológicos de uma

Netterstrøm e Hansen (2000) mudança no trabalho devido ao processo de terceirização

Sugumar, Kumaran, Raj e Xavier (2013)

Seklecka, Marek e Lacala (2013)
Identificar fatores específicos relacionados ao trabalho associados com o stress percebido no ambiente de trabalho
70 trabalhadores terceirizados em funções de auxiliar de limpeza ou de alimentação

33 motoristas de ônibus, sendo 13 terceirizados

200 trabalhadores terceirizados de TI e call center

86 profissionais administrativos terceirizados ocupacional

Doenças relacionadas ao trabalho e risco

Diminuição dos direitos trabalhistas e

salário

Estresse

Doenças relacionadas ao trabalho e risco

ocupacional

Sofrimento psíquico

Diminuição dos direitos trabalhistas e

salário

Estresse

Sofrimento psíquico

Estresse

Estresse 
Tabela 1 - Objetivo de pesquisa, participantes e subcategorias referentes aos artigos selecionados $(N=20)($ Continuação)

Autores (ano)

Objetivo
Participantes

65 funcionários de TI que

Examinar as influências das expectativas que outros trabalhadores exercem e a ambiguidade de papeis na performance do trabalho no compromisso afetivo e intenção de sair da organização

Santos, Lima, Murta e Motta (2009)

Costa (2007)

Lopes e Silva (2009)

\section{Compreender como a terceirização afeta a atividade e a saúde dos trabalhadores}

Investigar como os trabalhadores terceirizados percebem seu valor na sociedade e no mercado de trabalho, e como vivenciam subjetivamente a precarização a que estão expostos

Compreender a percepção de chances de carreira de profissionais terceirizados e suas relações com as organizações cabaram de ser terceirizados e

prestam o mesmo serviço para

a empresa que o empregava

Doenças relacionadas ao trabalho e risco ocupacional

\section{4 garis e 6 motoristas terceirizados}

Sofrimento psíquico

Diminuição dos direitos trabalhistas e salário

\section{Sofrimento psíquico}

20 trabalhadores terceirizados na Procuradoria-Geral de Justiça do Rio Grande do Sul

12 trabalhadores terceirizados de TI
Vínculo, identidade profissional e identificação com a empresa 
Tabela 1 - Objetivo de pesquisa, participantes e subcategorias referentes aos artigos selecionados $(N=20)($ Continuação)

Autores (ano)

Objetivo

Participante

Subcategorias
Rios e Gondim (2010)

Magno e Barbosa (2010)

Azevedo (2014)

Petean, Costa e Ribeiro (2014)
Comparar os contratos psicológicos de terceirizados e não-terceirizados que atuam nos setores público e privado

\section{0 trabalhadores do setor terciário, sendo 105} terceirizados

15 trabalhadores terceirizados, 2 dirigentes do Sindicato dos Metalúrgicos de Barcarena

Analisar como o processo de terceirização produz diferenciações na construção da identidade social

(SIMEB) e 1 diretor da Associação dos empregados do complexo industrial Albras/Alunorte (ABAN)

Apreender as implicações da reestruturação produtiva no mercado de trabalho e nas condições de trabalho de assistentes sociais

Compreender o trabalho de limpeza hospitalar e descrever as repercussões da ambiência hospitalar sobre o cotidiano de

vida e trabalho dos trabalhadores
4 assistentes sociais que prestam consultorias

5 trabalhadores de limpeza terceirizados

Vínculo, identidade profissional e identificação com a empresa

Diferenças de benefícios e tratamento

Vínculo, identidade profissional e identificação com a empresa

Precarização das condições de trabalho

Diferenças de benefícios e tratamento

Precarização das condições de trabalho Diferenças de benefícios e tratamento 
Alvarez, Suarez, Pereira, Figueiredo \& Athayde (2007)

Analisar como a reestruturação produtiva contribuiu para a precarização do trabalho

Demonstrar como a flexibilização no trabalho conduz ao emprego precário

Analisar a construção das formas identitárias no trabalho em serviços

Analisar criticamente o sofrimento ancorado no trabalho precarizado de limpeza

Examinar como a privatização impacta os

Zuberi e Ptashnick (2011) trabalhadores, suas condições de trabalho e de cuidados de saúde
9 técnicos terceirizados de atividades diversas, 1 gerente de $\mathrm{RH}, 1$ diretor da área da saúde e meio ambiente, 1 médico do trabalho e 1 advogado

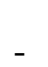

12 trabalhadores de limpeza terceirizados

70 governantas hospitalares terceirizadas
Diferenças de benefícios e tratamento

Diferenças de benefícios e tratamento Diminuição dos direitos trabalhistas e salário

Diferenças de benefícios e tratamento Diminuição dos direitos trabalhistas e salário

Diferenças de benefícios e tratamento

Precarização das condições de trabalho 
Tabela 1 - Objetivo de pesquisa, participantes e subcategorias referentes aos artigos selecionados $(N=20)$ (Conclusão)

Autores (ano)

Objetivo
Participantes

Subcategorias
Zimmermann e Ravishankar

Hasle (2007)
Examinar como o arranjo da prática de terceirização e colaboração com funcionários fixos influencia a reconfiguração dos papeis de identidade profissional

\section{Examinar como a terceirização altera a} responsabilidade do empregador em relação à saúde e segurança
30 trabalhadores contratados e 20 terceirizados

50 profissionais envolvidos na contratação de motoristas terceirizados no serviço de transporte público (empreiteiros, especialitas, gerentes, diretores,

representantes dos motoristas)
Falta de suporte à saúde e à segurança

\section{Diferenças de benefícios e tratamento}




\subsubsection{Impactos nas condições de trabalho}

Segundo o levantamento realizado pelo DIEESE (2004), as diferenças entre os trabalhadores contratados e os terceirizados não se restringem apenas às diferenças salariais, mas incluem questões relacionadas à discriminação social, como a restrição do uso de espaços coletivos ou diferenciação dos espaços físicos entre trabalhadores terceirizados e trabalhadores contratados, o que acontece frequentemente em relação a áreas de descanso, refeitórios e sanitários. Os resultados apontados na revisão de literatura permitiram identificar tais diferenças entre os trabalhadores, sendo que diferenças na qualificação, treinamento, remuneração e benefícios (Alvarez et al., 2007; Magno \& Barbosa, 2010; Rios \& Gondim, 2010; Tjandraningsih, 2012) e desvalorização social em relação aos outros profissionais (Padilha, 2014; Petean et al., 2014; Nunes, 2014; Zimmermann \& Ravishankar, 2011) foram encontradas em locais de trabalho onde há terceirização.

Sabe-se que a prática de terceirizar também envolve a diminuição dos salários e, frequentemente, a redução dos direitos trabalhistas (Alvarez et al., 2007; Chillida \& Cocco, 2004; Costa, 2007; Santos et al., 2009; Tjandraningsih, 2012; Zuberi, 2011). Para R. Silva (2015), a diminuição da proteção social refere-se à subtração dos custos com direitos trabalhistas e sociais, gerando o descumprimento de obrigações trabalhistas como o recolhimento do Fundo de Garantia por Tempo de Serviço (FGTS), o recolhimento de taxas do Ministério da Previdência Social (INSS), o pagamento de férias, adicionais de periculosidade e insalubridade, a indenização por rompimento do contrato de trabalho e demais irregularidades na assinatura da carteira de trabalho. Tais fatores foram encontrados nas pesquisas realizadas por Alvarez et al. (2007) e Tjandraningsih (2012).

De acordo com o DIEESE (2017), entre 2007 e 2014, a diferença entre o salário de profissionais contratados e profissionais terceirizados manteve-se, em média, entre $23 \%$ e $27 \%$, sendo que em 2014 a remuneração média de atividades contratantes foi de $\mathrm{R} \$ 2.639,00$, enquanto a remuneração média de atividades terceirizadas foi de $\mathrm{R} \$ 2.021,00$. Devido a essa diferença no salário, muitos profissionais terceirizados optam por trabalhar em mais de um emprego para conseguir complementar a própria renda (Chillida \& Cocco, 2004; Costa, 2007; Santos et al., 2009; Zuberi, 2011).

A revisão de literatura também permitiu identificar os aspectos que compõem a precarização das condições de trabalho terceirizado. Segundo Lima (2010), apesar da 
flexibilização do trabalho e da terceirização não implicarem necessariamente a precarização, estes elementos acabam tornando-se sinônimos. A precarização, de acordo com o autor, refere-se ao aumento da instabilidade e insegurança no trabalho decorrentes do processo de terceirização, que implica na diminuição da intervenção do Estado enquanto regulador do mercado de trabalho, a diminuição proteção social dos trabalhadores e a reorganização do trabalho.

A precarização dos processos e das relações de trabalho está vinculada a uma maior desregulamentação da força de trabalho, assim como uma intensificação do mesmo, além da redução dos custos com direitos trabalhistas e sociais. A precarização é constituída principalmente pela insegurança e instabilidade no trabalho devido à transferência da responsabilidade de manter o emprego para o trabalhador, por meio da intensa valorização de atitudes, formação e qualificação flexíveis.

Para Vasapollo (2005), a flexibilização da produção impacta os trabalhadores de diversas formas. A empresa tem liberdade de despedir parte de seus funcionários sem penalidades, assim como tem liberdade para alterar os horários e os turnos de trabalho sem aviso prévio, de pagar salários mais baixos que a média do mercado e de contratar trabalhadores em regime de trabalho temporário.

A intensificação do trabalho, segundo Garza et al. (2012), é um dos fatores que mais contribui para a precarização, causada principalmente pelo esforço em eliminar os tempos ociosos no trabalho e pela exigência de funcionários que sejam polivalentes. Tais fatores resultam em um aumento significatvo da quantidade de trabalho, intensificada pelo aumento da jornada e do ritmo de trabalho e pelo acúmulo de funções (Azevedo, 2014; R. Silva, 2015). A alta rotatividade, o número reduzido de funcionários e a falta de treinamento (Costa, 2007; Magno \& Barbosa, 2010) também foram apontados como componentes importantes da precarização do trabalho.

Ademais, pode-se citar a ambiguidade de papeis (Solli-Sæther, 2011), o sentimento de não pertencimento à empresa (Lopes \& Silva, 2009) e a dificuldade em estabelecer relacionamentos de longo prazo e em se identificar com a organização (Costa, 2007) como impactos negativos também decorrentes da terceirização.

\subsubsection{Impactos para a saúde}

$\mathrm{Na}$ revisão de literatura em questão, entre os impactos para a saúde dos trabalhadores identificados, o estresse foi o impacto mais recorrente nas pesquisas. 
Alguns estudos apenas identificaram a percepção de estresse no trabalho por parte dos terceirizados (Chillida \& Cocco, 2004; Zuberi, 2011) e outros mensuraram tal efeito por meio de indicadores físicos e comportamentais, como pressão sanguínea, amostras de sangue (Netterstrøm \& Hansen, 2000), alterações no peso, irritabilidade e distúrbios do sono (Sugumar et al., 2013).

Foram identificados alguns fatores associados à percepção do estresse nos trabalhadores, sendo eles: ausência de clareza acerca do papel profissional, falta de oportunidades de crescimento profissional, dificuldade em conciliar demandas do trabalho e da vida privada (Seklecka et al., 2013) e expectativa do gerente que contrata o serviço terceirizado no que se refere à subordinação dos trabalhadores terceirizados e à exibição de comportamentos de flexibilidade e solidariedade por parte destes (SolliSæther, 2011).

A ausência de sentido do trabalho e as relações interpessoais baseadas em constrangimento, desrespeito e autoritarismo também foram identificadas como prejudiciais à saúde dos trabalhadores terceirizados (Santos et al., 2009), assim como a ausência de suporte entre colegas, insatisfação com o trabalho (Netterstrøm \& Hansen, 2000), sentimento de inferioridade (Costa, 2007) e insegurança (Zuberi, 2011). Segundo Lima (2010), a insegurança e instabilidade no trabalho são os principais fatores que constituem a precarização, e ocorrem devido à transferência da responsabilidade de manter o emprego para o trabalhador, por meio da intensa valorização de atitudes, formação e qualificação flexíveis.

Os resultados da revisão de literatura também permitiram identificar a incidência de doenças relacionadas à natureza das atividades e o risco de acidentes (Chillida \& Cocco, 2004; Santos et al., 2009; Zuberi, 2011), além da ausência de suporte à saúde e segurança (Hasle, 2007) como impactos negativos decorrentes da terceirização. A partir das informações apresentadas, foi possível verificar que, apesar da terceirização acarretar prejuízos significativos à saúde dos profissionais terceirizados, a produção científica referente a esses danos é menor que a referente aos impactos nas condições de trabalho.

Segundo o DIEESE (2004), o excesso de trabalho, o aumento do ritmo e das horas de trabalho e a falta de equipamentos adequados, fatores relacionados à terceirização, estão associados ao aumento do estresse ocupacional, de psicopatologias como a depressão e de patologias como hipertensão arterial e lesões por esforço repetitivo. 


\subsection{Serviço de limpeza terceirizado}

Com as mudanças no cenário político e econômico brasileiro, já descritas na seção 1.3, um dos setores de maior relevância para a economia brasileira é o setor de serviços, que abrange diversas atividades, como comércio, serviços de transporte e serviços de limpeza, entre outros. Segundo dados publicados pelo Ministério da Indústria, Comério Exterior e Serviços (2017), nos anos de 2003 a 2016, tal setor representou 73,3\% do Produto Interno Bruto (PIB) do país, ou seja, dos bens e serviços finais produzidos no Brasil.

Do mesmo modo que a fragmentação dos processos, a busca por homogeneidade das atividades realizadas, o controle da qualidade dos produtos e a busca constante pelo aumento da produtividade configuravam a produção industrial clássica, parte significativa das ocupações no setor de serviços também passou a adotar esses mesmos paradigmas (Sznelwar, Lancman, Wu, Alvarinho \& Santos, 2004).

De acordo com Nunes (2014), o setor de serviços, apesar de heterogêneo em relação às ocupações, é composto essencialmente por atividades com vínculos de baixa qualificação, como o serviço de limpeza, que tem sido cada vez mais terceirizado. Tal atividade mostra-se como essencial para a sociedade, devido à contribuição para a prevenção de diversos problemas de saúde pública e de problemas ambientais (Gomes \& Oliveira, 2013).

Os trabalhadores que prestam serviços relacionados à limpeza são agrupados pela Classificação Brasileira de Ocupações (CBO) como Trabalhadores nos Serviços de Manutenção de Edificações, e suas atividades são descritas da seguinte forma:

Executam serviços de manutenção elétrica, mecânica, hidráulica, carpintaria e alvenaria, substituindo, trocando, limpando, reparando e instalando peças, componentes e equipamentos. Conservam vidros e fachadas, limpam recintos e acessórios e tratam de piscinas. Trabalham seguindo normas de segurança, higiene, qualidade e proteção ao meio ambiente. (http://www.mtecbo.gov.br/cbosite/pages/pesquisas/Busca PorTituloResultado.jsf).

Estas podem variar de acordo com a função dos trabalhadores, sendo que as principais funções categorizadas são: limpador de vidros, auxiliar de manutenção predial, limpador de fachadas, faxineiro, trabalhador da manutenção de edificações, e limpador de piscinas (CBO). De modo geral, as funções relacionadas à realização de 
atividades no ambiente externo são executadas por homens, enquanto as atividades dentro dos prédios, ou seja, a função de faxineira, é desempenhada por mulheres (Nunes, 2014). A fim de facilitar o entendimento, neste trabalho o serviço de faxina será chamado de serviço de limpeza.

Além do perfil predominantemente feminino (Araújo, Jesus, Aquino \& Longhi, 2009; Chillida \& Cocco, 2004; Gemma, Fuentes-Rojas \& Soares, 2017; Krause, Scherzer \& Rugulies, 2005; Petean et al., 2014), as agentes de limpeza possuem baixa escolaridade, sendo que a maioria não chegou a concluir o Ensino Fundamental (Chillida \& Cocco, 2004; Gemma et al., 2017; Pataro \& Fernandes, 2014). Segundo Diogo (2005), uma das razões para a escolha desta profissão está associada à baixa escolaridade, seguida pela necessidade econômica.

Em relação ao salário, o piso salarial mínimo referente a esta ocupação é de $\mathrm{R} \$$ 1.110,70 para aqueles trabalhadores que cumprem jornada de 44 horas semanais no estado de São Paulo (SIEMACO, 2018). Os resultados de diversas pesquisas indicam que tal valor é considerado baixo em relação ao número de tarefas realizadas (Araújo et al., 2009; Diogo, 2005; Holley \& Rainnie, 2012; Krause et al., 2005; Padilha, 2014; Zuberi, 2011), o que pode levar ao acúmulo de dois ou mais empregos como forma de obter mais dinheiro (Diogo, 2005; Zuberi, 2011).

Além do salário baixo, sabe-se que essa categoria de trabalhadores realiza atividades repetitivas que exigem intenso esforço físico, como a movimentação de materiais e equipamentos de limpeza, o transporte de sacos de lixo pesados o deslocamento por longos trajetos e os movimentos repetitivos que compõem a tarefa de varrer ou passar pano nas superfícies (Gemma et al., 2017), e está constantemente exposta a riscos químicos, físicos, biológicos e ergonômicos no trabalho (Araújo et al., 2009; Gemma et al., 2017).

A falta de equipamentos adequados (Gemma et al., 2017; Krause et al., 2005; Sznelwar et al., 2004), a inadequação da estrutra predial, que obriga os trabalhadores a adotar posturas desconfortáveis (Gemma et al., 2017; Seifert \& Messing, 2006; Sznelwar et al., 2004), e a precariedade dos locais destinados ao descanso e realização das refeições (Gemma et al., 2017; Padilha, 2014; Petean et al., 2014) compõem os problemas identificados relacionados ao espaço físico e aos equipamentos utilizados, o que pode desencadear danos físicos à saúde, como a prevalência de dores no corpo, encontrada nos estudos realizados por Krause et al. (2005) e Pataro e Fernandes (2014). 
A utilização de produtos de limpeza tóxicos também pode afetar diretamente a saúde desses profissionais, principalmente devido à falta de conhecimento destes em relação aos riscos de intoxicação (Sznelwar et al., 2004) e a ausência de oferecimento de treinamentos ou cursos de capacitação por parte da empresa para a realização do serviço de limpeza (Araújo et al., 2009; Diogo, 2005).

No que diz respeito à organização do trabalho, diversos estudos identificaram que as agentes de limpeza trabalham em ritmo acelerado (Krause et al., 2005; Padilha, 2011; Pataro \& Fernandes, 2014; Seifert \& Messing, 2006) e adotam estratégias como pular seus intervalos (Krause et al., 2005; Padilha, 2011) para conseguir cumprir todas as tarefas solicitadas. A maioria dos agentes de limpeza terceirizados que trabalhava em um hospital universitário, participante da pesquisa de Chillida e Cocco (2004), mencionou a ausência de tempo para planejar o futuro, realizar atividades de lazer e ficar com a família. Tais questões podem decorrer principalmente do número reduzido de funcionários de limpeza dentro das organizações (Gemma et al., 2017; Padilha, 2014; Sznelwar et al., 2004).

Ademais, segundo Sznelwar et al. (2004), o serviço de limpeza é geralmente associado à realização de tarefas fora da rotina, que geralmente incluem a interferência de clientes e colegas de trabalho que podem atrasar o andamento das atividades, como a solicitação de informações, a solicitação de limpeza de algum cômodo por parte dos funcionários da organização e a necessidade de buscar mais produtos de limpeza.

A relação com os supervisores, por sua vez, também pode constituir um fator negativo para os agentes de limpeza (Padilha, 2011). Na pesquisa realizada por Padilha (2014) com agentes de limpeza terceirizados que trabalhavam em shopping centers, a pesquisadora identificou que os trabalhadores são constantemente avaliados por seus superiores de dois modos: pelas câmeras de segurança do shopping, que acabam captando imagens do andamento do trabalho, e pelo "cliente oculto", que consiste em um avaliador disfarçado de cliente, que pede informações aos trabalhadores, conversa com os eles e grava a situação com uma câmera escondida. A partir da gravação, os funcionários terceirizados são avaliados em relação à apresentação física (limpeza do uniforme, cabelo e maquiagem), ao modo como conversam com o cliente e à limpeza do local, e podem ser desligados da empresa de acordo com o resultado final da avaliação.

A questão do reconhecimento e valorização do serviço de limpeza também é apontada como problemática por diversos estudos. Os participantes dos estudos realizados por Diogo (2005) e Gemma et al. (2017) relataram que seus superiores e 
colegas de trabalho não reconhecem as atividades que eles realizam, e que geralmente só recebem retorno em relação ao trabalho quando este está incompleto ou insatisfatório. Além disso, os agentes de limpeza que participaram do estudo realizado por Sznelwar et al. (2004) indicaram que não são reconhecidos pela chefia quando realizam atividades além daquelas prescritas, e que muitas vezes os clientes ou seus colegas de trabalho não contribuem com a preservação da limpeza no ambiente.

Sabe-se que o serviço de limpeza é socialmente desvalorizado principalmente devido às tarefas consideradas desagradáveis que compõem tal atividade, à baixa remuneração e qualificação dos profissionais (Diogo, 2005; Seifert \& Messing, 2006) e às poucas oportunidades de crescimento profissional (Krause et al., 2005). Segundo Sznelwar et al. (2004), alguns trabalhadores incorporam esse preconceito e acabam se sentindo inferiores e envergonhados por terem tal ocupação, podendo ter dificuldades em reconhecer a importância do trabalho.

Por fim, deve-se ressaltar que, apesar desta categoria de serviços estar exposta a vários fatores relacionados às condições precárias de trabalho que podem afetar a saúde e o bem-estar dos trabalhadores, a maioria dos estudos realizados teve como foco os aspectos ergonômicos e os riscos físicos e químicos a que os agentes de limpeza estão sujeitos (Gemma et al., 2017). 


\section{Capítulo 2. Estresse, saúde e fatores de risco psicossocial}

\section{Objetivo do capítulo 2}

O capítulo 2 visa introduzir o conceito de fatores de risco psicossocial e apresentar suas variáveis, assim como sua relação com o estresse ocupacional e com a saúde dos trabalhadores.

\subsection{Estresse ocupacional}

As primeiras pesquisas relacionadas ao estresse no trabalho foram publicadas a partir de 1950, após a 2a Guerra Mundial (Cooper \& Dewe, 2004). Desde então, o termo “estresse" vem sendo estudado e concebido por diferentes áreas do meio científíco e tem sido empregado em contextos variados, o que contribui para o frequente uso impreciso do termo (Codo, Soratto \& Vasques-Menezes, 2004). Apesar de atualmente existirem inúmeras teorias acerca da definição e estudo do estresse, é possível classificá-las em 3 principais abordagens: teorias baseadas em estímulos, teorias baseadas em respostas e teorias contemporâneas (Cox et al., 2000; Leka \& Houdmont, 2010), conforme demonstrado na Figura 3.

As teorias baseadas em estímulos são derivadas da Engenharia, e consistem em um modelo mecanicista e linear que concebe o estresse como uma variável independente, resultado de eventos no ambiente externo e causador de doenças. Para as teorias baseadas em respostas, derivadas da Medicina, o estresse constitui-se como uma variável dependente, como uma resposta fisiológica a características aversivas do ambiente. Tais abordagens não consideram as diferenças individuais de natureza psicológica e não incluem as interações específicas entre indivíduo e ambiente (Cox et al., 2000; Leka \& Houdmont, 2010).

As teorias contemporâneas surgiram a partir de 1970 e constituem uma abordagem psicológica. Elas consideram a interação de fatores ambientais e contextos psicossociais e organizacionais, e atribuem um papel mais ativo para as pessoas nessa interação, sendo que compreendem a participação de processos psicológicos no reconhecimento do estresse, como percepção, cognição e emoção. Tais teorias são compostas por dois modelos distintos: o interacional e o transacional. O primeiro modelo enfatiza as características estruturais presentes na interação do indivíduo com o 
ambiente, enquanto o segundo foca nos mecanismos psicológicos implícitos nessa interação, como a avaliação cognitiva e os modos de enfrentamento (coping). Devido à integração das diferenças individuais e dos processos psicológicos para a compreensão do estresse, segundo essas teorias, a mensuração do estado de estresse deve ser baseada em medidas de autorrelato (Cox et al., 2000; Leka \& Houdmont, 2010).

Figura 3 - Classificação das teorias de estresse no trabalho

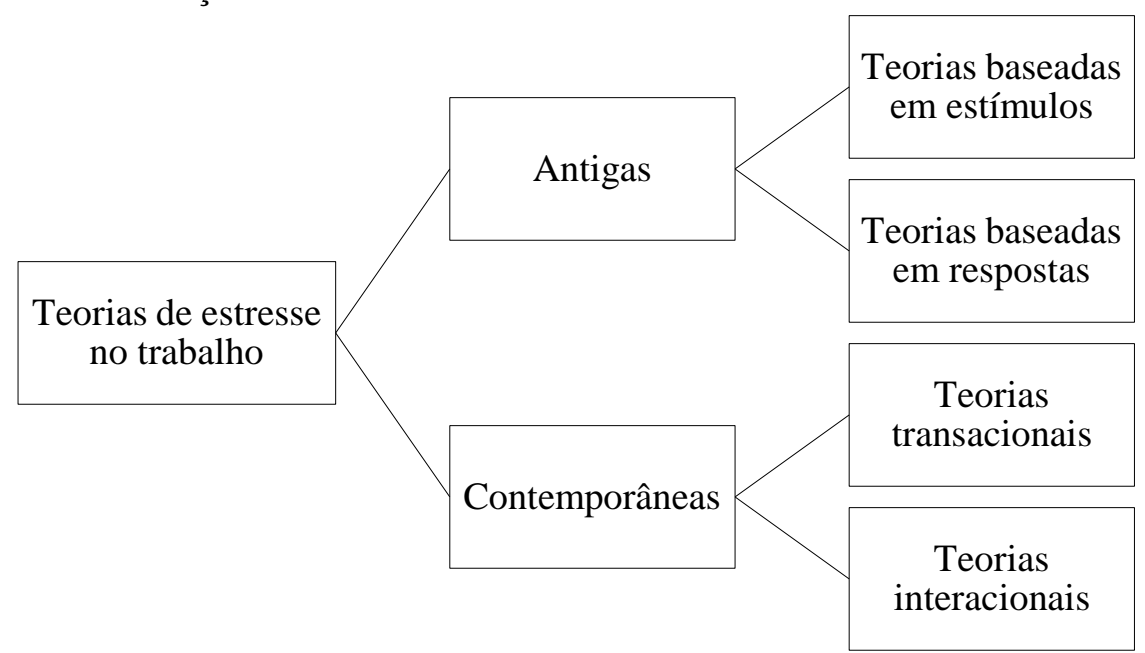

Fonte: traduzido de Leka e Houdmont, 2010 (2010, p. 35).

De modo geral, há certo consenso em relação à definição do estresse no trabalho. De acordo com as teorias contemporâneas, o estresse é um estado emocional desagradável desencadeado pela avaliação do trabalhador sobre seu contexto de trabalho, e pode desencadear significativas mudanças fisiológicas, e no modo de pensar e de se comportar, elevando o risco de doenças (Leka \& Houdmont, 2010). Ocorre quando o indivíduo percebe excessivas demandas no ambiente de trabalho ou demandas com as quais não consegue lidar, ou quando percebe que seu esforço não é devidamente recompensado. A experiência de estresse pode ser intensificada se o indivíduo percebe ausência de controle sobre a situação e limitado suporte social (Cox et al., 2000; Leka \& Houdmont, 2010).

\subsubsection{Consequências do estresse}

Segundo a Organização Internacional do Trabalho (International Labour Organization-ILO, 2016), o estresse no trabalho é um fenômeno de ampla prevalência e 
impacto, visto ser causa de implicações consideráveis na saúde e relações familiares dos indivíduos, no desempenho das funções, nas organizações e na economia.

A experiência emocional negativa que compõe o estresse frequentemente altera o modo como as pessoas sentem, pensam e se comportam, além de produzir mudanças nas funções fisiológicas, prejudicar a qualidade de vida e diminuir a sensação de bemestar (Cooper \& Dewe, 2004). A depender das características do indivíduo e das circunstâncias, tais mudanças podem contribuir para a diminuição da performance no trabalho, para o surgimento de problemas psicológicos e sociais, para o empobrecimento da saúde e para a redução da capacidade de lidar com as adversidades (Cox et al., 2000).

Nas últimas décadas houve um aumento no número de pesquisas realizadas acerca do impacto do estresse na saúde, segurança e bem-estar dos trabalhadores e na performance organizacional. No que diz respeito aos impactos na saúde, o estresse pode contribuir para o desenvolvimento de transtornos mentais e do comportamento, tais como ansiedade, depressão e burnout (ILO, 2016; NIOSH). A síndrome de burnout é considerada um estado de exaustão física, emocional e mental, resultado do envolvimento em situações de trabalho emocionalmente exigentes em longo prazo (Schaufeli \& Greenglass, 2001).

Danos físicos como pressão alta, níveis elevados de colesterol (Krumm, 2013), problemas cardiovasculares (Belkic, Landsbergis, Schnall \& Baker, 2004; Kivimäki et al., 2012; NIOSH) e distúrbios músculo-esqueléticos (Deeney \& O’Sullivan, 2009; NIOSH) também foram relacionados ao estresse no trabalho, além do aumento no risco de acidentes devido a distrações, erros de julgamento e falhas em atividades realizadas diariamente (Glasscock, Rasmussen, Carstensen \& Hansen, 2006; Ghosh, Bhattacherjee $\&$ Chau, 2004). Por fim, alguns estudos identificaram o impacto do estresse no aumento da utilização de estratégias de enfrentamento prejudiciais à saúde e comportamentos de risco, como o abuso de álcool e outras drogas, alimentação inadequada, gerando sobrepreso ou obesidade, e diminuição da qualidade do sono ou de horas destinadas ao mesmo (Silva \& Barreto, 2012; Tsai, 2012).

Em relação às consequências para as organizações, evidências apontam que o estresse influencia no aumento do absenteísmo e presenteísmo, fenômeno relacionado à diminuição da produtividade no trabalho, no aumento da rotação de funcionários (turnover) e transferências dos mesmos, na intenção de deixar a empresa, na diminuição da satisfação e criatividade dos trabalhadores, e no empobrecimento da imagem pública 
da organização (Krumm, 2013; Michie, 2002; NIOSH; Spurgeon, Harrington \& Cooper, 1997; van den Berg, Elders, Zwart \& Burdorf, 2009). Tais consequências impactam diretamente a produtividade e a competitividade das empresas, gerando gastos diretos ou indiretos (Schabracq \& Cooper, 2000).

A prevalência de dados referentes aos impactos do estresse para os indivíduos, organizações e economia varia de acordo com o país, sendo que os principais estudos realizados nessa temática são publicados por pesquisadores de países europeus e norteamericanos. Na França, por exemplo, o custo total do país com os impactos do estresse no trabalho, no ano de 2007, foi estimado entre 1,9 e 3 bilhões de euros, incluindo os custos referentes à assistência médica (entre 124 e 199 milhões de euros), ao absenteísmo (entre 826 e 1.284 milhões de euros) e à perda de produtividade devido à morte prematura de trabalhadores (entre 166 e 279 milhões de euros) (Jain, Leka \& Zwetsloot, 2018).

No ano mesmo ano, a União Europeia registrou uma estimativa de 40 milhões de pessoas afetadas pelo estresse relacionado ao trabalho, sendo que, em 2009, de $50 \%$ a $60 \%$ de todos os dias de trabalho perdidos nesses países foram devidos ao estresse (ILO, 2016). Nos países da América, em 2012, aproximadamente 20\% dos trabalhadores relataram se sentir constantemente sob estresse e relataram a experiência de perder 0 sono devido a preocupações referentes às condições de trabalho (ILO, 2016).

Para Zanelli, Calzaretta, García, Lipp e Chambel (2010), o estresse é um dos fatores mais frequentemente implicados em processos trabalhistas, sendo que, no ano de 2017, entre todos os previdenciários e acidentários, 10.371 trabalhadores brasileiros receberam benefícios cedidos por auxílio-doença devido ao estresse no trabalho (Previdência Social, 2018).

\subsection{Fatores psicossociais no trabalho}

O termo fatores psicossociais relacionados ao trabalho foi inicialmente adotado e utilizado pela ILO (1984), que definiu tal termo como interações entre o ambiente de trabalho, o conteúdo das tarefas, as condições organizacionais e as capacidades, necessidades, cultura e outras características individuais dos trabalhadores, sendo que essas interações podem influenciar a saúde, o desempenho e a satisfação no trabalho através das percepções e experiências dos profissionais. Tal definição evidencia a 
interação dinâmica entre o ambiente de trabalho e as características individuais, conforme ilustrado na Figura 4.

Figura 4 - Diagrama dos fatores psicossociais relacionados ao trabalho

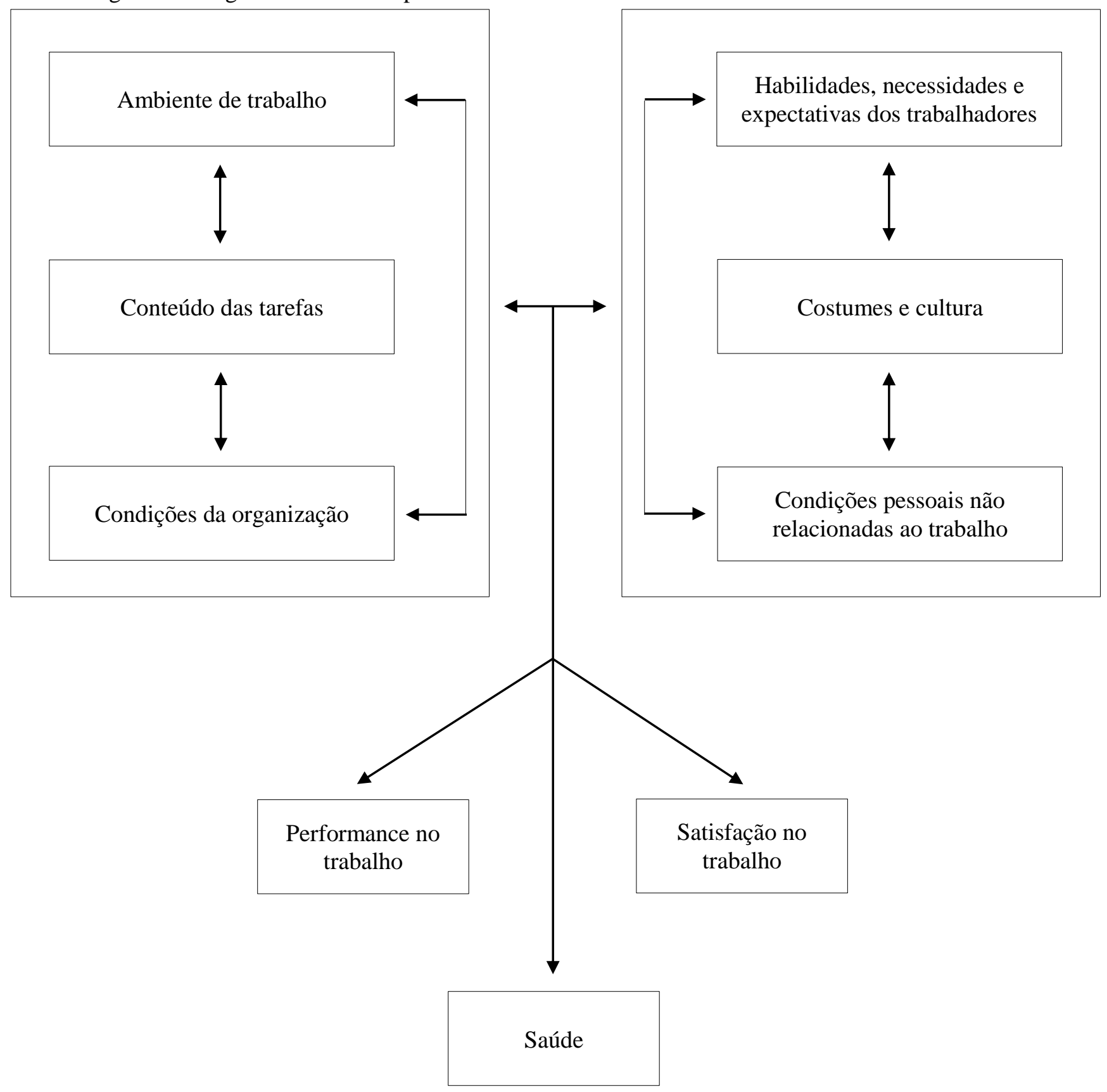

Fonte: adaptado de ILO (1984, p.4).

Segundo o diagrama da Figura 4, uma dos primeiros modelos produzidos e reconhecidos acerca dessa temática, o ambiente de trabalho, o conteúdo das tarefas e as condições da organização representam fatores organizacionais que podem desencadear tensão ou estresse, a depender das características individuais como habilidades, 
necessidades, expectativas, costumes e outros elementos da vida privada. A interação entre tais fatores organizacionais e individuais pode ser negativa ou positiva, sendo que uma interação negativa pode contribuir para efeitos adversos no desempenho e na satisfação em relação ao trabalho, e pode causar transtornos emocionais, problemas comportamentais e alterações fisiológicas, elevando o risco de desenvolvimento de doenças físicas e mentais. Uma interação equilibrada entre esses fatores, por sua vez, pode gerar resultados positivos para a saúde e performance, como aumento da motivação e da capacidade de trabalho e sensação de bem-estar (ILO, 1984).

Ao longo dos anos, o termo "fatores psicossociais" foi modificado pela comunidade científica, evoluindo de "estressores" para "fatores psicossociais", e deste para "fatores de risco psicossocial" (ILO, 2016). Recentemente, o termo "fatores de risco psicossocial” refere-se aos aspectos relacionados à organização, gestão, ambiente de trabalho e características da própria atividade, ou seja, aos fatores psicossociais, que podem causar efeitos adversos físicos ou psicológicos na saúde dos trabalhadores, por meio da experiência de estresse (Cox et al., 2000; Leka et al., 2003; Schabracq et al., 2003).

Segundo Moncada, Llorens, Andrés, Moreno \& Molinero (2014), os fatores de risco psicossocial geram respostas de natureza fisiológica, emocional, cognitiva e comportamental, e podem contribuir para o desenvolvimento de doenças, a depender da intensidade, frequência e duração da exposição a tais riscos. Para Cox et al. (2000), a exposição aos fatores de risco psicossocial pode afetar a saúde física e psicológica por meio de dois processos, sendo que um deles consiste em um mecanismo físico direto e o outro corresponde a um mecanismo psicológico mediado pelo estresse.

Os fatores de risco psicossocial e o estresse ocupacional são reconhecidos como os principais problemas de saúde e segurança no trabalho, juntamente com a violência, o bullying e o assédio no ambiente laboral (Leka \& Cox, 2008), gerando altos gastos para a saúde pública. Devido à relevância do assunto para a saúde e o bem-estar dos trabalhadores, e para as organizações e sociedade, o impacto dos fatores de risco psicossocial tem sido objeto de estudo de numerosas pesquisas, e seus resultados foram sistematizados na Figura 5. 
Figura 5 - Resultados da exposição aos fatores de risco psicossocial

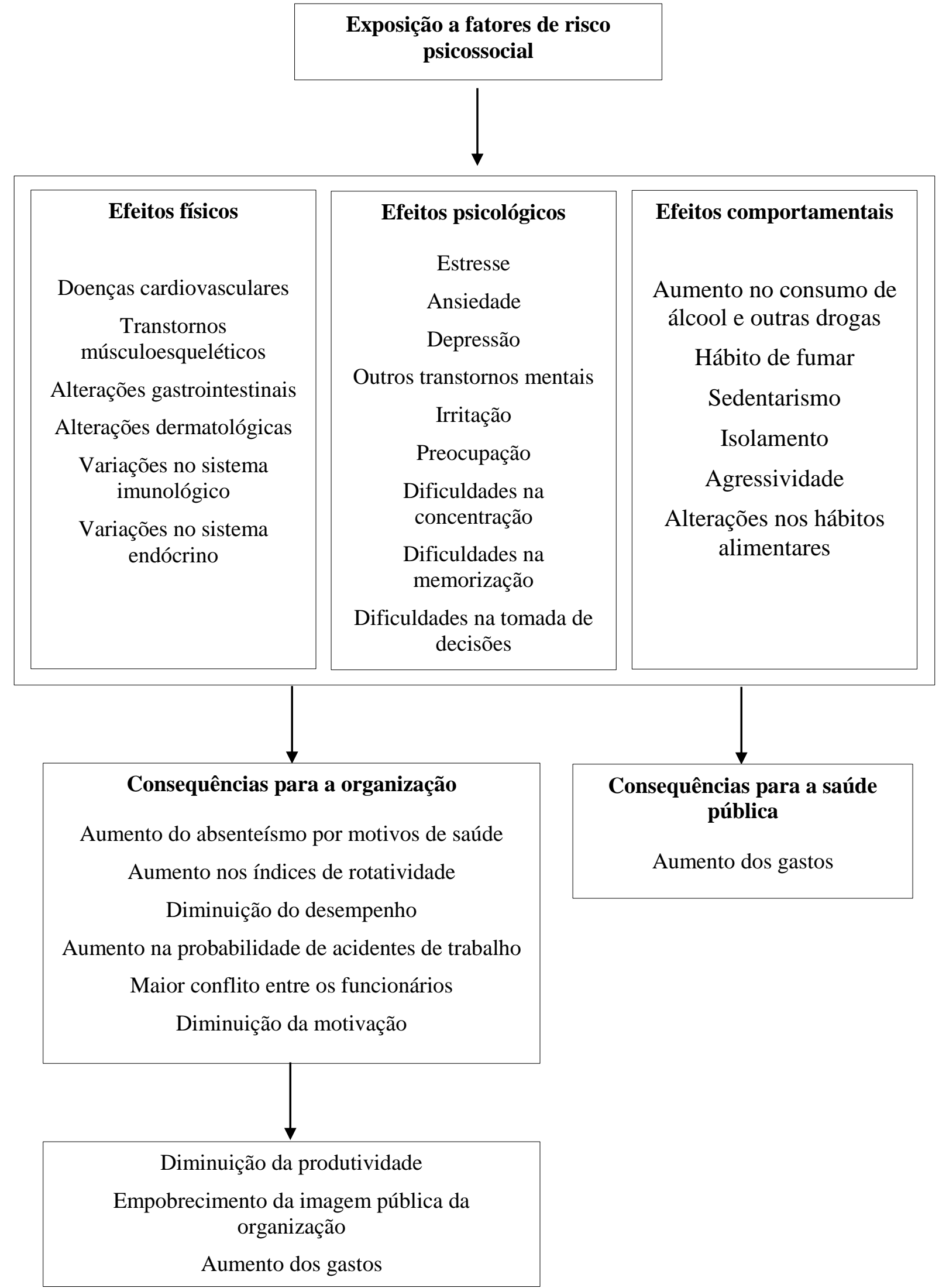

Fonte: elaboração da autora. 
Sabe-se que a exposição a fatores de risco psicossocial no ambiente de trabalho tem sido relacionada a alterações físicas na saúde, como o desenvolviemento doenças cardiovasculares (Belkic et al., 2004; ILO, 1984; Kivimäki et al., 2012; Kristensen, Hannerz, Høgh \& Borg, 2005; NIOSH) e transtornos músculoesqueléticos (Deeney \& O’Sullivan, 2009; Kristensen et al., 2005; Larsman \& Hanse, 2009; NIOSH), alterações gastrointestinais e dermatológicas e variações no sistema imunológico e endócrino (Moncada et al., 2014; Rosário, 2013; C. Silva; 2011).

Os efeitos psicológicos adversos resultados da exposição aos fatores de risco psicossocial também são amplamente investigados, sendo que a probabilidade de desenvolver estresse e transtornos mentais como ansiedade e depressão é o impacto mais recorrente nos estudos (Andrea, Bültmann, van Amelsvoort \& Kant, 2009; ILO, 1984; Kristensen et al., 2005; Moncada et al., 2014; C. Silva; 2011; Stansfeld \& Candy, 2006; Szeto \& Dobson, 2013; Wieclaw et al., 2008), seguido pelos sintomas de irritação, preocupação, dificuldades na concentração, memorização e tomada de decisões (ILO, 1984; Rosário, 2013).

Por fim, os resultados das pesquisas indicam que a exposição a fatores de risco psicossocial no trabalho pode gerar sintomas comportamentais, como o aumento no consumo de álcool e outras drogas (Head, Stansfeld \& Siegrist, 2004; ILO, 1984; Martinez, 2002; Moncada et al., 2014; Rosário, 2013), hábito de fumar, sedentarismo, isolamento, agressividade e alterações nos hábitos alimentares (Martinez, 2002; Moncada et al., 2014; Rosário, 2013).

Os impactos derivados dos fatores de risco psicossocial também interferem em aspectos organizacionais, tais quais aumento do absenteísmo por motivos de saúde (ILO, 1984; Nieuwenhuijsen, Bruinvels \& Frings-Dresen, 2010; Rugulies et al., 2007), aumento nos índices de rotatividade, diminuição do desempenho, aumento na

probabilidade de acidentes de trabalho, maior conflito entre os funcionários (Moncada et al., 2014; NIOSH; Rosário, 2013) e diminuição da motivação (Kristensen et al., 2005).

\subsection{Fatores de risco psicossocial}

Os primeiros fatores de risco psicossocial relacionados com o estresse foram o conflito, a ambiguidade e a sobrecarga de papeis. $O$ primeiro consiste na exigência simultânea da execução de papeis distintos na organização, de modo que o cumprimento 
de um dificulta o cumprimento do outro, o segundo refere-se à ausência de disponibilidade da informação necessária para o desempenho de determinada função dentro da organização (Kahn, Wolfe, Quinn, Snoek \& Rosenthal, 1965), e a sobrecarga de papeis é definida como a necessidade de se realizar uma grande quantidade de trabalho no limite de tempo disponível (Cooper \& Dewe, 2004). Segundo esses autores, tais fatores eram e ainda são as causas de estresse mais mensuradas cientificamente.

Assim como a sobrecarga de papeis foi identificada como um fator de risco psicossocial que influencia no estresse e, consequentemente, na saúde dos trabalhadores, a subcarga também foi apontada como um fator relevante, sendo definida como a necessidade de se realizar tarefas que exigem consideravelmente menos tempo que o disponível (Sales, 1970).

Nesse período, muitos pesquisadores reuniram esforços visando aumentar o foco e a compreensão acerca dos fatores que contribuíam para o estresse no ambiente de trabalho. Os fatores de risco psicossocial, até então conhecidos como estressores, identificados na época foram: sobrecarga quantitativa, referente à quantidade de trabalho a ser realizado no tempo disponível, sobrecarga qualitativa, que se refere a demandas do trabalho que ultrapassam as habilidades do trabalhador (Cooper \& Dewe, 2004), fatores intrínsecos ao trabalho, papeis na organização, desenvolvimento de carreira, estrutura organizacional e clima, relacionamentos no trabalho e condições externas às organizações (Beehr \& Newman, 1978; Cooper \& Marshall, 1976).

Atualmente, parece existir um consenso no que diz respeito aos fatores psicossociais que oferecem risco à saúde e ao estresse dos trabalhadores. Tais fatores não se operam isoladamente, e seus efeitos podem ser cumulativos (Leka \& Houdmont, 2010). Além disso, os fatores podem ser divididos em dois grupos: fatores de risco relacionados ao conteúdo do trabalho e fatores de risco relacionados ao contexto do trabalho, sendo que o primeiro grupo refere-se às condições de trabalho e organização das tarefas, enquanto o segundo grupo diz respeito aos fatores pertencentes à organização do trabalho e às relações interpessoais (ILO, 2016), conforme representado nas Figura 6 e 7.

Os fatores de risco psicossocial relacionados ao conteúdo do trabalho podem ser agrupados nos seguintes fatores: ambiente e equipamentos, conteúdo das tarefas, carga de trabalho e ritmo, e horários de trabalho. A disponibilidade de equipamentos inadequados (Camelo \& Angerami, 2008; Leka \& Houdmont, 2010; NIOSH; Schabracq et al., 2003) e as condições ambientais adversas, como espaço restrito, iluminação 
precária, barulho excessivo e exposição constante a risco físico (Camelo \& Angerami, 2008; ILO, 1984; Leka \& Houdmont, 2010; NIOSH; Schabracq et al., 2003), são os principais fatores que compõem o fator ambiente e equipamentos.

O conteúdo das tarefas, por sua vez, é composto pelos seguintes fatores de risco psicossocial: falta de variedade das tarefas e monotonia (Camelo \& Angerami, 2008; Leka \& Houdmont, 2010; Schabracq et al., 2003; C. Silva, 2011), poucas oportunidades de aprendizado (Camelo \& Angerami, 2008), trabalho fragmentado (Leka \& Houdmont, 2010; Schabracq et al., 2003), ausência de sentido no trabalho (Leka \& Houdmont, 2010; Moncada et al., 2014; NIOSH; Schabracq et al., 2003), pouco uso das habilidades no desempenho das tarefas (Camelo \& Angerami, 2008; ILO, 1984; Leka \& Houdmont, 2010; Moncada et al., 2014; NIOSH; Schabracq et al., 2003), realização de atividades que demandam responsabilidade e atenção (Camelo \& Angerami, 2008), necessidade de esconder emoções (Moncada et al., 2014) e sobrecarga qualitativa (ILO, 1984; Leka \& Houdmont, 2010).

A sobrecarga ou subcarga no trabalho (Camelo \& Angerami, 2008; ILO, 1984; Leka \& Houdmont, 2010; Moncada et al., 2014; NIOSH; Schabracq et al., 2003; C. Silva, 2011) e ritmo acelerado e pressão para realizar as atividades (Camelo \& Angerami, 2008; Leka \& Houdmont, 2010; Moncada et al., 2014; Schabracq et al., 2003) referem-se aos fatores de carga e ritmo de trabalho, enquanto o trabalho realizado em turnos (ILO, 1984; Leka \& Houdmont, 2010; Schabracq et al., 2003), as longas horas de trabalho (Camelo \& Angerami, 2008; Leka \& Houdmont, 2010; NIOSH; Schabracq et al., 2003; C. Silva, 2011) e os horários inflexíveis ou imprevisíveis (Leka \& Houdmont, 2010; Schabracq et al., 2003) dizem respeito ao fatores relacionados aos horários de trabalho.

Os fatores de risco psicossocial relacionados ao contexto do trabalho, por sua vez, são agrupados nos seguintes fatores: controle, cultura organizacional, desenvolvimento profissional, relacionamentos interpessoais, interface trabalho-família e papeis na organização. A baixa participação nas tomadas de decisão (Camelo \& Angerami, 2008; Leka \& Houdmont, 2010; NIOSH; Schabracq et al., 2003) e a falta de controle sobre o trabalho, no que diz respeito à carga, ritmo, horários e no modo de realizar as tarefas (Camelo \& Angerami, 2008; ILO, 1984; Leka \& Houdmont, 2010; Moncada et al., 2014; NIOSH; Schabracq et al., 2003), compõem o fator controle.

A cultura organizacional é composta pela comunicação precária (Camelo \& Angerami, 2008; Leka \& Houdmont, 2010; NIOSH; Schabracq et al., 2003), baixos 
níveis de suporte social para a resolução de problemas e desenvolvimento pessoal (Camelo \& Angerami, 2008; Leka \& Houdmont, 2010; Moncada et al., 2014; NIOSH; Schabracq et al., 2003), falta de definição sobre os objetivos organizacionais (Camelo \& Angerami, 2008; Leka \& Houdmont, 2010; Schabracq et al., 2003), práticas administrativas inapropriadas (Camelo \& Angerami, 2008), liderança inadequada (Camelo \& Angerami, 2008; Moncada et al., 2014), supervisão punitiva (Camelo \& Angerami, 2008), criatividade e iniciativa restringidas (Camelo \& Angerami, 2008), e ausência ou escassez de reconhecimento no trabalho (Camelo \& Angerami, 2008; Moncada et al., 2014).

Constituem o fator desenvolvimento profissional os seguintes fatores de risco psicossocial: estagnação na carreira e falta de oportunidades de se desenvolver profissionalmente (Camelo \& Angerami, 2008; Leka \& Houdmont, 2010; NIOSH; Schabracq et al., 2003), insegurança no trabalho (Camelo \& Angerami, 2008; Leka \& Houdmont, 2010; NIOSH; Schabracq et al., 2003; C. Silva, 2011), inadequação do salário (Camelo \& Angerami, 2008; ILO, 1984; Leka \& Houdmont, 2010; Schabracq et al., 2003) e baixo valor social atribuído ao trabalho exercido (Camelo \& Angerami, 2008; Leka \& Houdmont, 2010; Schabracq et al., 2003).

Os relacionamentos interpessoais compreendem o isolamento físico ou social (Leka \& Houdmont, 2010; NIOSH; Schabracq et al., 2003), o relacionamento precário com os superiores (Camelo \& Angerami, 2008; ILO, 1984; Leka \& Houdmont, 2010; Schabracq et al., 2003), os conflitos interpessoais (ILO, 1984; Leka \& Houdmont, 2010; Schabracq et al., 2003) e a exposição a comportamentos antissociais, tais quais violência física e verbal, bullying e assédio verbal e sexual (Camelo \& Angerami, 2008; Leka \& Houdmont, 2010; C. Silva, 2011). A interface trabalho-família, por sua vez, é composta pelos fatores referentes ao conflito entre as demandas do trabalho e da família (Camelo \& Angerami, 2008; Leka \& Houdmont, 2010; Moncada et al., 2014; Schabracq et al., 2003) e ao baixo suporte familiar (Leka \& Houdmont, 2010; Schabracq et al., 2003).

Por fim, os papeis na organização compreendem os fatores de risco psicossocial relacionados à ambiguidade e conflito de papel (Camelo \& Angerami, 2008; Leka \& Houdmont, 2010; NIOSH; Schabracq et al., 2003), à responsabilidade por outras pessoas no ambiente de trabalho (Camelo \& Angerami, 2008; Leka \& Houdmont, 2010; Schabracq et al., 2003) e à sobrecarga de papeis (Camelo \& Angerami, 2008; Leka \& Houdmont, 2010). 
Figura 6 - Fatores de risco psicossocial relacionados ao conteúdo do trabalho Fatores de risco psicossocial relacionados ao conteúdo do trabalho

Ambiente e equipamentos

Conteúdo das tarefas

Carga de trabalho e ritmo

Horários de trabalho
Equipamentos inadequados

Condições ambientais adversas

Falta de variedade das tarefas e monotonia Poucas oportunidades de aprendizado

Trabalho fragmentado

Ausência de sentido no trabalho

Pouco uso das habilidades

Realização de atividades que demandam

responsabilidade e atenção

Necessidade de esconder emoções

Sobrecarga qualitativa

Sobrecarga ou subcarga no trabalho

Ritmo acelerado e pressão para realizar as atividades

Trabalho realizado em turnos

Longas horas de trabalho

Horários inflexíveis ou imprevisíveis

Fonte: elaboração da autora. 
Figura 7 - Fatores de risco psicossocial relacionados ao contexto do trabalho

Fatores de risco psicossocial relacionados ao contexto do trabalho

Controle

Cultura organizacional

\section{Desenvolvimento profissional}

\section{Relacionamentos interpessoais}

\section{Interface trabalho-família}

\section{Papeis na organização}

Fonte: elaboração da autora.

\author{
Baixa participação nas tomadas de decisão \\ Falta de controle sobre o trabalho \\ Comunicação precária \\ Baixos níveis de suporte social \\ Falta de definição sobre os objetivos \\ organizacionais \\ Práticas administrativas inapropriadas \\ Liderança inadequada \\ Supervisão punitiva \\ Criatividade e iniciativa restringidas \\ Ausência ou escassez de reconhecimento \\ Estagnação na carreira e falta de \\ oportunidades de se desenvolver \\ Insegurança no trabalho \\ Inadequação do salário \\ Baixo valor social \\ Isolamento físico ou social \\ Relacionamento precário com os superiores \\ Conflitos interpessoais \\ Exposição a comportamentos antissociais \\ Conflito entre as demandas do trabalho e da \\ família \\ Baixo suporte familiar \\ Ambiguidade e conflito de papel \\ Responsabilidade por outras pessoas \\ Sobrecarga de papeis
}

Deve-se ressaltar que constantes mudanças ocorridas nos locais de trabalho, principalmente devido às novas formas flexíveis de trabalho, são apontadas por vários estudos como fontes de estresse que podem levar ao adoecimento (Benach, Muntaner, Benavides, Amable \& Jodar, 2002; Borg \& Kristensen, 1999; Reis, Fernandes \& Gomes, 2010; Sparks, Faragher \& Cooper, 2001). Segundo Davis-Blake e Broschak (2009), a prática de terceirizar os serviços acarreta diversas mudanças significativas no local de trabalho, incluindo alterações na natureza das tarefas e na organização do trabalho e dos relacionamentos entre funcionários. Os fatores de risco psicossocial associados a esses novos métodos de trabalho têm sido identificados como uma das principais causas do empobrecimento da saúde dos trabalhadores. 
Capítulo 3. Revisão de literatura: fatores de risco psicossocial e estresse em trabalhadores terceirizados

\section{Objetivo do capítulo 3}

O presente capítulo tem como objetivo apresentar a revisão sistemática da literatura realizada no estudo, cujo objetivo foi identificar e sistematizar os fatores de risco psicossocial que podem contribuir para o estresse e afetar a saúde de trabalhadores terceirizados.

\subsection{Revisão sistemática da litertura: descrição do percurso}

A fim de identificar e sistematizar os principais resultados advindos de artigos científicos que abordaram os fatores de risco psicossocial em contexto de trabalho terceirizado, foi realizada uma revisão sistemática da literatura em bases de dados eletrônicas, que resultou em um artigo aceito para publicação na Revista Pesquisa em Psicologia.

A revisão sistemática da literatura, segundo Petticrew e Roberts (2006), é um método que possibilita organizar informações, mapear áreas escassas em estudos e identificar a necessidade de novas pesquisas, além de contribuir para responder questões de pesquisa. Entretanto, apesar de constituir uma metodologia robusta, a qualidade das revisões sistemáticas deixa a desejar em muitos estudos, principalmente devido às variações nos métodos e critérios para identificar, analisar e sintetizar os dados. Para garantir a qualidade metodológica de estudos de revisão, muitos pesquisadores utilizam ferramentas que auxiliam na organização, análise e síntese das informações encontradas (Zoltowski, Costa, Teixeira \& Koller, 2014).

Esta revisão foi realizada segundo as seguintes diretrizes propostas no guia prático para revisões sistemáticas no campo das ciências sociais, publicado por Petticrew e Roberts (2006): definição clara e objetiva da questão de pesquisa; definição do protocolo de pesquisa, composto pela questão principal, métodos a serem utilizados, tipos de estudo, desenhos de pesquisa, critérios de inclusão e exclusão e modo como tais informações serão apresentadas e sintetizadas; realização da busca; leitura dos títulos e resumos, e exclusão dos estudos irrelevantes; avaliação e seleção dos estudos a partir dos critérios de inclusão e exclusão; extração dos dados relevantes e avaliação crítica 
dos mesmos; síntese dos resultados encontrados; reflexão acerca dos vieses e redação dos achados.

Além disso, foi utilizada uma ferramenta para auxiliar na organização, análise e síntese dos dados encontrados: StArt. O software State of Art through Systematic Review (StArt), versão 1.6.3, desenvolvido pelo Laboratório de pesquisa em Engenharia de Software da Universidade Federal de São Carlos (UFSCar) é uma ferramenta que auxilia o planejamento, execução e análise final dos trabalhos encontrados, contribuindo para a realização de uma revisão sistemática mais ágil, precisa e replicável (Hernandes, Zamboni, Fabbri \& Thommazo, 2012).

A presente revisão de literatura objetivou identificar e sistematizar os fatores de risco psicossocial que podem contribuir para o estresse e afetar a saúde de trabalhadores terceirizados. Para alcançar tal objetivo, foram realizadas buscas por artigos científicos nacionais e internacionais disponíveis nas bases eletrônicas de dados SciELO, LILACS, Web of Science, PubMed, Scopus e PsycINFO, considerando os estudos publicados no período de 2002 a 2017. Tais bases foram selecionadas por serem referência na área de Psicologia, Saúde e Administração, disciplinas que abordam o tema.

A fim de se alcançar o maior número de estudos relevantes relacionados à temática proposta, foram determinadas as seguintes palavras-chave: terceiriza* (outsourc*), estresse (stress), estresse organizacional (organizational stress), estresse relacionado ao trabalho (work stress), estresse ocupacional (occupational stress), bemestar psicológico (psychological well-being), saúde ocupacional (occupational health), ambiente psicossocial (psychosocial environment) e risco psicossocial (psychosocial risk). Tais palavras-chave foram selecionadas após pesquisa de descritores no Vocabulário de Termos em Psicologia, cadastrados na Biblioteca Virtual em Saúde Psicologia (BVS-Psi) e após verificação das palavras-chave que mais apareciam nos artigos relacionados ao tema. A palavra-chave terceiriza* (outsourc*) foi utilizada em todas as buscas e foi combinada com cada palavra-chave, individualmente (exemplo: terceiriza* AND estresse).

Os critérios de inclusão definidos foram: a) trabalhos publicados na língua inglesa, portuguesa ou espanhola, (b) relatos de pesquisa, revisões de literatura e artigos de comunicação breve, (c) estudos que abordaram o estresse/saúde e fatores de risco psicossocial em trabalhadores terceirizados. Os critérios de exclusão compreenderam: (a) livros, capítulos de livros, dissertações e teses, (b) trabalhos que, apesar de 
abordarem a terceirização e o estresse/saúde, focavam em outros trabalhadores que não os terceirizados, (c) estudos com acesso restrito.

O período de busca ocorreu entre Dezembro de 2016 e Março de 2017. A princípio, foram excluídos os artigos duplicados. Em seguida, os títulos e resumos dos estudos foram avaliados, sendo excluídos aqueles considerados irrelevantes para a revisão. Por fim, os trabalhos considerados relevantes foram analisados de acordo com os critérios de inclusão e exclusão, sendo excluídos aqueles que não abordavam o tema. Apenas os estudos que identificaram, diretamente ou indiretamente, fatores de risco psicossocial relacionados ao estresse e saíde de trabalhadores terceirizados foram selecionados para a revisão.

Um banco de dados foi criado pelo software StArt para documentar as principais características de cada estudo: a) metodologia empregada, b) tipo de pesquisa; c) ano de publicação, d) instrumentos utilizados, e) área de atuação dos participantes, f) síntese dos principais resultados. Após a leitura e avaliação das produções científicas, as informações foram analisadas a partir do referencial da análise temática (Smith, 2015), de modo que foi identificado, examinado e relatado os padrões de temas referentes aos fatores de risco psicossocial presentes nas pesquisas, resultando na criação de categorias que se referem à identificação de tais fatores.

A seleção inicial resultou em 5.800 artigos. Destes, 2.633 não eram duplicados e 104 foram considerados relevantes. Estes 104 artigos foram lidos na íntegra e 25 deles atenderam a todos os critérios de inclusão previamente estabelecidos. Destes, 5 foram publicados na língua portuguesa e 20 na língua inglesa. A Figura 8 representa as fases empreendidas na seleção dos artigos da revisão sistemática. 
Figura 8 - Fases componentes da seleção dos artigos da revisão sistemática

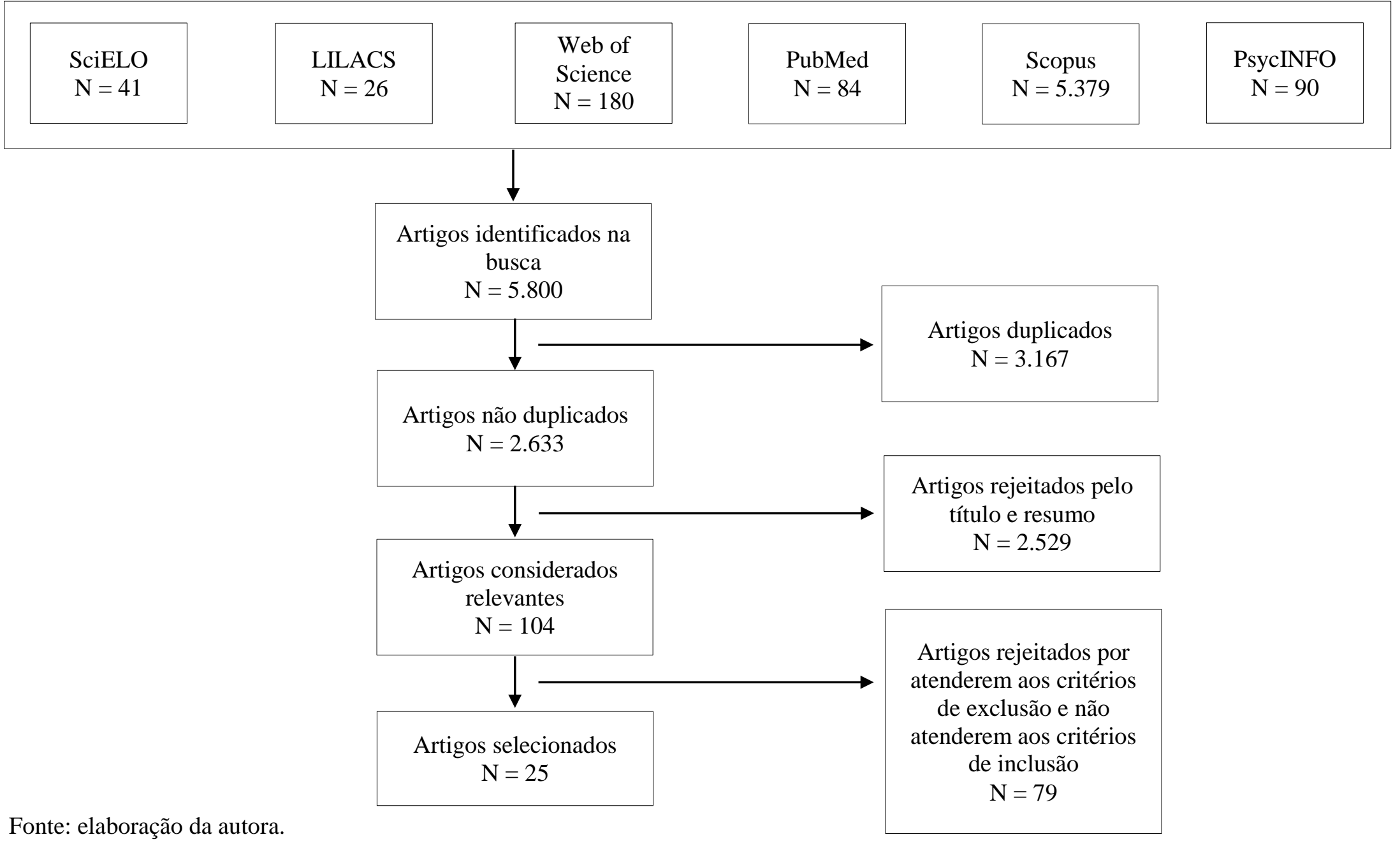


Em relação às principais características dos estudos selecionados, destaca-se que a maioria utilizou como metodologia o estudo de caso $(n=13 ; 52 \%)$ e quase metade dos trabalhos constituiu o tipo de pesquisa qualitativa $(n=12 ; 48 \%)$. A utilização de instrumentos foi diversa, sendo que a maior parte das pesquisas utilizou uma combinação de dois ou mais tipos de instrumento $(n=11 ; 44 \%)$. No que diz respeito aos participantes dos estudos empíricos, a maioria das pesquisas foi realizada com trabalhadores que atuavam em call centers $(n=9 ; 45 \%)$, sendo que 3 das 5 revisões de literatura foram realizadas a partir de estudos com trabalhadores deste mesmo setor.

A Tabela 2 apresenta as informações referentes à identificação dos pesquisadores e do ano de publicação dos estudos, assim como suas respectivas metodologias, tipos de pesquisa, áreas de atuação dos participantes e instrumentos utilizados. 
Tabela 2 - Objetivo, metodologia, tipo de pesquisa, participantes e instrumentos referentes aos artigos selecionados $(N=25)($ Continua $)$

\begin{tabular}{|c|c|c|c|c|c|}
\hline Autores (ano) & Objetivo & Metodologia & Tipo de pesquisa & Participantes & Instrumentos \\
\hline Thite (2010) & $\begin{array}{l}\text { Identificar as principais } \\
\text { questões e desafios na } \\
\text { retenção de talentos no setor } \\
\text { de negócios terceirizados }\end{array}$ & Estudo de caso & Mista & $\begin{array}{l}638 \text { funcionarios do } \\
\text { setor de TI e call } \\
\text { center e } 15 \\
\text { profissionais de RH }\end{array}$ & $\begin{array}{l}\text { Entrevista e } \\
\text { questionário }\end{array}$ \\
\hline $\begin{array}{l}\text { Jain, Giga \& Cooper } \\
\text { (2013) }\end{array}$ & $\begin{array}{l}\text { Examinar o papel mediador } \\
\text { do compromisso funcionário- } \\
\text { empresa na relação entre } \\
\text { estressores organizacionais, } \\
\text { saúde física e bem-estar } \\
\text { psicológico em trabalhadores } \\
\text { terceirizados de call centers }\end{array}$ & Survey & Quantitativa & $\begin{array}{l}401 \text { funcionários do } \\
\text { setor de call center }\end{array}$ & Questionário \\
\hline Hechanova (2013) & $\begin{array}{c}\text { Compreender a relação entre } \\
\text { conflito trabalho-família e a } \\
\text { intenção de deixar a empresa, } \\
\text { e exanimar o papel moderador } \\
\text { da percepção de suporte } \\
\text { organizacional }\end{array}$ & Survey & Mista & $\begin{array}{c}30 \text { agentes de call } \\
\text { center (quali)/ } 991 \\
\text { agentes de call center } \\
\text { (quanti) }\end{array}$ & $\begin{array}{l}\text { Entrevista e } \\
\text { questionário }\end{array}$ \\
\hline $\begin{array}{l}\text { Ram, Kurpad \& } \\
\text { Swaminathan (2014) }\end{array}$ & $\begin{array}{l}\text { Explorar os comportamentos } \\
\text { relacionados à saúde dos } \\
\text { trabalhadores }\end{array}$ & Estudo de caso & Qualitativa & $\begin{array}{l}28 \text { funcionários do } \\
\text { setor de TI e call } \\
\text { center }\end{array}$ & Entrevista \\
\hline
\end{tabular}


Tabela 2 - Objetivo, metodologia, tipo de pesquisa, participantes e instrumentos referentes aos artigos selecionados $(N=25)($ Continuação)

\begin{tabular}{|c|c|c|c|c|c|}
\hline Autores (ano) & Objetivo & Metodologia & Tipo de pesquisa & Participantes & Instrumentos \\
\hline Zuberi (2011) & $\begin{array}{c}\text { Descrever como a } \\
\text { terceirização tem } \\
\text { consequências negativas para } \\
\text { os trabalhadores, suas } \\
\text { famílias e o sistema de saúde }\end{array}$ & Estudo de caso & Qualitativa & $\begin{array}{c}70 \text { funcionários em } \\
\text { funções de apoio em } \\
\text { um hospital } \\
\text { (limpeza/alimentação) }\end{array}$ & Entrevista \\
\hline $\begin{array}{l}\text { Hsiao \& Mor Barak } \\
(2014)\end{array}$ & $\begin{array}{l}\text { Explorar a relação entre } \\
\text { estressores relacionados ao } \\
\text { trabalho, suporte social e } \\
\text { conflito trabalho-família }\end{array}$ & Estudo de caso & Mista & $\begin{array}{l}168 \text { trabalhadores de } \\
\text { uma indústria têxtil } \\
\text { (quanti)/ } 33 \\
\text { trabalhadores de uma } \\
\text { indústria têxtil (quali) }\end{array}$ & $\begin{array}{l}\text { Entrevista e } \\
\text { questionário }\end{array}$ \\
\hline $\begin{array}{l}\text { Ratnesh, Sultana \& } \\
\text { Sinha (2016) }\end{array}$ & $\begin{array}{c}\text { Compreender como o } \\
\text { trabalho e fatores familiares } \\
\text { influenciam o trabalho das } \\
\text { funcionárias de call center } \\
\text { terceirizadas e sua } \\
\text { produtividade. Identificar } \\
\text { questões relacionadas à saúde } \\
\text { física e mental e segurança } \\
\text { das mulheres que trabalham } \\
\text { em turnos noturnos }\end{array}$ & $\begin{array}{l}\text { Revisão de } \\
\text { literatura }\end{array}$ & Qualitativa & $\begin{array}{c}\text { Contexto de call } \\
\text { center }\end{array}$ & $\begin{array}{l}\text { Revisão de } \\
\text { literatura }\end{array}$ \\
\hline
\end{tabular}


Tabela 2 - Objetivo, metodologia, tipo de pesquisa, participantes e instrumentos referentes aos artigos selecionados $(N=25)($ Continuação)

Autores (ano)

Objetivo
Metodologia

Tipo de pesquisa

Participantes

Instrumentos
Alvarez et al. (2007)

Analisar como a adoção e ampliação da terceirização contribui para a precarização do trabalho

\section{Discutir o estado da}

Druck (2016)

Deery, Nath \& Walsh

(2013)

Snell, Schmitt, Glavas

\& Bamberry (2015) terceirização no Brasil e seus efeitos nas condições de

$$
\text { trabalho e saúde }
$$

Compreender os motivos da intenção de deixar a empresa por parte dos agentes de call center

Investigar se os trabalhadores de contextos organizacionais diferentes experimentam estresse relacionado à perda de emprego de forma semelhante
9 trabalhadores e

1 gerente de $\mathrm{RH}$ de

uma indústria

petrolífera; 1 diretor da Entrevista,

área de saúde e meio observação e grupo

ambiente do de discussão

Sindipetro NF; 1

médico do trabalho; 1

advogado

\section{Revisão de \\ literatura}

Qualitativa

$-$

Revisão de

literatura

Estudo de caso

Mista

211 agentes de call center

Entrevista e questionário

35 funcionários de uma indústria de

Estudo de caso Qualitativa geração de energia (contratados e terceirizados)
Entrevista, análise documental e observação 
Tabela 2 - Objetivo, metodologia, tipo de pesquisa, participantes e instrumentos referentes aos artigos selecionados $(N=25)($ Continuação)

\begin{tabular}{|c|c|c|c|c|c|}
\hline Autores (ano) & Objetivo & Metodologia & Tipo de pesquisa & Participantes & Instrumentos \\
\hline $\begin{array}{l}\text { Chillida \& Cocco } \\
\text { (2004) }\end{array}$ & $\begin{array}{c}\text { Traçar o perfil dos } \\
\text { trabalhadores terceirizados } \\
\text { que atuam no serviço de } \\
\text { limpeza de um hospital } \\
\text { universitário em relação à } \\
\text { escolaridade e rotatividade no } \\
\text { serviço. Identificar a } \\
\text { percepção e perspectivas } \\
\text { desses profissionais em } \\
\text { relação ao processo saúde- } \\
\text { doença e ao seu futuro }\end{array}$ & Estudo de caso & Mista & $\begin{array}{l}50 \text { agentes de limpeza } \\
\text { de um hospital }\end{array}$ & $\begin{array}{l}\text { Entrevista, } \\
\text { questionário e } \\
\text { observação }\end{array}$ \\
\hline $\begin{array}{l}\text { D'Cruz \& Noronha } \\
\text { (2008) }\end{array}$ & $\begin{array}{l}\text { Examinar experiências } \\
\text { subjetivas de trabalho de } \\
\text { agentes terceirizados }\end{array}$ & Estudo de caso & Qualitativa & $\begin{array}{l}81 \text { funcionários de call } \\
\text { center }\end{array}$ & Entrevista \\
\hline Seklecka et al. (2013) & $\begin{array}{l}\text { Identificar fatores } \\
\text { relacionados ao trabalho } \\
\text { associados ao estresse } \\
\text { percebido por trabalhadores } \\
\text { terceirizados de contabilidade }\end{array}$ & Survey & Quantitativa & $\begin{array}{l}86 \text { funcionários do } \\
\text { setor de contabilidade }\end{array}$ & Questionário \\
\hline Santos et al. (2009) & $\begin{array}{c}\text { Compreender como a } \\
\text { terceirização afeta a atividade } \\
\text { e a saúde dos garis } \\
\text { terceirizados }\end{array}$ & Estudo de caso & Qualitativa & 24 garis & $\begin{array}{c}\text { Entrevista, análise } \\
\text { documental e } \\
\text { observação }\end{array}$ \\
\hline
\end{tabular}


Tabela 2 - Objetivo, metodologia, tipo de pesquisa, participantes e instrumentos referentes aos artigos selecionados $(N=25)($ Continuação)

\begin{tabular}{|c|c|c|c|c|c|}
\hline Autores (ano) & Objetivo & Metodologia & Tipo de pesquisa & Participantes & Instrumentos \\
\hline Revathi (2016) & $\begin{array}{l}\text { Identificar o impacto do } \\
\text { pacote salarial sobre o } \\
\text { estresse de funcionários } \\
\text { terceirizados }\end{array}$ & Survey & Quantitativa & $\begin{array}{l}100 \text { funcionários de } \\
\text { call center }\end{array}$ & Questionário \\
\hline Nadeem (2009) & $\begin{array}{c}\text { Explorar as implicações } \\
\text { temporais da terceirização de } \\
\text { serviços na Índia }\end{array}$ & Estudo de caso & Qualitativa & $\begin{array}{l}129 \text { funcionários de TI } \\
\text { e call center, gestores } \\
\text { e executivos }\end{array}$ & Entrevista \\
\hline Raja \& Bhasin (2014) & $\begin{array}{l}\text { Descrever os problemas } \\
\text { relacionados à saúde de } \\
\text { funcionários terceirizados que } \\
\text { trabalham em call centers na } \\
\text { Índia }\end{array}$ & $\begin{array}{l}\text { Revisão de } \\
\text { literatura }\end{array}$ & Qualitativa & $\begin{array}{l}\text { Contexto de call } \\
\text { center }\end{array}$ & $\begin{array}{l}\text { Revisão de } \\
\text { literatura }\end{array}$ \\
\hline $\begin{array}{l}\text { Taylor, D'Cruz, } \\
\text { Noronha \& Scholarios } \\
\text { (2013) }\end{array}$ & $\begin{array}{l}\text { Examinar a extensão e a } \\
\text { natureza da pressão percebida } \\
\text { diariamente no trabalho, e } \\
\text { identificar os principais } \\
\text { preditores de pressão de } \\
\text { trabalho relacionados à } \\
\text { organização do trabalho }\end{array}$ & Estudo de caso & Mista & $\begin{array}{l}618 \text { funcionários de } \\
\text { call center (quanti)/ } 25 \\
\text { funcionários de call } \\
\text { center (quali) }\end{array}$ & $\begin{array}{l}\text { Entrevista e } \\
\text { questionário }\end{array}$ \\
\hline
\end{tabular}


Tabela 2 - Objetivo, metodologia, tipo de pesquisa, participantes e instrumentos referentes aos artigos selecionados $(N=25)($ Continuação)

\begin{tabular}{|c|c|c|c|c|c|}
\hline Autores (ano) & Objetivo & Metodologia & Tipo de pesquisa & Participantes & Instrumentos \\
\hline $\begin{array}{l}\text { Kesavachandran, } \\
\text { Rastogi, Das \& Khan } \\
\text { (2006) }\end{array}$ & $\begin{array}{c}\text { Realizar uma revisão da } \\
\text { literatura acerca da } \\
\text { organização do trabalho, bem- } \\
\text { estar psicossocial e problemas } \\
\text { de saúde em trabalhadores } \\
\text { terceirizados de TI }\end{array}$ & $\begin{array}{l}\text { Revisão de } \\
\text { literatura }\end{array}$ & Qualitativa & Contexto de TI & $\begin{array}{l}\text { Revisão de } \\
\text { literatura }\end{array}$ \\
\hline $\begin{array}{l}\text { Budhwar, Varma, } \\
\text { Malhotra \& } \\
\text { Mukherjee (2009) }\end{array}$ & $\begin{array}{l}\text { Destacar os principais } \\
\text { problemas enfrentados pela } \\
\text { indústria indiana de call } \\
\text { center e analisar o cenário } \\
\text { relacionado à alta rotatividade } \\
\text { de funcionários nesse setor }\end{array}$ & Survey & Mista & $\begin{array}{l}204 \text { agentes de call } \\
\text { center e funcionários } \\
\text { da área de RH }\end{array}$ & $\begin{array}{l}\text { Entrevista e } \\
\text { questionário }\end{array}$ \\
\hline $\begin{array}{l}\text { Quinlan \& Bohle } \\
\text { (2008) }\end{array}$ & $\begin{array}{c}\text { Revisar e avaliar pesquisas } \\
\text { internacionais sobre os efeitos } \\
\text { da subcontratação e trabalho } \\
\text { em casa na saúde ocupacional } \\
\text { e segurança dos trabalhadores } \\
\text { nos últimos } 20 \text { anos }\end{array}$ & $\begin{array}{l}\text { Revisão de } \\
\text { literatura }\end{array}$ & Qualitativa & - & $\begin{array}{l}\text { Revisão de } \\
\text { literatura }\end{array}$ \\
\hline
\end{tabular}


Tabela 2 - Objetivo, metodologia, tipo de pesquisa, participantes e instrumentos referentes aos artigos selecionados $(N=25)($ Conclusão $)$

$\begin{array}{lllll}\text { Autores (ano) } & \text { Objetivo } & \text { Metodologia } & \text { Tipo de pesquisa } & \text { Participantes }\end{array}$

\begin{tabular}{|c|c|c|c|c|c|}
\hline Gemma et al., (2017) & $\begin{array}{l}\text { Analisar a percepção dos } \\
\text { agentes de limpeza } \\
\text { terceirizados de uma } \\
\text { faculdade pública sobre a } \\
\text { atividade de trabalho e } \\
\text { determinar seu índice de } \\
\text { capacidade para o trabalho }\end{array}$ & Estudo de caso & Mista & 22 agentes de limpeza & $\begin{array}{c}\text { Questionário e } \\
\text { grupos de discussão }\end{array}$ \\
\hline $\begin{array}{l}\text { Nandialath, Das \& } \\
\text { Mohan (2012) }\end{array}$ & $\begin{array}{l}\text { Compreender como a } \\
\text { qualidade de relacionamento } \\
\text { supervisor-funcionário e } \\
\text { expectativas de crescimento } \\
\text { individual e da empresa } \\
\text { afetam as percepções } \\
\text { individuais de estresse }\end{array}$ & Survey & Quantitativa & $\begin{array}{l}268 \text { funcionários de } \\
\text { call center }\end{array}$ & Questionário \\
\hline $\begin{array}{l}\text { Papadopoulos, } \\
\text { Georgiadou, } \\
\text { Papazoglou \& } \\
\text { Michaliou (2010) }\end{array}$ & $\begin{array}{l}\text { Analisar as consequências das } \\
\text { mudanças no ambiente de } \\
\text { trabalho na saúde } \\
\text { ocupacional, segurança e vida } \\
\text { social dos trabalhadores }\end{array}$ & $\begin{array}{l}\text { Revisão de } \\
\text { literatura }\end{array}$ & Qualitativa & $\begin{array}{l}\text { Contexto de call } \\
\text { center }\end{array}$ & $\begin{array}{l}\text { Revisão de } \\
\text { literatura }\end{array}$ \\
\hline
\end{tabular}




\subsection{Componentes do modelo de investigação: achados de pesquisa}

Nesta seção são descritos e discutidos os resultados alcançados a partir da realização da revisão sistemática da literatura. Como descrito na seção anterior, a partir das informações dos artigos selecionados, foram identificados, examinados e relatados os padrões de temas pertinentes ao objetivo da revisão. Sendo assim, foram criadas categorias referentes à identificação dos fatores de risco psicossocial que podem contribuir para o estresse e afetar a saúde dos trabalhadores terceirizados.

$\mathrm{Na}$ Tabela 3 foram sistematizadas as categorias concebidas a partir da análise dos fatores de risco psicossocial identificados, assim como a frequência e as relações que cada fator de risco psicossocial estabelece com o estresse. Foram identificadas as seguintes categorias: Organização do trabalho e conteúdo das tarefas $(n=20 ; 80 \%)$, Exigências no trabalho ( $n=19 ; 76 \%)$ e Relações sociais e liderança $(n=17 ; 68 \%)$.

Cada categoria refere-se a um agrupamento de fatores de risco psicossocial. A categoria Organização do trabalho e conteúdo das tarefas compreendeu os seguintes fatores de risco psicossocial: Conteúdo das tarefas, possibilidade de desenvolvimento e condições físicas $(n=19 ; 76 \%)$, Influência no trabalho e monitoramento constante $(n=$ $10 ; 40 \%)$, e Insegurança $(n=7 ; 28 \%)$.

A categoria Exigências no trabalho abrangeu os fatores de risco psicossocial Exigências, ritmo de trabalho e número de trabalhadores $(n=16 ; 64 \%)$ e Horários de trabalho e conflito trabalho-família $(n=15 ; 60 \%)$. Por fim, a categoria Relações sociais e liderança compreendeu os fatores de risco psicossocial Relacionamento interpessoal e liderança $(n=12 ; 48 \%)$ e Reconhecimento, salário e benefícios $(n=10 ; 40 \%)$. 
Tabela 3 - Fatores de risco psicossocial, número de artigos e relação com o estresse

\begin{tabular}{|c|c|c|c|}
\hline Categorias & $\begin{array}{c}\text { Fatores de risco } \\
\text { psicossocial } \\
\text { identificados } \\
\end{array}$ & $\begin{array}{l}\mathbf{N}^{\circ} \text { de } \\
\text { artigos }\end{array}$ & Relação com o estresse \\
\hline \multirow{3}{*}{$\begin{array}{l}\text { Organização } \\
\text { do trabalho e } \\
\text { conteúdo das } \\
\text { tarefas } \\
(n=20)\end{array}$} & $\begin{array}{l}\text { Conteúdo das tarefas, } \\
\text { possibilidade de } \\
\text { desenvolvimento e } \\
\text { condições físicas }\end{array}$ & 19 & $\begin{array}{l}\text { Maiores índices de acidentes de trabalho e } \\
\text { doenças ocupacionais } \\
\text { Tédio e dificuldade de manter a atenção no } \\
\text { trabalho } \\
\text { Diminuição do sentido, prazer e bem-estar no } \\
\text { trabalho } \\
\text { Diminuição do controle sobre o trabalho }\end{array}$ \\
\hline & $\begin{array}{l}\text { Influência no } \\
\text { trabalho e } \\
\text { monitoramento } \\
\text { constante }\end{array}$ & 10 & $\begin{array}{l}\text { Diminuição do sentido, prazer e bem-estar no } \\
\text { trabalho } \\
\text { Diminuição da autonomia e controle }\end{array}$ \\
\hline & Insegurança & 7 & $\begin{array}{l}\text { Aumento das exigências } \\
\text { Diminuição do controle sobre o trabalho }\end{array}$ \\
\hline \multirow{2}{*}{$\begin{array}{l}\text { Exigências } \\
\text { no trabalho } \\
(n=19)\end{array}$} & $\begin{array}{l}\text { Exigências, ritmo de } \\
\text { trabalho e número de } \\
\text { trabalhadores }\end{array}$ & 16 & $\begin{array}{l}\text { Aumento das exigências } \\
\text { Realização de práticas inseguras no trabalho }\end{array}$ \\
\hline & $\begin{array}{l}\text { Horários de trabalho } \\
\text { e conflito trabalho- } \\
\text { família }\end{array}$ & 15 & $\begin{array}{l}\text { Alterações físicas e problemas de saúde } \\
\text { Diminuição do bem-estar e da qualidade dos } \\
\text { relacionamentos pessoais e familiares }\end{array}$ \\
\hline \multirow{2}{*}{$\begin{array}{l}\text { Relações } \\
\text { sociais e } \\
\text { liderança } \\
(n=17)\end{array}$} & $\begin{array}{l}\text { Relacionamento } \\
\text { interpessoal e } \\
\text { liderança }\end{array}$ & 12 & $\begin{array}{l}\text { Diminuição do prazer e bem-estar no } \\
\text { trabalho } \\
\text { Dificuldade de manter a atenção no trabalho } \\
\text { Intensificação da insegurança } \\
\text { Não atendimento das demandas }\end{array}$ \\
\hline & $\begin{array}{l}\text { Reconhecimento, } \\
\text { salário e benefícios }\end{array}$ & 10 & $\begin{array}{l}\text { Diminuição do reconhecimento e } \\
\text { recompensa } \\
\text { Necessidade de trabalhar em outros locais } \\
\text { Diminuição do prazer e bem-estar no } \\
\text { trabalho }\end{array}$ \\
\hline
\end{tabular}

\subsubsection{Organização do trabalho e conteúdo das tarefas}

Conteúdo das tarefas, possibilidade de desenvolvimento e condições físicas

Nas pesquisas selecionadas, muitos trabalhadores ocupavam funções que demandavam a realização de tarefas monótonas, pouco variadas e que exigiam a realização de movimentos repetitivos, principalmente nas ocupações referentes ao setor de serviços, um dos mais terceirizados atualmente (Chillida \& Cocco, 2004; 
Kesavachandran et al., 2006; Nadeem, 2009; Raja \& Bhasin, 2014; Ratnesh et al., 2016; Taylor et al., 2013). O trabalho monótono foi identificado como um fator que contribuiu para o estresse no trabalho (Seklecka et al., 2013), visto que dificulta o envolvimento dos trabalhadores com suas tarefas e torna o trabalho mais custoso, tedioso e sem sentido (Cox et al., 2000; Schabracq et al., 2003).

Tais ocupações ofereceram chances limitadas de desenvolvimento profissional aos trabalhadores, o que foi considerado uma fonte de insatisfação (Budhwar et al., 2009; Deery et al., 2013; Hechanova, 2013; Papadopoulos et al., 2010; Thite, 2010). Além disso, foi considerado comum que os trabalhadores terceirizados tivessem menos acesso a treinamentos profissionais quando comparados com os trabalhadores contratados (Alvarez et al., 2007; Jain et al., 2013; Santos et al., 2009), e quando participavam de treinamentos, estes geralmente apresentavam baixa qualidade ou eram inadequados (Druck, 2016; Quinlan \& Bohle, 2008), elevando o risco de acidentes de trabalho (Papadopoulos et al., 2010; Santos et al., 2009) e contribuindo para a diminuição do controle no trabalho (Zanelli et al., 2010).

Além do trabalho monótono com baixas chances de desenvolvimento profissional, alguns estudos identificaram a inadequação do ambiente e dos materiais de trabalho como um fator de risco psicossocial, que, somado aos protocolos de segurança inadequados, contribuiu diretamente para o aumento nos índices de acidentes de trabalho e doenças ocupacionais (Gemma et al., 2017; Jain et al., 2013; Zuberi, 2011). Por fim, foram apontadas a realização de atividades em ambientes de trabalho mal planejados (Quinlan \& Bohle, 2008), com exposição a ruídos e adoção de posições corporais desconfortáveis (Papadopoulos et al., 2010) e ausência de informação sobre riscos e medidas de segurança no trabalho.

\section{Influência no trabalho e monitoramento constante}

O elevado grau de monitoramento e avaliação do desempenho e a ausência de possibilidade de influenciar o modo como o trabalho é organizado e realizado foi identificado como um fator de risco psicossocial por 10 estudos (Budhwar et al., 2009; Deery et al., 2013; Jain et al., 2013; Kesavachandran et al., 2006; Nadeem, 2009; Papadopoulos et al., 2010; Raja \& Bhasin, 2014; Ratnesh et al., 2016; Taylor et al., 2013; Zuberi, 2011). 
Com a finalidade de controlar a qualidade do trabalho realizado, eram estabelecidos padrões de tarefas a serem executados, sendo que tais padrões eram constantemente monitorados pelos superiores e acarretavam na redução da autonomia e do controle dos trabalhadores sobre seu próprio trabalho (Papadopoulos et al., 2010). Na pesquisa realizada por Zuberi (2011), a avaliação do desempenho das agentes de limpeza era feita regularmente por meio de inspeções e auditorias realizadas pela empresa contratante. Nos casos em que os resultados dessas avaliações eram considerados insatisfatórios, a empresa terceirizada recebia advertências e seu contrato tinha grandes chances de ser finalizado.

Assim como o trabalho monótono, a realização de tarefas excessivamente controladas torna o trabalho fatigante e sem sentido (Schabracq et al., 2003), pois reduz a utilização das habilidades do trabalhador e intensifica a realização de movimentos prescritos, gerando tensão, sentimentos de inutilidade e diminuição do bem-estar (Leka \& Houdmont, 2010).

\section{Insegurança}

Aspectos relacionados à insegurança no trabalho também foram apontados como fatores de risco psicossocial nas pesquisas (Gemma et al., 2017; Jain et al., 2013; Papadopoulos et al., 2010; Taylor et al., 2013). Os trabalhadores que participaram da pesquisa realizada por Snell et al., (2015), contratados pela indústria de geração de energia, relataram tensão emocional por não saberem quando e se perderiam seus empregos, já que as negociações entre as empresas eram realizadas de forma sigilosa. Como consequência, eles apresentavam um alto grau de incerteza financeira, relacionada principalmente ao receio de perder o emprego e à incerteza referente ao próximo pagamento, o que levava estes trabalhadores a almejar por um emprego permanente.

A avaliação da empresa terceirizada pela empresa contratante também desempenhou um papel relevante no que diz respeito à insegurança no trabalho. Como o contrato estabelecido entre as empresas determinava as questões referentes às tarefas e ao quadro de funcionários, alterações neste contrato, muitas vezes derivadas das avaliações realizadas, geravam mudanças significativas para os terceirizados, como sua demissão ou aumento no número de atividades (Druck, 2016; Zuberi, 2011). 
Sendo assim, esses trabalhadores experimentavam um estado de tensão constante relacionado ao baixo controle sobre o trabalho, aos altos índices de insegurança e ao esforço frequente para garantir uma avaliação de desempenho elevada como tentativa de assegurar o emprego atual (Zanelli et al., 2010).

\subsubsection{Exigências no trabalho}

\section{Exigências, ritmo de trabalho e número de trabalhadores}

A sobrecarga de trabalho, geralmente acompanhada pela imposição de metas inatingíveis, foi identificada como um fator de risco psicossocial relacionado ao trabalho terceirizado (Druck, 2016; Hsiao \& Mor Barak, 2014; Quinlan \& Bohle, 2008). De acordo com a pesquisa realizada por Zuberi (2011), após a terceirização dos serviços de apoio em um hospital, os funcionários relataram um aumento na quantidade de trabalho devido ao número inadequado de profissionais. Além disso, a negligência da variabilidade e a complexidade das tarefas foi apontado como um fator que contribuiu para a intensificação do trabalho (Gemma et al., 2017), o que pode acarretar na realização de práticas inseguras que favorecem o desenvolvimento de doenças físicas e o risco de acidentes no trabalho (Papadopoulos et al., 2010).

Como consequência, o ritmo de trabalho tornou-se acelerado e foi percebida pressão constante para a realização das atividades de forma satisfatória no tempo estipulado (Hechanova, 2013; Jain et al., 2013; Kesavachandran et al., 2006; Nadeem, 2009; Raja \& Bhasin, 2014), sendo que alguns trabalhadores relataram não terem tempo suficiente para realizar suas refeições (Ram et al., 2014), fazer intervalos (D’Cruz \& Noronha, 2008) ou interagir com os colegas de trabalho (Taylor et al., 2013).

Outras exigências foram identificadas nos estudos realizados em empresas de call center e TI que atendiam outros países (offshoring): a necessidade de utilizar a língua de origem dos clientes durante o trabalho e adequar seu sotaque e o cuidado em esconder sua identidade para evitar reações agressivas e preconceituosas por parte dos clientes. Tais exigências geraram um aumento no número de demandas e constituíram novas fontes de estresse (Deery et al., 2013; Ratnesh et al., 2016). 


\section{Horários de trabalho e conflito trabalho-família}

Questões relacionadas ao horário de trabalho foram identificadas como prejudiciais aos trabalhadores, sendo o número extenso de horas de trabalho e o trabalho noturno os principais fatores de risco psicossocial apontados nos estudos (Budhwar et al., 2009; D’Cruz \& Noronha, 2008; Hechanova, 2013; Nadeem, 2009; Ram et al., 2014; Taylor et al., 2013). A realização do trabalho no período noturno foi identificada como uma prática regular para os trabalhadores nos setores de call center e tecnologia da informação (TI) que prestavam serviços a clientes de outros países, prática conhecida como offshoring (Davis-Blake \& Broschak, 2009).

Segundo Raja e Bhasin (2014) e Papadopoulos et al. (2010), trabalhar em horários noturnos pode alterar o ritmo circadiano do indivíduo, resultando em alterações físicas e problemas de saúde relacionados ao sono, irritabilidade, fadiga crônica e estresse. Ao trocar o dia pela noite ou cumprir longas horas de trabalho, os trabalhadores dispunham de menos tempo para conviver com a família e amigos, para se engajar em atividades sociais e de lazer e para cumprir as responsabilidades familiares esperadas (Chillida \& Cocco, 2004; Hsiao \& Mor Barak, 2014; Jain et al., 2013; Ratnesh et al., 2016; Seklecka et al., 2013; Zuberi, 2011), resultando no aumento do estresse e na diminuição do bem-estar e da qualidade dos relacionamentos pessoais e familiares (Papadopoulos et al., 2010).

\subsubsection{Relações sociais e liderança}

\section{Relacionamento interpessoal e liderança}

Os seguintes aspectos referentes às características da liderança e do relacionamento entre os trabalhadores e superiores foram identificados como fatores de risco psicossocial: ausência de critérios para promoção de funcionários (Budhwar et al., 2009; Deery et al., 2013; Seklecka et al., 2013), baixos níveis de suporte dos superiores ou colegas de trabalho (Jain et al., 2013; Kesavachandran et al., 2006) e baixa qualidade dos relacionamentos no ambiente de trabalho, caracterizada principalmente pela comunicação escassa (Nandialath et al., 2012; Quinlan \& Bohle, 2008). Segundo Schabracq et al. (2003), aspectos negativos referentes ao relacionamento no trabalho dificultam o estabelecimento de vínculos significativos, sentimentos de pertencimento 
ao grupo e manutenção da atenção no trabalho, e contribuem para a diminuição do prazer e bem-estar.

No que diz respeito à liderança, foi apontada a utilização da gestão baseada no medo, assédio moral e abuso de poder (Druck, 2016), o que ficou evidente no estudo realizado por Santos et al. (2009), em que foi verificada a utilização de expressões depreceativas para se referir aos trabalhadores, realização de ameaças constantes de demissão e rotatividade como forma de punição, intensificando a insegurança no trabalho.

Por fim, o fato do trabalho terceirizado ser constituído por dupla hierarquia (superiores da empresa contratante e superiores da empresa terceira) tornou mais difusa tanto a autonomia dos superiores quanto sua responsabilidade sobre os trabalhadores, sendo que estes relataram dificuldade em ter suas demandas atendidas pelos superiores (Gemma et al., 2017; Hsiao \& Mor Barak, 2014; Taylor et al., 2013).

\section{Reconhecimento, salário e benefícios}

Verificou-se nos estudos que aspectos relacionados ao reconhecimento, salário e benefícios constituíram fatores de risco psicossocial. Entre tais fatores, destaca-se a ausência de reconhecimento, tanto pela chefia da empresa terceirizada quanto da empresa contratante (Gemma et al., 2017), o estigma negativo relacionado ao trabalho (Hechanova, 2013; Santos et al., 2009; Thite, 2010) e o salário baixo ou insuficiente (Alvarez et al., 2007; Deery et al., 2013; Revathi, 2016). As recompensas financeiras, segundo Jain et al. (2013), contribuem para o estilo de vida do trabalhador e influenciam a percepção sobre seu próprio valor para a organização, já que representam um meio de reconhecimento pelo trabalho executado.

No estudo realizado por Zuberi (2011), os participantes relataram enfrentar dificuldades para arcar com seus gastos devido à redução do salário quando passaram de funcionários contratados para funcionários terceirizados. Essa diferença nos salários também foi ressaltada por Druck (2016), sendo que isso levou os trabalhadores a fazer hora extra e a trabalhar em mais de um local ou mais de um turno, o que interferiu negativamente no tempo disponível para realizar atividades sociais ou de lazer.

Além do baixo salário, destacou-se a impossibilidade de usufruir de alguns benefícios exclusivos aos trabalhadores contratados diretamente pela organização, como o uso do restaurante universitário (Gemma et al., 2017) e do sistema de saúde da 
empresa, além da participação em comitês de saúde e segurança no trabalho (Zuberi, 2011), participação nos lucros e transporte (Druck, 2016). 


\section{Capítulo 4. Método}

\section{Objetivo do capítulo 4}

O presente capítulo descreve o delineamento do estudo, os instrumentos de medida utilizados, as características da organização participante e os trabalhadores participantes do estudo. Também apresenta o procedimento da coleta de dados, a análise dos mesmos e as considerações éticas envolvidas.

\subsection{Delineamento do estudo}

Esta pesquisa consiste em um estudo de caso, de caráter exploratório, com utilização do método misto. Tal método caracteriza-se pela combinação do uso de métodos quantitativos e qualitativos no mesmo estudo, sendo que a proposta e a premissa central é que o uso de abordagens quantitativas e qualitativas, juntas, possibilitam uma melhor compreensão dos fenômenos (Abbad, Puente-Palácios \& Gondim, 2014; Azorín \& Cameron, 2010). Sendo assim, pode-se dizer que o objetivo principal desse método é a integração de métodos quantitativos e qualitativos, e não apenas a soma dos dois métodos.

Tendo em vista a Psicologia Organizacional e do Trabalho, área em que se insere este estudo, apesar de ainda não ser muito utilizado no Brasil, esse método tende a ser cada vez mais empregado, principalmente em razão dessa área pertencer a um campo multidisciplinar que envolve Sociologia, Economia, Psicologia e Administração, de se mostrar sensível às demandas para resolução de problemas sociais e de ter o objetivo de oferecer soluções aos problemas e desafios organizacionais (Abbad et al., 2014).

Segundo Creswell (2013), a combinação dos métodos quantitativos e qualitativos ocorre tanto na coleta de dados quanto na análise dos mesmos. A partir do pressuposto que cada tipo de coleta e análise de dados tem suas próprias limitações e vantagens, pode-se considerar que as vantagens podem ser combinadas a fim de se desenvolver uma compreensão mais fiel das questões ou problema de pesquisa, de modo que as vantagens de se utilizar ambos os métodos ultrapassem as limitações de cada um deles. 
Sendo assim, optou-se por utilizar o método misto neste estudo com a finalidade de se obter maior aprofundamento e compreensão completa do problema de pesquisa, o que é possível a partir do acesso a diferentes faces do mesmo fenômeno em questão (Abbad et al., 2014; Creswell, 2013).

Em relação ao delineamento da pesquisa, a partir do objetivo proposto e dos arranjos disponíveis na literatura acerca do método misto, os métodos quantitativo e qualitativo foram utilizados simultaneamente, estratégia denominada arranjo convergente. Este delineamento é caracterizado pela realização da coleta e análise de dados em duas fases relativamente independentes, uma quantitativa e a outra qualitativa, sendo que ambas utilizam as mesmas variáveis ou construtos (Tashakkori, Teddlie, \& Sines, 2012), o permite a convergência entre os dados quantitativos e qualitativos e a comparação de ambos, a fim de se verificar se os achados se confirmam ou não (Creswell, 2013). A Figura 9 ilustra o delineamento de pesquisa a partir desse arranjo.

Figura 9 - Delineamento de pesquisa a partir do arranjo convergente

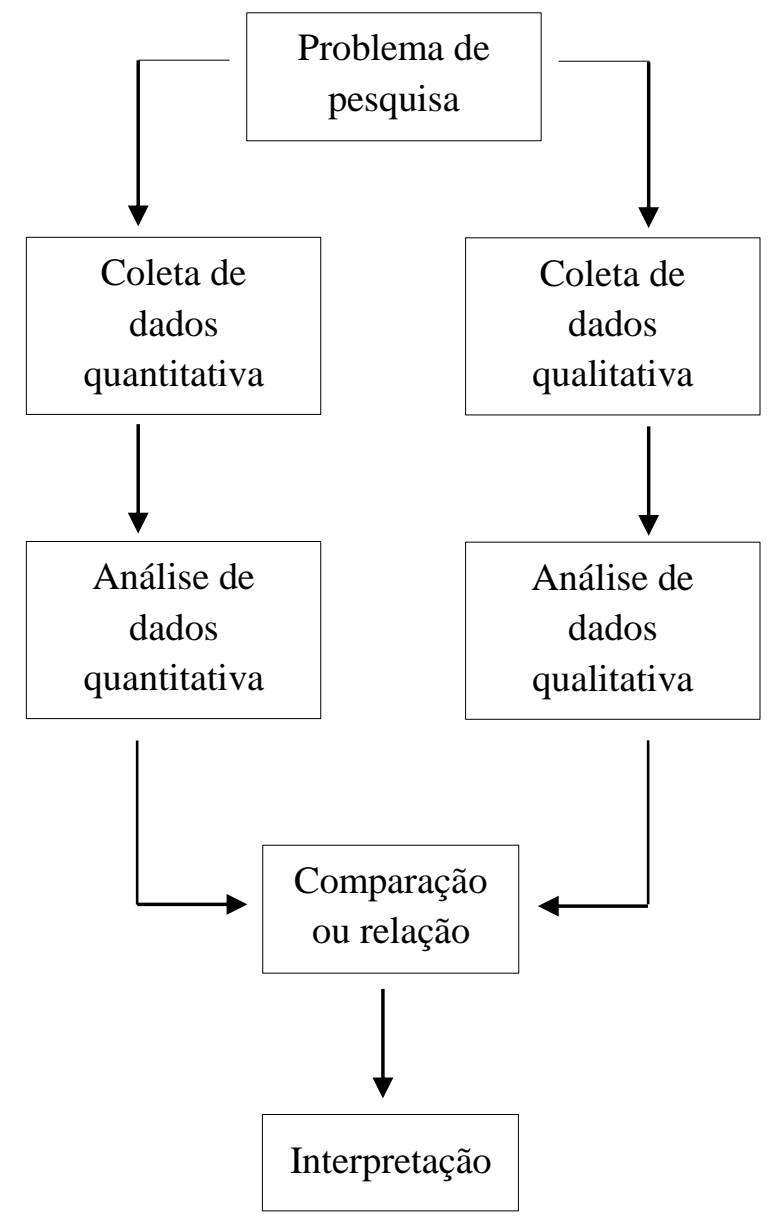

Fonte: elaboração da autora. 
Para fins didáticos, as duas metodologias utilizadas foram descritas separadamente nas próximas seções.

\subsection{Abordagem quantitativa}

A metodologia quantitativa neste estudo foi composta pela utilização de dois instrumentos na coleta de dados: o questionário de dados sociodemográficos e o Questionário Copenhagen Psychosocial Questionnaire II (COPSOQ II), conforme apresentado na Figura 10. Os dois instrumentos foram submetidos a um estudo piloto, com o objetivo de torná-los adequados aos participantes da pesquisa.

Figura 10 - Origem e objetivo dos instrumentos utilizados na abordagem quantitativa

\begin{tabular}{llc}
\hline \multicolumn{1}{c}{ Instrumento } & \multicolumn{1}{c}{ Origem } & Objetivo \\
\hline $\begin{array}{l}\text { Questionário de } \\
\text { dados } \\
\text { sociodemográficos }\end{array}$ & $\begin{array}{l}\text { Instrumento elaborado pela autora, } \\
\text { submetido a um estudo piloto para } \\
\text { posterior aplicação }\end{array}$ & $\begin{array}{c}\text { Identificar o perfil dos } \\
\text { trabalhadores }\end{array}$ \\
\hline
\end{tabular}

Versão média do questionário, traduzida e validada para a língua

COPSOQ II portuguesa. Foi submetido à avaliação Identificar e quantificar os fatores de risco psicossocial e a percepção dos semântica e estudo piloto para posterior trabalhadores em relação à aplicação

Fonte: elaboração da autora.

\subsubsection{Questionário de dados sociodemográficos}

Com a finalidade de identificar o perfil dos agentes de limpeza terceirizados, utilizou-se um questionário de dados sociodemográficos (Apêndice A), elaborado pela autora para a realização desta pesquisa. Tal questionário foi constituído por 16 questões, sendo 8 de múltipla escolha e 8 perguntas abertas, abordando temas como escolaridade, constituição familiar, cargo atual e tempo de serviço, entre outros, conforme organizado na Tabela 4. 
Tabela 4 - Número de questões referente a cada tema abordado

\begin{tabular}{|c|c|}
\hline Temas abordados & $\mathbf{N}^{0}$ de questões \\
\hline Dados pessoais & 4 \\
\hline Escolaridade & 1 \\
\hline Dados familiares & 3 \\
\hline Dados relacionados ao trabalho & 8 \\
\hline
\end{tabular}

\subsubsection{COPSOQ II}

Para identificar e avaliar os fatores de risco psicossocial que oferecem risco à saúde e ao estresse dos agentes de limpeza terceirizados, foi utilizada a versão média portuguesa do COPSOQ II (Anexo A) (C. Silva, 2011). Este instrumento foi escolhido por cobrir uma grande variedade de fatores de risco psicossocial que podem existir no mundo do trabalho atual, incluindo aqueles apresentados na revisão de literatura do capítulo anterior, e por ter tradução para diversas línguas, incluindo português e espanhol (Tabanelli et al., 2008).

O COPSOQ foi desenvolvido com o objetivo de constituir um instrumento válido e relevante, capaz de aprimorar as avaliações e intervenções nos locais de trabalho, facilitar a comunicação entre os profissionais, pesquisadores e o próprio contexto de trabalho, e permitir a comparação entre diferentes países e regiões. Possui dimensões relacionadas a níveis organizacionais, de departamento, de tarefa, individuais e de interface entre indivíduo e trabalho, é genérico e pode ser aplicado em qualquer setor do mercado de trabalho (Kristensen et al., 2005). Além disso, o instrumento permite que os pesquisadores ou profissionais apliquem as dimensões ou subescalas de modo independente e flexível, e as versões disponíveis (longa, média e curta) apresentam dimensões que quantificam os fatores de risco psicossocial e indicadores do seu efeito, como a saúde, o estresse e a satisfação (C. Silva, 2011).

Os conceitos teóricos que servem de base para o COPSOQ não são relacionados a uma única teoria específica, mas são compostos por partes importantes dos modelos contemporâneos mais influentes em Psicologia e Saúde Ocupacional, sendo eles o Modelo das Características do Trabalho, o Modelo de Stresse Organizacional de Michigan, o Modelo de Desequilíbrio Esforço-Recompensa, o Modelo Vitamina e o Modelo Demanda-Controle-Apoio (Pejtersen, Kristensen, Borg \& Bjorner, 2010). A maioria das escalas que compõem o questionário são baseadas em instrumentos já 
validados e baseados nos modelos citados, enquanto algumas foram elaboradas especificamente para este instrumento (Kristensen et al., 2005).

Neste estudo, a versão média foi selecionada após o estudo piloto, com o objetivo de se ter acesso ao maior número de fatores de risco psicossocial dentro do tempo estimado para a coleta de dados. Apesar da versão média abranger 29 dimensões, para este estudo foram utilizadas 20 dimensões, selecionadas por representarem os fatores de risco psicossocial mais relevantes, conforme apontado pela revisão sistemática da literatura exposta no capítulo anterior.

Essas 20 dimensões são avaliadas por 52 questões fechadas de mesmo peso, mensuradas por uma escala de intensidade que varia de 0 a 5 graus $(0,25,50,75$ e 100), sendo que o resultado da avaliação das dimensões compõe um índice. Entre as 29 dimensões que compõem a versão média, foram selecionadas as seguintes: exigências quantitativas, ritmo de trabalho, exigências cognitivas, exigências emocionais, influência no trabalho, possibilidades de desenvolvimento, significado do trabalho, compromisso com o trabalho, previsibilidade, transparência de papel, recompensas, conflitos de papeis, apoio social de colegas, apoio social de superiores, qualidade da liderança, conflito trabalho-família, satisfação no trabalho, insegurança no trabalho, saúde geral e estresse. A Tabela 5 apresenta as escalas utilizadas suas dimensões e seus respectivos número de itens, valores de consistência interna e níveis.

Tabela 5 - Escalas, dimensões, número de itens, consistência interna e nível da dimensão utilizados da versão média portuguesa do COPSOQ II (Continua)

\begin{tabular}{ccccc}
\hline Escalas & Dimensões & $\begin{array}{c}\mathbf{N}^{\mathbf{o}} \mathbf{d e} \\
\text { itens }\end{array}$ & $\begin{array}{c}\boldsymbol{\alpha} \text { de } \\
\text { Cronbach }\end{array}$ & $\begin{array}{c}\text { Nível da } \\
\text { dimensão }\end{array}$ \\
\hline $\begin{array}{c}\text { Exigências no } \\
\text { trabalho }\end{array}$ & Exigências quantitativas & 3 & 0,63 & $\mathrm{~T}$ \\
& Ritmo de trabalho & 1 & $*$ & $\mathrm{~T}$ \\
\hline $\begin{array}{c}\text { Exigências cognitivas } \\
\text { trabalho e } \\
\text { conteúdo }\end{array}$ & Exigências emocionais & 1 & 0,60 & $\mathrm{~T}$ \\
& Possibilidades de desenvolvimento & 3 & 0,76 & $\mathrm{~T}$ \\
\hline & Significado do trabalho & 3 & 0,82 & $\mathrm{~T}$ \\
\hline Compromisso com o trabalho & 2 & 0,61 & $\mathrm{~T}, \mathrm{I}$ e O
\end{tabular}


Tabela 5 - Escalas, dimensões, número de itens, consistência interna e nível da dimensão utilizados da versão média portuguesa do COPSOQ II (Conclusão)

\begin{tabular}{|c|c|c|c|c|}
\hline Escalas & Dimensões & $\begin{array}{l}N^{o} \text { de } \\
\text { itens }\end{array}$ & $\begin{array}{c}\alpha \text { de } \\
\text { Cronbach }\end{array}$ & $\begin{array}{c}\text { Nível da } \\
\text { dimensão }\end{array}$ \\
\hline \multirow{7}{*}{$\begin{array}{c}\text { Relações sociais e } \\
\text { liderança }\end{array}$} & Previsibilidade & 2 & 0,72 & $\mathrm{D}$ \\
\hline & Transparência de papel & 3 & 0,76 & $\mathrm{~T}$ e $\mathrm{D}$ \\
\hline & Recompensas & 3 & 0,82 & $\mathrm{De} \mathrm{O}$ \\
\hline & Conflitos de papeis & 3 & 0,67 & $\mathrm{~T}$ e $\mathrm{D}$ \\
\hline & Apoio social de colegas & 3 & 0,71 & $\mathrm{~T}$ e D \\
\hline & Apoio social de superiores & 3 & 0,87 & T e D \\
\hline & Qualidade da liderança & 4 & 0,90 & $\mathrm{D}$ \\
\hline \multirow{3}{*}{$\begin{array}{l}\text { Interface trabalho- } \\
\text { indivíduo }\end{array}$} & Conflito trabalho-família & 3 & 0,86 & $\mathrm{I}-\mathrm{T}$ \\
\hline & Satisfação no trabalho & 4 & 0,82 & $\mathrm{I}-\mathrm{T}$ \\
\hline & Insegurança no trabalho & 1 & $*$ & $\mathrm{I}-\mathrm{T}$ \\
\hline \multirow{2}{*}{ Saúde e bem-estar } & Saúde geral & 1 & $*$ & I \\
\hline & Estresse & 2 & 0,73 & I \\
\hline
\end{tabular}

Notas: $\mathrm{T}=$ tarefa; $\mathrm{I}$ = individual; $\mathrm{O}$ = organizacional; $\mathrm{D}$ = departamento; $\mathrm{I}-\mathrm{T}$ = indivíduotrabalho

* $\mathrm{O} \alpha$ de Cronbach não foi calculado um vez que a subescala é constituída por um único item.

\subsubsection{Análise dos dados}

Foram realizadas análises descritivas (média, desvio-padrão e moda) e correlações bivariadas entre os fatores de risco psicossocial e os indicadores de saúde e estresse por meio do software Statistical Package for the Social Sciences (SPSS) versão 21.0, a fim de se analisar a relação entre tais variáveis.

\subsection{Abordagem qualitativa}

Esta abordagem consistiu na realização de entrevistas com os gestores da organização (supervisor geral, encarregados e líderes de unidades) e com os trabalhadores, conforme exposto na Figura 11. 
Figura 11 - Resumo das informações sobre os instrumentos a serem utilizados na abordagem qualitativa

\begin{tabular}{|c|c|c|}
\hline Instrumento & Origem & Objetivo \\
\hline $\begin{array}{l}\text { Roteiro de entrevista } \\
\text { semiestruturado } \\
\text { (gestores) }\end{array}$ & $\begin{array}{c}\text { Elaborado pela autora a partir de } \\
\text { recomendações propostas pela } \\
\text { literatura para o levantamento de } \\
\text { informações sobre a empresa- } \\
\text { alvo }\end{array}$ & $\begin{array}{l}\text { Compreender o contexto de } \\
\text { trabalho e suas características, e } \\
\text { identificar ações e estratégias }\end{array}$ \\
\hline $\begin{array}{l}\text { Roteiro de entrevista } \\
\text { semiestruturado } \\
\text { (funcionários } \\
\text { terceirizados) }\end{array}$ & $\begin{array}{c}\text { Elaborado pela autora a partir } \\
\text { dos fatores de risco psicossocial } \\
\text { identificados na revisão } \\
\text { sistemática da literatura. Foi } \\
\text { submetido a um estudo piloto } \\
\text { para posterior aplicação }\end{array}$ & $\begin{array}{c}\text { Identificar os fatores de risco } \\
\text { psicossocial, compreender a } \\
\text { rotina de trabalho, identificar } \\
\text { ações e estratégias sugeridas } \\
\text { pelos trabalhadores e } \\
\text { identificar a percepção dos } \\
\text { trabalhadores em relação à sua } \\
\text { saúde e estresse }\end{array}$ \\
\hline
\end{tabular}

Fonte: elaboração da autora.

\subsubsection{Roteiro de entrevista semiestruturada utilizado com os gestores}

As entrevistas com os gestores foram realizadas com a finalidade de se compreender o contexto de trabalho e suas características, bem como identificar ações e estratégias que podem ser adotadas pela empresa para melhorar o trabalho e minimizar os impactos negativos da terceirização para os funcionários terceirizados. $\mathrm{O}$ roteiro semiestruturado utilizado (Apêndice B) foi constituído por 19 questões e elaborado pela autora a partir das recomendações propostas por Abrahão, Sznelwar, Silvino, Sarmet e Pinho (2009) para o levantamento de informações sobre a empresa-alvo, conforme exposto na Tabela 6 . 
Tabela 6 - Número de questões referente a cada tema abordado no roteiro de entrevista utilizado com os gestores

\begin{tabular}{lc}
\hline \multicolumn{1}{c}{ Temas abordados } & $\mathbf{N}^{\mathbf{0}}$ de questões \\
\hline História da organização e contexto & 2 \\
Normas e indicadores & 2 \\
Processo de produção e organização das tarefas & 2 \\
Informações referentes aos funcionários & 2 \\
Espaço físico e materiais & 1 \\
Práticas de Gestão de Pessoas & 3 \\
Comunicação & 1 \\
Dificuldades encontradas & 2 \\
Percepções acerca da terceirização & 3 \\
\hline
\end{tabular}

\subsubsection{Roteiro de entrevista semiestruturada utilizado com os trabalhadores}

$\mathrm{O}$ roteiro de entrevista semiestruturado utilizado com os trabalhadores terceirizados (Apêndice C) foi elaborado pela autora a partir das informações encontradas na revisão sistemática da literatura. As 13 questões foram formuladas com o objetivo de abordar os principais fatores de risco psicossocial identificados na revisão, a fim de convidar os trabalhadores a compartilhar sua percepção acerca de tais fatores. Além disso, tal roteiro também teve como objetivo compreender a rotina de trabalho, identificar ações e estratégias sugeridas pelos trabalhadores para minimizar os impactos negativos decorrentes do processo de terceirização e identificar percepções acerca da saúde. Os seguintes fatores de risco psicossocial foram abordados nas questões: exigências quantitativas, cognitivas e emocionais, ritmo de trabalho, possibilidades de desenvolvimento, recompensas, conflito de papeis, relacionamento interpessoal, insegurança no trabalho, conflito trabalho-família, significado do trabalho.

Este roteiro de entrevista foi submetido a um estudo piloto com a finalidade de adaptar sua linguagem à realidade dos participantes.

A Tabela 7 apresenta os temas abordados no roteiro e o respectivo número de questões. 
Tabela 7 - Número de questões referente a cada tema abordado no roteiro de entrevista utilizado com os trabalhadores

\begin{tabular}{lc}
\hline \multicolumn{1}{c}{ Temas abordados } & $\mathbf{N}^{\mathbf{0}}$ de questões \\
\hline Rotina de trabalho & 1 \\
Fatores de risco psicossocial & 9 \\
Estresse e saúde & 3 \\
\hline
\end{tabular}

\subsubsection{Análise dos dados}

A análise dos dados qualitativos foi realizada a partir do método da análise temática, que consiste em um processo utilizado para codificar informações qualitativas, a partir da identificação, análise e informação dos padrões temáticos que se relacionam com a questão de pesquisa, a partir do conjunto de dados coletados pelo pesquisador (Braun \& Clarke, 2006). Tal método de análise é utilizado por pesquisadores de diversas áreas e permite que as informações coletadas sejam analisadas sistematicamente, resultando no destaque dos temas mais relevantes para a compreensão do fenômeno estudado (Joffe, 2012).

Segundo Boyatzis (1998), um tema representa um padrão identificado que descreve e organiza informações a partir dos dados coletados. Os temas podem ser identificados em nível manifesto, a partir das informações explícitas presentes nos dados, ou em nível latente, que envolve a intepretação dos dados coletados. Também podem ser gerados exclusivamente a partir dos dados brutos, o que é chamado de abordagem indutiva, a partir de temas já destacados na literatura ou de interesses específicos do pesquisador, denominada abordagem dedutiva, ou, ainda, a partir de ambas as abordagens (Boyatzis, 1998). Neste estudo, os temas foram identificados em nível manifesto e foram utilizadas as abordagens dedutiva e indutiva para a elaboração dos mesmos.

A fim de garantir maior rigor científico, o guia de diretrizes proposto por Braun e Clarke (2006) foi utilizado para a realização desta análise. As fases que compõem tais diretrizes estão organizadas na Figura 12. 
Figura 12 - Fases da análise temática

\begin{tabular}{|c|c|}
\hline Fase & Descrição do processo \\
\hline $\begin{array}{l}\text { 1. Familiarizar-se com } \\
\text { os dados }\end{array}$ & $\begin{array}{c}\text { Transcrever os dados, ler e reler os dados, tomar nota das ideias } \\
\text { iniciais }\end{array}$ \\
\hline 2. Gerar códigos iniciais & $\begin{array}{c}\text { Codificar recursos interessantes dos dados de forma sistemática em } \\
\text { todo o conjunto de dados, agrupar dados relevantes para cada } \\
\text { código }\end{array}$ \\
\hline 3. Procurar por temas & $\begin{array}{c}\text { Transformar códigos em temas potenciais, reunir todos os dados } \\
\text { relevantes para cada tema potencial }\end{array}$ \\
\hline 4. Revisar os temas & $\begin{array}{c}\text { Checar se os temas trabalham em relação com os extratos } \\
\text { codificados e com todo o conjunto de dados, gerar um "mapa" } \\
\text { temático de análise }\end{array}$ \\
\hline $\begin{array}{l}\text { 5. Definir e nomear os } \\
\text { temas }\end{array}$ & $\begin{array}{l}\text { Analisar os temas para refinar as especificidades de cada tema e a } \\
\text { história geral que a análise conta, gerar definições e nomes claros } \\
\text { para cada tema }\end{array}$ \\
\hline 6. Relatar & $\begin{array}{c}\text { Selecionar exemplos de extratos vívidos e convincentes, analisar os } \\
\text { extratos selecionados, relacionar a análise com as questões de } \\
\text { pesquisa e dados da literatura }\end{array}$ \\
\hline
\end{tabular}

Fonte: adaptado de Braun e Clarke (2006, p. 87).

\subsection{Adaptação dos instrumentos de medida}

\subsubsection{Validação semântica}

A validação semântica visa identificar possíveis falhas presentes nos instrumentos de medida, a fim de corrigi-las. Inicialmente, a versão longa do COPSOQ II (versão portuguesa) foi selecionada como instrumento de coleta de dados. Tal questionário foi submetido à validação semântica por dois especialistas da área de Psicologia Organizacional e do Trabalho. A validação semântica constituiu no preenchimento de um formulário abordando os seguintes quesitos: clareza, precisão e objetividade dos itens, e adequação das palavras e das instruções de preenchimento. 


\subsubsection{Estudo piloto}

Em seguida à validação semântica, a versão modificada do COPSOQ II (versão longa) foi utilizada no estudo piloto. Além deste, o questionário sociodemográfico e o roteiro de entrevista semiestruturado também foram submetidos ao estudo piloto, que consistiu na avaliação da compreensão das instruções e dos instrumentos de medida por agentes de limpeza terceirizados. Este procedimento foi realizado com 3 agentes de limpeza da empresa participante e permitiu verificar falhas no procedimento de coleta de dados proposto, no que se refere às instruções e aos instrumentos.

Além disso, foi possível identificar grande dificuldade na realização da coleta devido ao receio explícito dos agentes de limpeza em participar da pesquisa, sendo que muitos, ao serem convidados a participar, logo recusaram ou relataram preocupação referente à divulgação das informações resultantes da coleta de dados e avaliação das mesmas pelos superiores.

\subsection{Características da organização participante}

A organização participante constitui uma das filiais de uma empresa que oferece serviços terceirizados de portaria, segurança, limpeza, serviços de copa e jardinagem geral para organizações privadas e públicas. A empresa possui 33 anos de atuação no mercado e 7000 funcionários. Sua matriz é localizada na cidade de São Paulo, e as filiais localizam-se nas cidades de Indaiatuba e Ribeirão Preto. Os serviços são oferecidos tanto nas cidades citadas quanto nas cidades vizinhas, e apesar da atuação estar concentrada no estado de São Paulo, a empresa já antende cidades do estado de Minas Gerais.

A organização participante presta serviços de limpeza a uma universidade pública brasileira há 12 anos e atualmente possui 170 funcionários trabalhando nas unidades da universidade, os quais ocupam as seguintes funções: supervisor geral, encarregado de unidade, líder e agente de limpeza.

\subsection{Participantes do estudo}

Participaram deste estudo 20 agentes de limpeza que prestam serviços a 4 unidades de uma universidade pública. Também participaram da pesquisa o supervisor 
geral da empresa terceirizada, 3 encarregados de unidade e uma líder de unidade. O número de participantes foi designado a partir da disponibilidade dos funcionários, portanto constitui-se em uma amostra por conveniência.

Em relação às agentes de limpeza participantes, estas apresentaram uma média de idade de 45,5 anos, sendo que todas moravam na mesma cidade em que trabalhavam, e a maioria era casada $(n=13,65 \%)$, tinha entre dois e três filhos $(n=10,50 \%)$ e morava com 3 ou 4 pessoas $(n=11,55 \%)$. No que diz respeito à escolaridade, a maioria não chegou a completar o Ensino Fundamental $(n=11,55 \%)$. Todas as participantes eram registradas com a função de Agente de Asseio e Conservação e a maioria trabalhava na empresa terceirizada, na universidade e na mesma função há mais de 3 anos $(n=15,75 \%)$. Apenas 3 funcionárias não tinham experiências anteriores com o trabalho de limpeza e somente 2 passaram mais de um dia afastadas do trabalho por motivos de saúde relacionada ao próprio trabalho no último ano. Esses resultados são expressos pela Tabela 8 , e as características individuais de cada participante estão organizadas na Figura 13.

Tabela 8 - Perfil das agentes de limpeza participantes (Continua)

\begin{tabular}{|c|c|c|}
\hline Variável & $F$ & $\%$ \\
\hline \multicolumn{3}{|l|}{ Sexo } \\
\hline Feminino & 20 & 100 \\
\hline \multicolumn{3}{|l|}{ Idade } \\
\hline Entre 31 e 40 anos & 5 & 25 \\
\hline Entre 41 e 50 anos & 11 & 55 \\
\hline Entre 51 e 60 anos & 3 & 15 \\
\hline Entre 61 e 70 anos & 1 & 5 \\
\hline \multicolumn{3}{|l|}{ Média (45,5 anos) } \\
\hline \multicolumn{3}{|l|}{ Estado civil } \\
\hline Casada/União estável & 13 & 65 \\
\hline Divorciada & 1 & 5 \\
\hline Viúva & 4 & 20 \\
\hline Solteira & 2 & 10 \\
\hline \multicolumn{3}{|l|}{ Escolaridade } \\
\hline Não estudou & 2 & 10 \\
\hline Ensino Fundamental incompleto & 11 & 55 \\
\hline Ensino Fundamental completo & 2 & 10 \\
\hline Ensino Médio incompleto & 3 & 15 \\
\hline Ensino Médio completo & 2 & 10 \\
\hline
\end{tabular}


Tabela 8 - Perfil das agentes de limpeza participantes (Conclusão)

\begin{tabular}{|c|c|c|}
\hline Variável & $\boldsymbol{F}$ & $\%$ \\
\hline \multicolumn{3}{|l|}{ Número de filhos } \\
\hline Entre 1 e 2 & 8 & 40 \\
\hline Entre 3 e 4 & 8 & 40 \\
\hline Entre 5 e 6 & 2 & 10 \\
\hline Entre 7 e 8 & 2 & 10 \\
\hline \multicolumn{3}{|l|}{ Mora com quantas pessoas? } \\
\hline Entre 1 e 2 & 4 & 20 \\
\hline Entre 3 e 4 & 11 & 55 \\
\hline Entre 5 e 6 & 4 & 20 \\
\hline Entre 7 e 8 & 1 & 5 \\
\hline \multicolumn{3}{|l|}{ Cargo atual } \\
\hline Agente de asseio e conservação & 20 & 100 \\
\hline \multicolumn{3}{|c|}{ Tempo de serviço na empresa terceirizada } \\
\hline Até 3 anos & 8 & 40 \\
\hline De 4 a 7 anos & 9 & 45 \\
\hline De 8 a 11 anos & 3 & 15 \\
\hline \multicolumn{3}{|c|}{ Tempo de serviço na universidade e no cargo atual } \\
\hline Até 3 anos & 8 & 40 \\
\hline De 4 a 7 anos & 8 & 40 \\
\hline De 8 a 11 anos & 4 & 20 \\
\hline \multicolumn{3}{|l|}{ Já trabalhou no setor de limpeza antes? } \\
\hline Sim & 17 & 85 \\
\hline Não & 3 & 15 \\
\hline \multicolumn{3}{|c|}{$\begin{array}{l}N^{\circ} \text { de dias de afastamentos por problema de saúde relacionado } \\
\text { ao trabalho no último ano }\end{array}$} \\
\hline Nenhum & 18 & 90 \\
\hline Entre 1 e 3 dias & 1 & 5 \\
\hline Mais de 3 dias & 1 & 5 \\
\hline
\end{tabular}

Notas: $F=$ Frequência absoluta e $\%=$ Porcentagem. 
Figura 13 - Características individuais das participantes

\begin{tabular}{|c|c|c|c|c|c|}
\hline Participante & Idade & Escolaridade & $\begin{array}{l}\text { Estado } \\
\text { civil }\end{array}$ & $\begin{array}{l}N^{o} \text { de } \\
\text { filhos }\end{array}$ & $\begin{array}{c}\text { Tempo de } \\
\text { serviço na } \\
\text { empresa } \\
\end{array}$ \\
\hline Vivian & 46 & Médio incompleto & Casada & 2 & 3 anos \\
\hline Júlia & 35 & Médio incompleto & Casada & 1 & 4 anos \\
\hline Beatriz & 34 & $\begin{array}{c}\text { Fundamental } \\
\text { incompleto }\end{array}$ & Casada & 3 & 3 anos \\
\hline Rita & 43 & $\begin{array}{l}\text { Fundamental } \\
\text { incompleto }\end{array}$ & Casada & 1 & 4 anos \\
\hline Marcela & 50 & $\begin{array}{l}\text { Fundamental } \\
\text { incompleto }\end{array}$ & Casada & 3 & 2 anos \\
\hline Natália & 47 & $\begin{array}{l}\text { Fundamental } \\
\text { incompleto }\end{array}$ & Casada & 3 & 5 anos \\
\hline Carla & 54 & Não estudou & Viúva & 3 & 6 anos \\
\hline Mariana & 47 & $\begin{array}{l}\text { Fundamental } \\
\text { incompleto }\end{array}$ & Casada & 7 & 8 meses \\
\hline Helen & 50 & $\begin{array}{l}\text { Fundamental } \\
\text { incompleto }\end{array}$ & Divorciada & 2 & 5 meses \\
\hline Jéssica & 35 & $\begin{array}{l}\text { Fundamental } \\
\text { completo }\end{array}$ & Casada & 5 & 8 anos \\
\hline Laura & 48 & Médio completo & Casada & 2 & 6 anos \\
\hline Camila & 45 & Não estudou & Viúva & 4 & 7 anos \\
\hline Juliana & 32 & $\begin{array}{c}\text { Fundamental } \\
\text { incompleto }\end{array}$ & Solteira & 1 & 2 meses \\
\hline Amanda & 47 & Médio completo & Viúva & 4 & 4 anos \\
\hline Bruna & 62 & $\begin{array}{l}\text { Fundamental } \\
\text { incompleto }\end{array}$ & Viúva & 3 & 6 anos \\
\hline Fernanda & 52 & $\begin{array}{l}\text { Fundamental } \\
\text { incompleto }\end{array}$ & Casada & 5 & 8 anos \\
\hline Luíza & 31 & $\begin{array}{l}\text { Fundamental } \\
\text { incompleto }\end{array}$ & Casada & 2 & 2 anos \\
\hline Giovana & 57 & $\begin{array}{l}\text { Fundamental } \\
\text { incompleto }\end{array}$ & Casada & 7 & 5 anos \\
\hline Isadora & 50 & Médio incompleto & Casada & 2 & 8 anos \\
\hline Gabriela & 45 & $\begin{array}{c}\text { Fundamental } \\
\text { incompleto }\end{array}$ & Solteira & 4 & 3 anos \\
\hline
\end{tabular}

Fonte: elaboração da autora.

\subsection{Considerações éticas}

O projeto de pesquisa foi submetido e aprovado pelo Comitê de Ética em Pesquisa da Faculdade de Filosofia, Ciências e Letras de Ribeirão Preto (FFCLRP- 
USP), sendo que seu número identificador que corresponde ao Certificado de Apresentação para Apreciação Ética é 62738416.7.0000.5407. O supervisor geral da organização participante foi contatado, recebeu uma carta de apresentação do projeto de pesquisa (Apêndice D) e foi esclarecido sobre os objetivos da pesquisa e os procedimentos a serem utilizados. Mediante sua autorização a partir do Termo de Autorização para Participação em Pesquisa, foi possível a realização do projeto piloto e foi concluída a coleta de dados.

Foram elaborados e aprovados pelo Comitê de Ética referido dois Termos de Consentimento Livre e Esclarecido (TCLE), sendo que um foi elaborado para os agentes de limpeza (Apêndice E) e outro para o supervisor geral e os encarregados e líderes das unidades (Apêndice F). Para a realização da coleta, a pesquisadora realizou a leitura do TCLE para cada participante e apresentou as informações em relação ao objetivo da pesquisa, aos procedimentos de coleta, ao caráter voluntário da participação, à manutenção do sigilo e anonimato, à autorização para gravação de áudio, aos possíveis riscos referentes à participação e à solicitação de autorização para o uso das informações coletadas, sendo que as coletas só foram iniciadas após a compreensão e assinatura do TCLE pelos participantes. No estudo piloto, esses procedimentos também foram adotados.

\subsection{Procedimento de coleta dos dados}

O procedimento da coleta de dados foi realizado individualmente e pessoalmente no horário de trabalho dos participantes, sendo que foi combinado com cada participante o melhor dia e horário, a fim de não interferir na rotina de trabalho.

Com os agentes de limpeza, após a apresentação e esclarecimento do TCLE, foi aplicado o questionário de dados sociodemográficos, a entrevista semiestruturada foi realizada e em seguida o COPSOQ II foi aplicado. A fim de garantir que os participantes compreendessem os questionários, a leitura e preenchimento dos mesmos foi realizada pela pesquisadora.

Com os gestores (supervisor geral, encarregados e líder), após a apresentação do TCLE, a entrevista semiestruturada foi realizada. Em ambos os casos, os áudios derivados das entrevistas foram gravados pelo celular da pesquisadora e posteriormente transcritos na íntegra. Em relação ao local destinado à coleta de dados, este foi previamente combinado com cada participante, sendo que a coleta de dados foi 
realizada em salas disponíveis localizadas dentro das próprias unidades em que os participantes atuavam. Tanto a coleta de dados com as agentes de limpeza quanto a coleta com os gestores tiveram duração média de 50 a 60 minutos.

\subsection{Procedimento de análise de dados}

Após a realização da análise quantitativa e qualitativa, descritas nas seções 4.2.3 e 4.3.3, os resultados de ambas as análises foram comparados e interpretados a partir da triangulação dos dados. Segundo Jick (1979), a triangulação é um modo de se investigar o mesmo fenômeno a partir de mais de uma fonte de dados, sendo que tal prática contribui para o enriquecimento da compreensão da questão de pesquisa. A comparação entre os dados também permite a confirmação ou contraposição dos resultados, além de facilitar a manifestação de novos problemas de pesquisa (Creswell, 2013). 


\section{Capítulo 5. Resultados}

\section{Objetivo do capítulo 5}

O presente capítulo tem como objetivo apresentar os resultados desta pesquisa. São apresentados os resultados da validação semântica e do estudo piloto, os fatores de risco psicossocial identificados pelas análises quantitativas e qualitativas, as sugestões de estratégias para a melhoria do trabalho terceirizado e uma síntese dos resultados obtidos.

\subsection{Adaptação dos instrumentos de medida}

\subsubsection{Validação semântica}

As alterações sugeridas pelos especialistas consistiram em pequenas modificações na redação de alguns itens, mantendo o sentido original - por exemplo, a frase "Pode influenciar a quantidade de trabalho que lhe compete a si?" foi substituída por "Pode influenciar a quantidade de trabalho a ser realizado?". Tais alterações foram sistematizadas no Apêndice G.

\subsubsection{Estudo piloto}

Após a realização do estudo piloto com os agentes de limpeza, as instruções de preenchimento do COPSOQ II foram reformuladas e os instrumentos também foram adaptados, sendo que identificou-se a necessidade de adicionar uma questão ao questionário sociodemográfico e alterar alguns itens do roteiro de entrevista semiestruturado, no que se refere ao conteúdo e à linguagem. Em relação ao COPSOQ II (versão longa), notou-se que a aplicação de tal instrumento pela pesquisadora ultrapassou o limite de tempo estabelecido para a coleta de dados, portanto optou-se pela utilização da versão média do questionário. As alterações resultantes do estudo piloto foram sistematizadas no Apêndice H. Além disso, foi criada uma representação visual para as opções de resposta deste instrumento (nunca; raramente; às vezes; frequentemente; sempre) (Apêndice I), a fim de auxiliar na compreensão deste pelos participantes. 


\subsection{Análise quantitativa}

\subsubsection{Análises descritivas}

Os resultados descritivos das 20 dimensões do instrumento COPSOQ II podem ser visualizados na Tabela 9 e a os valores de consistência interna de cada escala e das dimensões estresse e saúde foram apresentados na Tabela 10.

Tabela 9 - Resultados descritivos das dimensões referentes ao COPSOQ II

\begin{tabular}{|c|c|c|c|c|c|c|c|}
\hline \multirow{2}{*}{ Escalas } & \multirow{2}{*}{ Dimensões } & \multirow{2}{*}{ Média } & \multirow{2}{*}{$\begin{array}{l}\text { Desvio- } \\
\text { Padrão }\end{array}$} & \multirow{2}{*}{ Moda } & \multicolumn{3}{|c|}{$\begin{array}{c}\text { Concentração de } \\
\text { respostas (\%) }\end{array}$} \\
\hline & & & & & $1-2$ & 3 & 4-5 \\
\hline \multirow{4}{*}{$\begin{array}{l}\text { Organização } \\
\text { do trabalho } \\
\text { e conteúdo }\end{array}$} & Significado do trabalho & 4,43 & 0,66 & 5 & 5 & 15 & 80 \\
\hline & $\begin{array}{l}\text { Possibilidades de } \\
\text { desenvolvimento }\end{array}$ & 3,63 & 0,87 & 5 & 15 & 32 & 53 \\
\hline & $\begin{array}{l}\text { Compromisso com o } \\
\text { trabalho }\end{array}$ & 3 & 1,03 & 3 & 30 & 32,5 & 37,5 \\
\hline & Influência no trabalho & 1,93 & 0,8 & 1 & 69 & 20 & 11 \\
\hline \multirow{7}{*}{$\begin{array}{l}\text { Relações } \\
\text { sociais e } \\
\text { liderança }\end{array}$} & Transparência de papel & 4,28 & 0,87 & 5 & 13 & 8 & 79 \\
\hline & Recompensas & 4,2 & 0,78 & 5 & 7 & 23 & 70 \\
\hline & Qualidade da liderança & 3,74 & 1,21 & 5 & 24 & 16 & 60 \\
\hline & Previsibilidade & 3,25 & 1,24 & 5 & 32,5 & 25 & 42,5 \\
\hline & Apoio social de superiores & 2,93 & 1,27 & 5 & 43 & 22 & 35 \\
\hline & Conflitos de papeis & 2,58 & 0,86 & 3 & 40 & 45 & 15 \\
\hline & Apoio social de colegas & 2,5 & 1,07 & 1 & 57 & 15 & 28 \\
\hline \multirow{4}{*}{$\begin{array}{l}\text { Exigências } \\
\text { no trabalho }\end{array}$} & Ritmo de trabalho & 3,4 & 1,31 & 4 & 25 & 25 & 50 \\
\hline & Exigências emocionais & 2,75 & 1,33 & 3 & 35 & 45 & 20 \\
\hline & Exigências cognitivas & 2,72 & 0,64 & 1 & 47 & 23 & 30 \\
\hline & Exigências quantitativas & 2,05 & 0,74 & 1 & 64 & 23 & 13 \\
\hline \multirow{3}{*}{$\begin{array}{l}\text { Interface } \\
\text { trabalho- } \\
\text { indivíduo }\end{array}$} & Insegurança no trabalho & 3,55 & 1,57 & 5 & 20 & 30 & 50 \\
\hline & Satisfação no trabalho & 3,06 & 0,47 & 3 & 34 & 31 & 35 \\
\hline & Conflito trabalho-família & 2,93 & 0,95 & 1 & 37 & 25 & 38 \\
\hline \multirow{2}{*}{$\begin{array}{l}\text { Saúde e } \\
\text { bem-estar }\end{array}$} & Saúde geral & 3,4 & 1,1 & 3 & 20 & 45 & 35 \\
\hline & Estresse & 2,83 & 1,29 & 1 & 52,5 & 10 & 37,5 \\
\hline
\end{tabular}

Notas: $1=$ Nunca/quase nunca, $2=$ Raramente, $3=$ As vezes, $4=$ Frequentemente, $5=$ Sempre. $\mathrm{Na}$ dimensão Saúde geral, 1=Excelente, 2=Muito boa, 3=Boa, 4=Razoável, 5=Ruim. 
Tabela 10 - Valores de consistência interna das escalas e das dimensões Estresse e Saúde referentes ao COPSOQ II

\begin{tabular}{lc}
\hline \multicolumn{1}{c}{ Escalas } & $\boldsymbol{\alpha}$ de Cronbach \\
\hline Organização do trabalho e conteúdo & 0,6 \\
Relações sociais e liderança & 0,86 \\
Exigências no trabalho & 0,506 \\
Interface trabalho-indivíduo & 0,531 \\
\hline Dimensões & $\boldsymbol{\alpha}$ de Cronbach \\
\hline Estresse & 0,458 \\
Saúde & $*$ \\
$*$ O $\alpha$ de Cronbach não foi calculado um vez que a dimensão é constituída por um único \\
item.
\end{tabular}

A média das dimensões teve uma variação de 1,93 a 4,43. Das 20 dimensões presentes no questionário, 11 apresentaram maior concentração de respostas nos pontos mais altos da escala (entre 35\% e 80\%), 3 concentraram-se nos pontos médios (45\%), e em 6 dimensões a concentração de respostas manteve-se nos pontos mais baixos (entre $43 \%$ e $69 \%$ ). Os valores da moda mostraram-se diversificados, obtendo pontuações que passaram por $1,3,4$ e 5 .

As 4 dimensões que apresentaram as médias mais altas foram: significado do trabalho $(M=4,43 ; D P=0,66)$, transparência de papel $(M=4,28 ; D P=0,87)$, recompensas $(M=4,2 ; D P=0,78)$ e qualidade da liderança $(M=3,74 ; D P=1,21)$. Dessas dimensões, três fazem parte do agrupamento de fatores de risco psicossocial denominado Relações sociais e liderança, que engloba as dimensões transparência de papel, recompensas e qualidade da liderança.

As médias mais baixas, por sua vez, foram identificadas em 4 dimensões: influência no trabalho $(M=1,93 ; D P=0,8)$, exigências quantitativas $(M=2,05 ; D P=$ $0,74)$, apoio social de colegas $(M=2,5 ; D P=1,07)$ e conflito de papeis $(M=2,58 ; D P$ $=0,86)$. As duas últimas dimensões também pertencem ao agrupamento de fatores de risco psicossocial denominado Relações sociais e liderança, enquanto a primeira pertence ao agrupamento Organização do trabalho e conteúdo, e a dimensão exigências quantitativas faz parte do agrupamento Exigências no trabalho.

Em relação aos valores de consistência interna de cada escala, foi possível identificar que apenas a escala Relações sociais e liderança apresentou um valor considerado aceitável $(\alpha=0,86)$. As demais escalas e a dimensão estresse apresentaram valores de $\alpha$ considerados baixos $(\alpha<0,5)$ (George $\&$ Mallery, 2006). Segundo Maroco 
e Garcia-Marques (2006), um $\alpha$ de Cronbach muito baixo pode refletir a codificação equivocada de itens ou a mistura de itens de dimensões diferentes, o que exige a reavaliação da base teórica subjacente à construção do instrumento. Não foi possível calcular a consistência interna da dimensão saúde, visto que tal dimensão foi composta por apenas um item.

A partir do cálculo da consistência interna das escalas, optou-se pela exclusão da dimensão satisfação no trabalho na escala Interface trabalho-indivíduo, devido ao fato de que os itens componentes de tal dimensão apresentaram baixa correlação com o total da escala, gerando um baixo valor de $\alpha$. Também optou-se pela utilização das dimensões saúde e estresse separadamente devido ao baixo valor de consistência interna da escala Saúde e bem-estar.

Ainda no que diz respeito às análises descritivas, C. Silva (2011) propõe que os dados resultantes da aplicação do COPSOQ II sejam organizados visualmente. Segundo este autor, além da interpretação das dimensões que compõem o instrumento a partir das médias, pode-se situar as médias das dimensões do COPSOQ II em tercis, que correspondem à divisão das possibilidades de resposta aos itens (de 1 a 5) em três partes iguais, com pontos de corte de 2,33 e 3,66. Tal divisão constitui uma interpretação do impacto que a exposição de cada dimensão representa para a saúde, sendo que uma situação favorável para a saúde é representada pela cor verde, uma situação intermediária que merece atenção é representada pela cor amarela e uma situação que apresenta risco à saúde é representada pela cor vermelha, conforme exposto na Figura 14. 
Figura 14 - Dimensões do COPSOQ II organizadas de acordo com os tercis

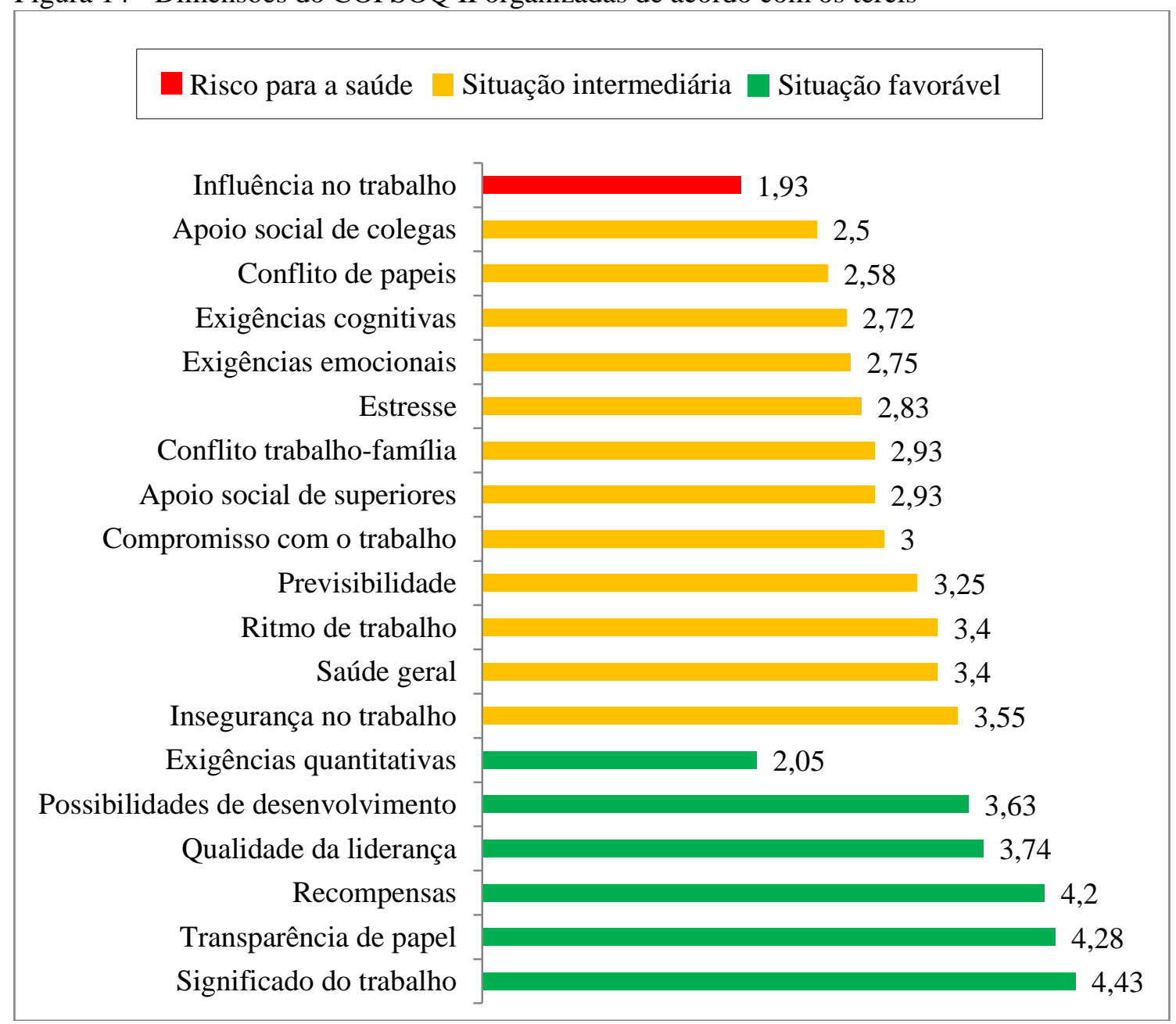

Fonte: elaboração da autora.

No contexto de trabalho em que se insere este estudo, a partir da percepção das participantes, identificou-se que a influência no trabalho oferece riscos à saúde dos trabalhadores. A média da dimensão influência no trabalho foi situada no primeiro tercil, portanto, pode-se sugerir que as participantes perceberam baixa influência, ou seja, pouca possibilidade de influenciar o ambiente, as condições de trabalho, as pessoas com quem trabalham e a quantidade e o tipo de tarefas a serem realizadas. A partir de tal análise, esse fator deveria ser o primeiro a receber algum tipo de intervenção, já que oferece riscos aos trabalhadores.

Os fatores apoio social de colegas e superiores, conflitos de papeis, exigências cognitivas e emocionais, estresse, conflito trabalho-família, compromisso com o trabalho, previsibilidade, ritmo de trabalho, saúde geral e insegurança foram situados no segundo tercil. A partir disso, pode-se inferir que as participantes da pesquisa avaliaram o apoio de colegas e superiores como insuficiente, perceberam a existência de conflito 
de papeis, insegurança, estresse e conflitos entre o trabalho e a família, identificaram a presença de certa exigência emocional e cognitiva, e qualificaram o compromisso com o trabalho, a previsibilidade, o ritmo de trabalho e a própria saúde como medianos. Sendo assim, tais fatores deveriam ser analisados com mais profundidade a fim de se propor melhorias.

Foram localizados no terceiro tercil os fatores possibilidades de desenvolvimento, qualidade da liderança, recompensas, transparência de papel e significado do trabalho, o que representa uma percepção positiva em relação a estes fatores. As exigências quantitativas foram localizadas no primeiro tercil, ou seja, foram percebidas como baixas, o que indica que as agentes de limpeza não consideraram a quantidade de atividades a serem realizadas como extensa ou exagerada. Deste modo, esses fatores, representados no Gráfico 1 com a cor verde, correspondem aos fatores avaliados pelas participantes como favoráveis à saúde.

\subsubsection{Distribuição normal dos dados}

Em relação à distribuição dos dados, foram identificados valores extremos (outliers) nas dimensões transparência de papel, recompensas e exigências cognitivas, sendo que esta última dimensão apresentou 4 valores extremos, conforme apresentado na Figura 15. Os casos extremos foram excluídos das análises com a finalidade de não comprometer as análises estatísticas. 
Figura 15 - Valores extremos correspondentes às dimensões do COPSOQ II

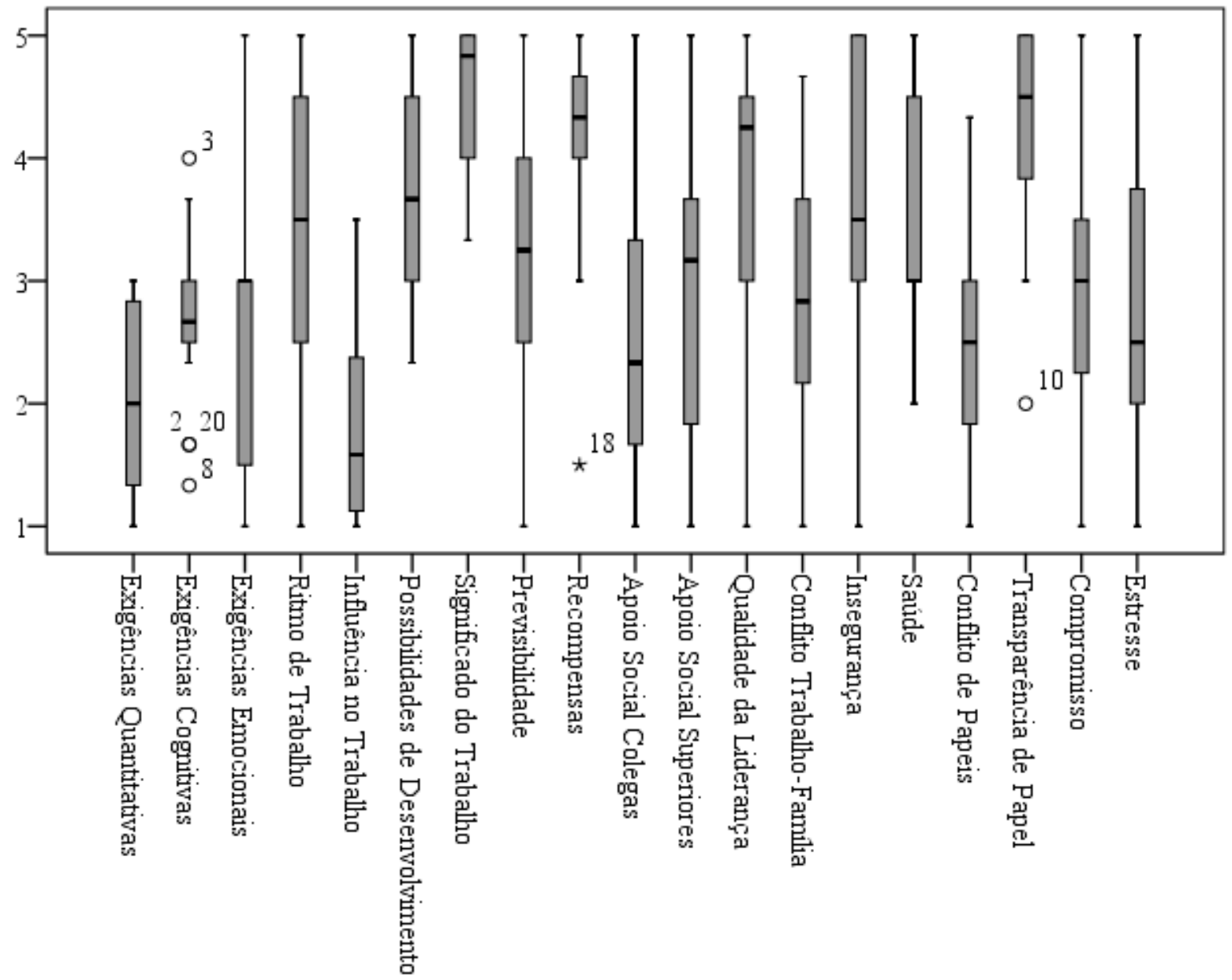

Fonte: elaboração da autora.

A fim de se verificar a normalidade dos dados, foi observada a assimetria (skewness) e a curtose (kurtosis) das variáveis (Tabela 11). Quando a distribuição das variáveis é normal, os valores de assimetria e curtose são iguais a zero. Entretanto, a ocorrência de distribuições normais com valores de assimetria e curtose iguais a zero é bastante rara, principalmente em pesquisas realizadas na área de Ciências Sociais. Sendo assim, os valores de referência para a assimetria e a curtose considerados neste estudo foram de -2 a 2 (George \& Mallery, 2010; Gravetter \& Wallnau, 2014; Trochim \& Donnelly, 2006). 
Tabela 11 - Valores de assimetria e curtose das dimensões referentes ao COPSOQ II

\begin{tabular}{lcccc}
\hline Dimensões & Assimetria & Erro padrão & Curtose & Erro padrão \\
\hline $\begin{array}{l}\text { Exigências } \\
\text { quantitativas }\end{array}$ & $\mathbf{0 , 0 1 3}$ & 0,512 & $\mathbf{- 1 , 4 4 8}$ & 0,992 \\
$\begin{array}{l}\text { Ritmo de trabalho } \\
\text { Exigências cognitivas }\end{array}$ & $-0,377$ & 0,512 & $-0,838$ & 0,992 \\
$\begin{array}{l}\text { Exigências } \\
\text { emocionais }\end{array}$ & 0,644 & 0,564 & 0,908 & 1,091 \\
$\begin{array}{l}\text { Influência no } \\
\text { trabalho }\end{array}$ & 0,213 & 0,512 & $-0,634$ & 0,992 \\
$\begin{array}{l}\text { Possibilidades de } \\
\text { desenvolvimento }\end{array}$ & 0,450 & 0,512 & $-0,896$ & 0,992 \\
$\begin{array}{l}\text { Previsibilidade } \\
\text { Transparência de }\end{array}$ & 0,141 & 0,512 & $-1,187$ & 0,992 \\
papel & $-0,413$ & 0,512 & $-0,626$ & 0,992 \\
$\begin{array}{l}\text { Recompensas } \\
\text { Conflito de papeis }\end{array}$ & $-0,836$ & 0,524 & $-0,461$ & 1,014 \\
$\begin{array}{l}\text { Apoio social de } \\
\text { colegas }\end{array}$ & $-0,292$ & 0,524 & $-0,976$ & 1,014 \\
$\begin{array}{l}\text { Apoio social de } \\
\text { superiores }\end{array}$ & 0,386 & 0,512 & $\mathbf{0 , 1 4 9}$ & 0,992 \\
$\begin{array}{l}\text { Qualidade da } \\
\text { liderança }\end{array}$ & 0,452 & 0,512 & $-0,136$ & 0,992 \\
$\begin{array}{l}\text { Significado do } \\
\text { trabalho }\end{array}$ & $-0,166$ & 0,512 & $-0,704$ & 0,992 \\
$\begin{array}{l}\text { Compromisso } \\
\text { Insegurança no } \\
\text { trabalho }\end{array}$ & $\mathbf{- 1 , 0 1 9}$ & 0,512 & 0,241 & 0,992 \\
$\begin{array}{l}\text { Saúde } \\
\text { Conflito trabalho e } \\
\text { família }\end{array}$ & $-0,556$ & 0,512 & $-1,475$ & 0,992 \\
Estresse & 0,081 & 0,512 & $-0,182$ & 0,992 \\
\hline & $-0,599$ & 0,512 & $-1,061$ & 0,992 \\
& 0,416 & 0,512 & $-1,1$ & 0,992 \\
& $-0,137$ & 0,512 & $-0,652$ & 0,992 \\
& 0,268 & 0,512 & $-0,918$ & 0,992 \\
\hline
\end{tabular}

Conforme exposto na Tabela 11, todas as variáveis apresentaram valores de assimetria e curtose abaixo dos valores de referência (-2 e 2), sendo que os valores de assimetria variaram entre -1,019 e 0,013, e os valores de curtose variaram entre -1,448 e 0,149. Tais resultados representam uma aproximação da normalidade na distribuição dos dados.

Ainda em relação à distribuição normal dos dados, foi verificada a igualdade das variâncias dos dados apresentados por meio da realização do teste de Levene (Field, 2009). A partir dos resultados, identificou-se que todos os valores de significância se mantiveram maiores que 0,05 , o que representa a similaridade e homogeneidade das variâncias (Tabela 12). 
Tabela 12 - Valores do teste de Levene das dimensões referentes ao COPSOQ II

\begin{tabular}{lcc}
\hline Dimensões & Levene Statistic & Significância \\
\hline Exigências Quantitativas &, 476 &, 630 \\
Ritmo de Trabalho &, 594 &, 564 \\
Exigências Cognitivas & 2,734 &, 105 \\
Exigências Emocionais & 1,224 &, 320 \\
Influência no Trabalho &, 125 &, 883 \\
Possibilidades de Desenvolvimento & 1,177 &, 334 \\
Previsibilidade &, 364 &, 701 \\
Transparência de Papel &, 318 &, 732 \\
Recompensas & 1,030 &, 381 \\
Conflito de Papeis &, 982 &, 396 \\
Apoio Social de Colegas & 1,814 &, 195 \\
Apoio Social de Superiores &, 966 &, 402 \\
Qualidade da Liderança &, 623 &, 549 \\
Significado do Trabalho & 1,692 &, 215 \\
Compromisso &, 182 &, 835 \\
Insegurança no Trabalho &, 875 &, 436 \\
Saúde & 2,489 &, 115 \\
Conflito Trabalho e Família & 1,523 &, 248 \\
Estresse &, 011 &, 989 \\
\hline
\end{tabular}

\subsubsection{Análises de correlações bivariadas}

Com a finalidade de se identificar a existência ou não de relacionamento entre as escalas que compõem o COPSOQ II e as dimensões de estresse e saúde, foram realizadas análises de correlações bivariadas entre tais escalas e estas duas dimensões. Inicialmente, foram avaliados os diagramas de dispersão dos dados para verificar a tendência geral dos mesmos, e em seguida foram realizadas as análises de correlação. Devido à distribuição dos dados seguir uma distribuição normal, conforme apresentado na subseção anterior, a análise de correlação foi realizada a partir do coeficiente de correlação $r$ de Pearson (Field, 2009), conforme exposto na Tabela 13. 
Tabela 13 - Valores do coeficiente de correlação de Pearson $(r)$ das escalas referentes ao COPSOQ II

\begin{tabular}{lcccc}
\hline & \multicolumn{2}{c}{ Estresse } & \multicolumn{2}{c}{ Saúde } \\
Escalas & $\begin{array}{c}\text { Coeficiente } \\
\text { de correlação } \\
\text { de Pearson } \\
(\boldsymbol{r})\end{array}$ & $\begin{array}{c}\text { Significância } \\
\text { bilateral }\end{array}$ & $\begin{array}{c}\text { de } \\
\text { correlação } \\
\text { de Pearson } \\
(\boldsymbol{r})\end{array}$ & $\begin{array}{c}\text { Significância } \\
\text { bilateral }\end{array}$ \\
\hline $\begin{array}{l}\text { Organização do trabalho e } \\
\text { conteúdo }\end{array}$ & $-0,149$ & 0,532 & $-0,086$ & 0,718 \\
$\begin{array}{l}\text { Relações sociais e liderança } \\
\text { Exigências no trabalho }\end{array}$ & $-0,033$ & 0,889 & $-0,134$ & 0,572 \\
$\begin{array}{l}\text { Interface trabalho- } \\
\text { indivíduo }\end{array}$ & 0,318 & 0,171 & $\mathbf{- 0 , 4 8 3}$ & $\mathbf{0 , 0 3 1}$ \\
\hline
\end{tabular}

A maioria das correlações apresentou um valor baixo $(0<r<0,4)$, indicando um relacionamento fraco entre as escalas e as dimensões de estresse e saúde. A escala Exigências no trabalho apresentou um coeficiente de correlação significativo com intensidade considerada moderada $(r=-0,483$; significância $=0,031)$, o que indica a existência de um relacionamento moderado genuíno entre as exigências no trabalho e a saúde, ou seja, quanto maiores são as exigências, menores são os índices de saúde dos trabalhadores. A seguir está representado visualmente o diagrama de dispersão desta escala e da dimensão saúde (Figura 16).

Figura 16 - Diagrama de dispersão da escala Exigências no Trabalho e da dimensão Saúde

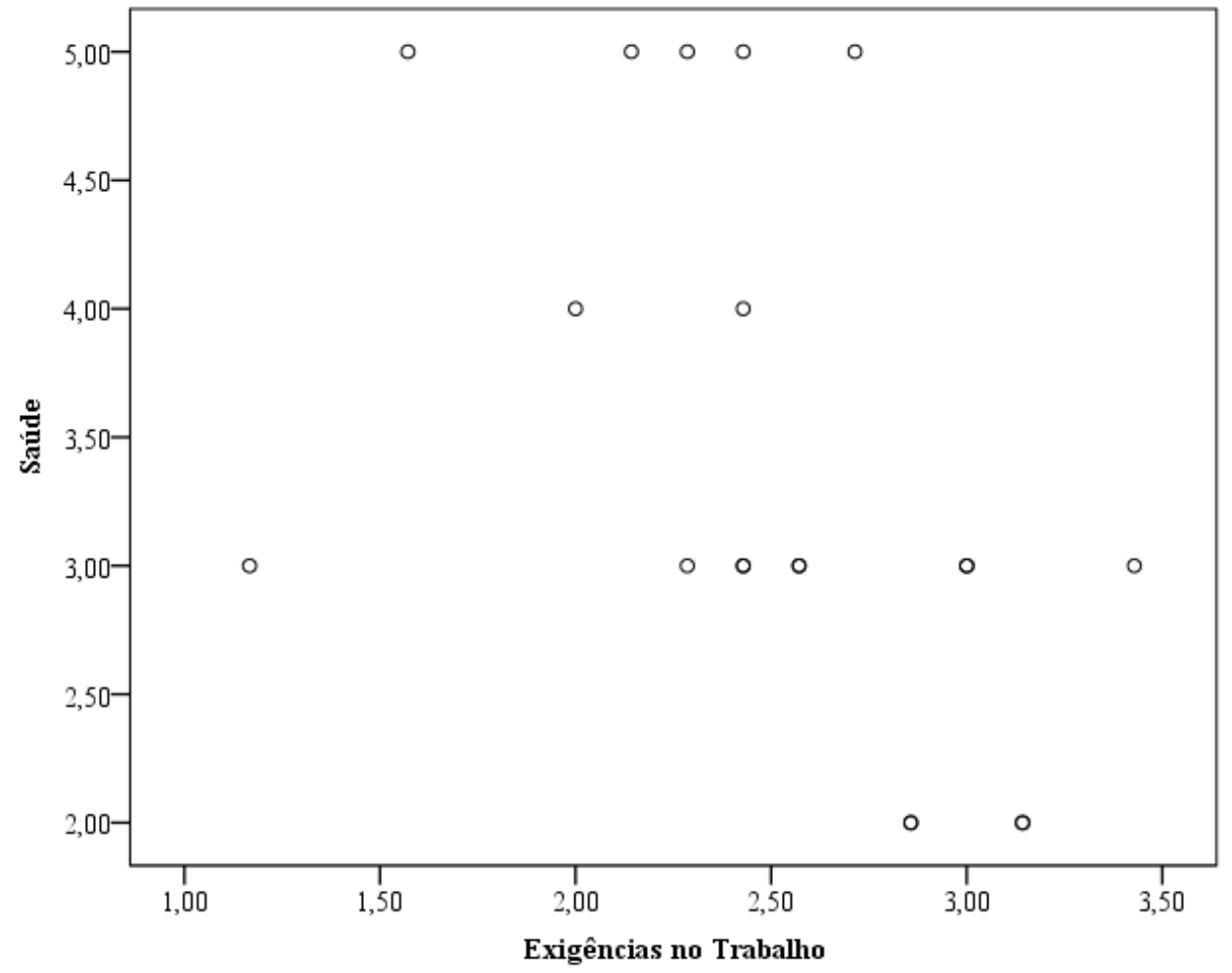


A fim de se verificar a existência de relacionamentos particulares entre as dimensões que compõem o COPSOQ II, realizou-se uma análise da correlação bivariada entre as dimensões componentes do instrumento e as dimensões de estresse e saúde. Os diagramas de dispersão também foram analisados previamente e a análise de correlação também foi realizada a partir do coeficiente de correlação $r$ de Pearson (Tabela 14).

Tabela 14 - Valores do coeficiente de correlação de Pearson $(r)$ das dimensões referentes ao COPSOQ II

\begin{tabular}{|c|c|c|c|c|}
\hline \multirow[b]{2}{*}{ Dimensões } & \multicolumn{2}{|c|}{ Estresse } & \multicolumn{2}{|c|}{ Saúde } \\
\hline & $\begin{array}{c}\text { Coeficiente } \\
\text { de correlação } \\
\text { de Pearson } \\
(r)\end{array}$ & $\begin{array}{c}\text { Significância } \\
\text { bilateral }\end{array}$ & $\begin{array}{c}\text { Coeficiente } \\
\text { de correlação } \\
\text { de Pearson } \\
(r)\end{array}$ & $\begin{array}{c}\text { Significância } \\
\text { bilateral }\end{array}$ \\
\hline $\begin{array}{l}\text { Exigências } \\
\text { quantitativas }\end{array}$ & 0,174 & 0,463 & $-0,694$ & 0,001 \\
\hline Ritmo de trabalho & 0,261 & 0,267 & $-0,044$ & 0,854 \\
\hline Exigências cognitivas & 0,003 & 0,991 & $-0,078$ & 0,775 \\
\hline Exigências emocionais & $\mathbf{0 , 5 5 5}$ & $\mathbf{0 , 0 1 1}$ & $-0,18$ & 0,447 \\
\hline Influência no trabalho & $-0,051$ & 0,830 & $-0,114$ & 0,633 \\
\hline $\begin{array}{l}\text { Possibilidades de } \\
\text { desenvolvimento }\end{array}$ & $-0,138$ & 0,561 & $-0,04$ & 0,866 \\
\hline Previsibilidade & $-0,004$ & 0,986 & $-0,116$ & 0,626 \\
\hline Transparência de papel & 0,183 & 0,453 & 0,244 & 0,315 \\
\hline Recompensas & 0,067 & 0,785 & 0,034 & 0,891 \\
\hline Conflito de papeis & 0,741 & $\mathbf{0}$ & $-0,426$ & 0,061 \\
\hline Apoio social de colegas & 0,276 & 0,24 & 0,015 & 0,95 \\
\hline $\begin{array}{l}\text { Apoio social de } \\
\text { superiores }\end{array}$ & 0,046 & 0,847 & $-0,22$ & 0,352 \\
\hline Qualidade da liderança & $-0,326$ & 0,161 & $-0,016$ & 0,947 \\
\hline Significado do trabalho & $-0,071$ & 0,765 & $-0,18$ & 0,448 \\
\hline Compromisso & 0,089 & 0,708 & $-0,14$ & 0,555 \\
\hline $\begin{array}{l}\text { Insegurança no } \\
\text { trabalho }\end{array}$ & 0,193 & 0,416 & $-0,134$ & 0,572 \\
\hline $\begin{array}{l}\text { Conflito trabalho e } \\
\text { família }\end{array}$ & 0,133 & 0,577 & $-0,309$ & 0,184 \\
\hline
\end{tabular}

As dimensões que apresentaram um coeficiente de correlação com intensidade alta $(0,7<r<1)$ e moderada $(0,4<r<0,7)$ em relação à variável estresse foram o conflito de papeis $(r=0,741$; significância $=0)$ e as exigências emocionais $(r=0,555$; significância $=0,011$ ), sendo que ambas apresentaram um valor de significância menor que 0,05, ou seja, existe uma probabilidade de menos de 0,05 de que estes coeficientes de correlação tenham ocorrido por acaso em uma amostra com 20 participantes. Sendo assim, pode-se assumir que existe um relacionamento forte genuíno entre o conflito de papeis e o estresse, e um relacionamento moderado genuíno entre as exigências 
emocionais e o estresse no trabalho, de modo que quanto maiores são as exigências emocionais e o conflito de papeis, maior é o índice de estresse.

As dimensões que apresentaram um coeficiente de correlação com intensidade moderada $(0,4<r<0,7)$ em relação à variável saúde, por sua vez, foram: exigências quantitativas $(r=-0,694$; significância $=0,001)$ e conflito de papeis $(r=-0,426$; significância $=0,061)$. Entre elas, apenas a dimensão exigências quantitativas apresentou um valor de significância menor que 0,05 , o que representa uma probabilidade menor que 0,001 de que este coeficiente de correlação tenha ocorrido por acaso em uma amostra com 20 participantes. A partir desses dados, identificou-se a existência de um relacionamento genuíno de intensidade moderada entre as exigências quantitativas e a saúde das participantes, ou seja, quanto maiores são as exigências quantitativas no trabalho, menores são os índices de saúde dos trabalhadores.

A seguir estão representados visualmente os diagramas de dispersão das dimensões que tiveram seu coeficiente de correlação com intensidade moderada ou forte e significância menor que 0,05 , ou seja, nos casos em que se identificou a existência de um relacionamento genuíno de intensidade moderada ou forte entre as variáveis em questão.

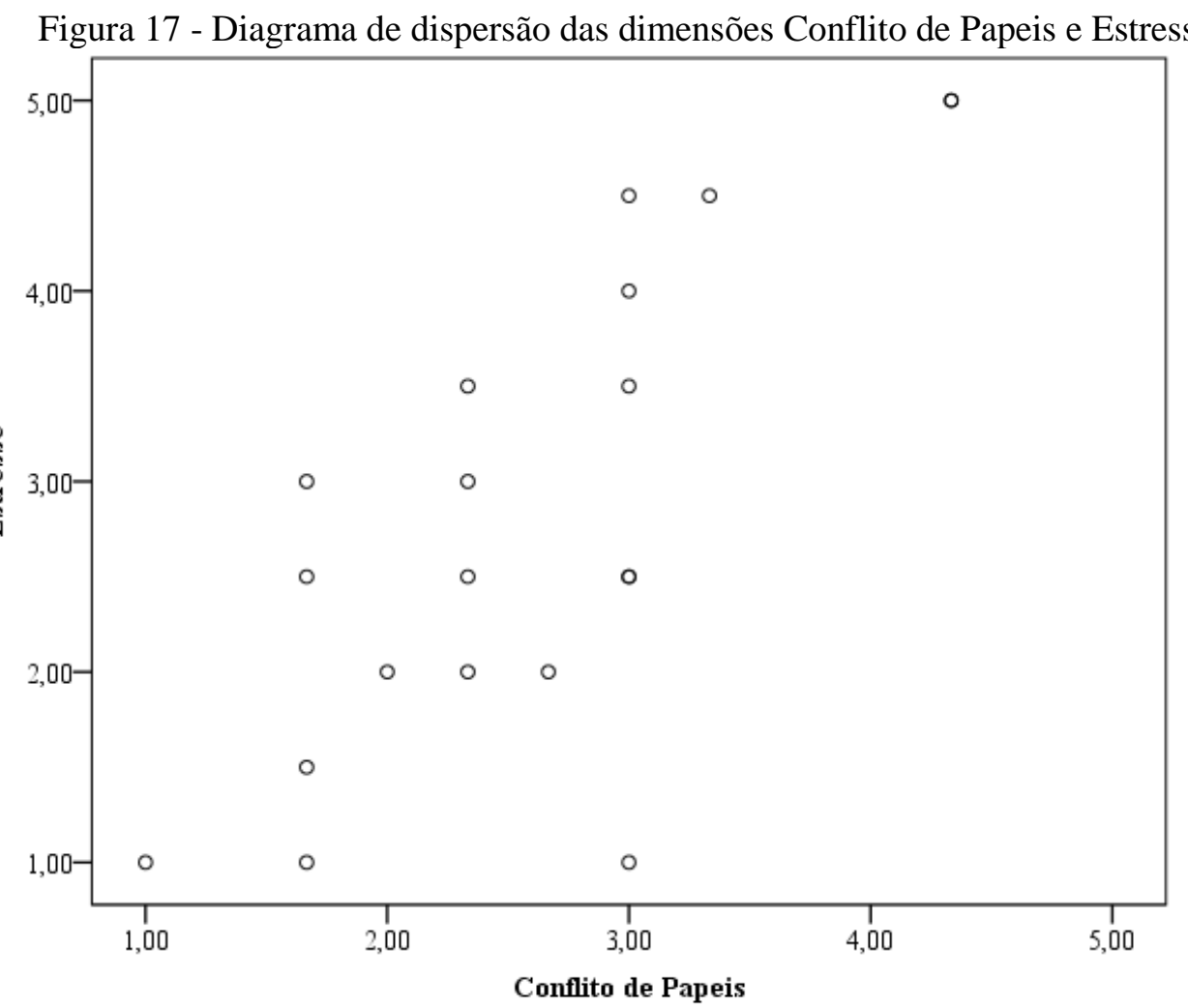


Figura 18 - Diagrama de dispersão das dimensões Exigências Emocionais e Estresse

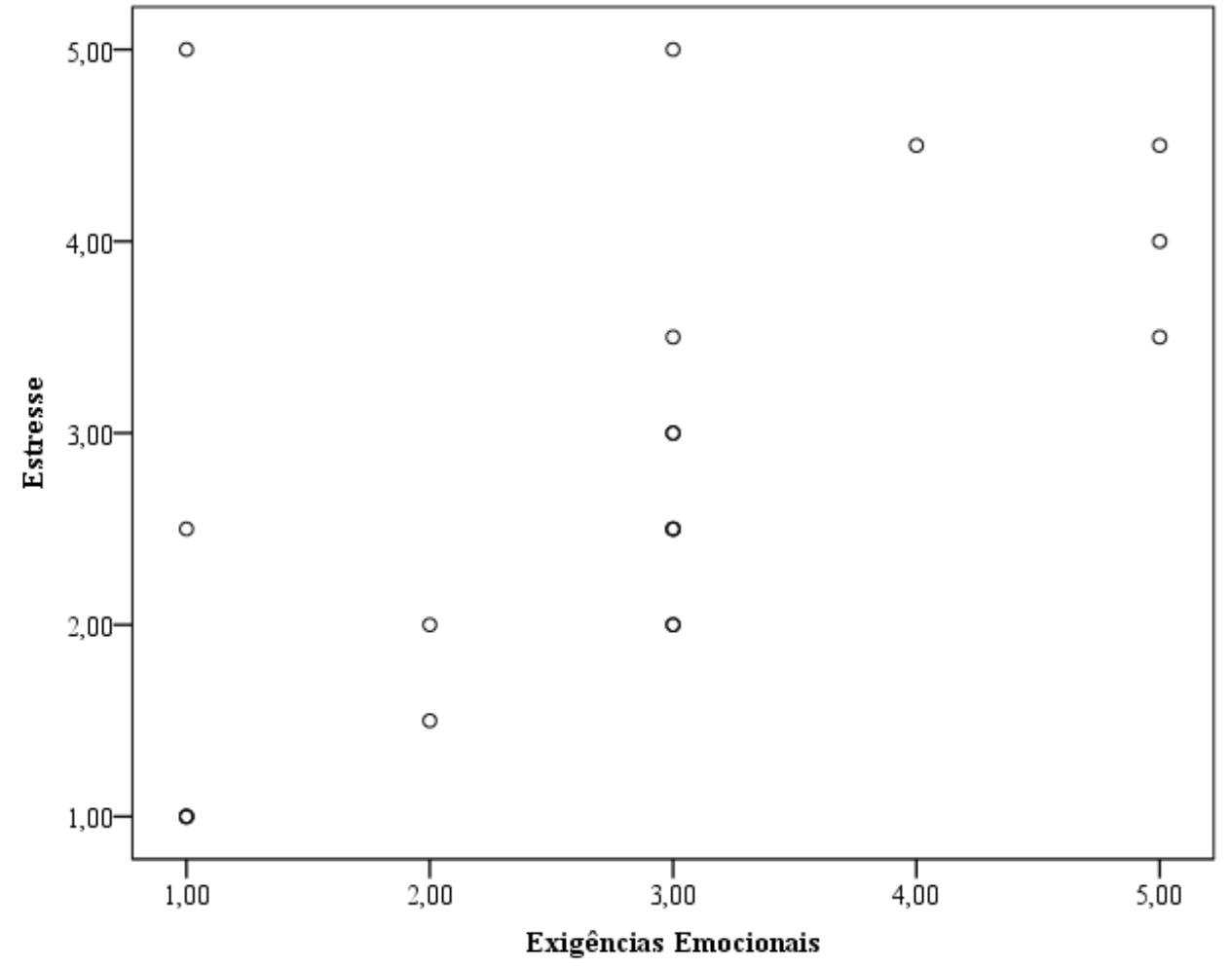

Figura 19 - Diagrama de dispersão das dimensões Exigências Quantitativas e Saúde

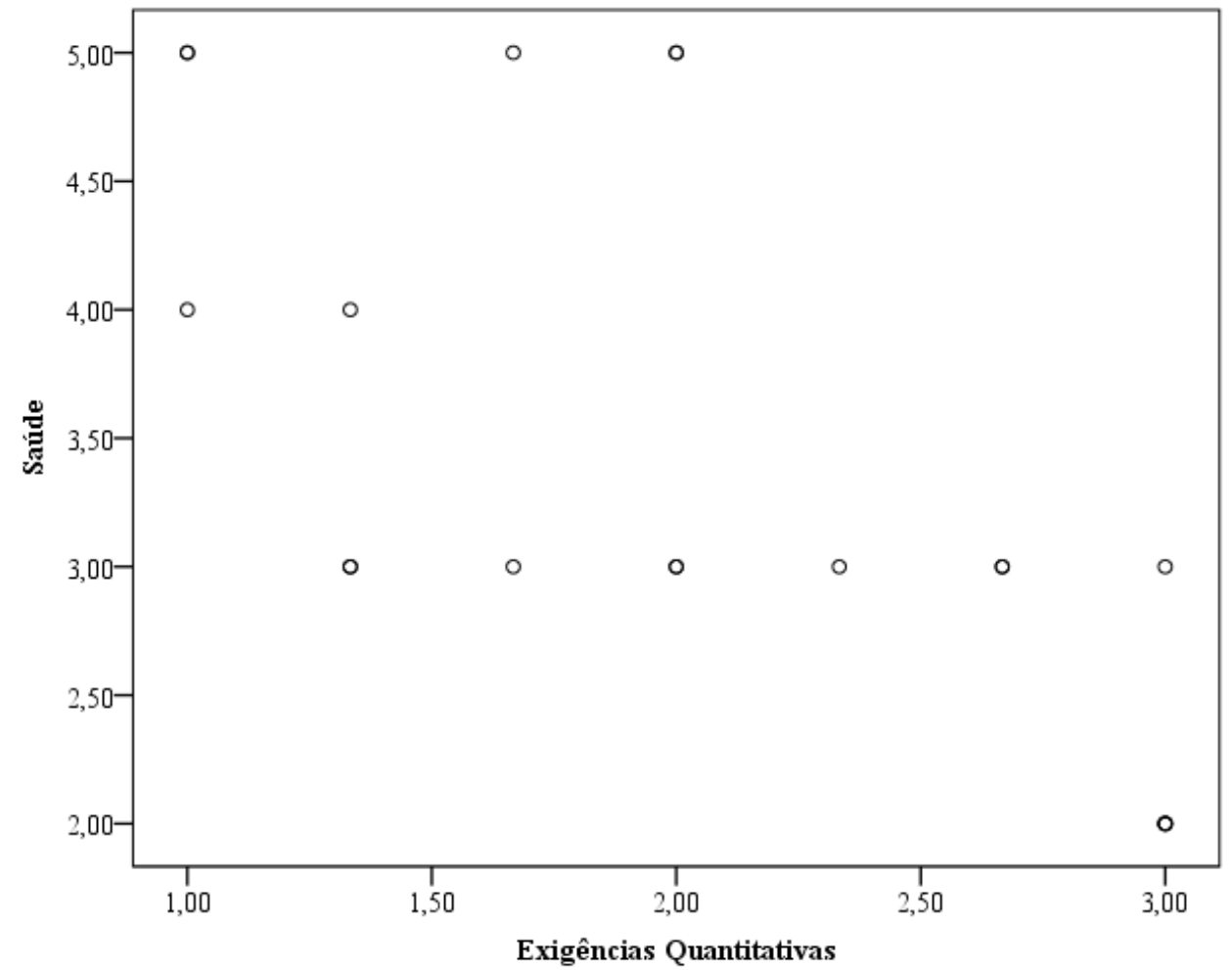




\subsection{Análise qualitativa}

A partir da análise das transcrições das entrevistas realizadas, foram elaborados 5 agrupamentos de temas a fim de organizar as informações referentes aos dados qualitativos. Os temas referem-se à Organização do trabalho e conteúdo das tarefas, às Relações sociais e liderança, às Exigências no trabalho, à Interface família-indivíduo e à Saúde e estresse. Também foram sistematizadas as sugestões de melhoria fornecidas pelos participantes.

\subsubsection{Organização do trabalho e conteúdo das tarefas}

\section{Contrato de trabalho}

O contrato de trabalho estabelecido entre a empresa terceirizada e a univerisdade tinha duração máxima de 5 anos, porém anualmente era verificado nas unidades a manutenção do interesse em renová-lo, sendo que no final do quinto ano o contrato era encerrado e era aberta uma nova licitação. Nesse processo, diversas empresas que ofereciam serviços terceirizados poderiam se inscrever e a universidade selecionava uma delas. Desde 2007, o contrato definia apenas o serviço a ser realizado e a área a ser limpa, em metros quadrados, e o número de funcionários para realiza-lo ficava a critério da empresa terceirizada, assim como os produtos e equipamentos a serem utilizados.

"Se ela (a empresa) quiser comprar um robô que vai executar, limpar 10 salas ao mesmo tempo, a gente pode colocar um robô. Hoje não exige mais quadro de funcionários." (Lucas, supervisor geral)

Como o contrato exigia apenas a realização do serviço, independente de quem iria executá-lo, tanto os agentes de limpeza quanto os líderes e encarregados de unidade poderiam ser realocados entre as unidades da universidade, o que era uma prática comum pela empresa. Nesses casos, o supervisor geralmente selecionava os funcionários que manifestavam interesse em mudar de unidade, que demonstravam menor produtividade ou aqueles que tiveram algum desentendimento com outros funcionários do mesmo setor. $\mathrm{O}$ contrato também exigia que a empresa adotasse os programas e exibisse os laudos do PPRA (Programa de Prevenção dos Riscos 
Ambientais) e PCMSO (Programa de Controle Médico de Saúde Ocupacional), cujo objetivo é garantir a preservação da saúde dos trabalhadores frente aos riscos presentes no contexto de trabalho. Além destes, era exigida a realização frequente de exames médicos e de treinamentos semestrais que abordassem temas de segurança no trabalho, organização do trabalho, horários e faltas, advertâncias, utilização dos equipamentos de proteção individual e manuseio de equipamentos e produtos químicos. A presença dos trabalhadores em tais treinamentos era obrigatória, e estes geralmente eram realizados no período de férias escolares.

A empresa participante prestava serviços de limpeza à universidade há 12 anos e tinha sido novamente selecionada na licitação ocorrida no ano de 2016, em que um novo contrato foi estipulado, com algumas alteração em relação ao anterior. A partir do novo contrato, o número de funcionários havia sido reduzido de 230 para 170 e os serviços a serem realizados, antes organizados em dias da semana, passaram a ser cobrados por frequência. Com exceção dos banheiros e copas, que eram limpos diaramente, a limpeza dos outros locais era realizada semanalmente.

"Porque assim, antigamente tinha horário pra tudo, tinha uma escala de cronograma de todos os dias o que podia ser feito. Então agora mudou isso, agora é por frequência. Uma administração é limpa uma vez por semana, mas não tem mais horário, ela tem que ser limpa das 7 às 16h48, que é o horário que a gente tem no contrato." (Lucas, supervisor geral)

Segundo o supervisor, as alterações decorrentes do novo contrato geravam certas dificuldades. A diminuição do quadro de funcionários, dos serviços realizados e dos produtos utilizados, provocada pela redução dos gastos pela universidade, gerava reclamações por parte dos funcionários da própria universidade, que apontavam tal diminuição como ausência de vontade da empresa realizar o serviço. Além disso, na percepção da líder e dos encarregados entrevistados, tais modificações acarretavam em mudanças na rotina de trabalho dos trabalhadores terceirizados.

"Sala de aula, a gente arrumava carteira, né, organizava toda a sala pra poder o professor entrar e dar aula, hoje a gente não faz mais esse trabalho. [...] Então tipo, a sala tá desorganizada, a gente vai lá e deixou limpa, agora organizar é por conta deles 
(funcionários da universidade) [...] Então foi tirando muita coisa." (Cecília, encarregada de unidade)

"Vem pouco produto, diminuiu bastante a quantidade de produto [...] a gente acaba usando mais né, porque é água, põe muita água no produto, e acaba saindo às vezes uma coisa que, se fosse um produto melhor, se jogasse e limpasse, limpava melhor [...].” (Vivian, agente de limpeza)

\section{Horários e rotina de trabalho}

Em relação à rotina de trabalho, esta era estabelecida a partir das demandas e horários das atividades de cada unidade. A maioria dos funcionários trabalhava de Segunda a Sexta, das $7 \mathrm{~h}$ às $16 \mathrm{~h} 48$, e alguns trabalhavam das $6 \mathrm{~h}$ às $15 \mathrm{~h}$, das $10 \mathrm{~h}$ às $20 \mathrm{~h}$ ou das $13 \mathrm{~h}$ às $22 \mathrm{~h}$, sendo que todos faziam dois intervalos de 15 minutos e dispuham de 1 hora para almoçar ou jantar. Em todas as unidades, os intervalos e as refeições geralmente eram realizados nas copas disponíveis, que há alguns anos passou a ser de responsabilidade da universidade a partir do contrato.

“Antigamente o terceirizado era visto como ogro né, aqui dentro, agora ele tem... tem um espaço físico pra eles, pra eles poderem usufruir, tanto a hora do descanso quanto na hora da refeição. E a universidade, tá no contrato que ela tem que oferecer o local, geladeira, microondas... todos os itens que vai esquentar a comida deles, que vai ajudar eles ali." (Lucas, supervisor geral)

As unidades participantes apresentaram algumas diferenças em relação ao número de funcionários, superiores responsáveis, à realização ou não de multirões de limpeza, aos dias e horários de trabalho e aos ambientes limpos, conforme exposto na Figura 20. A equipe de trabalho da unidade A era composta por uma encarregada, uma líder e 13 funcionárias. Elas trabalhavam de Segunda a Sexta, das $6 \mathrm{~h}$ às $15 \mathrm{~h}$ ou das $13 \mathrm{~h}$ às $22 \mathrm{~h}$, e aos Sábados, das $7 \mathrm{~h}$ às $11 \mathrm{~h}$. A equipe da unidade $\mathrm{B}$, anexa à unidade $\mathrm{C}$, era composta por uma encarregada, também responsável pela unidade C, uma líder e 6 funcionárias que trabalhavam de Segunda a Sexta, das 6h às $15 \mathrm{~h} 48$ ou das $7 \mathrm{~h}$ às $16 \mathrm{~h} 48$. Estes também eram os dias e horários de trabalho das agentes de limpeza que 
trabalhavam na unidade D. O trabalho em ambas as faculdades era supervisionado por um encarregado, sendo que na unidade C havia 18 funcionárias, e na D, 23.

Figura 20 - Características das unidades participantes

\begin{tabular}{|c|c|c|c|c|}
\hline Unidades & $\mathbf{A}$ & B & $\mathrm{C}$ & D \\
\hline $\mathrm{N}^{\circ}$ funcionários & 13 & 6 & 18 & 23 \\
\hline $\mathbf{N}^{\circ}$ participantes & 6 & 2 & 4 & 8 \\
\hline Superiores & $\begin{array}{c}1 \text { encarregada } \\
1 \text { líder }\end{array}$ & $\begin{array}{c}1 \text { encarregada } \\
1 \text { líder }\end{array}$ & 1 encarregada & 1 encarregado \\
\hline Dias de trabalho & $\begin{array}{l}\text { Segunda a } \\
\text { Sábado }\end{array}$ & $\begin{array}{l}\text { Segunda a } \\
\text { Sexta }\end{array}$ & $\begin{array}{l}\text { Segunda a } \\
\text { Sexta }\end{array}$ & $\begin{array}{l}\text { Segunda a } \\
\text { Sexta }\end{array}$ \\
\hline Horários & $\begin{array}{l}6 \mathrm{~h} \text { às } 15 \mathrm{~h} \\
13 \mathrm{~h} \text { às } 22 \mathrm{~h} \\
7 \mathrm{~h} \text { às } 11 \mathrm{~h} \\
\text { (Sábado) }\end{array}$ & $\begin{array}{l}6 \mathrm{~h} \text { às } 15 \mathrm{~h} 48 \\
7 \mathrm{~h} \text { às } 16 \mathrm{~h} 48\end{array}$ & $\begin{array}{l}6 \mathrm{~h} \text { às } 15 \mathrm{~h} 48 \\
7 \mathrm{~h} \text { às } 16 \mathrm{~h} 48\end{array}$ & $\begin{array}{l}6 \mathrm{~h} \text { às } 15 \mathrm{~h} 48 \\
7 \mathrm{~h} \text { às } 16 \mathrm{~h} 48\end{array}$ \\
\hline $\begin{array}{l}\text { Ambientes limpos } \\
\text { pelas } \\
\text { participantes }\end{array}$ & $\begin{array}{l}\text { Salas de aula } \\
\text { Banheiros } \\
\text { Laboratórios } \\
\text { Corredores } \\
\text { Copas } \\
\text { Diretoria } \\
\text { Biotério } \\
\text { Anfiteatro }\end{array}$ & $\begin{array}{l}\text { Salas de aula } \\
\text { Banheiros } \\
\text { Laboratórios } \\
\text { Salas de } \\
\text { professores } \\
\text { Escadas } \\
\text { Rampas } \\
\text { Secretarias }\end{array}$ & $\begin{array}{l}\text { Salas de aula } \\
\text { Salas de } \\
\text { atendimento } \\
\text { Banheiros } \\
\text { Administração } \\
\text { Casas } \\
\text { Corredores } \\
\text { Copas } \\
\text { Diretoria } \\
\text { Laboratórios }\end{array}$ & $\begin{array}{l}\text { Salas de aula } \\
\text { Banheiros } \\
\text { Administração } \\
\text { Laboratórios } \\
\text { Corredores } \\
\text { Secretaria } \\
\text { Saguão } \\
\text { Espaço de } \\
\text { eventos } \\
\text { Salas de } \\
\text { professores } \\
\text { Casas } \\
\text { Anfiteatros } \\
\text { Salas do HC }\end{array}$ \\
\hline
\end{tabular}

Fonte: elaboração da autora.

Atribuição e conteúdo das tarefas

Os trabalhadores da empresa terceirizadas ocupavam as funções de supervisor geral, encarregado de unidade, líder e agente de limpeza. Segundo os relatos das entrevistas realizadas, o supervisor geral era responsável pelo contrato das unidades, pela realização de treinamentos com os funcionários, pela resolução de questões referentes à saúde e segurança no trabalho, pela comunicação com a empresa matriz, em São Paulo, pela resolução de conflitos entre os funcionários da empresa e os funcionários da universidade e pela comunicação com os chefes administrativos das unidades da universidade. Os encarregados de unidade eram responsáveis pela verificação do andamento do serviço na unidade, pela divisão das tarefas entre os 
funcionários, pela resolução de conflitos entre funcionários da empresa, pela comunicação entre os funcionários da unidade e o chefe administrativo da unidade, que era um funcionário da universidade, pelo recebimento, diluição e divisão dos produtos de limpeza entre os agentes de limpeza e por tarefas administrativas, como verificação do cartão de ponto e organização da folha de pagamento de cada funcionário. Os encarregados relataram dificuldades em relação à flexibilidade exigida no ambiente de trabalho, uma vez que respondiam tanto ao supervisor geral da empresa quanto ao chefe de unidade da universidade.

"[...] eu tenho que ver os 2 lados né... cê tem que ter um certo jogo de cintura, eu não posso favorecer a empresa né e prejudicar o lado da [universidade], nem também querer ver só a [universidade] e prejudicar a empresa [...] Tem que ver um meio pra tomar decisão que não prejudique nem um lado nem o outro, que ajude tanto um quanto o outro né." (Cecília, encarregada de unidade)

Alguns encarregados eram responsáveis por mais de uma unidade, sendo que estas poderiam ser distantes entre si. Nestes casos, os encarregados eram auxiliados pelos líderes, que também eram responsáveis pela divisão de tarefas dentro de uma unidade, pela resolução de conflitos e pela verificação do andamento do serviço, além da realização de serviços operacionais de limpeza. Os líderes respondiam apenas aos encarregados. Os agentes de limpeza, por sua vez, eram responsáveis pela limpeza dos prédios, pela manutenção da limpeza e pela substituição de outros agentes de limpeza, quando necessário. Estes funcionários respondiam aos líderes, se houvesse, ou diretamente aos encarregados de unidade.

As relações entre os funcionários da organização participante podem ser esquematizadas a partir da Figura 21. 
Figura 21 - Organograma funcional da empresa

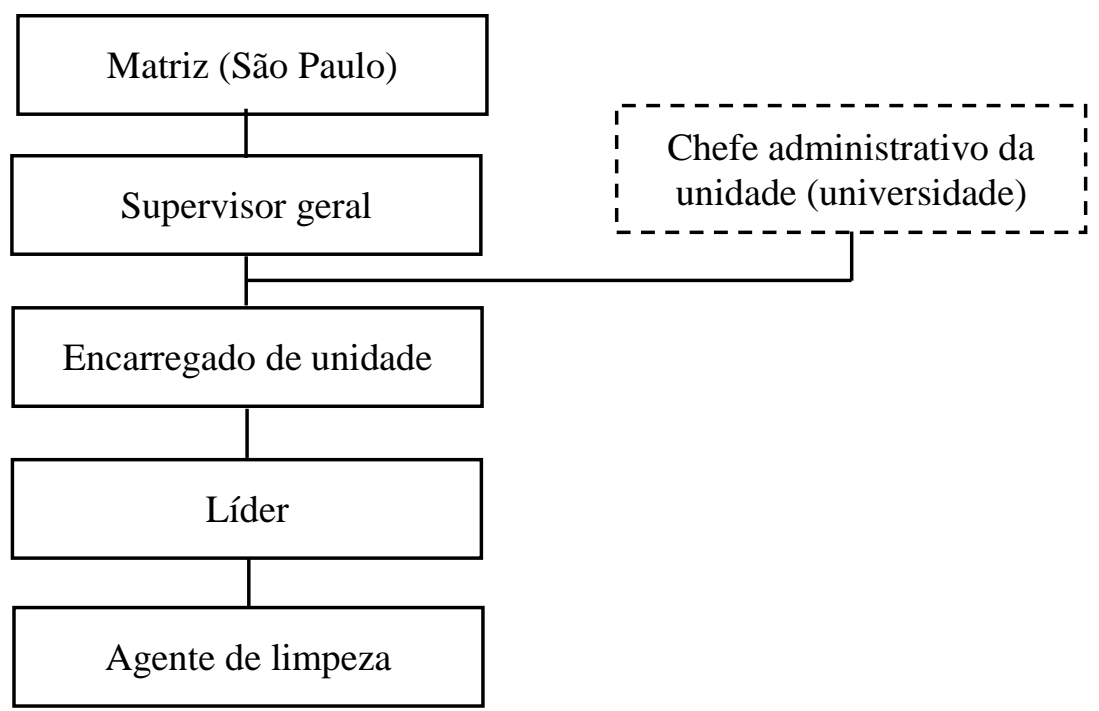

Fonte: elaboração da autora.

Em relação às atividades exigidas pelo contrato entre a universidade e a empresa terceirizada, estas incluíam a limpeza das salas de aula e de professores, banheiros, laboratórios, copas, casas, anfiteatros, diretorias, secretarias e outros prédios administrativos, biotérios, escadas, corredores e rampas, salas de atendimento, espaços reservados para eventos e os andares do Hospital das Clínicas (HC). Também abrangiam a manutenção dos locais limpos, o recolhimento e transporte dos lixos das unidades e a conservação dos materiais de limpeza, como a higienização dos panos utilizados.

Apesar da líder e dos encarregados relatarem que organizavam e distribuíam as tarefas a serem concluídas com o máximo de igualdade entre as funcionárias, 5 participantes apontaram que tal divisão era injusta e beneficiava apenas algumas agentes, que recebiam uma quantidade menor de atividades. Tal apontamento foi identificado como causador de sentimentos de injustiça e estresse.

"O que me deixa mais estressada é saber que eu tenho um monte de serviço e tem gente que consegue dormir ainda na hora do serviço. Não quer ajudar ninguém, dorme... e ganha a mesma coisa que eu ganho. É isso que estressa a gente sabe?" (Isadora, agente de limpeza)

"[...] tem umas que trabalha, umas que não trabalha... tem umas que folga em cima da outra [...] tem pessoas que têm bastante setor grande, tem pessoas que têm 
setor pequeno né, tem uns que trabalha mais, tem uns que trabalha menos... e você vê essas coisas, né [...].” (Fernanda, agente de limpeza)

\section{Influência no trabalho}

No que diz respeito à organização do trabalho, a partir do relato de 10 participantes foi possível identificar seu baixo grau de influência no contexto de trabalho, ou seja, as agentes de limpeza tinham poucas possibilidades de influenciar o ambiente e as condições de trabalho, o tipo de tarefas, a quantidade de trabalho a ser executado e as pessoas com quem trabalhariam. Os encarregados e a líder realizavam a divisão das atividades entre as funcionárias de acordo com a metragem e/ou a dificuldade do local, almejando uma divisão igual das tarefas. Além disso, eles realizavam um cronograma de atividades a serem cumpridas ao longo da semana para cada funcionária.

"Eu faço a divisão pelo tamanho e pela dificuldade do local, né. [...] Eu faço cronograma também pra elas, dou pra elas, elas sabem tudo que têm que fazer, tendeu? [...] marca tudo lá, onde tem que pegar a chave, em que hora, isso, aquilo outro... a professora não gosta que passa pano com roupalim, ou tal laboratório não pode passar, ou o laboratório tem que passar com roupalim... tudo isso elas marca nas coisa delas mesmo." (Rafaela, líder de unidade)

“[...] no contrato é assim, a gente divide por metragem, é tudo feito por metragem né, então a metragem é de $750 m^{2}$ pra cada funcionário." (Heloísa, encarregada de unidade)

As agentes de limpeza eram responsáveis por organizar sua rotina de trabalho a partir do cronograma estabelecido previamente e a partir dos horários e preferências dos funcionários da universidade.

“[...] tem gente que gosta que só usa álcool, a outra já gosta de ter um cheirinho diferente, né, aí com o tempo cê vai conhecendo cada um né." (Laura, agente de limpeza) 
“[...] elas mesma, com o próprio funcionário né da [universidade], elas entram em acordo, tipo 'olha, esse horário vai tá mais calmo, cê pode vim aqui limpar esse horário... 9h, $10 \mathrm{~h}$ da manhã' entendeu? Aí elas entram mesmo em acordo, e vai pegando aquela certa afinidade, se conhece... 'ah, agora não vai dá pra limpar, ce pode vir mais tarde?', tendeu?" (Heloísa, encarregada de unidade)

Elas também não exerciam controle sobre o local em que trabalhariam, devido à divisão de tarefas e à distribuição dos funcionários em setores constituir uma responsabilidade dos encarregados e líderes, e devido à possibilidade de serem transferidas de setores dentro da unidade ou até mesmo transferidos de unidade, mesmo que a contragosto.

"[...] aí me tiraram lá da unidade, eu vim chorando bem (risos), porque eu não queria sair de lá, aí eu vim pra cá, aí no começo foi difícil pra mim [...] De começo a gente não gosta né, a gente fica meio revoltado [...]" (Júlia, agente de limpeza)

“Às vezes a pessoa não tá dando certo num lugar [...] aí eles (encarregado e supervisor) manda pra outro lugar pra ver se dá certo [...]. Ou então, a rotatividade é assim, tá acontecendo algum problema, ou com a funcionária ou com o departamento, né, aí a gente muda ela de, ou às vezes eu mudo por exemplo de bloco né [...]." (Rafaela, líder de unidade)

\section{Possibilidades de desenvolvimento}

Em relação às possibilidades de aprendizagem e crescimento no trabalho, 8 agentes de limpeza relataram que o trabalho não acrescentava nada em suas vidas, principalmente por este ser repetitivo. Elas disseram que não havia possibilidade de crescer profissionalmente no contexto de serviço de limpeza, principalmente devido à baixa qualificação de quem realiza este serviço. Em contrapartida, 8 delas relataram que o trabalho possibilitava o aprendizado de coisas novas, como os produtos específicos indicados para cada tipo de superfície, novas formas de realizar a limpeza de um ambiente e resultados de experimentos realizados pelos alunos da faculdade. 
“Ah eu creio que não. Porque limpeza né, vai crescer como? [...] Ah, eu não me preparei né pra conseguir uma coisa melhor. Eu não fui atrás, eu não fiz nenhum curso, então... tá nisso." (Vivian, agente de limpeza)

\section{Significado do trabalho}

Quando questionadas sobre o significado do trabalho, todas as participantes relataram que o trabalho significava tudo para elas, que além de ser um modo de sobrevivência que garantia o sustento, ele era um meio de se manterem ocupadas e de se sentirem úteis. De forma geral, elas relataram que gostavam de trabalhar e identificaram o trabalho como algo necessário tanto para garantir a sobrevivência quanto para garantir sua existência enquanto indivíduos.

“[...] o meu trabalho pra mim é tudo, porque do meu trabalho eu tiro o meu sustento, sabe? Do meu trabalho eu ajudo meus filhos [...]. O meu trabalho me permite sorrir, andar de cabeça erguida, sabe... o meu trabalho me ajuda a realizar os meus sonhos. Não esse aqui, que a gente ganha uma miséria, mas é ele que me mantém no dia a dia, é ele que me faz levantar a cabeça e dizer 'vou em frente'. [...] Não tem como explicar pra você o que meu trabalho representa, meu trabalho me representa, eu sou o meu trabalho. Sem o meu trabalho eu não vou em lugar nenhum, sem o meu trabalho eu não tenho voz pra quase nada nessa vida." (Giovana, agente de limpeza)

“[...] eu não consigo ficar em casa. Se eu ficar sem trabalhar, eu acho que eu morro logo [...] o trabalho também é uma coisa que ocupa a mente da gente né e o tempo também, que a gente não fica pensando besteira." (Fernanda, agente de limpeza)

\section{Espaço físico}

Em uma das unidades participantes, a líder entrevistada relatou que as funcionárias não dispunham de um local apropriado para guardar seus materiais, sendo que ela frequentemente solicitava e saía em busca de armários inutilizados para serem aproveitados para o armazenamento dos materiais de limpeza. Além disso, segundo ela, não existia um espaço adequado para a realização das refeições e para o descanso das funcionárias, pois a copa utilizada por elas era um antigo depósito que não possuía 
muito espaço livre e era localizado próximo à secretaria, e devido a essa proximidade, elas precisavam estar sempre atentas ao barulho que faziam nos horários de café e almoço, a fim de não incomodar os funcionários da faculdade. Algumas das agentes de limpeza optavam por passar a hora do almoço dentro dos banheiros, onde era possível ficar sentada e cochilar.

Ainda em relação às características do espaço físico, 5 agentes de limpeza comentaram que a necessidade de subir e descer escadas e de se locomover frequentemente devido à distância entre os prédios era um fator que causava cansaço físico, gerava estresse e afetava negativamente a saúde.

"[...] E cê vai ficar onde essa uma hora de almoço? Sabe, às vezes tem algumas das menina aqui que fica aquela uma horinha de almoço, elas fica dentro de banheiro, senta lá, sabe, aquela horinha do descanso. [...] Entendeu? Aquele lugarzinho ali, pra gente, sabe, poder rir, né, que a gente não pode nem rir." (Rafaela, líder de unidade)

“[...] é no alto né, é escada, eu tenho que ficar descendo, subindo, toda hora... levar lixo, sobe, pega mais lixo, desce... é estressante isso aí." (Isadora, agente de limpeza)

\section{Controle do desempenho}

Outro ponto a ser destacado neste item é a avaliação da qualidade do serviço prestado pelas agentes de limpeza. Segundo o supervisor geral, cada unidade da faculdade possuía um livro de ocorrências, que era preenchido semanalmente pelo chefe administrativo da unidade com observações negativas a respeito da qualidade do serviço e a soliticação de providências por parte da empresa terceirizada. Os encarregados de unidade, por sua vez, conferiam tal livro, verificavam as observações, assinavam e comunicavam aos agentes de limpeza a quem se referiam tais observações negativas, a fim de resolver os serviços pendentes. Nos casos em que eram relatadas algumas reclamações do mesmo funcionário, o chefe administrativo solicitava que este fosse transferido de unidade, e a depender da gravidade das observações, o supervisor geral era convocado para assinar o livro de ocorrências.

Entretanto, algumas unidades não utilizavam este livro de ocorrências, e, nestes casos, segundo duas agentes de limpeza, as reclamações de funcionários da faculdade e 
dos gestores das unidades eram realizadas diretamente com o encarregado ou líder da unidade, ou com o próprio supervisor. Tal organização frequentemente gerava situações desfavoráveis para as funcionárias, sendo que elas não tinham a oportunidade de se explicar e muitas vezes passavam a ser mal vistas pelos outros funcionários da faculdade, pois algumas reclamações tomavam grandes proporções antes de serem resolvidas.

"[...] vamo supor, eu tô limpando sua sala, aí cê fala 'oh, eu quero que limpa agora', eu vou falar 'não posso', aí você liga no Lucas, aí o Lucas vai e liga, aí quem escuta é a gente, tendeu?" (Fernanda, agente de limpeza)

"Por causa de um papel toalha, teve uma repercussão de mais de 15 dias, falando que o banheiro não tava sendo lavado [...] que o banheiro tá deixando a desejar [...]. Era mais fácil falar 'pô, ceis quinta-feira não abasteceu, não deu manutenção no banheiro, vê se ceis presta atenção’ [...].” (Marcela, agente de limpeza)

“[...] se acontecer alguma coisa que ele (chefe administrativo) não aceita, que tá errado, ele coloca no livro. [...] Aí eu vou lá e assino, ele assina, então a gente tá ciente. Se eles quiserem multar a empresa por conta daquele serviço que não foi feito, ele pode, que ele tem uma prova ali naquele livro de que o serviço deixou de ser feito ali naquele dia. Então se a gente não fez, não tem porque receber." (Cecília, encarregada de unidade)

\section{Trabalho prescrito $x$ trabalho real}

Também deve ser considerado nesta sessão a diferença entre o trabalho prescrito e o trabalho real, citada por 9 participantes, por uma das encarregadas e pela líder. Enquanto o contrato estabelecido entre a universidade e a empresa definia o trabalho prescrito, ou seja, exigia a entrega de atividades específicas por parte da empresa, no dia a dia o número e variedade das atividades realizadas pelas agentes de limpeza eram maiores que aquelas prescritas. Algumas funcionárias acabavam realizando atividades além daquelas exigidas pelo contrato para agradar os funcionários da faculdade, outras faziam isso por considerarem que as atividades prescritas não eram suficientes para garantir um serviço de limpeza de qualidade. Segundo uma das participantes, como o 
contrato de trabalho era modificado com certa frequência, e, consequentemente, as atividades prescritas sofriam alterações constantes, as agentes de limpeza costumavam ter dúvidas em relação às tarefas que deveriam ou não ser executadas, e muitas vezes elas acabavam realizando um número maior de atividades justamente por não acompanharem tais mudanças.

"Aí manda eu limpar a cada 15 dias. Eu não limpo, eu limpo toda sexta. Imagina uma sala de aula a cada 15 dias? Não, dá pra limpar toda sexta, eu vou lá e limpo." (Gabriela, agente de limpeza)

"Sempre que a empresa tem licitação, aí chega e fala 'não é pra fazer aquilo, aquilo e aquilo outro', ai depois eles voltam atrás e quem é que vai ficar com cara de tacho e ter que ir lá desencardir tudo outra vez? Cê fica assim, cê não sabe o que você vai fazer [...]. Um dia 'é pra fazer', no outro 'não é pra fazer'." (Giovana, agente de limpeza)

A partir dos relatos também foi possível identificar que algumas das participantes chegaram a realizar tarefas que não estavam prescritas no contrato devido à pressão de funcionários da universidade, à necessidade de manter a limpeza e refazer o trabalho já finalizado, e a acontecimentos que fugiam da rotina, como a limpeza do ambiente após a finalização de um evento. Ao final da entrevista, um das participantes relatou que teve um problema de saúde causado pela utilização de formol na faxina de um laboratório logo nos primeiros meses de trabalho. Segundo ela, a técnica responsável pelo laboratório orientou que a limpeza deveria ser feita com a utilização do formol, atividade que era exclusiva dos próprios técnicos de laboratório. Por não ter conhecimento de que tal tarefa não era de sua responsabilidade e por não ter os equipamentos de proteção adequados, ela utilizou o formol na limpeza e em seguida foi levada ao pronto-socorro devido à intensa ardência em seus olhos. Um caso semelhante a este foi compartilhado por outra participante. De acordo com seu relato, alguns técnicos de laboratório exigiam que as agentes limpassem as salas de cultura de microorganismos, atividade que era de responsabilidade dos próprios técnicos.

"Ah, que nem, às vezes tem sala de cultura que a gente não pode limpar, tem bactérias né, e eles manda limpar [...]. Às vezes os funcionário vem falar pra gente 
limpar, mas a gente não ganha... eles ganha periculosidade pra limpar... a gente não ganha nem insalubridade. E às vezes passa pro chefe, pro supervisor e ele pega e libera pra limpar. Ai eles fica 'ah, porque não tem nada não', sendo que eles entram todos equipado lá dentro, e pra nóis fala que não tem nada a ver." (Isadora, agente de limpeza)

“[...] aqui tem muita árvore, muita folha [...]. Então assim, ela (funcionária) limpou o laboratório, ela tem que varrer ali na frente, porque se não todo mundo leva as folhinha pra dentro, e varrer ali na frente não é serviço dela. Mas faz, porque se não o serviço dela não vira [...] cê faz porque se não o seu serviço não vai aparecer... vai achar que cê não limpou lá hoje, e cê limpou, tendeu?" (Rafaela, líder de unidade)

"[...] a menina (funcionária) só limpa de manhã a sala, de tarde ela volta só pra fazer uma manutenção [...]. Você encontra copo de suco, garrafinha que joga por baixo das cadeiras, entendeu? [...] Copo de água, aí cai o restinho que fica dentro, cai no chão... aí que dizer, você acaba tendo que fazer a limpeza de novo né. E no contrato é só uma vez no dia. [...] E quando tem esses eventos. Tem um evento, aí sai da rotina, tem que sair da rotina de novo, porque tem os coffee break que fica no saguão. E suja e tem que voltar pra limpar." (Heloísa, encarregada de unidade)

\subsubsection{Relações sociais e liderança}

\section{Relacionamento interpessoal}

Segundo a maioria das participantes da pesquisa (13 relatos), o relacionamento entre elas e os funcionários e alunos da universidade geralmente era visto de forma positiva, sendo que a interação entre eles era limitada, devido principalmente ao número de tarefas a serem realizadas por ambas as partes, e a relação estabelecida entre eles foi relatada como cordial. As agentes de limpeza recebiam a orientação do supervisor e dos encarregados e líderes de não estabelecer vínculos com os funcionários da faculdade, a fim de prevenir possíveis problemas de relacionamento entre eles e facilitar a transferência para outra unidade, caso fosse necessário. Entretanto, algumas se consideravam próximas dos funcionários e alunos, e em alguns casos chegavam a ganhar presentes. 
"[...] sempre manter essa distância, sempre não ter contato direto com eles (funcionários da universidade), a gente pede, se acontecer alguma coisa com eles (agentes de limpeza), manter sempre contato direto com a encarregada, ou manda email lá pro gestor da unidade." (Lucas, supervisor geral)

"Eles tratam bem, demonstra gostar bastante de mim. Que nem, no final de ano elas (funcionárias da universidade) sempre tão me dando presente... Às vezes fazem vaquinha e me dá até em dinheiro [...]" (Isadora, agente de limpeza)

Apesar do relacionamento entre elas e os funcionários e alunos da faculdade ter sido relatado como positivo, 6 participantes compartilharam situações de desentendimento e discussão entre ambas as partes, relacionadas a cobranças fora do horário de serviço, humilhação e desconfiança. Segundo as agentes de limpeza, alguns alunos e funcionários tratavam-nas como pessoas desonestas, inferiores e sem valor, sendo que elas relataram situações em que funcionários e alunos gritaram com elas na frente de várias pessoas, acharam que elas furtavam objetos como celulares e notebooks e fizeram comentários racistas. Essas situações foram apontadas como fontes de estresse e aborrecimento. Em alguns casos, o mínimo desentendimento entre funcionários e agentes de limpeza ou entre alunos e agentes de limpeza era um dos motivos pelos quais o supervisor mudavam-nas de setor, sendo que raramente a razão da realozação de setor ou unidade era explicada, e muitas ficavam extremamente chateadas com a mudança. Segundo o supervisor geral, nos casos em que havia conflito entre os funcionários terceirizados e os funcionários ou alunos da universidade, inicialmente a desavença era mediada pelo encarregado da unidade, que era responsável por solucionar o desentendimento juntamente com o chefe administrativo da unidade. No entanto, se o conflito envolvesse danos materiais ou físicos, os funcionários terceirizados eram orientados pelo supervisor a procurarem a guarda universitária e a realizarem um boletim de ocorrência.

“[...] aí ele 'tá tudo sujo, nem parece que foi limpo', tendeu? Eu não gostei da forma que ele falou comigo. Vixe, aquele dia eu fiquei muito estressada, muito nervosa [...] Eu achei que deveria ter sido, né, ter falado com mais jeito, com mais educação, não chegar humilhando... porque eu tô num cargo abaixo, ele não tem o direito de ficar humilhando." (Amanda, agente de limpeza) 
“Ele virou e falou assim 'agora nóis tamo de gato preto agora?'. Como se diz, agora nóis tamo de gato preto, me chamou de nega né? [...] Então tem muita gente racista, tendeu, não gosta de gente escura... mas humilha a gente né [...]. A gente fica estressada. Porque eu acho que no comecinho eu tava querendo entrar em depressão né, porque tava estressada né [...] igual o povo da [universidade], sabe, fazer coisa e maltratar ou falar alguma coisa pra gente [...]" (Fernanda, agente de limpeza)

“[...] Às vezes o pessoal do setor não vai com a cara do funcionário, daí começa a implicar com o funcionário até pedir pra tá mudando de setor, daí a gente faz isso aí." (Paulo, encarregado de unidade)

“[...] hoje a terceirizada ela é acusada como... se o meu celular ou meu notebook sumiu, alguma coisa, qual que é a menor, o grau menor que passa ali? É a terceirizada ou a limpeza. É a terceirizada que roubou, que furtou, não é nunca o pessoal, a diretoria, alguma coisa assim, é sempre nós que somos acusados. E já teve casos que a gente foi acusado já por boletim de ocorrência e que a gente conseguiu provar o contrário [...] e a funcionária foi desligada, saiu em prantos, chorando, que foi acusada que sumiu o notebook da sala de um docente [...]” (Lucas, supervisor geral)

No que diz respeito ao relacionamento entre as agentes de limpeza, este foi relatado de forma ambivalente pelas participantes. De acordo com o conteúdo das entrevistas, a interação diária entre elas era tranquila, principalmente porque as funcionárias permaneciam em seus respectivos setores e só se encontravam nos horários de almoço ou café, momento em que elas geralmente conseguiam interagir. Entretanto, algumas participantes (6 relatos) contaram que já tiveram algum tipo de desentendimento ou discussão com colegas de trabalho, devido principalmente a fofocas e a dificuldades em trabalharem juntas e dividirem as atividades.

“[...] a gente quase não fica junto. É porque cada um tem seu setor né [...] só se encontra assim rapidinho [...] na hora do almoço que a gente senta aqui, todo mundo almoça [...] É bom que fique cada uma pro seu lado né. É melhor, acho melhor assim, que aí evita confusão, evita tudo." (Carla, agente de limpeza) 
"[...] já teve funcionária daqui, da nossa firma, que já fez rolo comigo, com negócio de pessoa de [universidade], um homem falou que ia até na minha casa com meu marido, ia passar a caminhonete em cima de mim, por causa de fofoca." (Fernanda, agente de limpeza)

O relacionamento entre as participantes e seus superiores, por sua vez, foi relatado como positivo em alguns casos e negativo em outros. De acordo com as 5 agentes de limpeza que percebiam esse relacionamento de forma negativa, a diferença de tratamento, a falta de responsabilidade com os funcionários e a humilhação constante por parte de alguns superiores foram apontadas como fontes de insatisfação, estresse e aborrecimento. Em alguns casos, os encarregados e líderes respondiam a essas situações solicitando ao supervisor geral a realocação dos funcionários envolvidos.

“[...] quando eu entrei aqui eu sofri muito, eu chorei muito muito muito muito, eu vivia chorando, porque sempre tava sendo humilhada [...] Mas eu tava quase entrando em depressão, eu chorava 24 horas, só que eu não podia pedir conta né porque eu falei 'a gente precisa trabalhar né', então... aguentei até hoje." (Fernanda, agente de limpeza)

"Ela (encarregada) falou que eu peguei e bati numa menina (colega de trabalho) dentro da faculdade, os aluno é que me tirou. Falou pro meu chefe. Meu chefe não veio falar comigo, ele acreditou nela e me tirou do setor." (Marcela, agente de limpeza)

"Diferença de tratamento, entende? Me deixa bem estressada. Ela (líder) me trata muito ruim. Tudo que eu faço é patada, entende? Eu não suporto. Todas ela trata diferente. Comigo não, é só patada." (Helen, agente de limpeza)

"(A líder) Queria que eu fosse no sindicato falar que o supervisor tava explorando nós. [...] E aí ela pegou no meu pé, ela queria que eu fosse no sindicato [...] aí como eu falei que não ia, ela pegou e começou a me perseguir. Começou a pôr defeito no meu serviço, até que chamou a encarregada e falou que não queria eu lá mais." (Vivian, agente de limpeza) 


\section{Suporte social}

Seis participantes relataram ter uma percepção negativa acerca de suas colegas de trabalho devido à ausência de apoio das mesmas em momentos em que elas precisavam de ajuda com a limpeza. Segundo essas participantes, o número elevado de tarefas a serem realizadas, o número insuficiente de funcionários e a falta de vontade de ajudar as colegas de trabalho eram as principais causas que contribuíam para a ausência de suporte entre elas.

“[...] aqui se você falar que tá apurada 'nossa, mas que que cêfez até agora?’, é desse jeito, ninguém ajuda não (risos). [...] neguinho não quer que você vai ajudar porque não quer te ajudar depois. Que ai tem aquela coisa de falar assim 'ah, nunca me ajudou, vou ajudar pra que?" (Marcela, agente de limpeza)

O apoio oferecido pelos encarregados e líderes, por sua vez, mostrou-se satisfatório a partir da percepção da maioria das participantes que comentaram sobre seus encarregados e líderes ( 8 relatos). De acordo com os relatos, por mais que eles não estivessem disponíveis em todos os momentos, na maioria das vezes eles ofereciam o suporte necessário assim que possível, tanto para sanar dúvidas e resolver conflitos quanto para fornecer uma quantidade maior de materiais de limpeza, e alguns chegavam a auxiliar nas tarefas operacionais de limpeza. A única crítica das participantes acerca do suporte dos superiores foi em relação à alocação de agentes de outros setores para auxiliar na limpeza em momentos em que havia sobrecarga de trabalho, o que ocorria devido ao número insuficiente de funcionários.

\section{Reconhecimento, salário e benefícios}

Outro ponto destacado por 14 participantes, por 2 encarregados e pela líder foi o baixo reconhecimento e o desrespeito pelo trabalho de limpeza e pelo trabalho terceirizado. Enquanto alguns alunos e funcionários da faculdade conseguiam apreciar o trabalho realizado por elas, elogiavam e até agradeciam pelo serviço, a maioria deles não demonstrava nenhum tipo de reconhecimento. A baixa valorização social mostrouse evidente nos relatos relacionados à limpeza dos banheiros. Segundo as agentes, era frequente entrar nos banheiros e encontrar papeis jogados no chão, nas pias e nas 
privadas, privadas entupidas e fezes e absorventes à mostra. Além disso, era comum que alunos entrassem no banheiro justamente quando este estava sendo limpo pelas funcionárias.

"Não respeita, entendeu? Tipo, tá lavando? Usa outro, não tem um banheiro só na faculdade. Aí querem entrar, quer usar o banheiro [...] Tem umas coisa que cê olha assim e cê fala 'incrível, não é possível', de, por exemplo, vai fazer o número 2, passa na parede [...] Absorvente também é o caso maior também. Usa, joga lá dentro do cesto lá tudo aberto [...] Ou então cola na parede, atrás da porta. Entra no banheiro, cê fecha a porta e dá de cara com aquilo [...].” (Heloísa, encarregada de unidade)

"[...] eles acha que a terceirizada não tem valor né [...] que a gente é terceirizada a gente tem que fazer tudo. Que nem dentro do banheiro lá, a moça, estudante, ela deixou tudo cheio de sangue [...] e eu falei pra ela que não era obrigada, aí ela falou 'mas a senhora é terceirizada, a senhora tem que lavar' [...]. Mas o pessoal humilha muito, humilha muito porque a gente é terceirizada mesmo." (Fernanda, agente de limpeza)

"Tem um funcionário que ele fuma dentro do banheiro. Ele joga a cinza do cigarro no chão, joga os toco do cigarro no chão e ainda faz assim com o pé, aperta com o pé pra poder apagar o cigarro e vai embora e deixa lá aquela coisa. Então assim, esse serviço nosso, por isso que eu vejo que não é muito... não é valorizado.[...] pra gente é humilhante, porque parece que faz pra humilhar. 'Porque tá aqui pra limpar, então eu posso jogar o toco de cigarro no chão, a cinza, de boa, que ela vem e limpa'." (Vivian, agente de limpeza)

A baixa valorização social do serviço de limpeza terceirizado frequentemente contribuiu para o retrabalho das agentes de limpeza, ou seja, elas refaziam o trabalho devido à baixa colaboração dos funcionários da universidade e dos alunos para manter o local limpo. Este ponto foi citado pelas participantes como uma das principais fontes de estresse no ambiente de trabalho.

"Cê acaba de limpar, cê lava, cê deixa tudo brilhando, limpinho. Se você der uma volta, dali meia hora, cê vai lá de novo e tá pior do que você deixou, parece que 
eles fazem de propósito. E eu ver esse propósito já tava me irritando, me estressando, tava me deixando muito louca, então eu já não podia mais ficar lá." (Giovana, agente de limpeza)

Em alguns relatos, foi possível identificar que o serviço de limpeza terceirizado era desvalorizado de forma geral, tanto pelos funcionários e alunos da universidade quanto pelas próprias agentes de limpeza. Quando foi perguntado a elas como seria se seus filhos também trabalhassem com limpeza, a maioria respondeu que preferia que isso não acontecesse, pois, de acordo com elas, o serviço de limpeza oferecia poucas oportunidades de aprendizagem e de crescimento profissional, possuía um piso salarial baixo, não era reconhecido nem respeitado, era cansativo e era uma das poucas alternativas de emprego para quem possuía baixa escolaridade.

"[...] porque nem sempre o faxineiro tem valor, cê é invisível, na realidade a gente é invisível, tendeu? Às vezes a pessoa alembra de vc quando 'poxa, caiu uma água, caiu um café no chão' ou quando tá bem sujo fala 'nossa, a moça da limpeza não passou por aqui' (risos) né? Aí é meio que complicado [...]" (Beatriz, agente de limpeza)

"[...] eu gosto do que eu faço, eu só fico chateada nesse sentido, porque ela (a profissão) não é reconhecida, entendeu, e ela poderia ser melhor [...] reconhecida pelas pessoas, e respeitada né. Eu sinto por isso. Ela não é nem reconhecida nem respeitada. [...] a gente não quer que os filhos passem o que a gente passou ou passa, né, por não ser bem remunerada e por não ser bem reconhecida." (Laura, agente de limpeza)

O reconhecimento por parte dos superiores também foi relatado como ambíguo. Segundo a percepção das funcionárias, alguns superiores reconheciam seu trabalho por meio de elogios ou pela ausência de reclamações. Entretanto, a sobrecarga de tarefas, o baixo salário, a ausência de elogios ou comentários relacionados à realização da limpeza e a falta de consideração com os funcionários foram as principais queixas das participantes em relação ao reconhecimento dos superiores.

"Porque eles não te perguntam 'olha Fulano, você dá conta de pegar mais isso e isso pra você fazer?'. Não. 'Oh Fulano, eu fiz essa lista aqui, 10 disso, 10 daquilo 
outro, cê tem que me dar isso todo dia', é assim. Aí a gente vai se tornando um polvo né, porque você vai esticando tentáculo pra tudo que é lado, e você é obrigado. Tá faltando funcionário pra certos setores? Tá. Tem pessoas aí que tá trabalhando e morrendo, tem pessoas aí que fica doente assim... e isso vai cansando sabe? Porque você faz, faz, faz e nunca merece nada." (Giovana, agente de limpeza)

"[...] pela firma a gente não é reconhecido não, só vão socando serviço e mais serviço em cima da gente. [...] eu faço o serviço de 3 pessoa e eu ganho 1 salário. A gente trabalha muito e ganha pouco pelo que a gente faz." (Isadora, agente de limpeza)

Em relação ao salário e benefícios das agentes de limpeza, estes estavam de acordo com a convenção coletiva do Sindicato dos Trabalhadores em Empresas de Prestação de Serviços de Asseio e Conservação e Limpeza Urbana de São Paulo (SIEMACO), sendo que os funcionários recebiam o salário no valor de $\mathrm{R} \$ 1.110,70$, vale-alimentação, ticket de refeição e vale-transporte, descontado a partir do pagamento. Das 20 participantes, 16 demonstraram insatisfação com o valor do salário, que era insuficiente, e disseram que aumentariam o valor, se pudessem. Apesar da instatisfação geral, algumas delas relataram gratidão por terem um emprego, principalmente no contexto atual de crise.

“[...] pelo que a gente tá vivendo hoje, um momento de crise né, porque a gente tem que olhar nosso lado né. Então assim, eu dou graças a Deus por essa porta de emprego aberta... pra mim tem sido uma bênção né, se a gente olhar o negócio tá feio. Mas porém, pelo que a gente faz aqui (risos) né, é pouco." (Júlia, agente de limpeza)

\subsubsection{Exigências no trabalho}

\section{Exigências quantitativas e ritmo de trabalho}

No novo contrato, além da rotina diária de limpeza, era exigido uma faxina completa antes do início das aulas, nos meses de Janeiro e Julho. Tal faxina consistia em retirar todas as carteiras de todas as salas de aula, lavar e encerar as salas, lavar as janelas, limpar as carteiras e colocá-las novamente nas salas de aula, e lavar os corredores dos blocos didáticos e os banheiros. De acordo com os encarregados e a 
líder, esses períodos que antecediam as aulas exigiam um ritmo de trabalho muito acelerado, devido principalmente à ausência de funcionários específicos para isso. Sendo assim, alguns dos encarregados acabavam aumentando o número de tarefas para cada agente de limpeza, que além de ser responsável pela limpeza e manutenção de seu setor, também era convocado a participar dos multirões de limpeza, em que vários funcionários se reuniam para realizar a limpeza de algum lugar específico.

“[...] nessa época, tanto tem lá pra fazer, como se diz, não tem funcionário lá específico pra isso, eu tenho que pegar os que eu tenho, e eles já têm os setores deles pra fazer, os prédios, então eles têm que fazer aqui, correr e ajudar lá, então eles têm que se organizar pra fazer de manhã, pra de tarde tá ajudando, ou vai lá de manhã e ajuda e à tarde vai pro setor. É um período mais puxado." (Cecília, encarregada de unidade)

Tais multirões aconteciam apenas nas unidades $\mathrm{B}$ e $\mathrm{C}$, sendo que, na primeira unidade os multirões eram organizados apenas na época das férias escolares, e na segunda, os multirões de limpeza aconteciam nas férias e pelo menos uma vez a cada semana. Duas participantes relataram de forma negativa sua participação nos multirões de limpeza, pois, segundo elas, sua participação exigia um deslocamento constante entre os setores e gerava uma sobrecarga de trabalho. A necessidade de realização dos multirões acontecia devido ao número reduzido de funcionários, resultado das modificações do novo contrato, e foi identificado como uma fonte de estresse pelas agentes de limpeza.

"[...] esse negócio de multirão acaba fazendo você trabalhar mais né [...] a gente cansa muito com esse negócio de multirão, porque cê tem que dar conta do seu setor [...] cê sai do seu setor, cê tem que ir lá, cê tem que parar o seu serviço pra ir lá ajudar [...] cê acabou (de ajudar no multirão), cê tá cansada, mas não interessa, cê tem que dar conta do seu setor também". (Vivian, agente de limpeza)

"[...] e aí sobrecarrega quem? Nós. Que nós já tem um setor grande, aí a gente tem que se deslocar daqui pra... ainda cobrir outro setor. [...] Eé na onde a gente se desdobra, e a gente acaba trabalhando mais... e querendo ou não, tipo assim, a gente precisa, mas às vezes é cansativo.” (Júlia, agente de limpeza) 
Catorze participantes identificaram um aumento significativo na quantidade de tarefas e no ritmo de trabalho, sendo que algumas delas não conseguiam realizar um serviço tão bem feito quanto gostariam. Tais situações eram apontadas por alguns funcionários da universidade como uma falha no serviço de limpeza e muitas vezes eram motivo de reclamações, o que frequentemente aborrecia as agentes de limpeza. A fim de encerrar suas atividades diárias de forma satisfatória e evitar reclamações, duas das participantes relataram que esporadicamente trabalhavam além do horário estipulado pela empresa.

“Às vezes tô me sentindo mal no meu setor porque não dá pra fazer o que é pra fazer, entendeu, porque antes fazia bem feitinho e agora a gente se sente mal. [...] Às vezes a gente tá tentando fazer mas não dá, e o horário, às vezes é o horário que não dá pra fazer, aí eu me sinto mal com isso. Parece que tá tudo sujo, entendeu?" (Natália, agente de limpeza)

"Eu gosto assim, cheguei, comecei, eu vou até o fim, seja a hora que for. Tanto que tem vez que na hora de picar o cartão eu venho, pico meu cartão e volto pra trás... que já deu meu horário, mas eu tenho que terminar o que eu comecei”. (Giovana, agente de limpeza)

\section{Número insuficiente de trabalhadores}

O número reduzido de funcionários, resultado do novo contrato entre a universidade e a empresa, foi apontado por 9 agentes de limpeza como uma fonte de estresse, sendo que a maioria delas (8 relatos) sugeriu o aumento no número de funcionários como forma de se alcançar uma melhoria nas condições de trabalho. De acordo com a percepção das agentes de limpeza, dos encarregados e da líder, devido à redução no número de trabalhadores, a quantidade e o ritmo de trabalho aumentaram significativamente, sendo que 2 participantes relataram que sentiam medo de não dar conta de cumprir todas as suas tarefas. Além disso, 5 delas avaliaram de modo injusto o salário em relação à quantidade de tarefas que desempenhavam. 
"Aqui era 16 funcionária pra esse mesmo tamanho aqui, agora a gente tá da limpeza em 6 [...] aí eu tive que distribuir o trabalho, que é aumentar o trabalho de todas elas.” (Rafaela, líder de unidade)

"Porque a gente não tem funcionário, [...] então a gente fica com mais serviço, fica com menos tempo, entendeu, até um pouco pra respirar né... até pelo menos pra gente falar assim 'poxa, eu vou sentar 5 minutos pra respirar' tendeu? Às vezes isso não acontece." (Beatriz, agente de limpeza)

“[...] na verdade eu costumo dizer que a gente tá precisando mais é de um psiquiatra, porque olha... estressa muito fácil. Igual, como diminuiu muito funcionários, sobrecarregou muito, a pessoa fica estressada, tem pessoas que tem medo de não dar conta do serviço, sabe?" (Jéssica, agente de limpeza)

\section{Atenção no trabalho}

Outra exigência no trabalho identificada por 15 participantes foi a necessidade de se manterem sempre atentas. Era exigido das funcionárias a manutenção constante da limpeza devido à não conservação do ambiente limpo por parte dos funcionários e alunos da universidade. De acordo com as agentes de limpeza, a fim de evitar reclamações, observações no livro de ocorrências e notificações para a empresa, era exigido que elas estivessem sempre atentas principalmente à manutenção dos banheiros, que requeria a reposição de materiais como papel higiênico, papel toalha e sabonete, e das salas de reuniões e de diretorias.

"Tem que prestar atenção porque se caso um professor entra e vê sujo, aí eles não fala com a gente né, porque não pode falar. Então eles fala com o João (funcionário da universidade que fiscaliza o serviço terceirizado na unidade) e o João fala com o Paulinho aqui embaixo, então a gente escuta né, então por isso que a gente tem que ficar atento. Tem que olhar as sala, varrer sala, ver como é que tá... olhar banheiro pra ver se tem papel higiênico, sabonete, essas coisa, porque se não, a gente que escuta depois." (Fernanda, agente de limpeza) 
Além da manutenção constante da limpeza, elas relataram que também estavam sempre atentas aos produtos que utilizavam, pois estes poderiam danificar os pisos e superfícies limpas, às secretarias e salas onde existiam muitos computadores, à utilização de luvas para mexer com o lixo, a fim de evitar contaminações, e aos laboratórios, devido à possibilidade de danificar os instrumentos e experimentos realizados. Uma das participantes relatou que, ao limpar um laboratório, encontrou uma agulha utilizada e, ao recolhê-la, teve sua luva perfurada. Com a finalidade de previnir qualquer tipo de contaminação pela agulha, a funcionária teve que tomar um coquetel de medicamentos por aproximadamente um mês após o ocorrido.

“Ah sim, ainda mais com produto químico né, [...] pra não manchar, não queimar piso né, tem que tá atenta. [...] Eu tenho medo assim de... às vezes com produto químico né, tipo limpar o laboratório, esbarrar o rodo, quebrar um daqueles solvente, alguma coisa assim, mas só." (Jéssica, agente de limpeza)

“[...] tem que prestar atenção porque tem muita coisa ali né? É laboratório... tem as coisa dos professor... não pode quebrar, tem que prestar muita atenção, tendeu? Se você fazer as coisa de qualquer jeito aí cê quebra, depois tem que pagar. Num é teu, é patrimônio da [universidade], né? E se derrubar um monitor daquele? Tem que tá sempre atento. E às vezes as coisa dos aluno também tem que tá atento." (Marcela, agente de limpeza)

\subsubsection{Interface família-indivíduo}

\section{Conflito trabalho-família}

Dez das participantes relataram que o tempo disponível para ficar com a família, descansar ou realizar atividades de lazer não era suficiente, sendo que a maioria delas considerou que a idade dos filhos era um fator decisivo para avaliar se a quantidade de tempo livre disponível era satisfatória ou não. Além do trabalho, as agentes de limpeza também eram responsáveis pela limpeza, conservação da casa e todas as outras tarefas domésticas, e 5 delas ainda trabalhavam com faxina particular após o expediente. Tais fatores constituíam fontes de sobrecarga de trabalho e geravam cansaço e estresse, além de contribuírem para a diminuição do tempo livre. 
"Ah a gente fica meio que estressado não pelo trabalho, que a gente sabe que tem que fazer e tem que ser feito, mas pelo cansaço né, porque... eu acho assim, o final de semana não é suficiente pra gente que é mulher, não é tão suficiente pra gente descansar mesmo né, porque devido que final de semana a gente acaba trabalhando às vezes até mais que você trabalha no seu serviço [...]." (Beatriz, agente de limpeza)

"Ah, é ruim né, o tempo que você fica você tem que dar atenção... a minha menininha mesmo, chego em casa, ela quer brincar. Como que você vai brincar com uma criança sabendo que você tem comida pra fazer, uma casa pra limpar... aí eu falo 'a mamãe não pode agora' [...].” (Luíza, agente de limpeza)

“[...] como aqui o meu salario é baixo, de final de semana eu tenho que fazer faxina pra ganhar por fora e aumentar minha renda. Todo final de semana, quer dizer, eu não tenho descanso. Aí eu faço faxina de sábado e de domingo, tem descanso nenhum." (Isadora, agente de limpeza)

\section{Insegurança no trabalho}

Algumas participantes da pesquisa (7 relatos) afirmaram sentir insegurança e preocupação frente às mudanças derivadas do novo contrato, principalmente devido ao grande número de funcionários dispensados. As formas citadas de lidar com a insegurança foram a espiritualidade e crença em certas religiões e a conformidade com a situação, sendo algumas mencionaram a situação de crise do país, o desemprego crescente e o sentimento de gratidão por estarem empregadas frente à crise. Segundo o supervisor geral, nos períodos próximos à finalização e renovação do contrato, era frequente que as agentes de limpeza ficassem preocupadas com a possibilidade de demissão.

"É, a gente pensa bastante, entendeu, quando chega notícia de algum corte, alguma coisa [...] porque como o desemprego tá meio que, tá difícil né, as coisa tá difícil, então eu fico com medo sim, tendeu, de perder o serviço. E não encontrar outro assim tão rápido né, ou às vezes leva tempo... às vezes leva meses, mas às vezes leva anos, e aí?" (Beatriz, agente de limpeza) 
"Misericórdia, (me preocupa) e muito! Eu sou sozinha, não posso ficar desempregada não. Sou pai e mãe. Misericórdia, nem penso na hipótese de ficar desempregada não. Aí eu fico doida de vez. Porque a gente que é sozinha, é complicado né. Meu filho tem problema, aí fica mais difícil ainda." (Helen, agente de limpeza)

\subsubsection{Saúde e estresse}

Quando questionadas sobre os aspectos relacionados ao trabalho que poderiam levar ao estresse, as participantes apontaram como principais os seguintes fatores: o ritmo de trabalho acelerado e a sobrecarga de atividades, a falta de colaboração dos alunos e funcionários da faculdade com a manutenção da limpeza, a ausência de suporte das colegas de trabalho, as dificuldades encontradas nos relacionamentos com as colegas de trabalho, com os superiores da empresa terceirizada e com os funcionários da universidade, o baixo reconhecimento por parte da empresa e da universidade, a divisão desigual do trabalho, o excesso de cobrança e o tempo escasso destinado ao descanso e lazer. Todos os fatores de risco psicossociais identificados pelas participantes, assim como o respectivo número de relatos, foram indicados na Figura 22.

"Muita forgação, fofoca, coisa que cê não falou... eu fico estressada assim da pessoa fazer as coisa e fazer que não... igual o povo da [universidade] sabe, fazer coisa e maltratar ou falar alguma coisa pra gente [...]." (Fernanda, agente de limpeza)

“[...] eu ficava até estressada mesmo, nossa, cheguei no escritório um dia que parece que nem era eu (risos), de tão transtornada que eu tava, né, por ser muito serviço mesmo pra uma pessoa só. [...] tava ficando doente, tomando medicação pra dor... é dor nas costa, dor nos braço... aí era muito estressante [...]." (Amanda, agente de limpeza) 
Figura 22 - Fatores de risco psicossocial identificados pelas participantes e associados ao estresse, frequência e exemplos de relatos (Continua)

\begin{tabular}{|c|c|c|c|}
\hline $\begin{array}{c}\text { Fatores de } \\
\text { risco } \\
\text { psicossocial } \\
\text { identificados }\end{array}$ & & Frequência & Exemplo de relato \\
\hline \multirow{6}{*}{$\begin{array}{l}\text { Organização } \\
\text { do trabalho e } \\
\text { conteúdo das } \\
\text { tarefas }\end{array}$} & $\begin{array}{l}\text { Influência no } \\
\text { trabalho }\end{array}$ & 10 & $\begin{array}{l}\text { "[...] aí me tiraram lá da unidade, eu } \\
\text { vim chorando bem (risos), porque eu } \\
\text { não queria sair de lá, aí eu vim pra } \\
\text { cá, aí no começo foi difícil pra mim } \\
\text { [...]" (Júlia, agente de limpeza) }\end{array}$ \\
\hline & $\begin{array}{l}\text { Trabalho prescrito } \\
\text { x trabalho real }\end{array}$ & 9 & $\begin{array}{l}\text { "Aí manda eu limpar a cada } 15 \text { dias. } \\
\text { Eu não limpo, eu limpo toda sexta. } \\
\text { Imagina uma sala de aula a cada } 15 \\
\text { dias? Não, dá pra limpar toda sexta, } \\
\text { eu vou lá e limpo." (Gabriela, agente } \\
\text { de limpeza) }\end{array}$ \\
\hline & $\begin{array}{l}\text { Possibilidades de } \\
\text { desenvolvimento }\end{array}$ & 8 & $\begin{array}{l}\text { "Ah eu creio que não. Porque } \\
\text { limpeza né, vai crescer como? [...] } \\
\text { Ah, eu não me preparei né pra } \\
\text { conseguir uma coisa melhor. Eu não } \\
\text { fui atrás, eu não fiz nenhum curso, } \\
\text { então... tá nisso." (Vivian, agente de } \\
\text { limpeza) }\end{array}$ \\
\hline & $\begin{array}{l}\text { Atribuição e } \\
\text { conteúdo das } \\
\text { tarefas }\end{array}$ & 5 & $\begin{array}{l}\text { "[...] tem umas que trabalha, umas } \\
\text { que não trabalha... tem umas que } \\
\text { folga em cima da outra [...] tem } \\
\text { pessoas que têm bastante setor } \\
\text { grande, tem pessoas que têm setor } \\
\text { pequeno né, tem uns que trabalha } \\
\text { mais, tem uns que trabalha menos } \\
\text { [...]." (Fernanda, agente de limpeza) }\end{array}$ \\
\hline & Espaço físico & 5 & $\begin{array}{l}\text { "[...] é é no alto né, é escada, eu tenho } \\
\text { que ficar descendo, subindo, toda } \\
\text { hora... levar lixo, sobe, pega mais } \\
\text { lixo, desce... é estressante isso aí." } \\
\text { (Isadora, agente de limpeza) }\end{array}$ \\
\hline & $\begin{array}{l}\text { Controle do } \\
\text { desempenho }\end{array}$ & 2 & $\begin{array}{l}\text { "[...] vamo supor, eu tô limpando sua } \\
\text { sala, aí cê fala 'oh, eu quero que } \\
\text { limpa agora', eu vou falar 'não } \\
\text { posso', aí você liga no Lucas, aí o } \\
\text { Lucas vai e liga, aí quem escuta é a } \\
\text { gente, tendeu?" (Fernanda, agente de } \\
\text { limpeza) }\end{array}$ \\
\hline
\end{tabular}


Figura 22 - Fatores de risco psicossocial identificados pelas participantes e associados ao estresse, frequência e exemplos de relatos (Continuação)

\begin{tabular}{|c|c|c|c|}
\hline $\begin{array}{l}\text { Fatores de } \\
\text { risco } \\
\text { psicossocial } \\
\text { identificados } \\
\end{array}$ & & Frequência & Exemplo de relato \\
\hline \multirow{6}{*}{$\begin{array}{l}\text { Relações } \\
\text { sociais e } \\
\text { liderança }\end{array}$} & $\begin{array}{c}\text { Salário e } \\
\text { benefícios }\end{array}$ & 16 & $\begin{array}{l}\text { "[...] eu dou graças a Deus por essa } \\
\text { porta de emprego aberta... pra mim } \\
\text { tem sido uma bênção né, se a gente } \\
\text { olhar o negócio tá feio. Mas porém, } \\
\text { pelo que a gente faz aqui (risos) né, } \\
\text { é pouco." (Júlia, agente de limpeza) }\end{array}$ \\
\hline & Reconhecimento & 14 & $\begin{array}{l}\text { "Cê acaba de limpar, cê lava, cêe } \\
\text { deixa tudo brilhando, limpinho. Se } \\
\text { você der uma volta, dali meia hora, } \\
\text { cê vai lá de novo e tá pior do que } \\
\text { você deixou, parece que eles fazem } \\
\text { de propósito." (Giovana, agente de } \\
\text { limpeza) }\end{array}$ \\
\hline & $\begin{array}{l}\text { Relacionamento } \\
\text { interpessoal } \\
\text { (agentes - } \\
\text { funcionários e } \\
\text { alunos da } \\
\text { universidade) }\end{array}$ & 6 & $\begin{array}{l}\text { "[...] ai ele 'tá tudo sujo, nem parece } \\
\text { que foi limpo', tendeu? Eu não } \\
\text { gostei da forma que ele falou } \\
\text { comigo. Vixe, aquele dia eu fiquei } \\
\text { muito estressada, muito nervosa [...] } \\
\text { deveria ter sido, né, ter falado com } \\
\text { mais jeito, com mais educação, não } \\
\text { chegar humilhando... porque eu tô } \\
\text { num cargo abaixo, ele não tem o } \\
\text { direito de ficar humilhando." } \\
\text { (Amanda, agente de limpeza) }\end{array}$ \\
\hline & $\begin{array}{l}\text { Relacionamento } \\
\text { interpessoal } \\
\text { (agentes - } \\
\text { agentes) }\end{array}$ & 6 & $\begin{array}{l}\text { "[...] já teve funcionária daqui, da } \\
\text { nossa firma, que já fez rolo comigo, } \\
\text { com negócio de pessoa de } \\
\text { [universidade], um homem falou que } \\
\text { ia até na minha casa com meu } \\
\text { marido, ia passar a caminhonete em } \\
\text { cima de mim, por causa de fofoca." } \\
\text { (Fernanda, agente de limpeza) }\end{array}$ \\
\hline & $\begin{array}{l}\text { Suporte social } \\
\text { (colegas) }\end{array}$ & 6 & $\begin{array}{l}\text { "[...] neguinho não quer que você vai } \\
\text { ajudar porque não quer te ajudar } \\
\text { depois. Que aí tem aquela coisa de } \\
\text { falar assim ah, nunca me ajudou, } \\
\text { vou ajudar pra que?"” (Marcela, } \\
\text { agente de limpeza) }\end{array}$ \\
\hline & $\begin{array}{l}\text { Relacionamento } \\
\text { interpessoal } \\
\text { (agentes - } \\
\text { superiores) }\end{array}$ & 5 & $\begin{array}{l}\text { "Ela (líder) me trata muito ruim. } \\
\text { Tudo que eu faço é patada, entende? } \\
\text { Eu não suporto. Todas ela trata } \\
\text { diferente. Comigo não, é só patada." } \\
\text { (Helen, agente de limpeza) }\end{array}$ \\
\hline
\end{tabular}


Figura 22 - Fatores de risco psicossocial identificados pelas participantes e associados ao estresse, frequência e exemplos de relatos (Conclusão)

\begin{tabular}{|c|c|c|c|}
\hline $\begin{array}{l}\text { Fatores de } \\
\text { risco } \\
\text { psicossocial } \\
\text { identificados }\end{array}$ & & Frequência & Exemplo de relato \\
\hline \multirow{3}{*}{$\begin{array}{l}\text { Exigências no } \\
\text { trabalho }\end{array}$} & $\begin{array}{l}\text { Atenção no } \\
\text { trabalho }\end{array}$ & 15 & $\begin{array}{l}\text { "Ah sim, ainda mais com produto } \\
\text { químico né, [...] pra não manchar, } \\
\text { não queimar piso né, tem que tá } \\
\text { atenta. [...] Eu tenho medo assim } \\
\text { de... às vezes com produto químico } \\
\text { né, tipo limpar o laboratório, } \\
\text { esbarrar o rodo, quebrar um } \\
\text { daqueles solvente [...]" (Jéssica, } \\
\text { agente de limpeza) }\end{array}$ \\
\hline & $\begin{array}{c}\text { Exigências } \\
\text { quantitativas e } \\
\text { ritmo de trabalho }\end{array}$ & 14 & $\begin{array}{l}\text { "Às vezes a gente tá tentando fazer } \\
\text { mas ná dá, e o horário, às vezes é o } \\
\text { horário que não dá pra fazer, aí eu } \\
\text { me sinto mal com isso. Parece que tá } \\
\text { tudo sujo, entendeu?" (Natália, } \\
\text { agente de limpeza) }\end{array}$ \\
\hline & $\begin{array}{l}\text { Número } \\
\text { insuficiente de } \\
\text { trabalhadores }\end{array}$ & 9 & $\begin{array}{l}\text { "Porque a gente não tem } \\
\text { funcionário, [...] então a gente fica } \\
\text { com mais serviço, fica com menos } \\
\text { tempo, entendeu, até um pouco pra } \\
\text { respirar né }[. . .] " \text { (Beatriz, agente de } \\
\text { limpeza) }\end{array}$ \\
\hline \multirow[b]{2}{*}{$\begin{array}{l}\text { Interface } \\
\text { família- } \\
\text { indivíduo }\end{array}$} & $\begin{array}{l}\text { Conflito trabalho- } \\
\text { família }\end{array}$ & 10 & $\begin{array}{l}\text { "Como que você vai brincar com } \\
\text { uma criança sabendo que você tem } \\
\text { comida pra fazer, uma casa pra } \\
\text { limpar... ai eu falo 'a mamãe não } \\
\text { pode agora' [...]." (Luíza, agente de } \\
\text { limpeza) }\end{array}$ \\
\hline & $\begin{array}{l}\text { Insegurança no } \\
\text { trabalho }\end{array}$ & 7 & $\begin{array}{l}\text { "É, a gente pensa bastante, } \\
\text { entendeu, quando chega notícia de } \\
\text { algum corte, alguma coisa [...] } \\
\text { porque como o desemprego tá meio } \\
\text { que, tá difícil né, as coisa tá difícil, } \\
\text { então eu fico com medo sim, tendeu, } \\
\text { de perder o serviço." (Beatriz, } \\
\text { agente de limpeza) }\end{array}$ \\
\hline
\end{tabular}

Fonte: elaboração da autora.

Em relação à saúde, a maioria das participantes apontou a organização do espaço físico, esforço físico intenso, o trabalho repetitivo, o risco de contaminação com o lixo e o risco de intoxicação devido à utilização de produtos químicos na limpeza como os principais fatores presentes no contexto de trabalho que poderiam causar prejuízos à 
saúde. Apenas uma das agentes indicou que o estresse e o cansaço também poderiam ser considerados aspectos prejudiciais à saúde. Os fatores de risco identificados pelas participantes e o respectivo número de relatos foram apresentados na Figura 23.

Figura 23 - Fatores de risco psicossocial identificados pelas participantes e associados à saúde, frequência e exemplos de relatos

\begin{tabular}{|c|c|c|}
\hline $\begin{array}{c}\text { Fatores de risco } \\
\text { identificados }\end{array}$ & Frequência & Exemplo de relato \\
\hline $\begin{array}{l}\text { Organização do } \\
\text { espaço físico }\end{array}$ & 5 & $\begin{array}{l}\text { "Até deu vontade de eu sair daqui, porque eu não tava } \\
\text { aguentando mais ficar subindo e descendo. Aí deu vontade } \\
\text { de eu pedir conta pra sair daqui, porque não tava } \\
\text { aguentando não." (Mariana, agente de limpeza) }\end{array}$ \\
\hline $\begin{array}{l}\text { Risco de } \\
\text { intoxicação pelos } \\
\text { produtos } \\
\text { químicos }\end{array}$ & 4 & $\begin{array}{l}\text { "Ah os produto né, os produto, que se a gente tá em contato } \\
\text { direto com os produto, inalando o cheiro de roupalim... por } \\
\text { mais diluído que seja é produto químico né?" (Júlia, agente } \\
\text { de limpeza) }\end{array}$ \\
\hline $\begin{array}{l}\text { Esforço físico } \\
\text { intenso }\end{array}$ & 4 & $\begin{array}{l}\text { "[...] eu perco muita energia aqui e eu como pouco... fora as } \\
\text { lixaiada aqui, o peso do lixo que eu tenho que ficar } \\
\text { carregando... e eu sozinha." (Isadora, agente de limpeza) }\end{array}$ \\
\hline $\begin{array}{l}\text { Trabalho } \\
\text { repetitivo }\end{array}$ & 3 & $\begin{array}{l}\text { "Só se for os braço né, porque acaba ficando dolorido, é } \\
\text { rodo, sempre o mesmo movimento [...]." (Gabriela, agente de } \\
\text { limpeza) }\end{array}$ \\
\hline $\begin{array}{l}\text { Risco de } \\
\text { contaminação } \\
\text { com o lixo }\end{array}$ & 1 & $\begin{array}{l}\text { "É mais isso, se cuidar pra não ter nenhuma contaminação } \\
\text { né... ainda mais limpeza né, a gente que mexe muito com } \\
\text { lixo, essas coisas, tem que ter a luva [...]." (Amanda, agente } \\
\text { de limpeza) }\end{array}$ \\
\hline $\begin{array}{l}\text { Estresse e } \\
\text { cansaço }\end{array}$ & 1 & $\begin{array}{l}\text { "[...] eu acho que devido a canseira né, devido ao dia a dia } \\
\text { que é corrido né, devido ao estresse do cansaço, tudo isso, } \\
\text { eu acho que chega uma hora o corpo não aguenta né [...]." } \\
\text { (Beatriz, agente de limpeza) }\end{array}$ \\
\hline
\end{tabular}

Fonte: elaboração da autora.

\subsubsection{Sugestões de melhoria}

As sugestões de melhoria para as condições de trabalho compartilhadas pelas agentes de limpeza e pela líder e encarregados envolviam aspectos relacionados ao reconhecimento, aumento do número de funcionários e diminuição do horário de trabalho. A maioria das sugestões realizadas referiram-se a alterações no nível macro, ou seja, a atributos globais da organização, enquanto apenas duas fizeram referência a alterações no nível meso, correspondente aos grupos de trabalho, unidades ou departamentos (conforme as definições de níveis utilizadas por Abbad et al., 2014). 
Onze participantes reforçaram a necessidade de se contar com um número maior de funcionários, a fim de contribuir com a diminuição do ritmo e da quantidade de trabalho, e, consequentemente, com a diminuição do estresse e do cansaço, além da melhoria na qualidade do serviço. Segundo uma das encarregadas, tanto os encarregados e líderes quanto os funcionários da universidade já haviam realizado tentativas de solicitar um aumento no número de funcionários para a reitoria da universidade. Em uma das tentativas, eles chegaram a organizar mensalmente uma avaliação do serviço de limpeza por parte dos funcionários da faculdade, que pontuavam na avaliação a necessidade da empresa terceirizada contratar mais funcionários. O resultado de tal avaliação era enviado por e-mail para o gestor geral de serviços terceirizados da universidade, entretanto, de acordo com a encarregada, eles nunca obtiveram nenhum posicionamento nem do gestor geral nem da reitoria da universidade.

"O pobrema aqui é que eu acho que precisava de mais gente pra pôr, pra gente ter mais atenção nas coisa né, porque a gente faz muito correndo as coisa. Às vezes tem coisa que a gente acha que tá bem feito e acho que não fica bem feito, tendeu?" (Natália, agente de limpeza)

"[...] eu acho que a única solução que teria aqui pra melhorar seria essa mesmo, tá aumentando funcionário [...] acho que ficaria ideal pra todo mundo né, tanto [universidade] ficaria satisfeita com o serviço melhor, quanto nós pra trabalhar né. Mas infelizmente é um problema que vem de lá né... se fosse na unidade a gente teria como resolver, tentar resolver, mas é uma coisa que vem de cima... a gente não tem como chegar lá né." (Heloísa, encarregada de unidade)

No que diz respeito ao reconhecimento, as participantes sugeriram um aumento no salário e nos benefícios oferecidos e uma melhoria na comunicação entre os superiores da empresa terceirizada e os agentes de limpeza. Algumas funcionárias também realizaram sugestões relacionadas ao oferecimento de incentivos e prêmios como forma de reconhecimento pelo trabalho realizado. Por fim, 4 das agentes que trabalhavam de Segunda a Sábado sugeriram que o trabalho fosse reorganizado e realizado apenas de Segunda a Sexta. 
“[...] alguma coisa que motivasse mais... tipo cê trabalhar o mês inteiro e ter tipo um dia de folga [...] um prêmio no final do mês pra quem não faltasse, trabalhasse certo... não sei, alguma motivação que segurasse mais [...]." (Jéssica, agente de limpeza)

As sugestões fornecidas foram sintetizadas na Figura 24, assim como as respectivas frequências e os níveis a que correspondem.

Figura 23 - Sugestões de melhoria fornecidas pelas participantes, frequência, nível a que se referem e exemplos re relatos

\begin{tabular}{|c|c|c|c|}
\hline Sugestões & Frequência & Nível & Exemplo de relato \\
\hline $\begin{array}{l}\text { Contratação de } \\
\text { mais funcionários }\end{array}$ & 11 & Macro & $\begin{array}{c}{[\ldots] \text { eu queria que eles contratasse mais }} \\
\text { gente, porque tem muita gente que tá } \\
\text { trabalhando demais né, judiando demais } \\
\text { né [...]." (Fernanda, agente de limpeza) }\end{array}$ \\
\hline $\begin{array}{l}\text { Aumento no } \\
\text { salário }\end{array}$ & 6 & Macro & $\begin{array}{c}\text { "Eu mudaria o salário (risos), com } \\
\text { certreza... o salário, ou colocaria um } \\
\text { convênio, qualquer coisa assim }[. . .] . " \\
\text { (Amanda, agente de limpeza) }\end{array}$ \\
\hline $\begin{array}{l}\text { Retirada do } \\
\text { Sábado como dia } \\
\text { de trabalho }\end{array}$ & 4 & Macro & $\begin{array}{c}\text { “Eu mudaria o sábado, porque o sábado } \\
\text { cê perde ele. Cê vem aqui, cê fica até } \\
11 \text { h, cê nem faz as coisa da sua casa e } \\
\text { nem fica [...] Porque cê perde muito } \\
\text { tempo, né??" (Camila, agente de limpeza) }\end{array}$ \\
\hline $\begin{array}{l}\text { Introdução de } \\
\text { formas concretas } \\
\text { de } \\
\text { reconhecimento }\end{array}$ & 2 & Macro & $\begin{array}{l}\text { "[...] alguma coisa que motivasse mais... } \\
\text { tipo cê trabalhar o mês inteiro e ter tipo } \\
\text { um dia de folga [...] um prêmio no final } \\
\text { do mês pra quem não faltasse, } \\
\text { trabalhasse certo... não sei, alguma, } \\
\text { motivação que segurasse mais [...]." } \\
\text { (Jéssica, agente de limpeza) }\end{array}$ \\
\hline $\begin{array}{l}\text { Melhoria no } \\
\text { relacionamento } \\
\text { entre superiores e } \\
\text { agentes }\end{array}$ & 1 & Meso & $\begin{array}{c}\text { "Eu mudaria a maneira dos líderes, dos } \\
\text { chefes tratar os funcionários... tratar eles } \\
\text { com mais respeito, tratar os menores com } \\
\text { mais igualdade um pouquinho, tratar } \\
\text { igual seres humanos [...]." (Giovana, } \\
\text { agente de limpeza) }\end{array}$ \\
\hline $\begin{array}{l}\text { Aumento do } \\
\text { apoio entre as } \\
\text { agentes }\end{array}$ & 1 & Meso & $\begin{array}{c}\text { “[...] um quadro de funcionário que, né, } \\
\text { um ajudasse mais o outro, em } \\
\text { companheirismo, essas coisa, invés de } \\
\text { falar, de criticar, ajudar né. Essa parte } \\
\text { eu mudaria [...]." (Jéssica, agente de } \\
\text { limpeza) }\end{array}$ \\
\hline
\end{tabular}

Fonte: elaboração da autora. 


\subsection{Triangulação e síntese dos dados}

A partir das análises dos dados quantitativos e qualitativos, foi possível realizar a triangulação dos resultados encontrados por meio da comparação entre os dados obtidos por ambas as análises. Tal comparação permitiu a confirmação de alguns dos resultados e a contraposição e complementação de outros.

Os seguintes fatores de risco psicossocial foram identificados pelas análises quantitativas e qualitativas: a baixa influência no ambiente de trabalho, o baixo apoio social dos colegas de trabalho e dos superiores, a baixa previsibilidade, relacionada às diferenças entre o trabalho prescrito e o trabalho real, as exigências emocionais, relacionadas à necessidade de lidar com relacionamentos interpessoais no ambiente de trabalho, o conflito entre o trabalho e a família, o ritmo de trabalho acelerado, as exigências cognitivas, relacionadas à necessidade de manter a atenção constante e a insegurança.

Os fatores de risco psicossocial conflito de papeis e compromisso com o trabalho foram identificados como fatores de risco apenas pela análise quantitativa e não foram mencionados de forma direta nas entrevistas realizadas com as participantes.

Por fim, os fatores de risco psicossocial identificados apenas pela análise qualitativa foram: salário e benefícios insuficientes, exigências quantitativas, baixo reconhecimento, número insuficiente de trabalhadores, poucas possibilidades de desenvolvimento, atribuição desigual das atividades e conteúdo das tarefas, espaço físico mal planejado, alto controle do desempenho, elevado risco de intoxicação e contaminação e esforço físico intenso. Deve-se destacar que os fatores relacionados ao salário e benefícios, às exigências quantitativas, ao reconhecimento e às possibilidades de desenvolvimento foram identificados como favoráveis aos trabalhadores na análise quantitativa. 


\section{Capítulo 6. Discussão}

\section{Objetivo do capítulo 6}

Este capítulo tem como objetivo discutir os resultados encontrados, relacionando-os com os objetivos estabelecidos e com os resultados apresentados pelos estudos considerados na revisão sistemática da literatura.

Este estudo visou identificar os fatores de risco psicossocial que podem interferir no estresse e na saúde de agentes de limpeza terceirizados, assim como apontar ações e estratégias organizacionais que possam minimizar a influência de tais fatores. Sendo assim, com a finalidade de facilitar a organização do texto a discussão foi dividida em duas seções: uma relacionada à identificação dos fatores de risco psicossocial e suas relações com o estresse e a saúde e outra referente à identificação de estratégias organizacionais.

\subsection{Fatores de risco psicossocial e suas relações com o estresse e a saúde}

Assim como apresentado no capítulo anterior, os fatores de risco psicossocial identificados nas análises quantitativa e qualitativa foram: a baixa influência no ambiente de trabalho, o baixo apoio social dos colegas de trabalho e dos superiores, a baixa previsibilidade e diferenças entre o trabalho prescrito e o trabalho real, as exigências emocionais e a necessidade de lidar com relacionamentos interpessoais no ambiente de trabalho, o conflito entre o trabalho e a família, o ritmo de trabalho acelerado, as exigências cognitivas e a necessidade de manter a atenção constante e a insegurança.

Deve-se destacar que o fator exigências emocionais teve uma correlação moderada positiva com a dimensão estresse e que a escala de Exigências no trabalho teve uma correlação moderada negativa com a dimensão saúde. Tais dados são condizentes com os relatos das participantes, que apontaram as dificuldades encontradas nos relacionamentos com colegas, funcionários da universidade e superiores como uma das principais fontes de estresse no ambiente de trabalho, que somado às exigências quantitativas, ao aumento no ritmo de trabalho e à necessidade de estarem sempre atentas, pode resultar em alterações significativas na saúde das mesmas. 
Com exceção dos fatores previsibilidade e exigências cognitivas, todos os outros fatores de risco psicossocial identificados neste estudo por ambas as análises também foram identificados nas pesquisas apresentadas na revisão sistemática da literatura (Alvarez et al., 2007; Budhwar et al., 2009; Chillida \& Cocco, 2004; D’Cruz \& Noronha, 2008; Deery et al., 2013; Druck, 2016; Gemma et al., 2017; Hechanova, 2013; Hsiao \& Mor Barak, 2014; Jain et al., 2013; Kesavachandran et al., 2006; Nadeem, 2009; Papadopoulos et al., 2010; Quinlan \& Bohle, 2008; Raja \& Bhasin, 2014; Ram et al., 2014; Ratnesh et al., 2016; Revathi, 2016; Santos et al., 2009; Seklecka et al., 2013; Snell et al., 2015; Taylor et al., 2013; Thite, 2010; Zuberi, 2011).

Em relação ao fator compromisso com o trabalho, identificado apenas pela análise quantitativa, acredita-se que este não foi apontado pela análise qualitativa pois tal variável não fez parte do roteiro de entrevista semiestruturado utilizado, de modo que não havia questões referentes a ela. O fator conflito de papeis, por sua vez, também foi identificado apenas pela análise quantitativa, apesar de inserido no roteiro de entrevista utilizado com as participantes, e foi verificada a existência de correlação positiva com o estresse. A partir deste dado, pode-se depreender que os instrumentos de medida, tanto o questionário quanto o roteiro de entrevista, podem apresentar erros em relação à mensuração dos constructos, e que as participantes podem ter apresentado dificuldade na compreensão e interpretação dos instrumentos.

Tais limitações também foram constatadas a partir da identificação dos fatores de risco psicossocial exigências quantitativas, reconhecimento e possibilidades de desenvolvimento apenas pela análise qualitativa e não pela análise quantitativa. $\mathrm{O}$ fator exigências quantitativas obteve uma correlação moderada negativa com a variável saúde e foi identificado como fator de risco psicossocial pela análise qualitativa, porém obteve uma média baixa e não foi identificado como fator de risco psicossocial pela análise quantitativa.

Tais resultados indicam que esta escala do COPSOQ II pode apresentar erros em sua construção e evidencia a necessidade de tal instrumento passar por uma validação e adaptação ao contexto brasileiro e por análises estatísticas mais robustas, como a análise fatorial exploratória e confirmatória. A baixa correlação entre as escalas e as dimensões do instrumento também indica a presença de falhas no COPSOQ II. Deve-se destacar que as propriedades psicométricas das medidas que compõem a versão média do COPSOQ I foram avaliadas em um estudo publicado por Silva, Wendt e Argimon (2017), cujo objetivo foi apresentar uma versão curta do instrumento adaptado ao 
contexto brasileiro. Entretanto, não foram identificados estudos semelhantes realizados com o COPSOQ II.

Em relação às participantes, em alguns casos elas demonstraram apreensão no preenchimento do COPSOQ II, principalmente no que diz respeito ao receio de tal questionário ser entregue aos superiores e ser utilizado como forma de avaliação ou justificativa para a demissão das mesmas. Este acontecimento pode ter influenciado os resultados encontrados, gerando diferenças na identificação dos fatores de risco psicossocial. Ademais, tal receio corrobora os relatos das participantes de existir uma constante avaliação e controle do desempenho no ambiente de trabalho por parte dos superiores.

Por fim, a partir da análise qualitativa foi possível identificar os fatores de risco psicossocial salário e benefícios, número de trabalhadores, conteúdo e divisão das tarefas, espaço físico, controle do desempenho, risco de intoxicação e contaminação e esforço físico. Tais variáveis não fizeram parte do COPSOQ II, e supõe-se que devido a isso elas não foram identificadas pela análise quantitativa.

A partir desses dados apresentados e discutidos, destaca-se a relevância do método misto enquanto método que permitiu a comparação dos resultados obtidos a partir da análise quantitativa e qualitativa. Essa comparação possibilitou a confirmação e complementação dos resultados encontrados em cada análise e a identificação de algumas divergências nos resultados encontrados, o que permite ao pesquisador repensar em sua pesquisa e reconhecer possíveis erros nos instrumentos utilizados ou no procedimento empregado, de forma geral.

No que diz respeito às relações entre os fatores de risco psicossocial identificados e o estresse e a saúde das participantes, foi possível estabelecer algumas relações a partir da análise qualitativa, sendo que parece haver relação entre tais variáveis e características específicas da terceirização e do trabalho de limpeza, além de questões referentes ao gênero das participantes.

Entre as especificidades do trabalho terceirizado, destaca-se a presença de dupla hierarquia e a influência do contrato de trabalho entre a universidade e a empresa terceirizada na rotina das agentes de limpeza. $\mathrm{O}$ fato das trabalhadoras terceirizadas responderem a duas figuras hierárquicas, sendo elas os superiores da empresa terceirizada e os gestores da universidade, aumenta a complexidade das relações interpessoais e, consequentemente, gera maior exigência emocional por parte das agentes. Essas relações também interferem no trabalho das participantes à medida que 
intensificam a possibilidade de realocação das mesmas devido a desentendimentos não só com as colegas de trabalho e superiores da empresa terceirizada, como também com os alunos e funcionários da universidade. Tal possibilidade de realocação pode estimular a percepção de insegurança no trabalho, conforme apontado por algumas participantes. Neste contexto, a avaliação do desempenho e o controle são realizados tanto pela empresa terceira quanto pela universidade, sendo que tal configuração intensifica a preocupação do trabalhador em garantir uma avaliação de desempenho elevada como tentativa de assegurar o emprego atual (Zanelli et al., 2010).

O contrato entre a universidade e a empresa terceira, por sua vez, parece exercer grande influência na rotina de trabalho das agentes de limpeza. A partir do contrato são definidos os serviços a serem realizados e a verba disponível para tal, sendo que o número de funcionários contratados e a disponibilidade dos materiais e produtos de limpeza depende exclusivamente da verba indicada no contrato. A definição dos serviços a serem executados e sua frequência reduzem a possibilidade das agentes de modificar o próprio trabalho, e a alteração frequente dessa definição dificulta que elas acompanhem as alterações realizadas no contrato, o que contribui para a execução de tarefas além daquelas necessárias e, consequentemente, para a sobrecarga de trabalho.

Os cortes de verba realizados pela universidade contribuíram para a redução no número de funcionários, o que gerou a necessidade de redistribuição das tarefas e um aumento na quantidade de trabalho e no ritmo para executá-lo. O aumento na quantidade de trabalho gerou maior esforço físico das agentes, aumentando o risco de lesões e acidentes de trabalho, além de contribuir com a insatisfação dos funcionários da universidade, que não têm todas as suas demandas atendidas, e para a diminuição do suporte entre as participantes, que relataram não ter tempo suficiente para dar auxílio umas às outras. A diminuição no número de funcionários também intensifica a insegurança relacionada ao medo de ser desligada da empresa e exerce um papel importante no controle do desempenho pelas próprias agentes, que permanecem atentas ao trabalho com a finalidade de evitar qualquer deslize que justifique sua demissão.

A partir dessa reflexão, nota-se que o contrato de trabalho terceirizado parece ser uma das principais características do trabalho terceirizado que reflete a flexibilidade deste tipo de arranjo. Segundo Lima (2010), a flexibilidade é uma característica fundamental da terceirização, e consiste essencialmente na adaptação da organização às exigências do mercado e na redução dos gastos relacionados à força de trabalho. Nesse contexto, as condições de trabalho tornam-se flexíveis, principalmente no que diz 
respeito aos horários e carga de trabalho, que tendem a gerar uma intensificação do trabalho devido ao esforço em eliminar os tempos ociosos e aumentar a produção (Garza et al., 2012). A redução dos gastos, principalmente àqueles relacionados à força de trabalho, reflete na contratação de menos funcionários e na diminuição do salário e do investimento em treinamentos e equipamentos adequados (R. Silva, 2015; Vasapollo, 2005).

As novas formas de organização do trabalho em que se insere a terceirização, caracterizadas pelo regime de acumulação flexível, geralmente são compostas por um número reduzido de funcionários responsáveis pela execução de um número elevado de tarefas. Além disso, a reestruturação produtiva das organizações, a constante redução no número de funcionários e a contratação de trabalhadores temporários contribuem para a percepção de insegurança no trabalho, que tem crescido nas últimas décadas (Abramides \& Cabral, 2003; Kompier, 2006; Sparks et al., 2001). A percepção da diminição do controle sobre o próprio trabalho também tem sido apontada na literatura como resultado da flexibilização das formas de trabalho. Segundo Sparks et al. (2001), tal percepção é resultado da insegurança no trabalho, do aumento do ritmo de trabalho e da necessidade de adaptação constante dos trabalhadores às mudanças no contexto de trabalho, como a introdução de novas tecnologias.

Segundo Schabracq e Cooper (2000), flexibilização das relações de trabalho contribui para a diferenciação de dois grupos de trabalhadores: um grupo de trabalhadores contratados regularmente, com níveis elevados de qualificação e que executam tarefas diversificadas, e um grupo de trabalhadores temporários, com baixo nível de qualificação e que executam tarefas relativamente simples. O segundo grupo de trabalhadores é apontado como aquele que mais sofre as consequências negativas decorrentes do trabalho flexível.

Características específicas do trabalho de limpeza também parecem exercer grande influência sobre o trabalho das agentes, podendo intensificar a exposição aos fatores de risco psicossocial. Sabe-se que este serviço envolve a realização de tarefas repetitivas que exigem intenso esforço físico (Gemma et al., 2017), baixa qualificação e remuneração (Diogo, 2005; Seifert \& Messing, 2006) e exposição a riscos químicos, físicos, biológicos e ergonômicos (Araújo et al., 2009; Gemma et al., 2017). Além disso, é um trabalho socialmente desvalorizado principalmente devido às tarefas consideradas desagradáveis que compõem tal atividade, à baixa remuneração e 
qualificação dos profissionais (Diogo, 2005; Seifert \& Messing, 2006) e às poucas oportunidades de crescimento profissional (Krause et al., 2005).

Por ser um trabalho que exige a realização de tarefas repetitivas e intenso esforço físico e expõe os trabalhadores a riscos, a possibilidade de modificar o próprio trabalho torna-se reduzida, o risco de lesões e acidentes de trabalho aumenta e a necessidade de se manter atento torna-se fundamental. Em relação ao reconhecimento, a partir dos dados coletados foi possível verificar que a baixa valorização do serviço de limpeza contribuiu para o retrabalho das agentes, para dificuldades nos relacionamentos interpessoais, muitas vezes pautados em relações de humilhação e desconfiança que poderiam levar à alocação das agentes, gerando insegurança, e para a ausência de um local destinado ao descanso e estoque dos materiais de trabalho em uma das unidades participantes. O salário baixo, por sua vez, levou algumas participantes a buscar outras fontes de renda, o que intensificou o conflito entre o trabalho e a família e a sobrecarga de trabalho realizado por elas.

A questão de gênero também parece estar envolvida com os fatores de risco psicossocial no trabalho de limpeza terceirizado. Segundo Barros (2014), historicamente a mulher é responsável por ficar em casa e cuidar dos filhos e dos serviços domésticos, enquanto o homem é aquele que sai para trabalhar e é encarregado de sustentar a família. A partir do estabelecimento desse modelo pré-definido dos papeis sociais masculino e feminino, é intensificada a segregação dos trabalhos, refletida na restrição das ocupações femininas e nas desvantagens de salários, carreiras e condições de trabalho. Sendo assim, o serviço de limpeza é frequentemente composto em sua maioria por mulheres, assim como observado nesta pesquisa e relatado em estudos anteriores (Araújo et al., 2009; Chillida \& Cocco, 2004; Gemma et al., 2017; Krause et al., 2005; Petean et al., 2014). Tal papel social empregado às agentes de limpeza contribuiu para a intensificação do trabalho das participantes e para o conflito entre o trabalho e a família, pois além de trabalharem na empresa terceirizada, e em alguns casos em outros locais, elas também eram responsáveis pela limpeza e manutenção da casa.

Para facilitar a visualização de tais relações entre os fatores de risco psicossocial, as características da terceirização e do serviço de limpeza e as questões de gênero, foram elaboradas as Figuras 25, 26 e 27, expostas a seguir. Deve-se destacar que tais resultados são exploratórios e as relações entre as variáveis são hipóteses formuladas a partir da análise dos dados qualitativos coletados. Deste modo, faz-se necessária a 
realização de estudos mais aprofundados que testem e confirmem a existência de tais relações.

Figura 25 - Relações entre as características da terceirização e os fatores de risco psicossocial

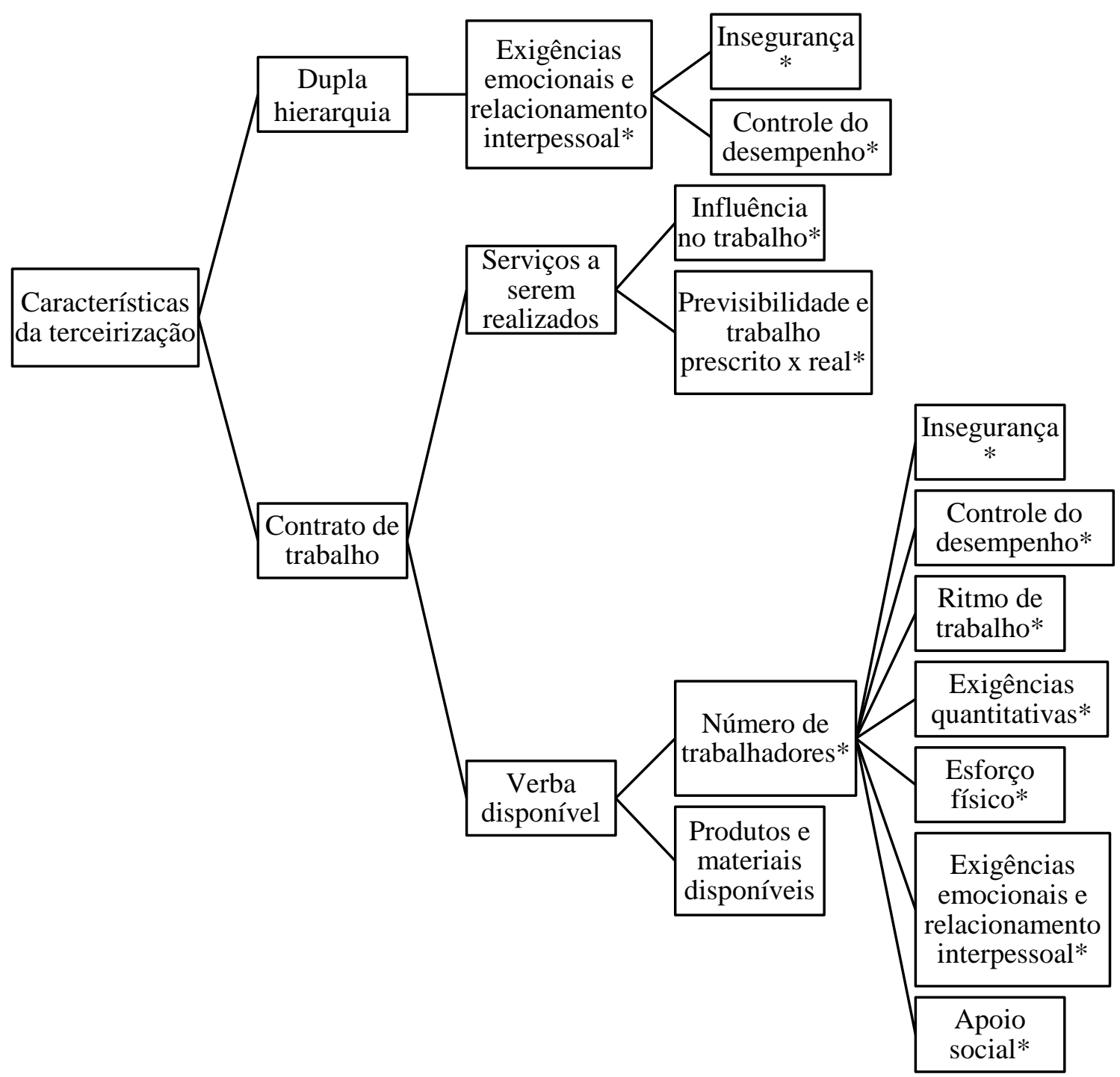

*Fatores de risco psicossocial identificados

Fonte: elaboração da autora. 
Figura 26 - Relações entre as características do serviço de limpeza e os fatores de risco psicossocial

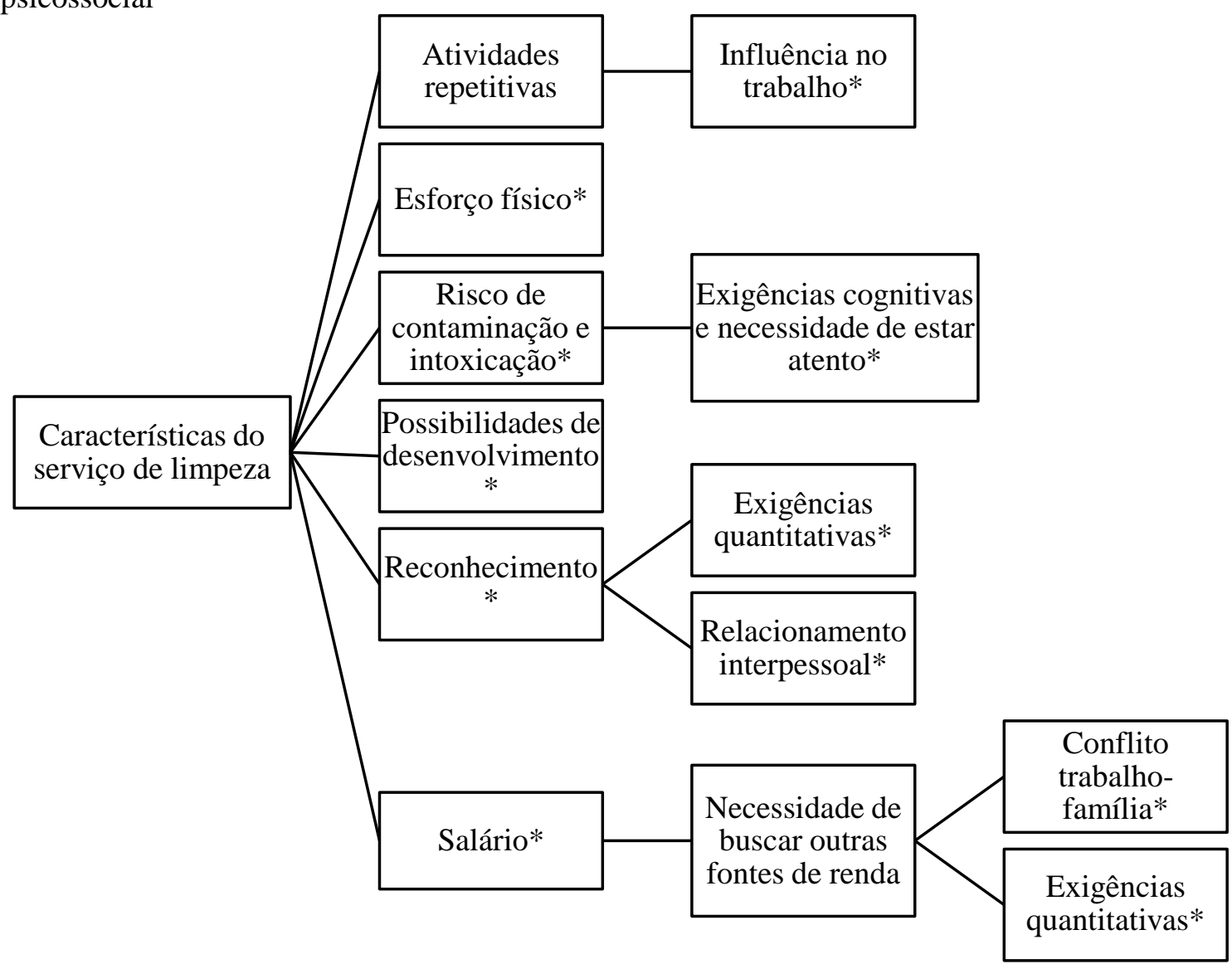

*Fatores de risco psicossocial identificados

Fonte: elaboração da autora.

Figura 27 - Relações entre o gênero e os fatores de risco psicossocial

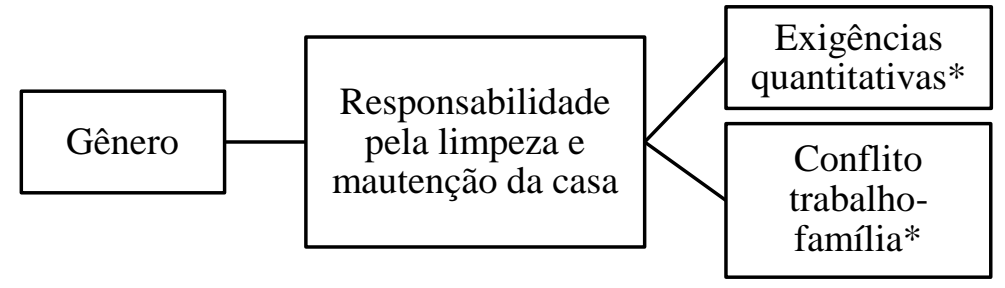

*Fatores de risco psicossocial identificados

Fonte: elaboração da autora.

\subsection{Estratégias organizacionais}

Entre as sugestões de melhoria para o trabalho de limpeza terceirizado, fornecidas tanto pelas agentes de limpeza quanto pelos seus gestores, a maioria era de nível macro, ou seja, referiu-se a mudanças organizacionais, e duas fizeram referência a 
alterações no âmbito do relacionamento interpessoal. Com exceção da sugestão de alteração dos dias de trabalho, todas as propostas de mudança estavam relacionadas diretamente aos fatores de risco psicossocial relacionados ao contexto de trabalho. Sendo assim, foram reconhecidas como sugestões de intervenção primária.

Segundo Leka e Houdmont (2010) e Schabracq et al. (2003), as intervenções que buscam promover o bem-estar no ambiente de trabalho são estratégias cujo objetivo é romper as relações prejudiciais entre o trabalho e a saúde dos trabalhadores. Tais estratégias podem ser classificadas em 3 níveis, sendo eles o nível primário, que busca intervir nas causas dos problemas, o nível secundário, cujo foco é a redução ou eliminação dos prejuízos que os trabalhadores vivenciam, mas não sua causa, e o nível terciário, direcionado aos trabalhadores que já são acometidos pelos danos relacionados às condições de trabalho.

Apesar da necessidade de mais estudos referentes às intervenções no ambiente de trabalho, as intervenções primárias são apontadas pela literatura como as mais efetivas em médio e longo prazo, visto que impactam diretamente a distribuição, organização e gestão do trabalho, ou seja, as variáveis que podem gerar prejuízos aos trabalhadores, e não focam apenas em seus efeitos indiretos. Entretanto, a organização desse tipo de intervenção pode exigir tempo, esforço e recursos financeiros, o que frequentemente é apontado como um obstáculo pelos gestores e gera certa resistência (Leka \& Houdmont, 2010).

Sendo assim, reconhecer e admitir os prejuízos que as condições de trabalho podem causar no estresse e na saúde dos trabalhadores, e também os danos que podem afetar a própria organização, é um passo fundamental para o planejamento de mudanças no ambiente de trabalho. É preciso que a gestão central da organização mantenha-se envolvida nesse processo e tenha ciência de que tais modificações geram benefícios para os trabalhadores e para a própria organização, porém demandam tempo e incluem alterações em nível organizacional, que visam oferecer maior suporte, segurança e reconhecimento aos trabalhadores (Zanelli et al., 2010).

Alguns autores sugerem a execução de atos informativos sobre o estresse no ambiente de trabalho, como a realização de palestras sobre o tema, com o objetivo de sensibilizar e informar os gestores e os funcionários acerca dos prejuízos que as condições de trabalho podem exercer para a saúde dos trabalhadores e para a própria organização. Outra ação sugerida é o estabelecimento de um comitê de controle do estresse nas empresas, composto por representantes de todos os níveis e divisões da 
organização, incluindo os gestores com autoridade e poder de decisão (Zanelli et al., 2010). A realização de auditorias internas para a avaliação constante do bem-estar dos trabalhadores e a criação de um novo posto de trabalho designado para avaliar, acompanhar, propor e implementar intervenções referentes à saúde dos trabalhadores também são estratégias sugeridas pela literatura (Schabracq et al., 2003). 


\section{Capítulo 7. Considerações finais}

Entre as principais contribuições teóricas do presente estudo, encontra-se o cumprimento dos objetivos estabelecidos: a identificação dos fatores de risco psicossocial que podem interferir no estresse e na saúde de agentes de limpeza terceirizados e a apresentação de propostas de ações e estratégias organizacionais que minimizem a influência dos fatores de risco psicossocial e contribuam para a melhoria da qualidade de vida dos profissionais, além da realização de correlações entre os fatores de risco psicossocial, o estresse e a saúde, e a identificação de características específicas da terceirização que podem interferir no estresse e na saúde.

Outra contribuição diz respeito à organização e sistematização dos fatores de risco psicossocial presentes no contexto de trabalho terceirizado, visto que o número de estudos realizados neste contexto ainda é escasso e os fatores de risco psicossocial já identificados na literatura geralmente são apresentados de forma isolada e difusa, sem que haja associação entre eles. Mais escassos ainda são os estudos voltados para os fatores de proteção no trabalho, ou seja, fatores relacionados ao trabalho que proporcionam amparo e proteção e que são considerados favoráveis à saúde dos trabalhadores, promovendo a construção de organizações saudáveis (Zanelli \& Kanan, 2018).

A partir dos fatores de risco psicossocial identificados, foi possível a realização de uma análise crítica em relação a tais fatores. O trabalho terceirizado vem sendo cada vez mais utilizado e foi legalizado para todas as ocupações a partir da aprovação do projeto de Lei 4330/2004, que autoriza a terceirização para qualquer tipo de atividade. Frente a isso, é essencial que se compreenda quais são os fatores de risco psicossocial a que esses trabalhadores estão submetidos, suas origens e as possíveis consequências para os trabalhadores terceirizados, e os achados obtidos neste trabalho podem favorecer a compreensão de tais fatores e suas relações com o estresse e a saúde.

Observou-se que questões referentes à dupla hierarquia e ao contrato de trabalho entre a empresa contratante e a terceirizada parecem contribuir para o surgimento de algumas particularidades no que diz respeito à origem e exposição dos fatores de risco psicossocial, assim como características específicas do serviço de limpeza e questões referentes ao gênero das participantes. Estes resultados evidenciam que a terceirização gera modificações na organização do trabalho e nos relacionamentos entre os indivíduos 
e empresas, e tais alterações podem contribuir significativamente para a emergência de fatores de risco psicossocial.

A principal contribuição metodológica do estudo refere-se à utilização do método misto, que possibilitou a identificação de fatores de risco psicossocial de forma mais abrangente e completa, já que a utilização de apenas um método não seria suficiente para identificar todos os fatores de risco psicossocial apontados nesta pesquisa. Além disso, a comparação entre as análises quantitativa e qualitativa contribuiu para o reconhecimento das falhas e limitações dos instrumentos utilizados e evidenciou a necessidade de se realizar estudos estatisticamente mais robustos com o COPSOQ II no contexto brasileiro.

Outra contribuição metodológica diz respeito ao desenvolvimento de técnicas para a coleta de dados com participantes de baixa escolaridade. Sabe-se que o número de pesquisas realizadas com trabalhadores de baixa escolaridade na área de Psicologia Organizacional e do Trabalho é escasso, o que gera problemas de ordem epistemológica, visto que os pesquisadores podem chegar a conclusões equivocadas em relação a seus objetos de estudo (Borges \& Pinheiro, 2002).

As contribuições práticas deste estudo referem-se à compreensão dos fatores de risco psicossocial e suas relações com o estresse e a saúde, além das orientações para melhoria do trabalho terceirizado. Tais dados podem ser utilizados por profissionais da área de Recursos Humanos, Gestão de Pessoas e Segurança do Trabalho, de modo que reflitam acerca da organização e aspectos que compõem a terceirização enquanto prática administrativa, a fim de se reduzir as fontes de estresse no trabalho e prevenir que esses fatores se transformem em um problema significativo para a saúde e segurança dos funcionários e para a empresa. Neste quesito, tais profissionais podem atuar tanto na identificação dos fatores de risco psicossocial dentro da organização quanto na sugestão e implementação de estratégias que visam à redução dos aspectos negativos relacionados à prática da terceirização, além da mensuração dos resultados de tais estratégias.

Além disso, a identificação de estratégias de níveis meso e macro que podem trazer melhorias para o trabalho terceirizado evidenciam que o estresse, a saúde e bemestar dos trabalhadores não dependem exclusivamente de características individuais, mas sofrem grande interferência de variáveis presentes no contexto de trabalho. Sendo assim, tal evidência enfatiza a importância da Psicologia Organizacional e do Trabalho enquanto área de conhecimento que permite a exploração de variáveis organizacionais. 
Pontua-se que ao longo do desenvolvimento do presente estudo foram vivenciadas dificuldades em relação à resistência dos agentes de limpeza em participar da pesquisa, o que resultou em um número reduzido de participantes. Devido a isso e ao tempo limitado para a realização deste estudo, não foi possível ter acesso aos agentes de limpeza de todas as unidades da universidade, o que pode ter influenciado os resultados obtidos e impede a generalização dos resultados para outros contextos, além de impossibilitar a realização de testes de relações entre as variáveis, a fim de se confirmar a existência de tais relações e sua relevância. Outras limitações deste estudo referem-se à utilização do COPSOQ II, instrumento não validado e adaptado ao contexto brasileiro e que pode apresentar limitações e falhas na elaboração de suas escalas e à mensuração das variáveis estresse e saúde a partir de um número reduzido de questões de autorrelato, visto que é uma técnica que se utiliza de medidas subjetivas.

Diante dos resultados e discussões promovidas na presente pesquisa, sugere-se a realização da seguinte agenda de pesquisa:

- Realizar replicações deste estudo com a inclusão da mensuração de variáveis individuais para a compreensão do fenômeno do estresse no ambiente de trabalho;

- Realizar replicações deste estudo em outros contextos de trabalho terceirizado, a fim de se comparar os resultados encontrados;

- Realizar a validação e adaptação do COPSOQ II para o contexto brasileiro, avaliar a construção de suas escalas e realizar análise fatorial exploratória e confirmatória, a fim de se corrigir as falhas do instrumento;

- Construir e validar um instrumento que englobe todos os fatores de risco psicossocial identificados no contexto de trabalho terceirizado;

- Analisar diferenças entre gêneros, idade, tempo de trabalho na empresa e ocupação no que diz respeito à percepção de estresse e saúde, assim como aos fatores de risco psicossocial envolvidos;

- Empreender análises estatísticas robustas com a finalidade de testar distintos relacionamentos entre as variáveis estudadas, incluindo relações de mediação, moderação, predição e correlação;

- Realizar estudos longitudinais que proponham intervenções que visem à redução do estresse e da exposição aos fatores de risco psicossocial nas organizações e que avaliem seus resultados ao longo do tempo; 
- Realizar estudos que identifiquem e auxiliem na compreensão dos fatores de proteção psicossocial no contexto de trabalho brasileiro. 


\section{Referências $^{1}$}

Abbad, G., Puente-Palácios, K., \& Gondim, S. M. G. (2014). Abordagens metodológicas em Psicologia Organizacional e do Trabalho. Revista Brasileira de $\begin{array}{llll}\text { Psicologia, } & \text { 1(2), 71-88. } & \text { Recuperado }\end{array}$ https://www.researchgate.net/profile/Sonia_Guedes-

Gondim/publication/269689528_Abordagens_Metodologicas_em_Psicologia_Organ izacional_e_do_Trabalho/links/54b5687e0cf28ebe92e5f439/Abordagens-

Metodologicas-em-Psicologia-Organizacional-e-do-Trabalho.pdf.

Abrahão, J., Sznelwar, L. I., Silvino, A., Sarmet, M., \& Pinho, D. (2009). Introdução à Ergonomia: da prática à teoria. São Paulo, SP: Editora Blucher.

Abramides, M. B. C., \& Cabral, M. S. R. (2003). Regime de acumulação flexível e saúde do trabalhador. São Paulo em Perspectiva, 17(1), 3-10. doi:10.1590/S010288392003000100002

Alvarez, D., Suarez, J. D., Pereira, R., Figueiredo, M., \& Athayde, M. (2007). Reestruturação produtiva, terceirização e relações de trabalho na indústria petrolífera offshore da Bacia de Campos (RJ). Gestão \& Produção, 14(1), 55-68. doi:10.1590/S0104-530X2007000100006

Andrea, H., Bültmann, U., van Amelsvoort, L. G., \& Kant, Y. (2009). The incidence of anxiety and depression among employees - the role of psychosocial work characteristics. Depression and Anxiety, 26(11), 1040-1048. doi:10.1002/da.20516

Antunes, R. (2002). As novas formas de acumulação de capital e as formas contemporâneas do estranhamento (alienação). Caderno CRH, 15(37), 23-45. Recuperado de https://portalseer.ufba.br/index.php/crh/article/view/18601/11975.

Araújo, A. P., Jesus, M. S. B., Aquino, M. C., \& Longhi, M. (2009). Condições de trabalho do pessoal de um serviço terceirizado de limpeza hospitalar no ano de 2007. Saúde Coletiva, 6(34), 244-248. Recuperado de http://www.redalyc.org/html/842/84212106005/.

Assunção-Matos, A., \& Bicalho, P. P. G. (2016). O trabalho, a terceirização e o Legislativo brasileiro: paradoxos e controvérsias. Revista Psicologia: Organizações e Trabalho, 16(2), 120-129. doi:10.17652/rpot/2016.2.644

Azevedo, F. C. (2014). Consultoria empresarial de serviço social: Expressões da precarização e da terceirização profissional. Serviço Social \& Sociedade, 118, 318338. doi:10.1590/S0101-66282014000200006

Azorín, J. M., \& Cameron, R. (2010). The application of mixed methods in organisational research: A literature review. The Electronic Journal of Business Research Methods, 8(2), 95-105. Recuperado de

\footnotetext{
${ }^{1}$ Referências elaboradas a partir da diretrizes propostas pela American Psychological Association (APA).
} 
https://www.researchgate.net/publication/228933128_The_Application_of_Mixed_ Methods_in_Organisational_Research_A_Literature_Review.

Baltar, P. E. A., \& Krein, J. D. (2013). A retomada do desenvolvimento e a regulação do mercado do trabalho no Brasil. Caderno CRH, 26(68), 273-292. doi:10.1590/S0103-49792013000200005

Bardhan, A. D., \& Kroll, C. A. (2003). The new wave of outsourcing. Fisher Center for Real Estate \& Urban Economics Research Report, 1103, 1-12. doi:10.2139/ssrn.985741

Barros, C. B. (2014). O impacto da cultura organizacional nas relações de trabalho e na construção de identidades: um estudo sobre as mulheres do serviço de limpeza da Universidade de Brasília. Monografia, Faculdade de Comunicação, Universidade de Brasília, Brasília.

Batista, E. L. (2006). Terceirização no Brasil e suas implicações para os trabalhadores. Dissertação de Mestrado, Universidade Estadual de Campinas, Campinas, São Paulo.

Beehr, T. A., \& Newman, J. E. (1978). Job stress, employee health, and organizational effectiveness: a facet analysis, model, and literature review. Personnel Psychology, 31, 665-699.

Belkic, K. L., Landsbergis, P. A., Schnall, P. L., \& Baker, D. (2004). Is job strain a major source of cardiovascular disease risk? Scandinavian Journal of Work, Environment \& Health, 30(2), 85-128. doi:10.5271/sjweh.769

Benach, J., Muntaner, C., Benavides, F. G., Amable, M., \& Jodar, P. (2002). A new occupational health agenda for a new work environment. Scandinavian Journal of Work, Environment \& Health, 28(3), 191-196. doi:10.5271/sjweh.664

Borg, V., \& Kristensen, T. S. (1999). Psychosocial work environment and mental health among travelling salespeople. Work \& Stress: an International Journal of Work, Health \& Organisations, 13(2), 132-143. doi:10.1080/026783799296101

Borges, L. O., \& Pinheiro, J. Q. (2002). Estratégias de coleta de dados com trabalhadores de baixa escolaridade. Estudos de Psicologia, 7, 53-63. doi:10.1590/S1413-294X2002000300007

Boyatzis, R. E. (1998). Transforming qualitative information: thematic analysis and code development. Thousand Oaks, CA: Sage.

Braun, V., \& Clarke, V. (2006). Using thematic analysis in psychology. Qualitative Research in Psychology, 3(2), 77-101. doi:10.1191/1478088706qp063oa

Budhwar, P. S., Varma, A., Malhotra, N., \& Mukherjee, A. (2009). Insights into the indian call centre industry: can internal marketing help high employee turnover? Journal of Services Marketing, 23(5), 351-362. doi:10.1108/08876040910973459 
Camelo, S. H. H., \& Angerami, E. L. S. (2008). Riscos psicossociais no trabalho que podem levar ao estresse: uma análise da literatura. Ciência, Cuidado e Saúde, 7(2), 232-240. doi:10.4025/cienccuidsaude.v7i2.5010

CBO (Classificação Brasileira de Ocupações). Recuperado de http://www.mtecbo.gov.br/cbosite/pages/pesquisas/BuscaPorTituloResultado.jsf.

Chahad, J. P. Z. (2002). Emprego flexível e mercado de trabalho no Brasil. Revista da $\begin{array}{llll}\text { ABET, } & 2(2), & \text { 37-70. } & \text { Recuperado }\end{array}$ http://periodicos.ufpb.br/index.php/abet/article/view/15466/8843.

Chillida, M. S. P., \& Cocco, M. I. M. (2004). Saúde do trabalhador e terceirização: perfil de trabalhadores de serviço de limpeza hospitalar. Revista Latino-Americana de Enfermagem, 12(2), 271-276. doi:10.1590/S0104-11692004000200018

Clott, C. B. (2004). Perspectives on global outsourcing and the changing nature of work. Business and Society Review, 109(2), 153-170. doi:10.1111/j.00453609.2004.00189.x

Codo, W., Soratto, L., \& Vasques-Menezes, I. (2004). Saúde mental e trabalho. In J. E. Zanelli, J. E. Borges-Andrade \& A. V. B. Bastos. Psicologia, organizações e trabalho no Brasil. (pp. 276-299). Porto Alegre, RS: Artmed.

Cooper, C. L., \& Dewe, P. (2004). Stress: a brief history. (1st Ed.). Oxford: Blackwell Publishing.

Cooper, C. L., \& Marshall, J. (1976). Occupational sources of stress: a review of the literature relating to coronary heart disease and mental ill health. Journal of Occupational Psychology, 49, 11-28.

Costa, G., \& Sartori, S. (2005). Flexible work hours, ageing and well-being. International Congress Series, 1280, 23-28. doi:10.1016/j.ics.2005.02.081

Costa, S. G. (2007). O pai que não é o patrão: Vivências de sujeitos terceirizados no Ministério Público do estado do Rio Grande do Sul. Organizações \& Sociedade, 14(42), 97-113. doi:10.1590/S1984-92302007000300006

Cox, T., Griffiths, A., \& Rial-González, E. (2000). Research on work-related stress. Luxembourg: Office of the Official Publications of the European Communities. Recuperado de https://osha.europa.eu/en/tools-andpublications/publications/reports/203.

Creswell, J. W. (2013). Research design: qualitative, quantitative and mixed methods approaches (4th Ed.). California, Thousand Oaks: Sage Publications.

D'Cruz, P., \& Noronha, E. (2008). Doing emotional labour: The experiences of Indian call centre agents. Global Business Review, 9(1), 131-147. doi:10.1177/097215090700900109 
Davis-Blake, A., \& Broschak, J. P. (2009). Outsourcing and the changing nature of work. Annual Review of Sociology, 35(1), 321-340. doi:10.1146/annurev.soc.34.040507.134641

Decreto $n^{o} 2.271$ (1997, 7 de julho). Dispõe sobre a contratação de serviços pela Administração Pública Federal direta, autárquica e fundacional e dá outras providências. Brasília, DF: Presidência da República. Recuperado de http://www.planalto.gov.br/ccivil_03/decreto/d2271.htm.

Deeney, C., \& O’Sullivan, L. (2009). Work related psychosocial risks and musculoskeletal disorders: potential risk factors, causation and evaluation methods. Work, 34(2), 239-248. doi:10.3233/WOR-2009-0921

Deery, S., Nath, V., \& Walsh, J. (2013). Why do off-shored Indian call centre workers want to leave their jobs? New Technology, Work and Employment, 28(3), 212-226. doi:10.1111/ntwe.12013

DIEESE (2004). A terceirização no Setor Público Brasileiro. In Seminário Terceirização: efeitos sobre as relações de trabalho (Caderno do participante). Coleção Seminários de Negociação. São Paulo.

DIEESE (2007). O processo de terceirização e seus efeitos sobre os trabalhadores no Brasil (Relatório Técnico). Rio de Janeiro, RJ.

DIEESE (2017). Terceirização e precarização das condições de trabalho: condições de trabalho e remuneração em atividades tipicamente terceirizadas e contratantes (Nota técnica). São Paulo. Recuperado de https://www.dieese.org.br/notatecnica/2017/notaTec172Terceirizacao.pdf

DIEESE; CUT (2014). Terceirização e desenvolvimento: uma conta que não fecha. Dossiê acerca do impacto da terceirização sobre os trabalhadores e propostas para garantir a igualdade de direitos. São Paulo: DIEESE/CUT. Recuperado de http://www.cut.org.br/system/uploads/ck/files/Dossie-Terceirizacao-eDesenvolvimento.pdf.

Diogo, M. F. (2005). De balde e vassoura na mão: os sentidos do trabalho para as mulheres que exercem suas funções no setor de limpeza e conservação em uma empresa prestadora de serviços em Santa Catarina. Dissertação de Mestrado, Universidade Federal de Santa Catarina, Santa Catarina, Florianópolis.

Druck, G. (2016). Unrestrained outsourcing in Brazil: more precarization and health risks for workers. Cadernos de Saúde Pública, 32(6), e00146315. doi:10.1590/0102$311 \mathrm{X} 00146315$

Druck, G., \& Borges, A. (2002). Terceirização: balanço de uma década. Caderno CRH, 37, 111-139. Recuperado de https://repositorio.ufba.br/ri/handle/ri/2490.

Field, A. (2009). Descobrindo a estatística usando o SPSS. Porto Alegre, RS: Artmed. 
Fontanella, D., Tavares, E., \& Leiria, J. S. (1995). O lado (des) humano da terceirização: o impacto da terceirização nas empresas, nas pessoas e como administrá-lo. (2 $2^{\text {a }}$ Edição). Salvador, BA: Casa da Qualidade.

Garza, E. G., Valencia, A. S., \& Fernández, D. C. (2012). Capital, trabajo y nueva organización obrera. México: Maporrúa.

Gemma, S. F. B., Fuentes-Rojas, M., \& Soares, M. J. B. (2017). Agentes de limpeza terceirizados: entre o ressentimento e o reconhecimento. Revista Brasileira de Saúde Ocupacional, 42(4), 1-10. doi:10.1590/2317-6369000006016

George, D., \& Mallery, M. (2010). SPSS for Windows step by step: a simple guide and reference, 17.0 update (10 $\mathrm{a}$ ed.). Boston: Pearson.

Ghosh, A. K., Bhattacherjee, A., \& Chau, N. (2004). Relationships of working conditions and individual characteristics to occupational injuries: a case-control study in coal miners. Journal of Occupational Health, 46(6), 470-480. Recuperado de https://www.jstage.jst.go.jp/article/joh/46/6/46_6_470/_article.

Glasscock, D. J., Rasmussen, K., Carstensen, O., \& Hansen, O. N. (2006). Psychosocial factors and safety behaviour as predictors of accidental work injuries in farming. Work \& Stress: an International Journal of Work, Health \& Organisations, 20(2), 173-189. doi:10.1080/02678370600879724

Gomes, C. C., \& Oliveira, R. S. (2013). Agentes de limpeza pública: um estudo sobre a relação prazer/sofrimento no ambiente laboral. Psicologia: Ciência e Profissão, 33, 138-153. Retirado de http://www.scielo.br/scielo.php?script=sci_arttext\&pid=S141498932013000500014.

Granjeiro, J. W. (2013). PL 4330: não à terceirização no serviço público. Congresso em Foco. Recuperado de http://congressoemfoco.uol.com.br/opiniao/colunistas/pl-4330nao-a-terceirizacao-no-servico-publico/.

Gravetter, F., \& Wallnau, L. (2014). Essentials of statistics for the behavioral sciences ( $8^{\mathrm{a}}$ ed.). Belmont, CA: Wadsworth.

Grossman, G. M., \& Helpman, E. (2005). Outsourcing in a global economy. Review of Economic Studies, 72(1), 135-159. doi: 10.1111/0034-6527.00327

Harvey, D. (2008). Condição pós-moderna: uma pesquisa sobre as origens da mudança cultural (17 ${ }^{\mathrm{a}}$ Ed.). São Paulo, SP: Edições Loyola.

Hasle, P. (2007). Outsourcing and employer responsibility: a case study of occupational health and safety in the Danish public transport sector. Relations Industrielles, 62(1), 96-117. doi:10.7202/015799ar

Head, J., Stansfeld, S. A., \& Siegrist, J. (2004). The psychosocial work environment and alcohol dependence: a prospective study. Occupational and Environmental Medicine, 61(3), 219-224. doi:10.1136/oem.2002.005256 
Hechanova, R. M. (2013). The call center as a revolving door: a Philippine perspective. Personnel Review, 42(3), 349-365. doi:10.1108/00483481311320444

Hernandes, E., Zamboni, A., Fabbri, S., \& Thommazo, A. (2012). Using GQM and TAM to evaluate StArt - a tool that supports systematic review. CLEI Electronic Journal, 15(1), 1-13. Recuperado de http://www.scielo.edu.uy/scielo.php?script=sci_arttext\&pid=S071750002012000100003.

Holley, S., \& Rainnie, A. (2012). Who cleans up? The declining earnings position of cleaners in Australia. The Economic and Labour Relations Review, 23(1), 143-160. doi:10.1177/103530461202300109

Hsiao, H.-Y., \& Mor Barak, M. E. (2014). Job-related stress, social support, and workfamily conflict among Mexican workers in a multinational company: A casa study of a Korean-owned, US-branded former "sweatshop" in Mexico. International Journal of Social Welfare, 23(3), 309-320. doi:10.1111/ijsw.12065

ILO (1984). Psychosocial factors at work: recognition and control. Report of the Joint ILO/WHO Committee on Occupational Health, Ninth Session, Geneva. Recuperado de http://www.ilo.org/public/libdoc/ilo/1986/86B09_301_engl.pdf.

ILO. (2016). Workplace stress: a collective challenge. World day for safety and health at work. 28 April 2016. Geneva: International Labour Office. Recuperado de http://www.ilo.org/wcmsp5/groups/public/---ed_protect/---protrav/--safework/documents/publication/wcms_466547.pdf.

Jain, A. K., Giga, S. I., \& Cooper, C. L. (2013). Stress, health and well-being: the mediating role of employee and organizational commitment. International Journal of Environmental Research and Public Health, 10(10), 4907-4924. doi:10.3390/ijerph10104907

Jain, A., Leka, S., \& Zwetsloot, G. I. J. M. (2018). Managing health, safety and wellbeing: ethics, responsibility and sustainability. The Netherlands: Springer.

Jick, T. D. (1979). Mixing qualitative and quantitative methods: triangulation in action. Administrative Science Quarterly, 24(4), 602-611. Recuperado de http://www.pm.lth.se/fileadmin/_migrated/content_uploads/Jick_1979_Mixing_qua litative_and_quantitative_methods_-_Triangulation_in_action.pdf.

Joffe, H. (2012). Thematic analysis. In D. Harper \& A. Thompson (Eds.). Qualitative research methods in mental health and psychotherapy: a guide for students and practitioners. (pp. 209-223). Chichester: Wiley-Blackwell.

Jorge, H. R. (2011). Terceirizar, flexibilizar, precarizar: um estudo crítico sobre a terceirização do trabalho. Dissertação de Mestrado, Universidade Estadual de Campinas, Campinas, São Paulo. 
Kahn, R. L., Wolfe, D. M., Quinn, R. P., Snoek, J. D., \& Rosenthal, R. A. (1965). Organizational stress: studies in role conflict and ambiguity. American Sociological Review, 10(1), 125-129. doi:10.2307/2091375

Kesavachandran, C., Rastogi, S. K., Das, M., \& Khan, A. M. (2006). Working conditions and health among employees at information technology - enabled services: a review of current evidence. Indian Journal of Medical Sciences, 60(7), 300-307. doi:10.4103/0019-5359.26606

Kivimäki et al. (2012). Job strain as a risk factor for coronary heart disease: a collaborative meta-analysis of individual participant data. Lancet, 380(9852), 14911497. doi:10.1016/S0140-6736(12)60994-5

Kompier, M. A. J. (2006). New systems of work organization and workers' health. Scandinavian Journal of Work, Environment \& Health, 32(6), 421-430. doi:10.5271/sjweh.1048

Krause, K., Scherzer, T., \& Rugulies, R. (2005). Physical workload, work intensification, and prevalence of pain in low wage workers: results from a participatory research project with hotel room cleaners in Las Vegas. American Journal of Industrial Medicine, 48(5), 326-337. doi:10.1002/ajim.20221

Krein, J. D. (2007). A tendência de flexibilização do tempo de trabalho. Revista ABET, 6(2), 47-72. Recuperado de http://periodicos.ufpb.br/index.php/abet/article/view/15294/8685.

Krein, J. D. (2013). As transformações no mundo do trabalho e as tendências das relações de trabalho na primeira década do século XXI no Brasil. Revista NECAT, 3, 6-25. Recuperado de http://incubadora.periodicos.ufsc.br/index.php/necat/article/view/2785.

Kristensen, T. S., Hannerz, H., Høgh, A., \& Borg, V. (2005). The Copenhagen Psychosocial Questionnaire - a tool for the assessment and improvement of the psychosocial work environment. Scandinavian Journal of Work, Environment \& Health, 31(6), 438-449. doi:10.5271/sjweh.948

Krumm, D. (2013). Estresse, segurança e saúde do empregado. In: Psicologia do Trabalho: uma introdução à Psicologia Industrial/Organizacional. (pp.277-299). Rio de Janeiro, RJ: LTC.

Larsman, P., \& Hanse, J. J. (2009). The impact of decision latitude, psychological load and social support at work on the development of neck, shoulder and low back symptoms among female human service organization workers. International Journal of Industrial Ergonomics, 39(2), 442-446. doi:10.1016/j.ergon.2009.01.002

Leka, S., \& Cox, T. (Eds.). (2008). The European framework for psychosocial risk management: PRIMA-EF. United Kingdom: Institute of Work, Health \& Organisations (I-WHO). Recuperado de http://www.primaef.org/uploads/1/1/0/2/11022736/prima-ef_ebook.pdf. 
Leka, S., Griffiths, A., Cox, T. (2003). Work Organization and Stress. Geneva: World Health Organization.

Leka, S., \& Houdmont, J. (2010). Occupational Health Psychology. Chichester: WileyBlackwell.

Lima, J. C. (2010). A terceirização e os trabalhadores: revisitando algumas questões. Cadernos de Psicologia Social do Trabaho, 13(1), 17-26. doi:10.11606/issn.19810490.v13i1p17-26

Lopes, A. L. S. V., \& Silva, J. R. G. (2009). Expectativas profissionais no discurso de terceirizados em TI. Revista de Administração de Empresas - Eletrônica, 8(2). doi:10.1590/S1676-56482009000200002

Magno, A., \& Barbosa, S. (2010). A naturalização da identidade social precarizada na indústria do alumínio primário paraense. Sociologias, 12(23), 268-303. doi:10.1590/S1517-45222010000100010

Mandarini, M. B., Alves, A. M., \& Sticca, M. G. (2016). Terceirização e impactos para a saúde e trabalho: uma revisão sistemática da literatura. Revista Psicologia: Organizações e Trabalho, 16(2), 143-152. doi:10.17652/rpot/2016.2.661

Marcelino, P., \& Cavalcante, S. (2012). Por uma definição de terceirização. Caderno CRH, 25(65), 331-346. doi:10.1590/S0103-49792012000200010

Maroco, J., \& Garcia-Marques, T. (2006). Qual a fiabilidade do alfa de Cronbach? Questões antigas e soluções modernas? Laboratório de Psicologia, 4(1), 65-90.

Martinez, M. C. (2002). As relações entre a satisfação com aspectos psicossociais no trabalho e a saúde do trabalhador. Dissertação de Mestrado, Faculdade de Saúde Pública, Universidade de São Paulo, São Paulo.

Martins, S. P. (2015). Flexibilização das condições de trabalho. (5 Edição). São Paulo, SP: Editora Atlas.

Matsuki, E. (2015). PL 4330/2004: entenda o que diz o projeto sobre terceirização de trabalhadores. Portal EBC. Recuperado de http://www.ebc.com.br/noticias/politica/2015/04/entenda-o-que-diz-o-projeto-de-leida-terceirizacao.

Michie, S. (2002). Causes and management of stress at work. Occupational \& Environmental Medicine, 59(1), 67-72. doi:10.1136/oem.59.1.67

Ministério da Indústria, Comério Exterior e Serviços (2017). A importância do setor terciário. Recuperado de http://www.mdic.gov.br/index.php/comercio-servicos/asecretaria-de-comercio-e-servicos-scs/402-a-importancia-do-setor-terciario.

Moncada, S., Llorens, C., Andrés, R., Moreno, N., \& Molinero, E. (2014). Manual del método CoPsoQ-istas21 (versión 2) para la evaluación y la prevención de los 
riesgos psicosociales en empresas con 25 o más trabajadores y trabajadoras VERSIÓN MEDIA. Barcelona: Instituto Sindical de Trabajo, Ambiente y Salud.

Nadeem, S. (2009). The uses and abuses of time: globalization and time arbitrage in India's outsourcing industries. Global Networks, 9(1), 20-40. doi:10.1111/j.14710374.2009.00240.x

Nandialath, A. M., Das, D., \& Mohan, R. (2012). Modelling heterogeneity in perceptions of stress in Indian call centres: a latent class analysis. International Journal of Business Innovation and Research, 6(5), 481-498. doi:10.1504/IJBIR.2012.048782

Netterstrøm, B., \& Hansen, A. M. (2000). Outsourcing and stress: Physiological effects on bus drivers. Stress Medicine, 16(3), 149-160. doi:10.1002/(SICI)10991700(200004)16:3<149::AID-SMI845>3.0.CO;2-X

Nieuwenhuijsen, K., Bruinvels, D., Frings-Dresen, M. (2010). Psychosocial work environment and stress-related disorders, a systematic review. Occupational Medicine, 60(4), 277-286. doi:10.1093/occmed/kqq081

NIOSH EUA - The National Institute for Occupational Safety and Health. Stress at work. Recuperado de https://www.cdc.gov/niosh/docs/99-101/pdfs/99-101.pdf.

Nunes, J. H. (2014). Dilemas identitários no mundo dos serviços: Da invisibilidade à interação. Sociologias, 16(35), 238-273. doi:10.1590/S1517-45222014000100009

Padilha, V. (2011). A realidade do trabalho subalterno de limpeza em shopping center. Perspectivas, $\quad 39, \quad 75-98 . \quad$ Recuperado de http://seer.fclar.unesp.br/perspectivas/article/view/4753/4055.

Padilha, V. (2014). Nojo, humilhação e controle na limpeza de shopping centers no Brasil e no Canadá. Caderno CRH, 27(71), 329-346. doi:10.1590/S010349792014000200008

Papadopoulos, G., Georgiadou, P., Papazoglou, C., \& Michaliou, K. (2010). Occupational and public health and safety in a changing work environment: an integrated approach for risk assessment and prevention. Safety Science, 48(8), 943949. doi:10.1016/j.ssci.2009.11.002

Pataro, S. M. S., \& Fernandes, R. C. P. (2014). Trabalho físico pesado e dor lombar: a realidade na limpeza urbana. Revista Brasileira de Epidemiologia, 17(1), 17-31. doi:10.1590/1809-4503201400010003ENG

Pejtersen, J. H., Kristensen, T. S., Borg, V., \& Bjorner, J. B. (2010). The second version of the Copenhagen Psychosocial Questionnaire. Scandinavian Journal of Public Health, 38(8), 8-24. doi:10.1177/1403494809349858

Petean, E., Costa, A. L. R. C., \& Ribeiro, R. L. R. (2014). Repercussões da ambiência hospitalar na perspectiva dos trabalhadores de limpeza. Trabalho, Educação e Saúde, 12(3), 615-635. doi:10.1590/1981-7746-sip00005 
Petticrew, M., \& Roberts, H. (2006). Systematic reviews in the Social Sciences: a practical guide. Oxford: Blackwell Publishing.

Pinto, A. E. S. (2017). Terceirização não derruba os salários, mostra estudo. Folha de $S$. Paulo. Recuperado de http://m.folha.uol.com.br/mercado/2017/09/1915215terceirizacao-nao-derruba-os-salarios-mostraestudo.shtml?utm_source=newsletter\&utm_medium=email\&utm_campaign=newsfol ha.

Pochmann, M. (2011). Trajetórias da terceirização. São Paulo: SINDEEPRES. Recuperado de http://sindeepres.org.br/images/stories/pdf/pesquisa/trajetorias1.pdf.

Previdência Social (2018, 01 de março). Acompanhamento mensal dos benefícios auxílios-doença acidentários, concedidos segundo os códigos da CID-10. Janeiro a Dezembro de 2017. Recuperado de http://www.previdencia.gov.br/wpcontent/uploads/2018/03/Auxilio-Doen\%C3\%A7a-

Acidentario_2017_completo_CID.pdf.

Previdência Social (2018, 01 de março). Acompanhamento mensal dos benefícios auxílios-doença previdenciários, concedidos segundo os códigos da CID-10. Janeiro a Dezembro de 2017. Recuperado de http://www.previdencia.gov.br/wpcontent/uploads/2018/03/Auxilio-Doen\%C3\%A7a-

Previdenciario_2017_completo_CID.pdf.

Previtali, F. S. (2009). O controle do trabalho pelo discurso da qualificação do trabalhador no contexto da reestruturação produtiva do capital. Publicatio UEPG: Ciências Humanas, Linguística, Letras e Artes, 17(2), 141-155. doi:10.5212/publ.humanas.v17i2.1768

Projeto de Lei $n^{o} 4330$ (2004). Dispõe sobre o contrato de prestação de serviço a terceiros e as relações de trabalho dele decorrentes. Brasília, DF: Câmara dos

Deputados. Recuperado de http://www.camara.gov.br/proposicoesWeb/prop_mostrarintegra;jsessionid=89CE14 4FC56C6AD5DFA2CAF8329FD307. proposicoesWebExterno2?codteor=246979\&fi lename=PL+4330/2004.

Quinlan, M., \& Bohle, P. (2008). Under pressure, out of control, or home alone? Reviewing research and policy debates on the occupational health and safety effects of outsourcing and home-based work. International Journal of Health Services, 38(3), 489-523. doi:10.2190/HS.38.3.g

Raja, J. D., \& Bhasin, S. K. (2014). Health Issues Amongst Call Center Employees, An Emerging Occupational Group in India. Indian Journal of Community Medicine, 39(3), 175-177. doi:10.4103/0970-0218.137156

Ram, A., Kurpad, A., \& Swaminathan, S. (2014). Understanding the health behaviors of India's information technology and business process outsourcing employee. International Journal of Workplace Health Management, 7(4), 213-228. doi:10.1108/IJWHM-07-2013-0029 
Ratnesh, M., Sultana, S., \& Sinha, A. R. (2016). Women employees in indian BPO industries towards balancing their professional and personal life: some key issues. International Journal of Applied Business and Economic Research, 14(6), 46474658. Recuperado

de http://www.serialsjournals.com/serialjournalmanager/pdf/1469790735.pdf.

Rego, J. M. (2000). Economia brasileira. São Paulo, SP: Saraiva.

Reis, A. L. P. P., Fernandes, S. R. P., \& Gomes, A. F. (2010). Estresse e fatores psicossociais. Psicologia: Ciência e Profissão, 30(4), 712-725. doi:10.1590/S141498932010000400004.

Revathi, G. (2016). A study on factors causing stress among the BPO employees in health sector Chennai City - with reference to educational qualification and pay package. International Journal of Pharmacy \& Technology, 8(3), 16575-16580. Recuperado de http://www.ijptonline.com/wp-content/uploads/2016/10/1657516580.pdf.

Rios, M. C., \& Gondim, S. M. G. (2010). Contratos psicológicos e terceirização: Um estudo das relações entre vínculos e as práticas de gestão de pessoas. Organizações \& Sociedade, 17(55), 689-703. doi:10.1590/S1984-92302010000400006

Rosário, S. K. A. (2013). Validação e adaptação linguística e cultural da versão longa do Questionário Copenhagen Psychosocial Questionnaire II (COPSOQ II) em Português. Dissertação de Mestrado, Faculdade de Engenharia da Universidade do Porto, Universidade do Porto, Porto.

Rugulies, R., Christensen, K. B., Borritz, M., Villadsen, E., Bültmann, U., Kristensen, T. S. (2007). The contribution of psychosocial work environment to sickness absence in human service workers: Results of a 3-year follow-up study. Work \& Stress, 21(4), 293-311. doi:10.1080/02678370701747549

Sales, S. M. (1970). Some effects of role overload and role underload. Organizational Behavior and Human Performance, 5, 592-608.

Santiago, R. (2013). Terceirizados: marco legal porá fim à era da discriminação e precarização. Congresso em Foco. Recuperado de http://congressoemfoco.uol.com.br/noticias/outros-destaques/terceirizados-marcolegal-pora-fim-a-era-da-discriminacao-e-precarizacao/.

Santos, M. C. O., Lima, F. P. A., Murta, E. P., \& Motta, G. M. V. (2009). Desregulamentação do trabalho e desregulamentação da atividade: $O$ caso da terceirização da limpeza urbana e o trabalho dos garis. Produção, 19(1), 202-213. doi:10.1590/S0103-65132009000100013

Santos, R. S., Ribeiro, E. M., Ribeiro, M. M., Santos, T. C. S., \& Costa, V. M. (2004). Reestruturação produtiva do Estado brasileiro na perspectiva do projeto neoliberal. Revista de Administração Pública, 38(1), 7-32. Recuperado de http://bibliotecadigital.fgv.br/ojs/index.php/rap/article/view/6525. 
Schabracq, M. J., \& Cooper, C. L. (2000). The changing nature of work and stress. Journal of Managerial Psychology, 15(3), 227-241. doi:10.1108/02683940010320589

Schabracq, M. J., Winnubst, J. A. M., \& Cooper, C. L. (2003). The handbook of work \& health psychology (2nd Ed.). Chichester: Wiley.

Schaufeli, W. B., \& Greenglass, E. (2001). Introduction to special issue on burnout and health. Psychology and Health, 16(5), 501-510. doi:10.1080/08870440108405523

Seifert, A. M., \& Messing, K. (2006). Cleaning up after globalization: an ergonomic analysis of work activity of hotel cleaners. Antipode, 38(3), 557-578. doi:10.1111/j.0066-4812.2006.00595.x

Seklecka, L., Marek, T., \& Lacala, Z. (2013). Work satisfaction, causes, and sources of job stress and specific ways of coping: a case study of white-collar outsourcing service employees. Human Factors and Ergonomics in Manufacturing \& Service Industries, 23(6), 590-600. doi:10.1002/hfm.20554

SIEMACO (Sindicato Trabalhadores Empresas Prestação de Serviços de Asseio e Limpeza Urbana de SP). (2017). Convenção coletiva de trabalho 2017/2018. Recuperado de http://www.siemaco.com.br/upload/convencao/img1-CCTSIEMACO-SP-X-SEAC---Vigencia-01-01-2-5143.pdf.

Silva, C. F. (2011). Copenhagen Psychosocial Questionnaire (COPSOQ): Versão portuguesa. Aveiro: FCT - Fundação para a Ciência e a Tecnologia.

Silva, R. M. (2015). Terceirização e precarização: o caso da Universidade Federal de Uberlândia no período de 2000-2014. Dissertação de Mestrado, Instituto de Ciências Sociais, Universidade Federal de Uberlândia, Uberlândia.

Silva, L. S., \& Barreto, S. M. (2012). Adverse psychosocial working conditions and poor quality of life among financial service employees in Brazil. Journal of Occupational Health, 54(2), 88-95. Recuperado de https://www.jstage.jst.go.jp/article/joh/54/2/54_11-0072-OA/_pdf.

Silva, M. P., Wendt, G. W., \& Argimon, I. I. L. (2017). Propriedades psicométricas das medidas do Questionário Psicossocial de Copenhague I (COPSOQ I), versão curta. REGE, 24(4), 348-359. doi: 10.1016/j.rege.2017.05.007

SINDEPRESTEM (2012). $5^{a}$ Pesquisa setorial 2010-2011. São Paulo: Hawaii Gráfica. Recuperado de: http://www.fenep.org.br/wpcontent/uploads/2012/09/Pesquisa_Setorial_2010-2011.pdf.

SINTIPq (Sindicato dos Trabalhadores em Pesquisa, Ciência e Tecnologia). (2015). CUT esclarece problemas do PL 4330. SINTIPq. Recuperado de http://sintpq.org.br/index.php/blog/item/3939-cut-apresenta-problemas-do-pl-4330.

Smith, J. A. (Ed.) (2015). Qualitative psychology: A practical guide to research methods (3rd Ed.). London: SAGE. 
Snell, D., Schmitt, D., Glavas, A., Bamberry, L. (2015). Worker stress and the prospect of job loss in a fragmented organisation. Qualitative Research in Organizations and Management: An International Journal, 10(1), 61-81. doi:10.1108/QROM-03-20141210

Solera, E. (2011). Las compañías españolas buscan un aliado flexible. El País. Recuperado de http://www.cincodias.com/articulo/especiales/companias-espanolasbuscanaliado-flexible/20111024cdsesp_1/.

Solli-Sæther, H. (2011). Transplants' role stress and work outcome in IT outsourcing relationships. Industrial Management \& Data Systems, 111(2), 227-245. doi:10.1108/02635571111115155

Sparks, K., Faragher, B., \& Cooper, C. L. (2001). Well-being and occupational health in the $21 \mathrm{st}$ century workplace. Journal of Occupational and Organizational Psychology, 74, 489-509. doi:10.1348/096317901167497

Spurgeon, A., Harrington, J. M., \& Cooper, C. L. (1997). Health and safety problems associated with long working hours: a review of the current position. Occupational \& Environmental Medicine, 54(6), 367-375. Recuperado de https://www.ncbi.nlm.nih.gov/pmc/articles/PMC1128796/pdf/oenvmed000900007.pdf.

Stansfeld, S., \& Candy, B. (2006). Psychosocial work environment and mental health a meta-analytic review. Scandinavian Journal of Work, Environment \& Health, 32(6), 443-462. doi:10.5271/sjweh.1050

Statistic Brain Research Institute (2017). Job overseas outsourcing statistics. Recuperado de http://www.statisticbrain.com/outsourcing-statistics-by-country/.

Sugumar, D., Kumaran, C. K. M., Raj, P. J., \& Xavier, S. J. (2013). Addressing health related challenges faced by the business process outsourcing (BPO) employees by stress. African Journal of Business Management, 7(12), 906-914. doi:10.5897/AJBM2013.1599

Súmula $n^{o}$ 331. (2011, 27, 30 e 31 de maio). Dispõe sobre o contrato de prestação de serviços. Brasília, DF: Tribunal Superior do Trabalho. Recuperado de http://www3.tst.jus.br/jurisprudencia/Sumulas_com_indice/Sumulas_Ind_301_350.ht $\mathrm{ml}$.

Szeto, A. C., \& Dobson, K. S. (2013). Mental disorders and their association with perceived work stress: an investigation of the 2010 Canadian Community Health Survey. Journal of Occupational Health Psychology, 18(2), 191-197. doi:10.1037/a0031806

Sznelwar, L. I., Lancman, S., Wu, M. J., Alvarinho, E., \& Santos, M. (2004). Análise do trabalho e serviço de limpeza hospitalar: contribuições da ergonomia e da psicodinâmica do trabalho. Produção, 14(3), 45-57. doi:10.1590/S010365132004000300006 
Tabanelli, M. C., Depolo, M., Cooke, R. M. T., Sarchielli, G., Bonfiglioli, R., Mattioli, S., \& Violante, F. S. (2008). Available instruments for measurement of psychosocial factors in the work environment. International Archives of Occupational and Environmental Health, 82, 1-12. doi:10.1007/s00420-008-0312-6

Tashakkori, A., Teddlie, C., \& Sines, M. C. (2012). Utilizing mixed methods in psychological research. In I. B. Weiner, J. A. Schinka, \& W. F. Velicer (Eds.). Handbook of psychology, Volume 2, Research methods in psychology (2nd Ed.). (pp.428-451). Hoboken, Nova Jersey: John Wiley \& Sons.

Taylor, P., D'Cruz, P., Noronha, E., \& Scholarios, D. (2013). The experience of work in India's domestic call centre industry. The International Journal of Human Resource Management, 24(2), 436-452. doi:10.1080/09585192.2011.561216

Thite, M. (2010). All that glitters is not gold: employee retention in offshored Indian information technology enabled services. Journal of Organizational Computing and Electronic Commerce, 20(1), 7-22. doi:10.1080/10919390903482390

Tjandraningsih, I. (2012). State-sponsored precarious work in Indonesia. American Behavioral Scientist, 57(4), 403-419. doi:10.1177/0002764212466236

Trochim, W. M., \& Donnelly, J. P. (2006). The research methods knowledge base (3 ed.). Cincinnati, OH: Atomic Dog.

Tsai, S. (2012). A study of the health-related quality of life and work-related stress of white-collar migrant workers. International Journal of Environmental Research and Public Health, 9(10), 3740-3754. doi:10.3390/ijerph9103740

van den Berg, T. I., Elders, L. A., Zwart, B. C., \& Burdorf, A. (2009). The effects of work-related and individual factors on the Work Ability Index: a systematic review. Occupational \& Environmental Medicine, 66(4), 211-220. doi:10.1136/oem.2008.039883

Vasapollo, L. (2005). O trabalho atípico e a precariedade. São Paulo: Expressão Popular.

Wieclaw, J., Agerbo, E., Mortensen, P. B., Burr, H., Tuchsen, F., \& Bonde, J. P. (2008). Psychosocial working conditions and the risk of depression and anxiety disorders in the Danish workforce. BMC Public Health onlice access. Recuperado de https://www.ncbi.nlm.nih.gov/pmc/articles/PMC2519085/pdf/1471-2458-8-280.pdf.

Zanelli, J. C., Calzaretta, A. V., García, A. J., Lipp, M. E. N., \& Chambel, M. J. (2010). Estresse nas organizações de trabalho: compreensão e intervenção baseadas em evidências. Porto Alegre, RS: Artmed.

Zanelli, J. C., \& Kanan, L. A. (2018). Fatores de risco, proteção psicossocial e trabalho. Florianópolis: Tuniplac.

Zoltowski, A. P. C., Costa, A. B., Teixeira, M. A. P., \& Koller, S. H. (2014). Qualidade metodológica das revisões sistemáticas em periódicos de psicologia brasileiros. 
Psicologia: Teoria e Pesquisa, 30(1), 97-104. doi:10.1590/S010237722014000100012

Zuberi, D. (2011). Contracting out hospital support jobs: The effects of poverty wages, excessive workload, and job insecurity on work and family life. American Behavioral Scientist, 55(7), 920-940. doi:10.1177/0002764211407835

Zuberi, D. M., \& Ptashnick, M. B. (2011). The deleterious consequences of privatization and outsourcing for hospital support work: the experiences of contracted-out hospital cleaners and dietary aids in Vancouver, Canada. Social Science \& Medicine, 72(6), 907-911. doi:10.1016/j.socscimed.2010.12.024

Zimmermann, A., \& Ravishankar, M. N. (2011). Collaborative IT offshoring relationships and professional role identities: reflections from a field study. Journal of Vocational Behavior, 78(3), 351-360. doi:10.1016/j.jvb.2011.03.016 
Anexos

\section{Anexo A - Questionário Copenhagen Psychosocial Questionnaire II (COPSOQ II)}

\section{Instruções de preenchimento}

As perguntas do questionário estão relacionadas com a saúde, o bem-estar e fatores do ambiente de trabalho. O questionário é sobre as suas condições de trabalho e a sua opinião acerca do mesmo.

O presente questionário é confidencial. Não existem respostas certas nem erradas.

O tempo previsto de preenchimento do questionário é de 30 minutos.

Por favor, responda a todas as questões assinalando com um $\mathrm{X}$ na resposta que considera mais adequada.

\section{1-Nunca/ quase nunca 2-Raramente 3-Às vezes $\quad$ 4-Frequentemente $\quad$ 5-Sempre}

\begin{tabular}{|l|l|l|l|l|l|}
\hline & $\mathbf{1}$ & $\mathbf{2}$ & $\mathbf{3}$ & $\mathbf{4}$ & $\mathbf{5}$ \\
\hline 1. A sua carga de trabalho se acumula por ser mal distribuída? & & & & & \\
\hline $\begin{array}{l}\text { 2. Com que frequência não tem tempo para completar todas as } \\
\text { tarefas do seu trabalho? }\end{array}$ & & & & \\
\hline 3. Precisa fazer horas-extra? & & & & & \\
\hline 4. Precisa trabalhar muito rapidamente? & & & & & \\
\hline 5. O seu trabalho exige a sua atenção constante? & & & \\
\hline 6. O seu trabalho requer que seja bom em propor novas ideias? & & & & & \\
\hline 7. O seu trabalho exige que tome decisões difíceis? & & & & \\
\hline 8. O seu trabalho é exigente do ponto de vista emocional? & & & & & \\
\hline 9. Tem um elevado grau de influência no seu trabalho? & & & & & \\
\hline 10. Participa na escolha das pessoas com quem trabalha? & & & & & \\
\hline 11. Pode influenciar a quantidade de trabalho a ser realizado? & & & & & \\
\hline 12. Tem alguma influência sobre o tipo de tarefas que faz? & & & & & \\
\hline 13. O seu trabalho exige que tenha iniciativa? & & & & & \\
\hline 14. O seu trabalho permite que você aprenda coisas novas? & & & & & \\
\hline 15. O seu trabalho permite que você use as suas habilidades? & & & & & \\
\hline $\begin{array}{l}\text { 16. No seu local de trabalho, é informado(a) com antecedência } \\
\text { sobre decisões importantes, mudanças ou planos para o futuro? }\end{array}$ & & & & & \\
\hline $\begin{array}{l}\text { 17. Recebe toda a informação de que necessita para fazer bem o } \\
\text { seu trabalho? }\end{array}$ & & & & & \\
\hline 18. O seu trabalho apresenta objetivos claros? & & & & & \\
\hline 19. Sabe exatamente quais são as suas responsabilidades? & & & & & \\
\hline 20. Sabe exatamente o que é esperado de si? & & & & & \\
\hline 21. O seu trabalho é reconhecido e apreciado pela sua gerência? & & & & & \\
\hline 22. A gerência do seu local de trabalho respeita-o(a)? & & & & & \\
\hline 23. É tratado(a) de forma justa no seu local de trabalho? & & & & & \\
\hline
\end{tabular}




\section{1-Nunca/ quase nunca 2-Raramente 3-Às vezes $\quad$ 4-Frequentemente $\quad$ 5-Sempre}

\begin{tabular}{|l|l|l|l|l|l|}
\hline & $\mathbf{1}$ & $\mathbf{2}$ & $\mathbf{3}$ & $\mathbf{4}$ & $\mathbf{5}$ \\
\hline $\begin{array}{l}\text { 24. No seu trabalho, faz coisas que uns concordam mas outros } \\
\text { não? }\end{array}$ & & & & \\
\hline $\begin{array}{l}\text { 25. Por vezes tem que fazer coisas que deveriam ser feitas de } \\
\text { outra maneira? }\end{array}$ & & & & & \\
\hline $\begin{array}{l}\text { 26. Por vezes tem que fazer coisas que considera } \\
\text { desnecessárias? }\end{array}$ & & & & \\
\hline $\begin{array}{l}\text { 27. Com que frequência tem ajuda e apoio dos seus colegas de } \\
\text { trabalho? }\end{array}$ & & & & \\
\hline $\begin{array}{l}\text { 28. Com que frequência os seus colegas estão dispostos a ouvi- } \\
\text { lo(a) sobre os seus problemas de trabalho? }\end{array}$ & & & & \\
\hline $\begin{array}{l}\text { 29. Com que frequência os seus colegas de trabalho falam sobre } \\
\text { a forma como você realiza seu trabalho? }\end{array}$ & & & & & \\
\hline $\begin{array}{l}\text { 30. Com que frequência seu superior direto fala com você a } \\
\text { sobre o andamento do seu trabalho? }\end{array}$ & & & & \\
\hline $\begin{array}{l}\text { 31. Com que frequência tem ajuda e apoio do seu superior } \\
\text { direto? }\end{array}$ & & & & & \\
\hline $\begin{array}{l}\text { 32. Com que frequência seu superior direto fala com você a } \\
\text { respeito do seu desempenho no trabalho? }\end{array}$ & & & & & \\
\hline
\end{tabular}

Em relação ao seu superior direto, até que ponto considera que...

\begin{tabular}{|l|l|l|l|l|l|}
\hline & $\mathbf{1}$ & $\mathbf{2}$ & $\mathbf{3}$ & $\mathbf{4}$ & $\mathbf{5}$ \\
\hline $\begin{array}{l}\text { 33. Oferece aos indivíduos e ao grupo boas oportunidades de } \\
\text { desenvolvimento? }\end{array}$ & & & & & \\
\hline 34. Dá prioridade à satisfação no trabalho? & & & & & \\
\hline 35. É bom(boa) no planejamento do trabalho? & & & & & \\
\hline 36. É bom(boa) em resolver conflitos?
\end{tabular}

\section{1-Nada/ quase nada 2-Um pouco 3-Moderadamente 4-Muito 5- Extremamente}

\begin{tabular}{|l|l|l|l|l|l|}
\hline & $\mathbf{1}$ & $\mathbf{2}$ & $\mathbf{3}$ & $\mathbf{4}$ & $\mathbf{5}$ \\
\hline 37. O seu trabalho tem algum significado para você? & & & & & \\
\hline 38. Sente que o seu trabalho é importante? & & & & & \\
\hline 39. Sente-se motivado(a) e envolvido(a) com o seu trabalho? & & & & & \\
\hline 40. Gosta de falar com os outros sobre o seu local de trabalho? & & & & & \\
\hline $\begin{array}{l}\text { 41. Sente que os problemas do seu local de trabalho são seus } \\
\text { também? }\end{array}$ & & & & & \\
\hline
\end{tabular}


Em relação ao seu trabalho em geral, o quão satisfeito está com...

\begin{tabular}{|l|l|l|l|l|l|}
\hline & $\mathbf{1}$ & $\mathbf{2}$ & $\mathbf{3}$ & $\mathbf{4}$ & $\mathbf{5}$ \\
\hline 42. As suas perspectivas de trabalho? & & & & & \\
\hline 43. As condições físicas do seu local de trabalho? & & & & & \\
\hline 44. A forma como as suas habilidades/competências são usadas? & & & & & \\
\hline 45. O seu trabalho, de uma forma geral? & & & & & \\
\hline 46. Sente-se preocupado em ficar desempregado? & & & & & \\
\hline
\end{tabular}

\begin{tabular}{|l|l|c|c|c|c|}
\hline & Excelente & $\begin{array}{c}\text { Muito } \\
\text { boa }\end{array}$ & Boa & Razoável & Ruim \\
\hline 47. Em geral, sente que a sua saúde é: & & & & & \\
\hline
\end{tabular}

As próximas três questões referem-se ao modo como o seu trabalho afeta a sua vida pessoal:

\section{1-Nada/ quase nada 2-Um pouco 3-Moderadamente 4-Muito 5-} Extremamente

\begin{tabular}{|l|l|l|l|l|l|}
\hline & $\mathbf{1}$ & $\mathbf{2}$ & $\mathbf{3}$ & $\mathbf{4}$ & $\mathbf{5}$ \\
\hline $\begin{array}{l}\text { 48. Sente que o seu trabalho exige muita energia, afetando } \\
\text { negativamente a sua vida privada? }\end{array}$ & & & & & \\
\hline $\begin{array}{l}\text { 49. Sente que o seu trabalho exige muito tempo, afetando } \\
\text { negativamente sua vida privada? }\end{array}$ & & & & & \\
\hline $\begin{array}{l}\text { 50. Os seus amigos e familiares dizem que você trabalha } \\
\text { demais? }\end{array}$ & & & & & \\
\hline
\end{tabular}

Com que frequência, durante as últimas 4 semanas, você sentiu...

\section{1-Nunca/ quase nunca 2-Raramente 3-Às vezes $\quad$ 4-Frequentemente 5-Sempre}

\begin{tabular}{|l|l|l|l|l|l|}
\hline & $\mathbf{1}$ & $\mathbf{2}$ & $\mathbf{3}$ & $\mathbf{4}$ & $\mathbf{5}$ \\
\hline 51. Irritado? & & & & & \\
\hline 52. Ansioso? & & & & & \\
\hline
\end{tabular}

Obrigada pela sua colaboração. 


\section{Apêndice A - Questionário de Dados Sociodemográficos}

Para finalizar, preencha os seguintes dados complementares:

Idade: anos

Sexo: ( ) Masculino ( ) Feminino

\section{Escolaridade}

( ) Ensino Fundamental Incompleto

( ) Ensino Fundamental Completo

( ) Ensino Médio Incompleto

( ) Ensino Médio Completo

( ) Superior Incompleto

( ) Superior Completo

Cargo Atual

Possui filhos?

( ) $\operatorname{Sim}$

( ) Não

Se sim, quantos?

Quantas pessoas moram com você

Tempo de Serviço na empresa terceirizada ano(s)

\section{Estado Civil}

( ) Solteiro

( ) Casado/União Estável

( ) Divorciado/Separado

( ) Viúvo

( ) Outro

Cidade em que reside

\section{Renda (salários mínimos)}
( ) Até 1
( ) 2-3
( ) 4-5
( ) 6-7

Recebe benefícios além do salário?
( ) $\operatorname{Sim}$
( ) Não

Quais?

Tempo de Serviço na universidade $\operatorname{ano}(\mathrm{s})$ 
Tempo de Serviço no Cargo Atual $\operatorname{ano}(\mathrm{s})$
Já trabalhou no setor de limpeza?

( ) $\operatorname{Sim}$

( ) Não

Afastamento do trabalho por problema de saúde relacionado ao trabalho no último ano:
( ) Nenhum
( ) Entre 1 e 3
( ) Mais de 3

Obrigada pela sua participação! 


\section{Apêndice B - Roteiro de Entrevista Semiestruturada (Gestores)}

1. História da organização: missão; objetivo; metas

2. Como a organização se situa dentro do contexto da universidade; de onde vem as tomadas de decisões; contratação da empresa pela universidade

3. Quais são as normas existentes: segurança, trabalho, saúde, produtividade

4. Organograma

5. Como é o processo de produção; relatar como é um dia comum de trabalho

6. Volume/demanda: como é organizada a distribuição de tarefas (limpeza por setor, por dia, por número de salas, por turno, etc)

7. Como se dá a organização das tarefas (identificar as principais tarefas) e a divisão do trabalho (responsáveis e quem executa)

8. Indicadores de produtividade e de qualidade

9. Como o espaço é organizado: máquinas, instrumentos, produtos, EPI's; local de descanso dentro da universidade; onde são feitas as refeições

10. Como os funcionários aprendem a lidar com os instrumentos/produtos (existe treinamento?)

11. Como funciona o processo de contratação e demissão

12. Informações sobre os funcionários: $n^{\circ}$ total de funcionários; $n^{\circ}$ por turno, por cargo; salário e benefícios; taxa de absenteísmo; rotatividade; indicadores de saúde e segurança; tarefas desempenhadas

13. A organização tem alguma estrutura específica para lidar com assuntos relacionados à gestão de pessoas? Se sim, como isso está organizado?

14. Como funciona a comunicação: dúvidas dos funcionários; comunicados; se existem reuniões

15. Dificuldades geralmente encontradas, acontecimentos não esperados

16. Dificuldades atuais

17. Visão em relação à terceirização (pontos positivos e negativos)

18. A organização adota ações e/ou estratégias para minimizar os impactos negativos da terceirização para os trabalhadores? Quais?

19. Em sua opinião, o que a organização pode fazer para melhorar o trabalho dos funcionários? 


\section{Apêndice C - Roteiro de Entrevista Semiestruturada (Funcionários Terceirizados)}

1. Fale-me sobre o seu dia-a-dia de trabalho:

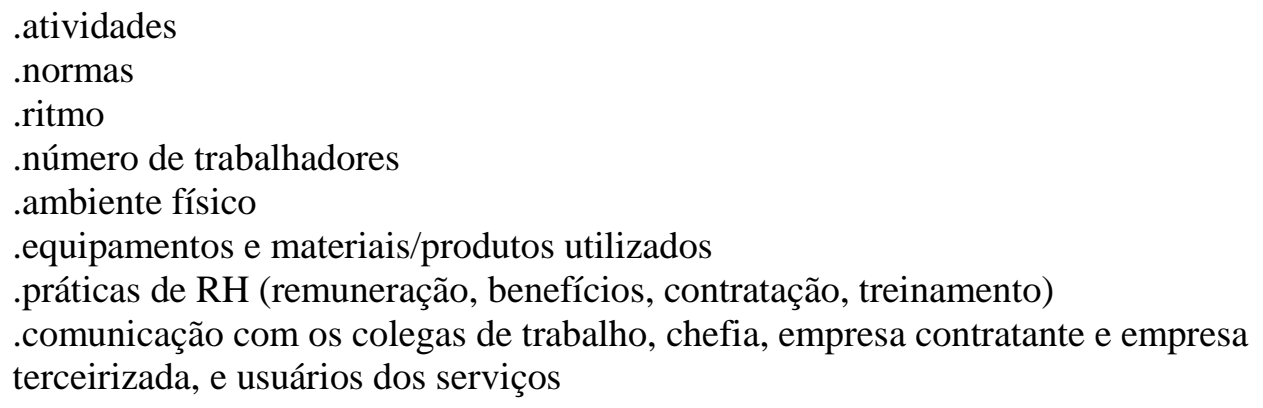

2. O que você acha sobre a quantidade de tarefas que precisa realizar ao longo do dia? O que você acha do tempo disponível para realizar essas tarefas? Qual o ritmo de trabalho que você tem que adotar para realizá-las? \{exigências quantitativas e ritmo de trabalho\}

3. Como você percebe a necessidade de estar atento ao trabalho? E como você percebe sua relação com as outras pessoas no trabalho? (Colegas, estudantes, professores e outros funcionários) \{exigências cognitivas e emocionais\}

4. Você acha que consegue aprender coisas novas no seu trabalho? Se sim, que tipo de coisas? \{possibilidades de desenvolvimento\} Você vê possibilidades de crescimento profissional?

5. O que você acha sobre o reconhecimento do seu trabalho? (Pelos superiores e colegas) E sobre seu salário e benefícios? \{recompensas\}

6. Existe alguma situação no seu trabalho que vai contra seus valores e princípios? Se sim, quais? \{conflito de papeis\}

7. O que você pensa sobre o apoio que recebe no trabalho dos colegas? O que você pensa sobre o apoio que recebe no trabalho dos superiores? \{apoio social de colegas e apoio social de superiores\} Como é seu relacionamento com eles? \{relacionamento interpessoal \}

8. O que você pensa sobre a possibilidade de ficar desempregado? E sobre a possibilidade do seu trabalho ser modificado? (Exemplo: ser transferido de unidade) \{insegurança no trabalho\}

9. Como você se sente ao chegar em casa após um dia de trabalho? Você se sente satisfeito com o tempo que consegue passar com seus familiares? \{conflito trabalho-família\}

10. O que você pensa sobre o estresse no trabalho? Como você acha que isso pode acontecer com você? Pensando nisso, que mudanças você faria em seu trabalho? \{estresse\}

11. De que forma o trabalho afeta sua saúde física? \{saúde geral\}

12. De que forma seu trabalho afeta sua saúde? \{saúde geral \}

13. O que o trabalho significa para você? \{significado do trabalho\}? 


\section{Apêndice D - Carta de Apresentação do Projeto de Pesquisa}

Aos gestores responsáveis pelo serviço de limpeza realizado pela empresa,

Venho por meio desta solicitar a autorização para coleta de dados com os agentes de limpeza e com os senhores para o projeto de pesquisa de Mestrado intitulado "Impactos de fatores organizacionais no estresse de agentes de limpeza de empresas terceirizadas", que está sendo desenvolvido pela aluna de Mestrado Marina Bernardo Mandarini, sendo orientada pela Prof $^{a}$. Dra . Marina Greghi Sticca, no Departamento de Psicologia da Faculdade de Filosofia, Ciências e Letras de Ribeirão Preto - Universidade de São Paulo (FFCLRP-USP). O projeto em questão tem como objetivo principal identificar o impacto de variáveis organizacionais para o estresse de trabalhadores terceirizados e identificar possíveis posicionamentos dos trabalhadores e da organização para lidar com tais aspectos negativos. Desta forma, pretende-se fornecer elementos que auxiliem na compreensão dos aspectos organizacionais que impactam negativamente a saúde dos trabalhadores em contexto de terceirização e apresentar possíveis formas de manejar e/ou reduzir essas vivências negativas manifestas no cotidiano desses trabalhadores, com o intuito de fornecer subsídios para intervenções de psicólogos que atuam na área de Psicologia Organizacional e do Trabalho, bem como para organizações que pretendem adotar ações a fim de melhorar as condições do trabalho terceirizado.

Em função do objetivo do estudo e da proposta metodológica, solicitamos a participação da empresa nas seguintes atividades: a) Contato com os agentes de limpeza; b) Aplicação de um instrumento e realização de entrevistas individuais, com o objetivo de identificar as variáveis organizacionais que impactam no estresse desses profissionais; c) Realização de entrevista individual com os senhores, a fim de identificar possibilidades de posicionamentos e/ou estratégias da organização para lidar com os impactos negativos da terceirização. As atividades serão desenvolvidas no primeiro e segundo semestres de 2017.

Cordialmente,

Marina Bernardo Mandarini

Prof $^{a}$. Dr ${ }^{\mathrm{a}}$. Marina Greghi Sticca

Laboratório de Psicologia Organizacional e do Trabalho - LabPOT

Departamento de Psicologia

Faculdade de Filosofia, Ciências e Letras de Ribeirão Preto

UNIVERSIDADE DE SÃO PAULO

Tel: +55 (16) 3315-4687

E-mail: marinagreghi@ffclrp.usp.br 


\section{Apêndice E - Termo de Consentimento Livre e Esclarecido (TCLE) - (Funcionários Terceirizados)}

Prezado(a) colaborador,

Meu nome é Marina Bernardo Mandarini, sou aluna de Mestrado do curso de pósgraduação em Psicologia da Faculdade de Filosofia, Ciências e Letras de Ribeirão Preto Universidade de São Paulo (FFCLRP-USP), e estou convidando você a participar da pesquisa que estou realizando, com o título "Impactos de fatores organizacionais no estresse de agentes de limpeza de empresas terceirizadas", orientada pela Prof ${ }^{\mathrm{a}}$. Dr $^{\mathrm{a}}$. Marina Greghi Sticca.

O objetivo deste estudo é identificar a influência de questões presentes no trabalho no estresse e identificar quais são as possíveis formas de você lidar com essa situação. Para isso, preciso de sua colaboração para que eu consiga obter as informações necessárias. O acesso a essas informações será realizado pessoalmente por mim, com o preenchimento de um questionário que irá abordar temas como ambiente de trabalho, rotina e organização do trabalho e saúde individual, com duração aproximada de 20 a 30 minutos. Para que eu conheça um pouco mais sobre você, seu trabalho e como você lida com situações relacionadas ao trabalho, também será realizada pessoalmente, por mim, uma entrevista individual com você, que terá a duração aproximada de 20 a 30 minutos, totalizando um tempo médio de 40 a 60 minutos. A entrevista será gravada em áudio e transcrita por mim, apenas para que eu não perca nenhum detalhe da sua fala; depois, a entrevista será apagada, para que ninguém tenha acesso a essas informações, garantindo, assim, o sigilo total. O local de aplicação desse questionário e realização da entrevista será combinado com você, de acordo com suas necessidades.

É importante que você saiba que seu nome não será utilizado em qualquer momento da pesquisa, e que suas informações confidenciais não serão divulgadas, ou seja, será garantido o seu anonimato, e ninguém, além de mim, terá acesso ao que foi dito por você.

Os possíveis riscos de participar dessa pesquisa estão apenas relacionados com a chance de você se sentir desconfortável com algum questionamento, e, nesse caso, eu mostrarei a você como acessar alguns serviços psicológicos gratuitos oferecidos na cidade de Ribeirão Preto, se for de seu interesse. Você também tem total liberdade para se recusar a participar da pesquisa ou deixar de participar em qualquer momento, e isso não causará nenhum tipo de prejuízo.

A participação nesse estudo não envolve nenhum gasto, mas se você tiver alguma despesa devido à participação, você terá o reembolso do valor dessa despesa. Além disso, é importante que você saiba que a participação é voluntária, ou seja, você não receberá nenhum benefício imediato ao participar da pesquisa.

Esse estudo será importante para compreender o processo de terceirização, como o trabalho pode influenciar a saúde dos trabalhadores e como os trabalhadores e as empresas podem lidar com essa situação. Os resultados obtidos serão divulgados em eventos científicos e/ou em revistas científicas, e serão utilizados para a conclusão do meu trabalho final na pósgraduação, lembrando que seu nome não será identificado em nenhum momento da pesquisa e da divulgação dos resultados.

Todo o procedimento está de acordo com as diretrizes da Resolução 466/12 do Conselho Nacional de Saúde, que podem ser acessadas no seguinte endereço digital:

\section{http://conselho.saude.gov.br/resolucoes/2012/Reso466.pdf}

Em caso de dúvidas ou reclamações sobre o aspecto ético da pesquisa, você poderá entrar em contato com o Comitê de Ética em Pesquisa FFCLRP-USP, responsável por verificar se essa pesquisa segue as diretrizes previstas na Resolução 466/12:

CEP - Comitê de Ética em Pesquisa da FFCLRP-USP

Avenida Bandeirantes, 3900 - Bloco 23 - Casa 37 - 14040-901 - Ribeirão Preto - SP - Brasil Telefone: (16) 3315-4811 / Fax: (16) 3633-2660 
E-mail: coetp@ffclrp.usp.br / homepage: http://www.ffclrp.usp.br

Se você estiver com alguma dúvida antes, durante ou após a realização da pesquisa, me coloco à disposição para esclarecer qualquer tipo de questionamento pelos seguintes meios:

Telefone: (16) 98198-9363

E-mail: marina.mandarini@usp.br

Você também poderá entrar em contato com a Prof ${ }^{a}$. Dra . Marina Greghi Sticca, responsável pela orientação deste projeto pelos seguintes meios:

Telefone: (16) 3315-9091

E-mail: marinagreghi@ffclrp.usp.br

Desde já agradeço sua atenção e colaboração.

\section{Termo de participação voluntária na pesquisa}

Ribeirão Preto, de de

Marina Bernardo Mandarini

Pesquisadora

Prof $^{a}$. Dr ${ }^{a}$. Marina Greghi Sticca

Orientadora

Assinatura do(a) participante 


\title{
Apêndice F - Termo de Consentimento Livre e Esclarecido (TCLE) -
}

\section{(Gestores)}

\author{
Prezado(a) gestor(a),
}

Meu nome é Marina Bernardo Mandarini, sou aluna de Mestrado do curso de pósgraduação em Psicologia da Faculdade de Filosofia, Ciências e Letras de Ribeirão Preto Universidade de São Paulo (FFCLRP-USP), e estou convidando você a participar da pesquisa que estou realizando, com o título "Impactos de fatores organizacionais no estresse de agentes de limpeza de empresas terceirizadas", orientada pela Prof ${ }^{a}$. Dr ${ }^{a}$. Marina Greghi Sticca.

O objetivo deste estudo é identificar a influência de questões presentes no trabalho no estresse dos trabalhadores e identificar quais são as possíveis formas que os trabalhadores e as empresas podem lidar com essa situação. Para isso, preciso de sua colaboração para que eu consiga obter as informações necessárias. $\mathrm{O}$ acesso a essas informações será realizado pessoalmente por mim, por meio de uma entrevista individual com o(a) senhor(a), em que serão abordada questões como organização, normas e procedimentos da empresa, informações sobre os funcionários, problemas enfrentados e como a empresa lida com eles. A entrevista terá a duração aproximada de 30 a 60 minutos, será gravada em áudio e transcrita por mim, apenas para que eu não perca nenhum detalhe da sua fala; depois, a entrevista será apagada, para que ninguém tenha acesso a essas informações, garantindo, assim, o sigilo total. O local de aplicação desses instrumentos e realização das entrevistas será combinado com o(a) senhor(a), de acordo com suas necessidades.

É importante destacar que seu nome não será utilizado em qualquer momento da pesquisa, e que suas informações confidenciais não serão divulgadas, ou seja, será garantido o anonimato, e ninguém, além de mim, terá acesso ao que foi dito pelo(a) senhor(a).

Os possíveis riscos de participar dessa pesquisa estão apenas relacionados com a chance do(a) senhor(a) se sentir desconfortável com algum questionamento, e, nesse caso, eu mostrarei ao(à) senhor(a) como acessar alguns serviços psicológicos gratuitos oferecidos na cidade de Ribeirão Preto, se for de seu interesse. $\mathrm{O}$ (a) senhor(a) também tem total liberdade para se recusar a participar da pesquisa ou deixar de participar em qualquer momento, e isso não causará nenhum tipo de prejuízo.

A participação nesse estudo não envolve nenhum gasto, mas se o(a) senhor(a) tiver alguma despesa devido à participação, será reembolsado do valor dessa despesa. Além disso, é importante ressaltar que a participação é voluntária, ou seja, não há nenhum benefício imediato ao participar da pesquisa.

Esse estudo será importante para compreender o processo de terceirização, como o trabalho pode influenciar a saúde dos trabalhadores e como os trabalhadores e as empresas podem lidar com essa situação. Os resultados obtidos serão divulgados em eventos científicos e/ou em revistas científicas, e serão utilizados para a conclusão do meu trabalho final na pósgraduação, lembrando que seu nome não será identificado em nenhum momento da pesquisa e da divulgação dos resultados.

Todo o procedimento está de acordo com as diretrizes da Resolução 466/12 do Conselho Nacional de Saúde, que podem ser acessadas no seguinte endereço digital:

\section{http://conselho.saude.gov.br/resolucoes/2012/Reso466.pdf}

Em caso de dúvidas ou reclamações sobre o aspecto ético da pesquisa, você poderá entrar em contato com o Comitê de Ética em Pesquisa FFCLRP-USP, responsável por verificar se essa pesquisa segue as diretrizes previstas na Resolução 466/12:

CEP - Comitê de Ética em Pesquisa da FFCLRP-USP

Avenida Bandeirantes, 3900 - Bloco 23 - Casa 37 - 14040-901 - Ribeirão Preto - SP - Brasil Telefone: (16) 3315-4811 / Fax: (16) 3633-2660 
E-mail: coetp@ffclrp.usp.br / homepage: http://www.ffclrp.usp.br

Caso surja alguma dúvida antes, durante ou após a realização da pesquisa, me coloco à disposição para esclarecer qualquer tipo de questionamento pelos seguintes meios:

Telefone: (16) 98198-9363

E-mail: marina.mandarini@usp.br

Também é possível entrar em contato com a Prof ${ }^{a}$. Dr ${ }^{a}$. Marina Greghi Sticca, responsável pela orientação deste projeto pelos seguintes meios:

Telefone: (16) 3315-9091

E-mail: marinagreghi@ffclrp.usp.br

Desde já agradeço sua atenção e colaboração.

\section{Termo de participação voluntária na pesquisa}

Ribeirão Preto, de de

Marina Bernardo Mandarini

Pesquisadora

Prof $^{a}$. Dr ${ }^{a}$. Marina Greghi Sticca

Orientadora

Assinatura do(a) participante 


\section{Apêndice G - Alterações realizadas no COPSOQ II a partir da validação semântica}

\begin{tabular}{|c|c|}
\hline Item original & Item final alterado \\
\hline $\begin{array}{r}\text { A sua carga de trabalho ac } \\
\text { mal distribuí }\end{array}$ & $\begin{array}{l}\text { A sua carga de trabalho se acumula por ser } \\
\text { mal distribuída? }\end{array}$ \\
\hline $\begin{array}{r}\text { O seu trabalho requer que } \\
\text { novas idei }\end{array}$ & $\begin{array}{c}\text { O seu trabalho requer que seja bom em propor } \\
\text { novas ideias? }\end{array}$ \\
\hline O seu trabalho exige emocionalmente de si? & $\begin{array}{c}\text { O seu trabalho é exigente do ponto de vista } \\
\text { emocional? }\end{array}$ \\
\hline $\begin{array}{l}\text { Pode influenciar a quantidade de trabalho que } \\
\text { lhe compete a si? }\end{array}$ & $\begin{array}{l}\text { Pode influenciar a quantidade de trabalho a } \\
\text { ser realizado? }\end{array}$ \\
\hline $\begin{array}{l}\text { O seu trabalho permite-lhe aprender coisas } \\
\text { novas? }\end{array}$ & $\begin{array}{l}\text { O seu trabalho permite que você aprenda } \\
\text { coisas novas? }\end{array}$ \\
\hline $\begin{array}{l}\text { O seu trabalho perm } \\
\text { habilidades }\end{array}$ & $\begin{array}{l}\text { O seu trabalho permite que você use as suas } \\
\text { habilidades? }\end{array}$ \\
\hline $\begin{array}{l}\text { No seu local de trabalho, é informado com } \\
\text { antecedência sobre decisões importantes, } \\
\text { mudanças ou planos para o futuro? }\end{array}$ & $\begin{array}{l}\text { No seu local de trabalho, é informado(a) com } \\
\text { antecedência sobre decisões importantes, } \\
\text { mudanças ou planos para o futuro? }\end{array}$ \\
\hline O seu trabalho apresenta objectivos claros? & O seu trabalho apresenta objetivos claros? \\
\hline $\begin{array}{l}\text { Sabe exactamente quais as suas } \\
\text { responsabilidades? }\end{array}$ & $\begin{array}{l}\text { Sabe exatamente quais são as suas } \\
\text { responsabilidades? }\end{array}$ \\
\hline Sabe exactamente o que é esperado de si? & Sabe exatamente o que é esperado de si? \\
\hline $\begin{array}{l}\text { A gerência do seu local de trabalho respeita- } \\
\text { o? }\end{array}$ & $\begin{array}{l}\text { A gerência do seu local de trabalho respeita- } \\
\qquad \text { o(a)? }\end{array}$ \\
\hline $\begin{array}{l}\text { É tratado de forma justa no seu local de } \\
\text { trabalho? }\end{array}$ & $\begin{array}{l}\text { É tratado(a) de forma justa no seu local de } \\
\text { trabalho? }\end{array}$ \\
\hline $\begin{array}{l}\text { Faz coisas no seu trabalho que uns concordam } \\
\text { mas outros não? }\end{array}$ & $\begin{array}{c}\text { No seu trabalho, faz coisas no seu trabalho } \\
\text { que uns concordam mas outros não? }\end{array}$ \\
\hline $\begin{array}{c}\text { Com que frequência os seus colegas estão } \\
\text { dispostos a ouvi-lo sobre os seus problemas } \\
\text { de trabalho? }\end{array}$ & $\begin{array}{c}\text { Com que frequência os seus colegas estão } \\
\text { dispostos a ouvi-lo(a) sobre os seus problemas } \\
\text { de trabalho? }\end{array}$ \\
\hline $\begin{array}{l}\text { Com que frequência os seus colegas falam } \\
\text { consigo acerca do seu desempenho laboral? }\end{array}$ & $\begin{array}{l}\text { Com que frequência os seus colegas de } \\
\text { trabalho falam sobre a forma como você } \\
\text { realiza seu trabalho? }\end{array}$ \\
\hline $\begin{array}{l}\text { Com que frequência o seu superior imediato } \\
\text { fala consigo sobre como está a decorrer o seu } \\
\text { trabalho? }\end{array}$ & $\begin{array}{l}\text { Com que frequência seu superior direto fala } \\
\text { com você sobre o andamento do seu trabalho? }\end{array}$ \\
\hline $\begin{array}{l}\text { Com que frequência é que o seu superior } \\
\text { imediato fala consigo em relação ao seu } \\
\text { desempenho laboral? }\end{array}$ & $\begin{array}{l}\text { Com que frequência seu superior direto fala } \\
\text { com você a respeito do seu desempenho no } \\
\text { trabalho? }\end{array}$ \\
\hline É bom no planeamento do trabalho? & É bom(boa) no planejamento do trabalho? \\
\hline É bom a resolver conflitos? & É bom (boa) em resolver conflitos? \\
\hline O seu trabalho tem algum significado para s & $\begin{array}{l}\text { O seu trabalho tem algum significado para } \\
\text { você? }\end{array}$ \\
\hline
\end{tabular}




\begin{tabular}{cc}
\hline $\begin{array}{c}\text { Sente-se motivado e envolvido com o seu } \\
\text { trabalho? }\end{array}$ & $\begin{array}{c}\text { Sente-se motivado(a) e envolvido(a) com o } \\
\text { seu trabalho? }\end{array}$ \\
\hline $\begin{array}{c}\text { A forma como as suas capacidades são } \\
\text { utilizadas? }\end{array}$ & $\begin{array}{c}\text { A forma como as suas } \\
\text { habilidades/competências são utilizadas? }\end{array}$ \\
\hline O seu trabalho de uma forma global? & O seu trabalho, de uma forma geral \\
\hline $\begin{array}{c}\text { Sente que o seu trabalho lhe exige muita } \\
\text { energia que acaba por afectar a sua vida } \\
\text { privada negativamente? }\end{array}$ & $\begin{array}{c}\text { Sente que o seu trabalho exige muita energia, } \\
\text { afetando negativamente a sua vida privada? }\end{array}$ \\
\hline $\begin{array}{c}\text { Sente que o seu trabalho lhe exige muito } \\
\text { tempo que acaba por afectar a sua vida } \\
\text { privada negativamente? }\end{array}$ & $\begin{array}{c}\text { Sente que o seu trabalho exige muito tempo, } \\
\text { afetando negativamente sua vida privada? }\end{array}$ \\
\hline $\begin{array}{c}\text { A sua família e os seus amigos dizem-lhe que } \\
\text { trabalha demais? }\end{array}$ & $\begin{array}{c}\text { Os seus amigos e familiares dizem que você } \\
\text { trabalha demais? }\end{array}$ \\
\hline
\end{tabular}




\section{Apêndice $\mathbf{H}$ - Alterações realizadas nos instrumentos a partir do estudo piloto}

\begin{tabular}{|c|c|}
\hline \multicolumn{2}{|c|}{ COPSOQ II } \\
\hline Instrução de preenchimento original & Instrução de preenchimento alterada \\
\hline $\begin{array}{l}\text { "Das seguintes afirmações indique }(\mathrm{X}) \text { a que } \\
\text { mais de adequa à sua resposta de acordo com } \\
\text { as seguintes alternativas" }\end{array}$ & $\begin{array}{l}\text { "As perguntas do questionário estão } \\
\text { relacionadas com a saúde, o bem-estar e } \\
\text { fatores do ambiente de trabalho. O } \\
\text { questionário é sobre as suas condições de } \\
\text { trabalho e a sua opinião acerca do mesmo. O } \\
\text { presente questionário é confidencial. Não } \\
\text { existem respostas certas nem erradas. O } \\
\text { tempo previsto de preenchimento do } \\
\text { questionário é de } 30 \text { minutos. Por favor, } \\
\text { responda a todas as questões assinalando com } \\
\text { um X na resposta que considera mais } \\
\text { adequada." }\end{array}$ \\
\hline
\end{tabular}

\begin{tabular}{|c|c|}
\hline \multicolumn{2}{|c|}{ Roteiro de Entrevista Semiestruturado utilizado com os agentes de limpeza } \\
\hline Item original & Item alterado \\
\hline $\begin{array}{l}\text { "Como você acha que seu trabalho afeta sua } \\
\text { saúde?" }\end{array}$ & $\begin{array}{l}\text { "De que forma o trabalho afeta sua saúde } \\
\text { física? De que forma seu trabalho afeta sua } \\
\text { saúde?" }\end{array}$ \\
\hline $\begin{array}{l}\text { "Como você se sente no final de um dia de } \\
\text { trabalho?" }\end{array}$ & $\begin{array}{l}\text { "Como você se sente ao chegar em casa após } \\
\text { um dia de trabalho? Você se sente satisfeito } \\
\text { com o tempo que consegue passar com seus } \\
\text { familiares?" }\end{array}$ \\
\hline $\begin{array}{l}\text { "Que mudanças você faria em seu trabalho?" } \\
\text { "O que você pensa sobre a saúde e a } \\
\text { segurança no seu trabalho?" }\end{array}$ & $\begin{array}{l}\text { "O que você pensa sobre o estresse no } \\
\text { trabalho? Como você acha que isso pode } \\
\text { acontecer com você? Pensando nisso, que } \\
\text { mudanças você faria em seu trabalho?" }\end{array}$ \\
\hline Itens excluídos & Itens adicionados \\
\hline $\begin{array}{l}\text { "Como você percebe a sua relação com a } \\
\text { empresa (terceirizada e contratante)?" }\end{array}$ & $\begin{array}{l}\text { "O que você acha sobre a quantidade de } \\
\text { tarefas que precisa realizar ao longo do dia? O } \\
\text { que você acha do tempo disponível para } \\
\text { realizar essas tarefas? Qual o ritmo de } \\
\text { trabalho que você tem que adotar para realizá- } \\
\text { las?" }\end{array}$ \\
\hline $\begin{array}{l}\text { "Como você percebe a sua relação com os } \\
\text { funcionários da Universidade (professores e } \\
\text { outros)? E com os alunos?" }\end{array}$ & $\begin{array}{l}\text { "Como você percebe a necessidade de estar } \\
\text { atento ao trabalho? E como você percebe sua } \\
\text { relação com as outras pessoas no trabalho?" }\end{array}$ \\
\hline $\begin{array}{l}\text { "Quais são os pontos positivos do seu } \\
\text { trabalho?" }\end{array}$ & $\begin{array}{l}\text { "Você acha que consegue aprender coisas } \\
\text { novas no seu trabalho? Se sim, que tipo de } \\
\text { coisas? Você vê possibilidades de } \\
\text { crescimento profissional?" }\end{array}$ \\
\hline
\end{tabular}




\begin{tabular}{|c|c|}
\hline $\begin{array}{l}\text { "Você encontra dificuldades no dia-a-dia do } \\
\text { trabalho (com as atividades, chefia, colegas de } \\
\text { trabalho, alunos, empresa contratante e } \\
\text { terceirizada)? Quais? Como você lida com } \\
\text { isso?" }\end{array}$ & $\begin{array}{l}\text { "O que você acha sobre o reconhecimento do } \\
\text { seu trabalho? E sobre seu salário e } \\
\text { benefícios?" }\end{array}$ \\
\hline & $\begin{array}{l}\text { "Existe alguma situação no seu trabalho que } \\
\text { vai contra seus valores e princípios? Se sim, } \\
\text { quais?" }\end{array}$ \\
\hline & $\begin{array}{l}\text { "O que você pensa sobre o apoio que recebe } \\
\text { no trabalho dos colegas? O que você pensa } \\
\text { sobre o apoio que recebe no trabalho dos } \\
\text { superiores? Como é seu relacionamento com } \\
\text { eles?" }\end{array}$ \\
\hline & $\begin{array}{l}\text { "O que você pensa sobre a possibilidade de } \\
\text { ficar desempregado? E sobre a possibilidade } \\
\text { do seu trabalho ser modificado?" }\end{array}$ \\
\hline & "O que o trabalho significa para você?" \\
\hline \multicolumn{2}{|c|}{ Questionário Sociodemográfico } \\
\hline & Item adicionado \\
\hline & $\begin{array}{l}\text { "Já trabalhou no setor de limpeza? } \\
\text { ( ) Sim ( ) Não" }\end{array}$ \\
\hline
\end{tabular}


Apêndice I - Representação visual para auxiliar no preenchimento do COPSOQ II

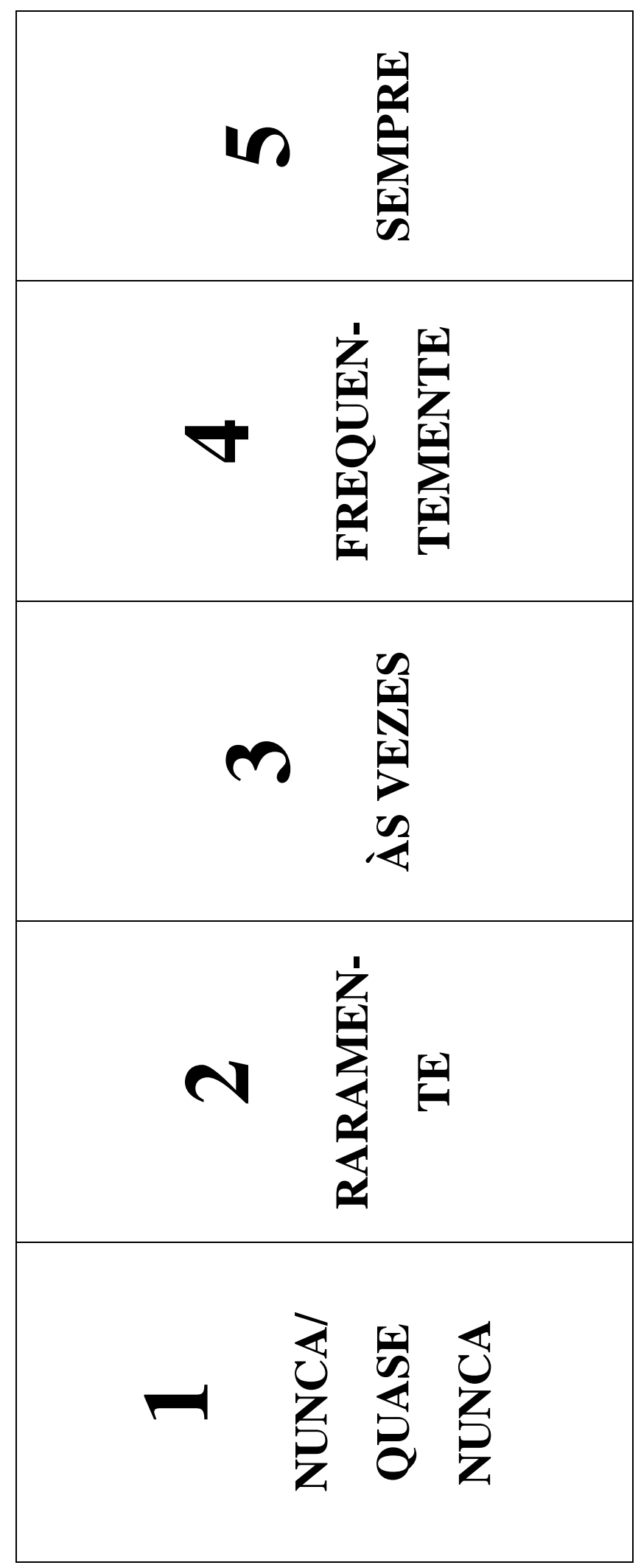

